\title{
Dissecting the psychosis continuum
}

Citation for published version (APA):

van der Steen, Y. C. O. (2018). Dissecting the psychosis continuum: risk factors along the pathway from experiences to disorder. [Doctoral Thesis, Maastricht University]. Gildeprint Drukkerijen. https://doi.org/10.26481/dis.20180615ys

Document status and date:

Published: 01/01/2018

DOI:

10.26481/dis.20180615ys

Document Version:

Publisher's PDF, also known as Version of record

\section{Please check the document version of this publication:}

- A submitted manuscript is the version of the article upon submission and before peer-review. There can be important differences between the submitted version and the official published version of record.

People interested in the research are advised to contact the author for the final version of the publication, or visit the DOI to the publisher's website.

- The final author version and the galley proof are versions of the publication after peer review.

- The final published version features the final layout of the paper including the volume, issue and page numbers.

Link to publication

\footnotetext{
General rights rights.

- You may freely distribute the URL identifying the publication in the public portal. please follow below link for the End User Agreement:

www.umlib.nl/taverne-license

Take down policy

If you believe that this document breaches copyright please contact us at:

repository@maastrichtuniversity.nl

providing details and we will investigate your claim.
}

Copyright and moral rights for the publications made accessible in the public portal are retained by the authors and/or other copyright owners and it is a condition of accessing publications that users recognise and abide by the legal requirements associated with these

- Users may download and print one copy of any publication from the public portal for the purpose of private study or research.

- You may not further distribute the material or use it for any profit-making activity or commercial gain

If the publication is distributed under the terms of Article $25 \mathrm{fa}$ of the Dutch Copyright Act, indicated by the "Taverne" license above, 


\title{
DISSECTING THE PSYCHOSIS CONTINUUM RISK FACTORS ALONG THE PATHWAY FROM EXPERIENCES TO DISORDER
}

\author{
Yori van der Steen
}


Layout and printing: Gildeprint, Enschede, the Netherlands Cover: Johan Lataster

ISBN: $978-94-6233-968-2$

(C) Yori van der Steen

All rights reserved. No part of this publication may be reproduced or used in any manner whatsoever without prior written permission from the author. 


\title{
DISSECTING THE PSYCHOSIS CONTINUUM RISK FACTORS ALONG THE PATHWAY FROM EXPERIENCES TO DISORDER
}

\author{
PROEFSCHRIFT
}

ter verkrijging van de graad van doctor aan de Universiteit Maastricht

en de Katholieke Universiteit Leuven,

op gezag van de Rector Magnifici Prof. dr. Rianne M. Letschert and Prof. dr. Luc Sels, volgens het besluit van het College van Decanen,

in het openbaar te verdedigen op

vrijdag 15 juni 2018 om 14.00 in Maastricht

door

Yori Caroline Olga van der Steen

Geboren op 26 juli 1986 te Roermond 


\section{Promotor}

Prof. dr. I. Myin-Germeys (Katholieke Universiteit Leuven en Universiteit Maastricht)

\section{Copromotor}

Prof. dr. R. van Winkel (Katholieke Universiteit Leuven)

\section{Beoordelingscommissie}

Prof. dr. T.A.M.J. van Amelsvoort (voorzitter; Universiteit Maastricht)

Prof. dr. M. de Hert (Katholieke Universiteit Leuven)

Prof. dr. P.A.E.G. Delespaul (Universiteit Maastricht)

Prof. dr. N. Jacobs (Open Universiteit)

Prof. dr. P. Kuppens (Katholieke Universiteit Leuven)

Prof. dr. M.C. Wichers (Universitair Medisch Centrum Groningen)

The research presented in this thesis was performed at the Department of Psychiatry and Neuropsychology of the School of Mental Health and Neuroscience, Maastricht University, The Netherlands and at the Center for Contextual Psychiatry of the Department of Neuroscience of the Katholieke Universiteit Leuven, Belgium. This research was funded by the 'Op de Pedalen Fonds'. 
Voor Mark en Iris 


\section{Paranimfen}

Sanne Peeters

Tirza Wagenvoort 


\section{TABLE OF CONTENTS}

Chapter 1 General introduction 9

Chapter 2 'False positive' self-reported psychotic experiences in the general population: an investigation of outcome, predictive factors and clinical relevance

Chapter 3 Evidence that polygenic risk for psychotic disorder is expressed in the domain of neurodevelopment, emotion regulation and attribution of salience

Chapter 4 Clinical High Risk for psychosis: the association between momentary stress, affective and psychotic symptoms.

Chapter 5 Temporal dynamics of hallucinations and suspiciousness in clini105 cal high risk and first episode psychosis

Chapter 6 General discussion

Epilogue Summary

Samenvatting

161

Valorisation

165

Dankwoord

171

Curriculum Vitea

175

Publications

177

Thesis defences from MHeNS 


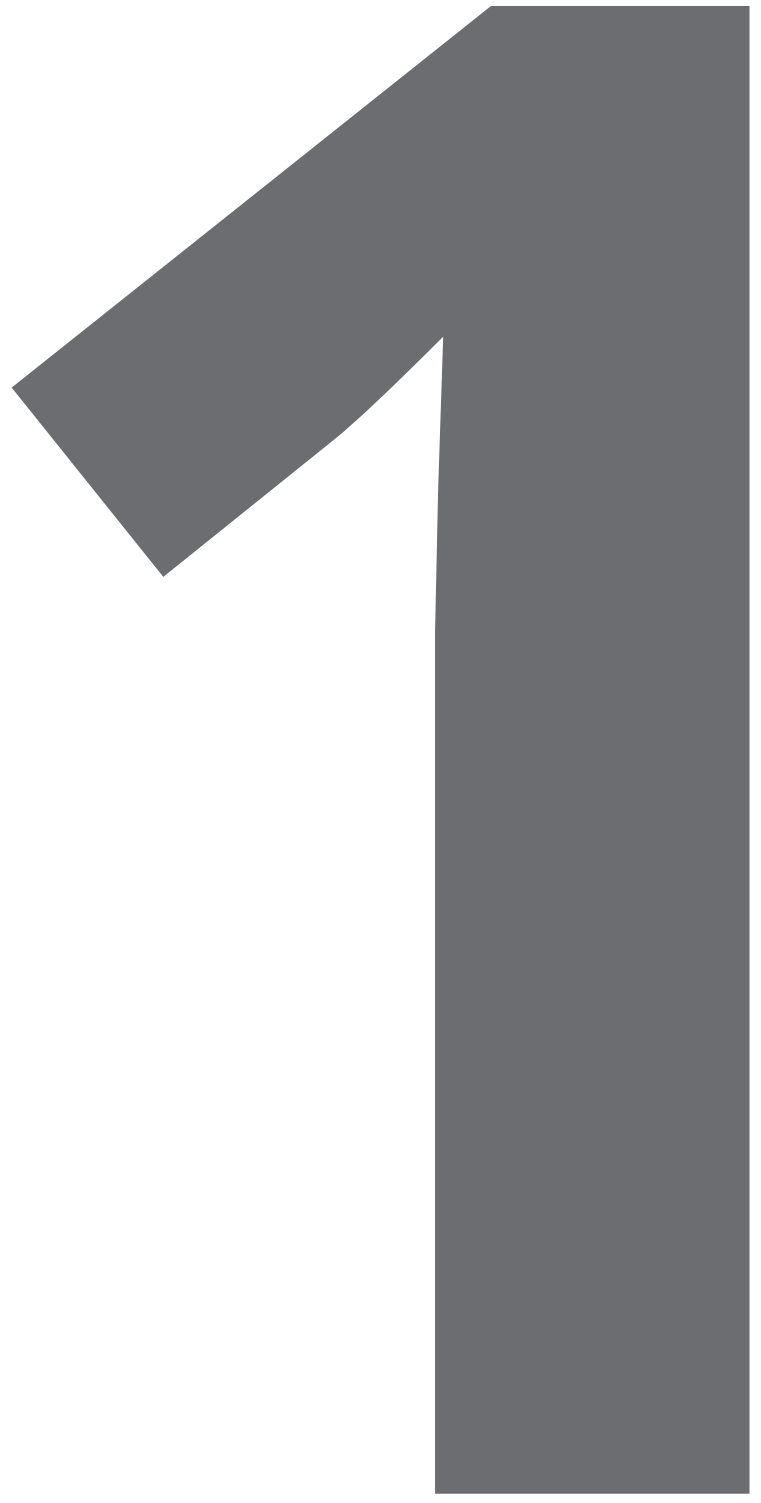




\section{Chapter 1}

General introduction 

Eric (21): "Since a couple of weeks, whenever I go outside of my house, I get the feeling that I am being watched by someone through cameras. I do not know who is watching me or why I am being watched, but it makes me very uncomfortable. Although I am not a $100 \%$ sure about it and when I am at home again I think I am being silly for thinking this, it prevents me from going outside of my house unless I really need to."

Eric also reported he was feeling more down and less energetic over the last couple of months. He was spending less time on his studies because he found it more difficult to focus. He also spent less time with his friends, because he felt uncomfortable when leaving his house, although when he was with his friends he could enjoy spending time with them.

Lisa (16): "When I am alone a male voice starts talking and sometimes even shouting at me... The voice is telling me I am dumb and ugly and that I have to hurt myself. The voice never stops when I am alone, the volume goes down a bit when I put music on very loud but it never goes away completely. It makes me very anxious and depressed, I can hardly sleep because of it and I cannot focus on anything else."

Lisa had been treated for over a year for depressive symptoms, she was failing in school, having dropped out in the last 4 weeks before the summer holiday and now sat alone in her room for most of the time. She had contact with one friend, although only via text messages. She had shared with her parents and her therapist that she had as a young girl been a victim of sexual abuse. However, she was very afraid to tell her parents and therapist about these frightening experiences that had slowly developed after her depressive symptoms had started.

These are just two examples of the many different (subclinical) psychotic symptoms reported by young people who shared their personal stories with me during the clinical diagnostic interviews I conducted in search for individuals at 'clinical high risk' for psychosis (CHR-P) and individuals who (had) experienced a first episode of psychosis (FEP). In addition to their psychotic experiences, both are reporting reduced social and role functioning. Lisa was experiencing an almost continuous auditory hallucination (statement 2) and was suffering from a psychotic episode. In contrast, Eric's suspicious beliefs (statement 1) were not fully crystallised and had not crossed the psychosis threshold. His symptoms were still at a 'subclinical' or 'attenuated' level that met criteria for being 'at clinical high risk' for the development of a psychotic episode. These statements illus- 
trate that both full-blown and subclinical psychotic symptoms are often associated with distress and a drop in social and role functioning.

\section{From psychotic-like experiences and subclinical symptoms to psychotic disorder}

Psychotic disorders are associated with a high burden for patients themselves as well as for their family members and friends. This is directly due to significant impairments in academic performance and occupational functioning, difficulties with interpersonal relationships and substantially compromised subjective quality of life, as well as a high financial burden due to costs for providing care and indirectly by loss of productivity ${ }^{1}$. It is therefore important to gain more insight in the developmental mechanisms of psychotic disorders, which will help to optimize early interventions targeting both symptom reduction and improvement of functioning and quality of life. The goal of early intervention is to prevent transition to full blown psychotic symptoms in CHR-P individuals as well as preventing the development of recurrent symptoms in those who have experienced a first psychotic episode.

In order to elucidate the complex and multi-factorial aetiology of psychotic disorder, in which genetic and environmental factors including obstetric complications, urbanization, migration, cannabis use, and childhood trauma as well as their interactions are implicat$e^{2,3}$, focus has shifted from the population of psychotic disorder patients, especially schizophrenic patients, to individuals with subclinical expressions of positive psychotic symptoms at the lower end of the psychosis continuum. These include psychotic-like experiences (PLEs, based on self-report measures) or true subclinical psychotic symptoms reported by individuals from the general population, CHR-P patients and unaffected first-degree relatives of psychotic patients. Investigation of subclinical symptoms allows examination of factors that precede transition to psychosis and more importantly impact on functioning, irrespective of an eventual specific psychotic disorder diagnosis.

From a research perspective using general population samples has the important advantage that subclinical psychotic symptoms are much more prevalent than psychotic disorders and inclusion does not dependent on help-seeking. This allows for true population-based epidemiological research into the pathophysiology, course and treatment of subclinical symptoms in representative population-based contexts. The advantage of studying CHR-P patients and unaffected first-degree relatives is that average transition rates of $22-36 \%{ }^{4}$ and $10 \%{ }^{6}$ respectively, are much higher than the transition rate of $0.6 \%$ in the general population ${ }^{4,5}$. This allows for investigation of factors related to transition 
as well as protective factors in non-converters. First-degree relatives of psychotic disorder patients also show an increased risk of developing psychotic disorder compared to individuals from the general population (respectively $10 \%$ compared to $0.6 \%)^{5,6}$. Additionally, these first-degree relatives also report more subclinical psychotic symptoms than healthy controls $s^{7-9}$ and they share both a genetic vulnerability and environmental risk factors with their affected relative. Investigation of PLEs and subclinical psychotic symptoms will help to determine the pathway from early expression on towards clinical needs, especially in longitudinal studies in which these samples are repeatedly assessed over time. This allows prospective investigation of psychosocial risk factors for psychotic illness development and the role of comorbid psychopathology in the progression toward psychosis. Another important benefit of studying individuals with PLEs and subclinical psychotic symptoms is that there is no confounding due to antipsychotic treatments or chronicity effects.

The first part of this thesis therefore focusses on the lowest end of the psychosis continuum: PLEs and subclinical psychotic symptoms reported by individuals of the general population and unaffected first-degree relatives of psychosis spectrum patients. As these can be assessed through measures of ('subjective') self-report and ('objective') clinical interviews, the studies in this first part focus on the distinction between self-reported psychotic experiences versus 'clinically validated' psychotic symptoms.

The second part of this thesis focusses on the group of help-seeking individuals with subclinical psychotic symptoms meeting the criteria for being 'at clinical high risk' for the development of psychosis (hereinafter: CHR-P). Studies using the Experience Sampling Method (ESM) in psychotic disorder patients have provided important information on the prevalence and phenomenology of psychotic symptoms in daily life and have shown that psychotic patients are characterised by increased emotional and symptomatic stress reactivity in response to small daily life hassles. Studies in CHR-P patients and patients with a first episode of psychosis will reveal whether these specific processes precede the onset of psychosis or if they are the result of illness progression. Specifically, studies in this part of the thesis investigate differences in emotional and symptomatic stress reactivity, phenomenology and temporal dynamics of emotional and psychotic symptoms between CHR-P and (first episode) psychotic patients in the context of daily life.

\section{Phenomenology of psychosis}

Psychotic disorders constitute a multidimensional syndrome that is expressed in a spec- 
trum of related diagnostic categories including schizophrenia, schizophreniform disorder, schizoaffective disorder, delusional disorder, brief psychotic disorder, depression/bipolar disorder with psychotic features, substance-induced psychotic disorder, psychotic disorder not otherwise classified, which affect around $3.5 \%$ of the population ${ }^{10}$. Psychosis rarely occurs before the age of 14 years, but there is a sharp increase in its prevalence between the ages of $15-17$ year $^{11}$. Overall, about $50 \%$ of people who develop a psychotic disorder will do so by the time they are in their early 20s. The mean age of onset tends to be a little younger in males (18-25 years) than females (25-35 years) $)^{11,12}$.

Psychotic disorders are characterised by problems recognizing and understanding reality. The positive psychotic symptoms can be distinguished into (1) delusions, bizarre or non-bizarre in nature; (2) hallucinations, visual, auditory, tactile, gustatory and/or olfactory in nature; and (3) disorganised behaviour. While these positive symptoms are thought of as specific characteristics or 'phenotypes', individuals with psychotic disorders often also experience other general symptoms in varying degrees across the diagnostic categories (i.e. transdiagnostic) forming the clinical psychosis spectrum. These are negative symptoms (i.e. restricted affect, anhedonia and motivational problems), affective dysregulation (depressive and/or (hypo) manic affect) and cognitive problems with regard to memory, attention, executive functioning and social cognition. Psychotic disorders are therefore characterised by high clinical heterogeneity and presence of psychotic symptoms typically waxes and wanes, with variety in severity of symptoms and symptom-free periods even in chronic patients ${ }^{13-15}$.

This high clinical heterogeneity is also found at the level of subclinical or attenuated psychotic symptoms. The "transdiagnostic and extended psychosis phenotype" ${ }^{16,17}$ has been proposed to account for the finding that (subclinical) psychotic symptoms are commonly reported by non-help seeking individuals from the general population, predominantly during adolescence and early adulthood ${ }^{18-20}$, with a prevalence of $\sim 7 \%{ }^{17,21}$. In $\sim 80 \%$ these are transient in nature, persistence occurs in the remaining $\sim 20 \%$ and $\sim 7 \%$

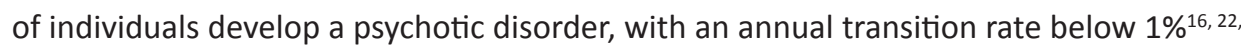
${ }^{23}$. In this model, at any phenomenological or temporal stage along the psychosis continuum may individuals become help seeking and meet CHR-P criteria, of which some will develop psychotic disorder. The model can account for the high comorbidity of symptoms ${ }^{24}$, especially anxiety and affective disturbances at clinical and subclinical level ${ }^{25-27}$. Importantly, this model is proposed to underlie the diagnostic categories of schizophrenia spectrum and bipolar disorders ${ }^{17}$, thereby overcoming the limitations of the current 
psychiatric classification systems which consider psychiatric disorders as separate entities that do not overlap.

Although population studies have consistently reported that subclinical psychotic symptoms are relatively common, prevalence rates seem to be dependent upon the assessment strategy used. Prevalence rates in studies that rely on self-report measures are more than three times higher than those of studies using interview-based assessments ${ }^{16}$. Furthermore, studies in which self-reported psychotic experiences (SRPE) were reassessed by clinical interview, only about $40 \%$ of those were then confirmed as truly psychotic in nature ${ }^{11,12}$. SRPE not confirmed by clinical interview are referred to as 'false positive' (FP) SRPE. These findings highlight an important discrepancy between 'subjective' self-report of psychotic experiences and the 'objective' evaluations of clinicians. Van Nierop and colleagues used data from the second Netherlands Mental Health Survey and Incidence Study (NEMESIS-2) ${ }^{28}$ and found that, compared to individuals from the general population who had never had a psychotic experience, individuals with FP SRPE were characterised by higher levels of non-psychotic psychopathology and neuroticism, had experienced more childhood adversity and were functioning less well physically, socially and mentally. However, associations with psychopathology, social functioning, psychosocial factors as well as help seeking in general and specifically for SRPE were generally less strong than for those with confirmed psychotic symptoms. FP SRPE were therefore suggested to represent the mildest form of risk along the extended psychosis continuum $^{28}$. However, very little is known about the course and development of FP SRPE over time and which psychopathological and psychosocial factors are predictive for possible differential outcomes.

\section{Genetics of psychosis}

The high clinical heterogeneity of psychotic disorders is mirrored by high genetic heterogeneity ${ }^{29}$. Although the high heritability estimates of $70-85 \%$ for schizophrenia and $60-85 \%$ for bipolar disorder ${ }^{30}$ indicate that about $60-85 \%$ of the observed individual differences in these patients are attributable to genetic individual differences while the remaining part is related to the environment, genetic studies have been unable to find 'the' psychosis gene. Genome-wide association studies (GWAS) in schizophrenia patients have led to the discovery of large numbers (100 thousand-1 million) of genetic variants called 'single nucleotide polymorphisms' (SNPs), each associated with very small effect sizes that even cumulatively explain only a modest proportion of the genetic predisposition for psychotic disorder ${ }^{31}$. However, the combined effect of these individual SNPs is 
captured in a Polygenic Risk Score (PRS) calculated for each individual, which can be used as an index for genetic risk in studies examining the complex interactions between genetic and environmental (GxE) factors underlying psychosis development. Furthermore, a genetic overlap between schizophrenia and affective disorders has been suggested by recent results of molecular genetic studies ${ }^{32,33}$.

\section{The clinical high risk for psychosis state}

As the statement of Eric at the start of this chapter in which he describes his feelings of being watched and the distress and disruption in normal function he is experiencing illustrates, some individuals with subclinical psychotic symptoms are help-seeking and meet criteria for being at clinical high risk for psychosis (CHR-P), also known as the "atrisk mental state" (ARMS), "prodromal" and ultra-high-risk (UHR) state. This construct of a clinical high-risk state for psychosis has been proposed in order to capture the pre-psychotic phase, describing people presenting with potentially prodromal symptoms, as retrospective studies showed that in around three-quarter of first admitted psychotic disorder patients the disorder began with a prodromal phase, which lasted, on average, 5 years $^{34,35}$

The CHR-P state can be diagnosed using CHR-P and/or basic symptoms (BS) criteria ${ }^{36}$ and requires the presence of 1 or more of the following: (i) subclinical or "attenuated" psychotic symptoms (unusual thought content, non-bizarre ideas, perceptual abnormalities and/or disorganised speech); (ii) brief limited intermittent psychotic episode (BLIP); (iii) trait vulnerability plus a marked decline in psychosocial functioning (i.e. genetic risk and deterioration syndrome [GRD]). The Comprehensive Assessment of At-Risk Mental State (CAARMS) ${ }^{37}$ and the Structured Interview for Prodromal Symptoms (SIPS) (including the companion Scale of Prodromal Symptoms [SOPS] $)^{38}$ are the most often used semi-structured interviews to determine CHR-P status. Basic symptoms are subjectively experienced disturbances of different domains, including perception, thought processing, language, and attention, that are distinct from classic psychotic symptoms in that they are independent of abnormal thought content and reality testing and insight into the symptoms psychopathologic nature is intact ${ }^{39}$. BS are assessed with the Schizophrenia Proneness Instrument, adult version (SPI-A) ${ }^{40}$.

Many individuals with psychotic experiences meeting CHR-P criteria have clinically debilitating symptoms of comorbid diagnoses. Most often reported are anxiety, depression and substance use disorders. Similar to psychotic disorder patients, CHR-P patients are 
often characterised by high neuroticism and high levels of negative symptoms. Significant impairments in academic performance and occupational functioning, difficulties with interpersonal relationships and a substantially compromised subjective quality of life are often observed ${ }^{41-46}$. A large meta-analysis has shown that transition risk from CHR-P to clinical psychosis is $\sim 22 \%$ after 1 year, which increases to $36 \%$ after 3 years ${ }^{4}$. Meta-analytic results also show that CHR-P state is heterogeneous in terms of longitudinal diagnoses, with $73 \%$ of transitions resulting in 'schizophrenic' psychoses and $11 \%$ in 'affective' psychosis, so current CHR-P diagnostic criteria appear to be strongly biased toward an identification of early phases of schizophrenic rather than affective psychoses ${ }^{47}$.

Overall, the majority of CHR-P studies have focussed on transition risk, although recent studies of outcome in non-converters show that while the majority of individuals do not convert to psychosis, full remission of CHR-P status occurs in less than half of non-converters, with the others still reporting subclinical psychotic symptoms ${ }^{48-52}$. Furthermore, nonpsychotic disorders have been found to co-occur with diagnosis of CHR-P status in most cases, and remain highly prevalent, in terms of incidence of new non-psychotic disorder and recurrence of previous disorder ${ }^{48,49}$. The CHR-P state is therefore predictive of broad psychopathology in addition to transition to psychotic disorder and fits well within the broad model of clinical staging in psychiatry ${ }^{53-57}$. This model uses the high risk paradigm in a broad context in which relatively non-specific sub diagnostic mental distress predicts not only psychotic but also non-psychotic outcome. Focus lies on early mental distress and non-specific interventions which can help prevent development of more severe, specific and relatively treatment-resistant psychiatric syndromes. This allows for stage-specific treatment, varying from non-specific non-pharmacological self-management approaches in the early stages to more active treatments in the advanced stages.

\section{The affective pathway to psychosis: evidence from experiences sampling method studies} It has long been suggested that stress plays an important role in the emergence and course of psychotic disorder ${ }^{58-62}$. The vulnerability-stress model states that whenever a stressor exceeds the individuals' vulnerability level psychotic symptoms will emerge. The individual's vulnerability level is assumed to be a stable within-person characteristic based on genetic predisposition. There is overwhelming epidemiological evidence that stressful life events ${ }^{63}$, childhood adversity ${ }^{64}$ and small everyday hassles ${ }^{65,66}$ are associated with the formation and progression of psychotic symptoms. These findings highlight the role that environmental stress-exposure plays in both the development of $\mathrm{PE}$ in the general population ${ }^{21}$ and the trajectory towards psychotic disorders ${ }^{61}$. 
Furthermore, poor self-esteem and neuroticism, a personality trait characterized by increased affective reactivity and sensitivity to stress ${ }^{67}$, often characterise psychotic patients and CHR-P individuals $\mathrm{s}^{46,68}$ and have been found to predict onset of psychotic symptoms ${ }^{69}$.

A promising approach to help elucidate the role of stress as a potential causal factor for psychosis development is to zoom into the microenvironment of everyday life. The Experience Sampling Method (ESM) is an excellent tool to capture subtle, moment-to-moment emotions and symptomatology and their dynamics and associations with contextual factors in the flow of daily life ${ }^{70-73}$. It is a structured within-day momentary self-assessment technique that provides frequent assessment of current mood, thoughts, symptoms imbedded in their context (e.g. location, company, activity), and these repetitive momentary assessments are ecologically valid and free of cognitive biases that hamper retrospective questionnaires ${ }^{71,74}$. Most of the ESM research in the last three decades has been performed by providing subjects with a digital wristwatch and a set of ESM self-assessment forms collected in a booklet for each day. Advancements in technology now allow electronic or digital ESM assessments by means of a PDA or mobile phone app. The ESM device (wristwatch, PDA or mobile phone) emits a signal (beep) at ten unpredictable moments in a semi-random schedule of 90-minute time blocks between 07:30 and 22:3071.

ESM has several advantages in comparison to conventional research methods in the field of psychopathology ${ }^{75}$. First, ESM studies are ecologically valid as they allow studying individuals within their own real-life environment. Second, in contrast to traditional retrospective assessment approaches, ESM assesses momentary experiences elicited by simple and straightforward questions that are less prone to biases and forgetting. Third, questionnaires and most interviews do not focus how contextual factors impact on the variation in symptoms, mood or other constructs in daily life. ESM on the other hand is situated in the complex context of daily life and is able to measure the variation in symptoms and mood in response to environmental factors present in daily life. Fourth, questionnaires and interviews require patients to be aware of the dynamics of symptoms and their interactions with other factors. However, as different constructs like symptoms, mood, stress and social company are measured separately from each other and only associated to each other in the analyses conducted by the researcher, ESM provides information of which the participant is not aware and therefore not influenced by an individual's own expectations. Fifth, ESM allows for cross-sectional (chapter 4) as well as 
longitudinal study (chapter 5) of variation and dynamic relationships as data collection results in multiple assessments over time.

Previous ESM studies have shown that when confronted with everyday small stressors psychotic disorder patients display increased emotional and symptomatic responses ${ }^{76,}$ 77. Increased reactivity to stress in daily life is especially found in patients with high levels of positive psychotic symptoms and low levels of negative symptoms ${ }^{78}$. Unaffected first-degree relatives of psychotic patients also display elevated emotional and behavioural responses in the face of everyday life stress ${ }^{76}$. Subsequent studies have shown that increased stress-reactivity clusters within families and a genetic correlation between increased stress reactivity and the positive psychotic dimension have been shown for clinical ${ }^{79}$ and subclinical symptoms ${ }^{80}$. Furthermore, there is a role for environmental factors as environmental exposures to stress in the form of life events ${ }^{81}$ and childhood trauma ${ }^{82}$ have been found to explain the elevations in stress reactivity in part. Taken together, these results suggest that increased emotional and symptomatic reactivity to stress, also referred to as 'behavioural sensitization' 83 , reflects an affective pathway to psychosis that is suggested to underlie a more reactive, episodic type of psychosis that characterises a subgroup of patients with predominantly positive psychotic symptoms ${ }^{59}$.

Examination of emotional and symptomatic stress reactivity in those at CHR-P will help determine if behavioural sensitization occurs before the onset of psychotic disorder and an elevated level of stress reactivity is a mechanism underlying psychosis development. Palmier-Claus and colleagues ${ }^{84}$ have examined stress-reactivity in a sample of CHR-P patients, psychotic disorder patients and healthy controls. Interestingly, it was the CHR-P group that showed significantly elevated emotional stress reactivity for stressful activities and social situations compared to healthy controls and psychotic patients. Intensity of symptomatic stress reactivity was comparable to psychotic patients. These results suggest that stress sensitization occurs before onset of psychotic disorder. Very recently, the study of Reininghaus and colleagues ${ }^{85}$ examined emotional and symptomatic stress-reactivity in CHR-P and FEP patients. Results echoed and expanded those of Palmier-Claus and colleagues ${ }^{84}$.

\section{Phenomenology and temporal dynamics of psychotic experiences in daily life}

The prospective, longitudinal character of ESM assessments allows for examination of the phenomenology and temporal dynamics of psychotic experiences in daily life ${ }^{71,74}$. Prevalence rates of hallucinations in daily life in psychotic disorder patients were be- 
tween $40-73 \%{ }^{86-88}$. Visual and auditory hallucinations were found to often co-occur. Oorschot and colleagues ${ }^{87}$ investigated the temporal dynamics of hallucinations and the relationships with emotions and delusions. Their results suggested that delusional ideation might precede hallucinatory episodes in daily life, rather than result from a hallucination. Additionally, affective dysregulation might not play a primary role in hallucination onset.

Prevalence rates of paranoia or persecutory delusions in daily life are between $49-67 \%$ in psychosis spectrum patients ${ }^{88,89}$. Results of studies across the psychosis continuum have indicated an important role for emotions, especially anxiety and low levels of self-esteem in triggering or contributing to the maintenance of paranoid symptoms ${ }^{90-94}$. Self-esteem is not constantly low but fluctuates in paranoid patients ${ }^{95}$. Furthermore, self-esteem instability was found to be specifically related to paranoid symptoms and not positive psychotic symptoms in general ${ }^{96}$. One ESM study of psychotic disorder patients demonstrated that an increase in the level of anxiety and a decrease in the level of self-esteem were predictive of the onset of a paranoid episode. Furthermore, negative emotions and a low level of self-esteem were associated with paranoid episodes ${ }^{97}$.

\section{Outline and aims and of the thesis}

The overall aim of this thesis is to identify risk factors for the development of psychotic disorder by examining the phenomenology of psychotic symptoms at a macro-level and at micro-level of daily life in those at the lower end of the psychosis continuum. The studies in this thesis examine (subclinical) psychotic symptoms and associated factors in individuals from the general population, unaffected first-degree relatives of psychotic disorder patients, CHR-P patients, FEP patients and long-term psychotic disorder patients, allowing for comparisons across different stages of the continuum. The first part of this thesis focusses on subclinical psychotic symptoms reported in the general population and unaffected first-degree relatives of psychotic disorder patients.

This thesis starts with an investigation of FP SRPE by individuals of the general population, using uses baseline and 3-year follow-up data from the second Netherlands Mental Health and Incidence Study (NEMESIS-2, n=4683), a longitudinal study of mental disorders in a representative cohort of Dutch adults. FP SRPE are proposed to represent the lowest risk for transition to psychosis along the extended psychosis continuum, as they are not confirmed as true psychotic symptoms through objective clinical evaluation. The study in chapter $\mathbf{2}$ is a prospective follow-up study of the previously investigated sample 
of individuals with FP SRPE at baseline ${ }^{28}$. We examine if baseline FP SRPE predict reduced psychosocial functioning and the occurrence of psychopathology at 3-year follow-up. Furthermore, we investigate which psychopathological and psychosocial factors predict the differential outcomes of persistence of FP SPRE and transition to validated psychotic symptoms.

The high expression of subclinical psychotic symptomatology in unaffected first-degree relatives of psychotic patients ${ }^{7,8}$ is likely attributable to both shared genes and environment with the patient relative. In contrast, the expression of subclinical psychotic symptomatology in general population samples is more likely to be associated with environmental effects ${ }^{16,98,99}$. As PRS reflects the influence of the genetic component on the clinical expression of the diverse psychotic symptoms, positive associations are assumed to exist between PRS as an index of genetic risk and self-report and clinical interview measures of subclinical psychotic symptoms. However, early reports on these associations were inconclusive ${ }^{100-102}$. Therefore, in chapter 3 the associations between PRS and subclinical psychotic symptoms assessed with a (subjective) self-report measure and an (objective) interview measure are examined in unaffected first-degree relatives of patients with psychotic disorders and healthy comparison subjects from the general population. Given that siblings of psychotic disorder patients have more genetic overlap with these patients than individuals from the general population, it is hypothesized that the association between PRS and measures of psychosis proneness will be stronger in relatives of patients than in individuals from the general population. Associations with affective episodes are also investigated as psychotic patients often show affective dysregulation and GWAS studies showing considerable overlap between schizophrenia and other psychiatric disorders including affective psychoses.

The second part of this thesis focusses on examination of psychotic symptoms in daily life in CHR-P patients, patients with a first episode of psychosis and long-term psychotic disorder patients. The study in chapter $\mathbf{4}$ investigates emotional and symptomatic stress reactivity in daily life in individuals at CHR-P, chronic psychotic disorder patients and healthy controls to further examine the role of elevated emotional and symptomatic stress-reactivity in the onset of psychotic disorder. Previous ESM studies with psychotic patients reported that elevation of the level of negative affect was associated with the occurrence of momentary psychotic symptoms ${ }^{88,103,104}$. We therefore examine the association between momentary psychotic symptoms and negative affect as a measure of distress in CHR-P individuals and long-term psychotic patients. 
To date no study has investigated prevalence of perceptual abnormalities or hallucinations and suspiciousness in daily life specifically in CHR-P or first episode psychosis patients, whereas this has been done previously in psychotic disorder patients. Similarly, the temporal dynamics of hallucinations and suspiciousness in daily life and the relationships with emotional processes, anxiety and self-esteem are unknown. The study in Chapter $\mathbf{5}$ is the first to examine the phenomenology of hallucinations and delusions in the realm of daily life and their temporal relationship to emotion, anxiety and self-esteem in CHR-P and FEP patients. Results of this study will help to further elucidate factors involved in the onset and maintenance of suspicious and hallucinatory symptoms. We compare current findings with previous findings in psychotic disorder patients.

Lastly, in chapter 6, the main results of the work presented in this thesis are integrated and discussed. In addition, clinical implications and future perspectives are addressed. 


\section{REFERENCES}

1. Rössler W, Joachim Salize H, van Os J, Riecher-Rössler A. Size of burden of schizophrenia and psychotic disorders. Eur Neuropsychopharmacol. 2005; 15:399-409.

2. van Os J, Kapur S. Schizophrenia. The Lancet. 2009; 374:635-645.

3. van Os J, Rutten BP, Poulton R. Gene-environment interactions in schizophrenia: review of epidemiological findings and future directions. Schizophr Bull. 2008; 34:1066-1082.

4. Fusar-Poli P, Bonoldi I, Yung AR, Borgwardt S, Kempton MJ, Valmaggia L, . . Mcguire P. Predicting psychosis: Meta-analysis of transition outcomes in individuals at high clinical risk. Arch Gen Psychiatry. 2012; 69:220-229.

5. Saha S, Chant D, Welham J, McGrath J. A systematic review of the prevalence of schizophrenia. PLoS Med. 2005; 2:e141.

6. Gottesman II. Schizophrenia genesis: The origins of madness. New York, NY, US: W H Freeman/Times Books/ Henry Holt \& Co; 1991.

7. Cardno AG, Marshall EJ, Coid B, Macdonald AM, Ribchester TR, Davies NJ, ... Murray RM. Heritability estimates for psychotic disorders: The maudsley twin psychosis series. Arch Gen Psychiatry. 1999; 56:162168.

8. Kendler KS, McGuire M, Gruenberg AM, O'Hare A, Spellman M, Walsh D. The Roscommon family study. III. Schizophrenia-related personality disorders in relatives. Arch Gen Psychiatry. 1993; 50:781-788.

9. Lataster T, Myin-Germeys I, Derom C, Thiery E, van Os J. Evidence that self-reported psychotic experiences represent the transitory developmental expression of genetic liability to psychosis in the general population. Am J Med Genet B Neuropsychiatr Genet. 2009; 150B:1078-1084.

10. Perala J, Suvisaari J, Saarni SI, Kuoppasalmi K, Isometsa E, Pirkola S, . . Lonnqvist J. Lifetime prevalence of psychotic and bipolar I disorders in a general population. Arch Gen Psychiatry. 2007; 64:19-28.

11. Kessler RC, Amminger GP, Aguilar-Gaxiola S, Alonso J, Lee S, Ustun TB. Age of onset of mental disorders: A review of recent literature. Curr Opin Psychiatry. 2007; 20:359-364.

12. Ochoa S, Usall J, Cobo J, Labad X, Kulkarni J. Gender Differences in Schizophrenia and First-Episode Psychosis: A Comprehensive Literature Review. Schizophr Res Treatment. 2012; 2012:916198.

13. Harrow M, Grossman LS, Jobe TH, Herbener ES. Do patients with schizophrenia ever show periods of recovery? A 15-year multi-follow-up study. Schizophr Bull. 2005; 31:723-734.

14. Jobe TH, Harrow M. Long-term outcome of patients with schizophrenia: a review. Can J Psychiatry. 2005; 50:892-900.

15. Reichenberg A, Rieckmann N, Harvey PD. Stability in schizophrenia symptoms over time: Findings from the Mount Sinai Pilgrim Psychiatric Center Longitudinal Study. J Abnorm Psychol. 2005; 114:363-372.

16. Linscott RJ, van Os J. An updated and conservative systematic review and meta-analysis of epidemiological evidence on psychotic experiences in children and adults: on the pathway from proneness to persistence to dimensional expression across mental disorders. Psychol Med. 2013; 43:1133-1149.

17. van Os J, Reininghaus U. Psychosis as a transdiagnostic and extended phenotype in the general population. World Psychiatry. 2016; 15:118-124.

18. Verdoux H, van Os J, Maurice-Tison S, Gay B, Salamon R, Bourgeois M. Is early adulthood a critical developmental stage for psychosis proneness? A survey of delusional ideation in normal subjects. Schizophr Res. 1998; 29:247-254.

19. Wigman JTW, Vollebergh WAM, Raaijmakers QAW, ledema J, van Dorsselaer S, Ormel J, . . van Os J. The Structure of The Extended Psychosis Phenotype in Early Adolescence-A Cross-sample Replication. Schizophr Bull. 2011; 37:850-860.

20. Yung AR, Nelson B, Baker K, Buckby JA, Baksheev G, Cosgrave EM. Psychotic-like experiences in a community sample of adolescents: implications for the continuum model of psychosis and prediction of schizophrenia. Aust N Z J Psychiatry. 2009; 43:118-128.

21. Johns LC, Cannon M, Singleton N, Murray RM, Farrell M, Brugha T, . . Meltzer H. Prevalence and correlates of self-reported psychotic symptoms in the British population. Br J Psychiatry. 2004; 185:298-305.

22. Kaymaz N, Drukker M, Lieb R, Wittchen HU, Werbeloff N, Weiser M, . . van Os J. Do subthreshold psychotic experiences predict clinical outcomes in unselected non-help-seeking population-based samples? A systematic review and meta-analysis, enriched with new results. Psychol Med. 2012; 42:2239-2253. 
23. Zammit S, Kounali D, Cannon M, David AS, Gunnell D, Heron J, . . . Lewis G. Psychotic experiences and psychotic disorders at age 18 in relation to psychotic experiences at age 12 in a longitudinal population-based cohort study. Am J Psychiatry. 2013; 170:742-750.

24. Kessler RC, Chiu WT, Demler O, Walters EE. Prevalence, Severity, and Comorbidity of Twelve-month DSMIV Disorders in the National Comorbidity Survey Replication (NCS-R). Arch Gen Psychiatry. 2005; 62:617627.

25. Hanssen M, Peeters F, Krabbendam L, Radstake S, Verdoux H, van Os J. How psychotic are individuals with non-psychotic disorders? Soc Psychiatry Psychiatr Epidemiol. 2003; 38:149-154.

26. Varghese D, Scott J, Welham J, Bor W, Najman J, O'Callaghan M, . . McGrath J. Psychotic-Like Experiences in Major Depression and Anxiety Disorders: A Population-Based Survey in Young Adults. Schizophr Bull. 2011; 37:389-393.

27. Wigman JTW, van Nierop M, Vollebergh WAM, Lieb R, Beesdo-Baum K, Wittchen H-U, van Os J. Evidence That Psychotic Symptoms Are Prevalent in Disorders of Anxiety and Depression, Impacting on Illness Onset, Risk, and Severity-Implications for Diagnosis and Ultra-High Risk Research. Schizophr Bull. 2012; 38:247-257.

28. van Nierop M, van Os J, Gunther N, Myin-Germeys I, de Graaf R, ten Have M, . . van Winkel R. Phenotypically continuous with clinical psychosis, discontinuous in need for care: evidence for an extended psychosis phenotype. Schizophr Bull. 2012; 38:231-238.

29. Van Winkel R, Esquivel G, Kenis G, Wichers M, Collip D, Peerbooms O, . . Van Os J. REVIEW: Genome-Wide Findings in Schizophrenia and the Role of Gene-Environment Interplay. CNS Neurosci Ther. 2010; 16:e185-e192.

30. Burmeister M, McInnis MG, Zollner S. Psychiatric genetics: progress amid controversy. Nat Rev Genet. 2008; 9:527-540.

31. Harrison PJ. Recent genetic findings in schizophrenia and their therapeutic relevance. J Psychopharmacol. 2015; 29:85-96.

32. Cross-Disorder Group of the Psychiatric Genomics C, Lee SH, Ripke S, Neale BM, Faraone SV, Purcell SM, ... International Inflammatory Bowel Disease Genetics Consortium. Genetic relationship between five psychiatric disorders estimated from genome-wide SNPs. Nat Genet. 2013; 45:984-994.

33. Cross-Disorder Group of the Psychiatric Genomics C. Identification of risk loci with shared effects on five major psychiatric disorders: a genome-wide analysis. Lancet. 2013; 381:1371-1379.

34. Hafner H, Maurer K, Loffler W, an der Heiden W, Munk-Jorgensen P, Hambrecht M, Riecher-Rossler A. The ABC Schizophrenia Study: a preliminary overview of the results. Soc Psychiatry Psychiatr Epidemiol. 1998; 33:380-386.

35. Hafner H, Maurer K, Loffler W, Riecher-Rossler A. The influence of age and sex on the onset and early course of schizophrenia. Br J Psychiatry. 1993; 162:80-86.

36. Olsen KA, Rosenbaum B. Prospective investigations of the prodromal state of schizophrenia: review of studies. Acta Psychiatr Scand. 2006; 113:247-272.

37. Yung AR, Yung AR, Pan Yuen H, McGorry PD, Phillips LJ, Kelly D, . . Buckby J. Mapping the onset of psychosis: the Comprehensive Assessment of At-Risk Mental States. Aust N Z J Psychiatry. 2005; 39:964-971.

38. Miller TJ, McGlashan TH, Rosen JL, Cadenhead K, Cannon T, Ventura J, . . . Woods SW. Prodromal assessment with the structured interview for prodromal syndromes and the scale of prodromal symptoms: predictive validity, interrater reliability, and training to reliability. Schizophr Bull. 2003; 29:703-715.

39. Schultze-Lutter F. Subjective Symptoms of Schizophrenia in Research and the Clinic: The Basic Symptom Concept. Schizophr Bull. 2009; 35:5-8.

40. Schultze-Lutter F, Addington J, Ruhrmann S, eds. Schizophrenia Proneness Instument, Adult version (SPI-A): Giovanni Fioriti Editore 2007.

41. Addington J, Penn D, Woods SW, Addington D, Perkins DO. Social functioning in individuals at clinical high risk for psychosis. Schizophr Res. 2008; 99:119-124.

42. Bechdolf A, Pukrop R, Köhn D, Tschinkel S, Veith V, Schultze-Lutter F, . . Klosterkötter J. Subjective quality of life in subjects at risk for a first episode of psychosis: A comparison with first episode schizophrenia patients and healthy controls. Schizophr Res. 2005; 79:137-143.

43. Lencz T, Smith CW, Auther A, Correll CU, Cornblatt B. Nonspecific and attenuated negative symptoms in patients at clinical high-risk for schizophrenia. Schizophr Res. 2004; 68:37-48. 
44. Piskulic D, Addington J, Cadenhead KS, Cannon TD, Cornblatt BA, Heinssen R, . . McGlashan TH. Negative symptoms in individuals at clinical high risk of psychosis. Psychiatry Res. 2012; 196:220-224.

45. Velthorst E, Nieman DH, Linszen D, Becker H, de Haan L, Dingemans PM, . . Ruhrmann S. Disability in people clinically at high risk of psychosis. Br J Psychiatry. 2010; 197:278-284.

46. Marshall C, Addington J, Epstein I, Liu L, Deighton S, Zipursky RB. Treating young individuals at clinical high risk for psychosis. Early Interv Psychiatry. 2012; 6:60-68.

47. Fusar-Poli P, Bechdolf A, Taylor MJ, Bonoldi I, Carpenter WT, Yung AR, McGuire P. At Risk for Schizophrenic or Affective Psychoses? A Meta-Analysis of DSM/ICD Diagnostic Outcomes in Individuals at High Clinical Risk. Schizophr Bull. 2013; 39:923-932.

48. de Wit S, Schothorst PF, Oranje B, Ziermans TB, Durston S, Kahn RS. Adolescents at ultra-high risk for psychosis: long-term outcome of individuals who recover from their at-risk state. Eur Neuropsychopharmacol. 2014; 24:865-873.

49. Lin A, Wood SJ, Nelson B, Beavan A, McGorry P, Yung AR. Outcomes of nontransitioned cases in a sample at ultra-high risk for psychosis. Am J Psychiatry. 2015; 172:249-258.

50. Simon AE, Borgwardt S, Riecher-Rössler A, Velthorst E, de Haan L, Fusar-Poli P. Moving beyond transition outcomes: Meta-analysis of remission rates in individuals at high clinical risk for psychosis. Psychiatry Res. 2013; 209:266-272.

51. Simon AE, Velthorst E, Nieman DH, Linszen D, Umbricht D, de Haan L. Ultra high-risk state for psychosis and non-transition: A systematic review. Schizophr Res. 2011; 132:8-17.

52. Ziermans TB, Schothorst PF, Sprong M, van Engeland H. Transition and remission in adolescents at ultra-high risk for psychosis. Schizophr Res. 2011; 126:58-64.

53. Fusar-Poli P, Yung AR, McGorry P, van Os J. Lessons learned from the psychosis high-risk state: towards a general staging model of prodromal intervention. Psychol Med. 2014; 44:17-24.

54. McGorry P, Keshavan M, Goldstone S, Amminger P, Allott K, Berk M, . . Hickie I. Biomarkers and clinical staging in psychiatry. World Psychiatry. 2014; 13:211-223.

55. McGorry P, Nelson B. Why we need a transdiagnostic staging approach to emerging psychopathology, early diagnosis, and treatment. JAMA Psychiatry. 2016; 73:191-192.

56. McGorry P, van Os J. Redeeming diagnosis in psychiatry: timing versus specificity. The Lancet. 2013; 381:343-345.

57. McGorry PD, Hickie IB, Yung AR, Pantelis C, Jackson HJ. Clinical Staging of Psychiatric Disorders: A Heuristic Framework for Choosing Earlier, Safer and more Effective Interventions. Aust N Z J Psychiatry. 2006; 40:616-622.

58. Corcoran CM, Walker E, Huot R, Mittal V, Tessner K, Kestler L, Malaspina D. The Stress Cascade and Schizophrenia: Etiology and Onset. Schizophr Bull. 2003; 29:671-692.

59. Myin-Germeys I, van Os J. Stress-reactivity in psychosis: evidence for an affective pathway to psychosis. Clin Psychol Rev. 2007; 27:409-424.

60. Phillips LJ, Francey SM, Edwards J, McMurray N. Stress and psychosis: Towards the development of new models of investigation. Clin Psychol Rev. 2007; 27:307-317.

61. van Winkel R, Stefanis NC, Myin-Germeys I. Psychosocial Stress and Psychosis. A Review of the Neurobiological Mechanisms and the Evidence for Gene-Stress Interaction. Schizophr Bull. 2008; 34:1095-1105.

62. Zubin J, Spring B. Vulnerability - a new view of schizophrenia. J Abnorm Psychol. 1977; 86:103-126.

63. Beards S, Gayer-Anderson C, Borges S, Dewey ME, Fisher HL, Morgan C. Life Events and Psychosis: A Review and Meta-analysis. Schizophr Bull. 2013; 39:740-747.

64. Varese F, Smeets F, Drukker M, Lieverse R, Lataster T, Viechtbauer W, . . Bentall RP. Childhood Adversities Increase the Risk of Psychosis: A Meta-analysis of Patient-Control, Prospective- and Cross-sectional Cohort Studies. Schizophr Bull. 2012; 38:661-671.

65. Malla AK, Cortese L, Shaw TS, Ginsberg B. Life events and relapse in schizophrenia. A one year prospective study. Soc Psychiatry Psychiatr Epidemiol. 1990; 25:221-224.

66. Norman RM, Malla AK. A prospective study of daily stressors and symptomatology in schizophrenic patients. Soc Psychiatry Psychiatr Epidemiol. 1994; 29:244-249.

67. McCrae RR, Costa Jr PT, Martin TA. The NEO-PI-3: a more readable revised NEO Personality Inventory. J Pers Assess. 2005; 84:261-270.

68. Horan WP, Subotnik KL, Reise SP, Ventura J, Nuechterlein KH. Stability and clinical correlates of personality characteristics in recent-onset schizophrenia. Psychol Med. 2005; 35:995-1005. 
69. Krabbendam L, Janssen I, Bak M, Bijl RV, de Graaf R, van Os J. Neuroticism and low self-esteem as risk factors for psychosis. Soc Psychiatry Psychiatr Epidemiol. 2002; 37:1-6.

70. Csikszentmihalyi M, Larson R. Validity and reliability of the Experience-Sampling Method. J Nerv Ment Dis. 1987; 175:526-536.

71. Myin-Germeys I, Oorschot M, Collip D, Lataster J, Delespaul P, van Os J. Experience sampling research in psychopathology: opening the black box of daily life. Psychol Med. 2009; 39:1533-1547.

72. de Vries MW. The experience of Psychopathology: Investigating Mental Disorders in their Natural Settings. Cambridge: Cambridge University Press; 1992.

73. Delespaul P. Assessing schizophrenia in daily life. Maastricht: Universitaire Pers; 1995.

74. Trull TJ, Ebner-Priemer U. Ambulatory Assessment. Annu Rev Clin Psychol. 2013; 9:151-176.

75. Oorschot M, Kwapil T, Delespaul P, Myin-Germeys I. Momentary assessment research in psychosis. Psychol Assess. 2009; 21:498-505.

76. Myin-Germeys I, Delespaul P, van Os J. Behavioural sensitization to daily life stress in psychosis. Psychol Med. 2005; 35:733-741.

77. Myin-Germeys I, van Os J, Schwartz JE, Stone AA, Delespaul P. Emotional reactivity to daily life stress in psychosis. Arch Gen Psychiatry. 2001b; 58:1137-1144.

78. Lataster T, Valmaggia L, Lardinois M, van Os J, Myin-Germeys I. Increased stress reactivity: a mechanism specifically associated with the positive symptoms of psychotic disorder. Psychol Med. 2013; 43:13891400.

79. Lataster T, Collip D, Lardinois M, Van Os J, Myin-Germeys I. Evidence for a familial correlation between increased reactivity to stress and positive psychotic symptoms. Acta Psychiatr Scand. 2010; 122:395-404.

80. Lataster T, Wichers M, Jacobs N, Mengelers R, Derom C, Thiery E, . . Myin-Germeys I. Does reactivity to stress cosegregate with subclinical psychosis? A general population twin study. Acta Psychiatr Scand. 2009; 119:45-53.

81. Myin-Germeys I, Krabbendam L, Delespaul PA, Van Os J. Do life events have their effect on psychosis by influencing the emotional reactivity to daily life stress? Psychol Med. 2003; 33:327-333.

82. Lardinois M, Lataster T, Mengelers R, Van Os J, Myin-Germeys I. Childhood trauma and increased stress sensitivity in psychosis. Acta Psychiatr Scand. 2011; 123:28-35.

83. Collip D, Myin-Germeys I, Van Os J. Does the concept of "sensitization" provide a plausible mechanism for the putative link between the environment and schizophrenia? Schizophr Bull. 2008; 34:220-225.

84. Palmier-Claus JE, Dunn G, Lewis SW. Emotional and symptomatic reactivity to stress in individuals at ultra-high risk of developing psychosis. Psychol Med. 2012; 42:1003-1012.

85. Reininghaus U, Kempton MJ, Valmaggia L, Craig TKJ, Garety P, Onyejiaka A, . . Morgan C. Stress Sensitivity, Aberrant Salience, and Threat Anticipation in Early Psychosis: An Experience Sampling Study. Schizophr Bull. 2016; 42:712-722.

86. Delespaul P, deVries M, van Os J. Determinants of occurrence and recovery from hallucinations in daily life. Soc Psychiatry Psychiatr Epidemiol. 2002; 37:97-104.

87. Oorschot M, Lataster T, Thewissen V, Bentall R, Delespaul P, Myin-Germeys I. Temporal dynamics of visual and auditory hallucinations in psychosis. Schizophr Res. 2012b; 140:77-82.

88. Peters E, Lataster T, Greenwood K, Kuipers E, Scott J, Williams S, ... Myin-Germeys I. Appraisals, psychotic symptoms and affect in daily life. Psychol Med. 2012; 42:1013-1023.

89. Ben-Zeev D, Ellington K, Swendsen J, Granholm E. Examining a Cognitive Model of Persecutory Ideation in the Daily Life of People With Schizophrenia: A Computerized Experience Sampling Study. Schizophr Bull. 2011; 37:1248-1256.

90. Appelbaum PS, Robbins PC, Roth LH. Dimensional approach to delusions: comparison across types and diagnoses. Am J Psychiatry. 1999; 156:1938-1943.

91. Bentall RP, Rowse G, Shryane N, Kinderman P, Howard R, Blackwood N, . . Corcoran R. The cognitive and affective structure of paranoid delusions: a transdiagnostic investigation of patients with schizophrenia spectrum disorders and depression. Arch Gen Psychiatry. 2009; 66:236-247.

92. Kesting $M-L$, Lincoln TM. The relevance of self-esteem and self-schemas to persecutory delusions: A systematic review. Compr Psychiatry. 2013; 54:766-789.

93. Krabbendam L, van Os J. Affective processes in the onset and persistence of psychosis. Eur Arch Psychiatry Clin Neurosci. 2005; 255:185-189. 
94. Smith B, Fowler DG, Freeman D, Bebbington P, Bashforth H, Garety P, ... Kuipers E. Emotion and psychosis: links between depression, self-esteem, negative schematic beliefs and delusions and hallucinations. Schizophr Res. 2006; 86:181-188.

95. Thewissen V, Bentall RP, Lecomte T, van Os J, Myin-Germeys I. Fluctuations in self-esteem and paranoia in the context of daily life. J Abnorm Psychol. 2008; 117:143-153.

96. Thewissen V, Myin-Germeys I, Bentall R, de Graaf R, Vollebergh W, van Os J. Instability in self-esteem and paranoia in a general population sample. Soc Psychiatry Psychiatr Epidemiol. 2007; 42:1-5.

97. Thewissen V, Bentall RP, Oorschot M, à Campo J, van Lierop T, van Os J, Myin-Germeys I. Emotions, self-esteem, and paranoid episodes: An experience sampling study. Br J Clin Psychol. 2011; 50:178-195.

98. Svrakic DM, Zorumski CF, Svrakic NM, Zwir I, Cloninger CR. Risk architecture of schizophrenia: the role of epigenetics. Curr Opin Psychiatry. 2013; 26:188-195.

99. van Os J, Kenis G, Rutten BP. The environment and schizophrenia. Nature. 2010; 468:203-212.

100. Jones HJ, Stergiakouli E, Tansey KE, et al. Phenotypic manifestation of genetic risk for schizophrenia during adolescence in the general population. JAMA Psychiatry. 2016; 73:221-228.

101. Sieradzka D, Power RA, Freeman D, Cardno AG, McGuire P, Plomin R, . . Ronald A. Are Genetic Risk Factors for Psychosis Also Associated with Dimension-Specific Psychotic Experiences in Adolescence? PLoS One. 2014; 9:e94398.

102. Zammit S, Hamshere M, Dwyer S, Georgiva L, Timpson N, Moskvina V, . . O'Donovan MC. A Population-Based Study of Genetic Variation and Psychotic Experiences in Adolescents. Schizophr Bull. 2013.

103. Lardinois M, Myin-Germeys I, Bak M, Mengelers R, Van Os J, Delespaul PAEG. The dynamics of symptomatic and non-symptomatic coping with psychotic symptoms in the flow of daily life. Acta Psychiatr Scand. 2007; 116:71-75.

104. Myin-Germeys I, Nicolson NA, Delespaul PA. The context of delusional experiences in the daily life of patients with schizophrenia. Psychol Med. 2001a; 31:489-498. 


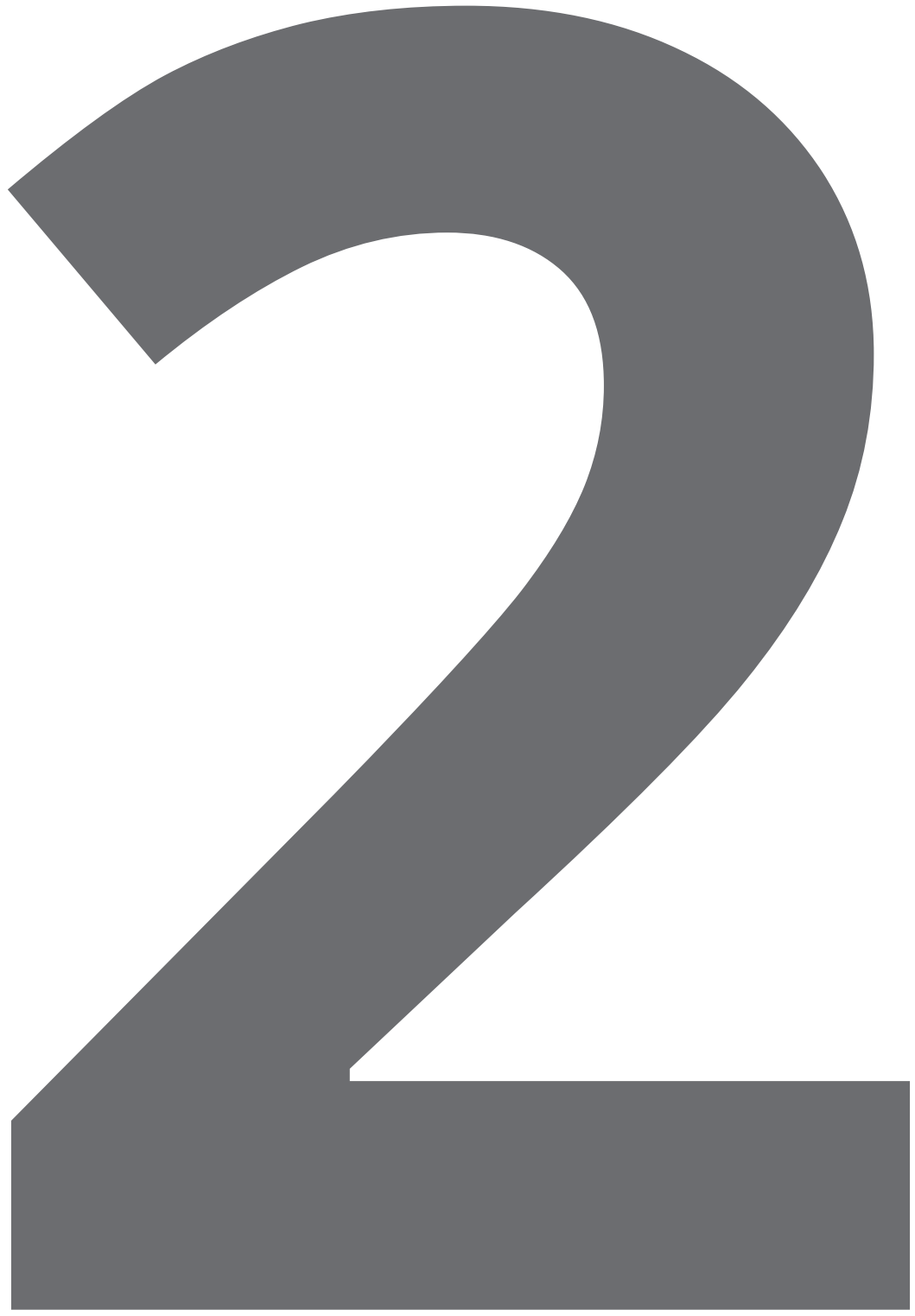




\section{Chapter 2}

\section{'False positive' self-reported psychotic experiences in the general population: an investigation of outcome, predictive factors and clinical relevance}

Y. van der Steen ${ }^{1,2}$, I. Myin-Germeys ${ }^{2}$, M. van Nierop², M. ten Have², R. de Graaf ${ }^{3}$, S. van Dorsselaer ${ }^{3}$, J. van Os ${ }^{1,4,5}$, R. van Winkel ${ }^{6,7}$

${ }^{1}$ Maastricht University, School for Mental Health and Neuroscience (MHeNS), Department of Psychiatry \& Neuropsychology, Maastricht, the Netherlands

${ }^{2} \mathrm{KU}$ Leuven, Department of Neuroscience, Research Group Psychiatry, Center for Contextual Psychiatry, Leuven, Belgium

${ }^{3}$ Netherlands Institute of Mental Health and Addiction, Utrecht, the Netherlands

${ }^{4}$ King's College London, King's Health Partners, Department of Psychosis Studies, Institute of Psychiatry, London, United Kingdom

${ }^{5}$ Department of Psychiatry, Brain Centre Rudolf Magnus, University Medical Centre Utrecht, Utrecht, the Netherlands

${ }^{6}$ University Psychiatric Center, KU Leuven, Campus Kortenberg, Leuvensesteenweg, Kortenberg, Belgium

${ }^{7} \mathrm{KU}$ Leuven, Department of Neuroscience, Research Group Psychiatry, Center for Clinical Psychiatry, Leuven, Belgium

Epidemiology and Psychiatric Sciences, 2018, online publication ahead of print 


\section{ABSTRACT}

Aims. Self-reported psychotic experiences (SRPE) by individuals from the general population are often unconfirmed by clinical interview and referred to as 'false positive' (FP) SRPE. FP SRPE have been suggested to represent the mildest form of risk along the extended psychosis continuum. However, little is known about their (clinical) outcome and evolution over time. Aims of this study were to prospectively examine, in individuals with FP SRPE, (1) the prevalence of remission, persistence and transition to validated PE at 3-year follow-up; (2) potential baseline psychopathological and psychosocial predictors of persistence of FP SRPE and transition to validated PE, and (3) whether those with persistent FP SRPE and validated PE already differed on psychopathology and psychosocial factors at baseline. We tested the hypotheses that (i) individuals with FP SRPE would be more likely to have SRPE and validated PE at follow-up, and (ii) that FP SRPE would be predictive of lower functioning and more psychopathology and help-seeking behaviour at follow-up.

Methods. Baseline ( $n=6646)$ and 3-year follow-up ( $n=5303)$ data of the second Netherlands Mental Health Survey and Incidence Study (NEMESIS-2), a general population research project on prevalence, incidence, course, and consequences of psychiatric disorders was used. Self-report of PE was followed by clinical interview to determine clinical validity. Presence of mood, anxiety and substance use disorders, childhood adversity, help-seeking and functioning as well as PE characteristics (number, frequency, distress and impact) were used in the analyses which included only individuals with complete data for both assessments waves ( $n=4683)$.

Results. At baseline, 454 participants had any FP SRPE; of these 372 participants had complete follow-up data available. Those with baseline FP SRPE were significantly more likely to report SRPE (OR=3.58; 95\% $\mathrm{Cl} 2.38-5.40, p<0.001)$ and validated PE $(\mathrm{OR}=6.26$; $95 \% \mathrm{Cl} 3.91-10.02, p<0.001)$ at follow-up. Baseline FP SRPE also predicted presence of mood and anxiety disorders, reduced functioning and help-seeking at follow-up. Several baseline psychopathological, psychosocial and PE characteristics were predictive for the persistence of SRPE. These factors also differentiated groups with FP SRPE or validated PE from those with remitted FP SRPE at follow-up.

Conclusions. 'False positive SRPE', are not truly 'false' as they index risk for development of clinically relevant psychotic symptoms, development of mood and anxiety disorders and reduced functioning. Self-reported PE, even unconfirmed, warrant 'watchful waiting' and follow-up over time especially when they are reported by individuals with reduced psychosocial functioning and general psychiatric problems. 


\section{INTRODUCTION}

There is evidence that the psychosis phenotype is expressed along a continuum, ranging from mild, subclinical psychotic experiences (PE) to full-blown psychotic disorder, also referred to as the "extended psychosis phenotype"1-3. The prevalence of PE of 5.8-7.2\% in the general population ${ }^{4,5}$ is much higher than the lifetime prevalence of $0.4 \%-0.7 \%$ for psychotic disorder in the schizophrenia spectrum ${ }^{6,7}$. Even though a large percentage of PE are not associated with distress and most are transitory in nature ${ }^{4,8}$, PE do predict transition to clinical psychotic disorder and hospital admission for psychosis, especially when PE are more severe in terms of frequency, number and persistence over time ${ }^{2}$ 3, 9 . Furthermore, PE have been found to be associated with (childhood) traumatic experiences, neuroticism, substance use and/or dependence, as well as global, cognitive, social, and role impairment and are often reported by individuals with non-psychotic illness ${ }^{10-16}$. Furthermore, the associations between PE and other mental disorders have been found to be bidirectional in nature ${ }^{17}$.

Although general population studies consistently report that PE are relatively common, there are substantial differences in reported prevalence rates. In their systematic reviews of prevalence and incidence of $\mathrm{PE}$, Linscott and Van $\mathrm{Os}^{4,18}$ reported that PE were most prevalent in studies using self-reports of participants, with rates were more than three times larger than in studies using interview-based assessments. Two studies in which self-reports were followed by clinical reassessment reported that $\sim 40 \%$ of self-reported psychotic experiences (SRPE) were confirmed by clinical interview ${ }^{19,20}$.

Little is known about the progression of PE over time and the characteristics of individuals who report SRPE that cannot be confirmed by clinical interview, also referred to as 'false positive' (FP) SRPE. Only one prospective population-based study examined risk for future psychotic disorder in those with FP SRPE and validated PE ${ }^{21}$. Both types of PE were associated with risk for psychotic disorder at 3-year follow-up, with greater risk for those with confirmed PE than those with FP SRPE. More recently, van Nierop et al. ${ }^{20}$ specifically compared cross-sectional psychopathological and psychosocial characteristics of groups with FP SRPE, clinically validated PE and controls without SRPE. Their results showed that, compared to individuals reporting no PE, those with at least one FP SRPE were more likely to have a lifetime mood, anxiety or substance use disorder, reported higher levels of neuroticism, were more likely to be characterized by psychosocial risk indicators including childhood adversity, bullying, recent negative life events as well as cannabis use. This group 
was also characterized by worse social, physical and mental functioning, assessed over the last month. However, when those with FP SRPE were compared to those with validated SRPE, associations with psychopathology, social functioning, psychosocial factors as well as help seeking in general and specifically for SRPE were generally less strong.

This evidence may suggest that FP SRPE are not 'truly' false-positive but represent the mildest expression of psychosis proneness along the extended psychosis continuum ${ }^{20}$. However, further investigation of the characteristics, course and outcomes of FP SRPE as well as examination of the impact of psychopathological and psychosocial factors on the outcomes of persistence and progression to validated PE is needed before such conclusion can be substantiated. Additionally, further examination of the impact of FP SRPE on later psychological and psychosocial functioning is necessary to determine the clinical relevance of FP SRPE in terms of the development of functional impairment and need for care.

In the present study, we therefore aimed to prospectively examine the development and clinical significance of FP SRPE at baseline over a 3-year follow-up period. We examined (1) rates of remission, persistence of FP SRPE and transition to validated PE; (2) if individuals with baseline FP SRPE were more likely to report new PE, both self-reported as well as clinically validated PE, than individuals without FP SRPE; and (3) the predictive value of FP SRPE on current mental, social, general functioning, the occurrence of recent mood, anxiety and/or substance disorders as well as need for care. Furthermore, we aimed to examine (4) which psychopathological and psychosocial characteristics measured at baseline were predictive of persistence of FP SRPE and transition to validated PE; and (5) if those with persistent FP SRPE and those who made the transition to validated $\mathrm{PE}$ at follow-up differed regarding the expression of psychopathological and psychosocial factors present at baseline compared to those with remitted FP SPRE at follow-up.

In line with the psychosis continuum model in which FP SRPE are suggested to be the mildest expression of risk for psychotic disorder ${ }^{20}$, we hypothesized that (1) individuals with baseline FP SRPE would be significantly more likely to report PE at follow-up, both FP SRPE and validated PE, than individuals without SRPE at baseline; (2) the presence of FP SRPE at baseline would be predictive of reduced functioning and presence of mood- anxiety and substance use disorders at follow-up; and (3) psychopathological and psychosocial factors, previously found to distinguish those with FP SRPE from those without SRPE and known to be associated with (transition to) psychotic disorder, would predict both the persistence of FP SRPE as well as the progression towards validated PE over the follow-up period. 


\section{METHODS}

\section{Study cohort}

This study used data from the first wave (baseline), performed from November 2007 to July 2009 and second wave collected three years later from November 2010 to June 2012, of the second Netherlands Mental Health Survey and Incidence Study (NEMESIS-2), version 2.0. This is a longitudinal study of prevalence, incidence, course, and consequences of psychiatric disorders in the Dutch general population aged 18 to 64 years. The study was approved by a Medical Ethics committee. After having been informed about the study aims, respondents provided written informed consent. For a more detailed description of the NEMESIS-2 methods see de Graaf et al.22,23. At baseline 6646 persons were interviewed (response rate: $65.1 \%$ ). All baseline respondents were approached for follow-up and 5303 persons could be interviewed again (response rate $80.4 \%$, with those deceased excluded). Attrition was not related to any 12-month mental disorder at baseline, after controlling for sociodemographic characteristics ${ }^{24}$. For the current analyses, only participants with complete data for both baseline and follow-up measurements were selected, which had to include clinical re-interview when PE were reported.

\section{Instruments}

\section{Assessment of PE}

Studies on earlier Composite International Diagnostic Interview (CIDI) versions concluded that the CIDI assesses common mental disorders with generally acceptable reliability and validity, with the exception of psychosis ${ }^{25}, 26$. Therefore, a psychosis add-on instrument was constructed, based on the section of psychotic symptoms in CIDI versions 1 and 2. It consisted of 20 PE, each rated 'yes', 'no', 'don't know' or 'refuse to answer', each assessed by a lay interviewer. As clinical relevance of PE may be difficult to diagnose by lay interviewers ${ }^{27}$ and interviewers made no clinical judgment about participants' answers, reported experiences may be considered an extension of 'self-report'. At baseline, the assessment period spanned the entire lifetime of a participant, at follow-up the assessment period spanned the time between baseline and follow-up. Whenever a PE was endorsed, the subject was asked to state, on a 1 (rarely) to 4 (almost always) scale, how often this experience occurred (Frequency), how much it bothered them (Distress), to what extent the experience had an influence on their daily professional and social activities (Impact) and at which age it first occurred. The age of first onset, number of SRPE, the averages of Frequency, Distress and Impact at baseline were used as predictors in the analyses. 
Individuals who endorsed at least one SRPE at baseline and/or one SRPE at follow-up at the respective initial interview were contacted within eight weeks for clinical re-interview over the telephone by an experienced clinician at the level of psychologist or psychiatrist. Re-interviews were conducted using questions from the Structured Clinical Interview for DSM-IV SCID-I, ${ }^{28}$ and all findings were discussed with a second clinician. At baseline, 1081 participants (16.3\%) endorsed at least one PE. Of these, 794 participated in clinical re-interview (73.5\%). For 454 (58.2\%) SRPE were determined as FP. At follow-up, 440 out of the total 5303 (8.3\%) participants reported that at least one SRPE had occurred since baseline. Of these, 367 (83.4\%) participants were available for re-interview.

For the analyses six relevant groups were selected (Figure 1). The 372 (of 454) participants with FP SRPE at baseline and all data available at follow-up were divided over three subgroups based on PE status at follow-up: (1) at least one SRPE confirmed by clinical re-interview: the 'Transition to validated PE' group; (2) one or more SRPE, all determined FP by clinical re-interview: the 'Persistent FP SRPE' group; (3) no SRPE: the 'Remitted FP SRPE' group. Given the small number of participants who made the transition to validated PE in the current study $(n=28)$ we chose not to examine transition to psychotic disorder as an outcome, as was done previously by Bak et al. ${ }^{21}$.

Participants without SRPE at baseline were similarly divided over subgroups based on PE status at follow-up: (4) one or more SRPE, with at least one confirmed PE by clinical re-interview: the 'Validated incident PE' group; (5) one or more SRPE, all non-confirmed by clinical re-interview: the 'FP incident SRPE' group; (6) absence of SRPE: the 'control' group.

\section{Demographics, risk factors and psychopathology at baseline}

Participants were interviewed at home by trained interviewers who were not clinicians with the CIDI version 3.029. Neuroticism was assessed using the Eysenck Personality Questionnaire (EPQ-revised short scale) ${ }^{30,31}$. Four types of childhood adversity (physical, emotional, sexual and psychological) and peer victimization were assessed using a questionnaire based on NEMESIS-1, and dichotomized (yes or no). Sexual abuse was assessed as 'yes' when it had happened at least once, physical, emotional and psychological abuse when it had happened sometimes or more often, and bullying when it had happened regularly before the age of 16 . Presence of ten possible negative life events in the previous twelve months was measured, based on the Brugha Life events section and 
dichotomized (yes or no) ${ }^{32}$. Cannabis use was assessed in the section Illegal Substance Use of the CIDI 3.0 and analysed as a dichotomous variable indicating regular use $(\geq 1$ time per week during the last year. Continuous ratings of general, mental and physical health and social functioning over the past month were assessed by the Medical Outcomes Study Short-form Health Survey (SF-36) ${ }^{33,34}$. Help seeking in the past 12 months from psychiatrists or psychologists for any psychiatric problem including drug or alcohol problems was also assessed.

\section{Baseline}

\section{3-year follow-up}

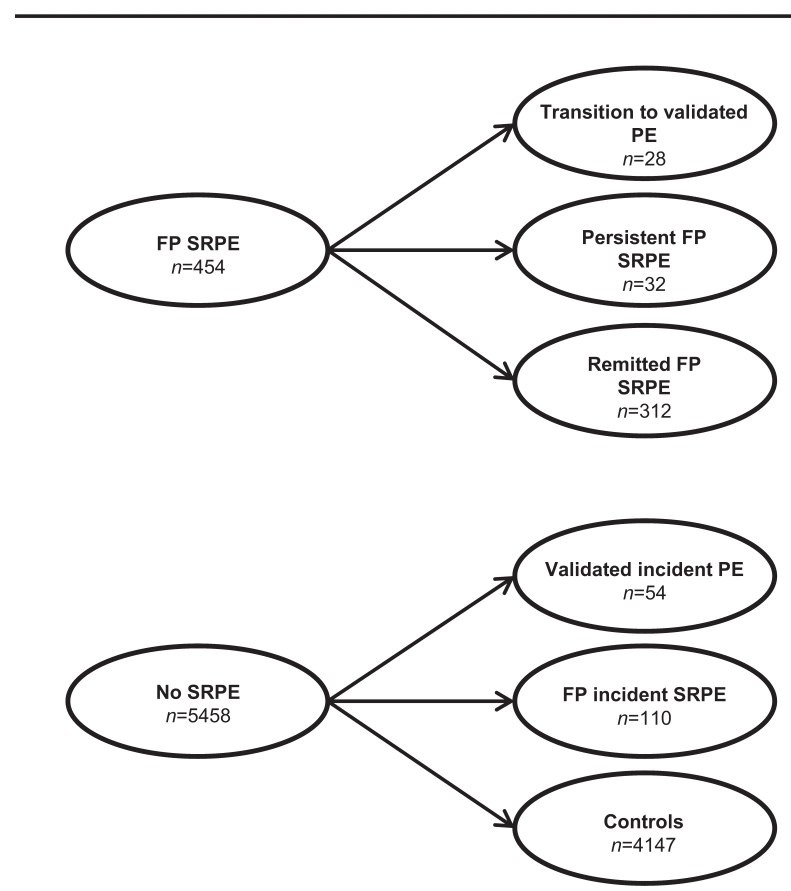

Fig. 1. Sample distribution at baseline and 3-year follow-up.

\section{Analyses}

All analyses were performed in STATA, version $13^{35}$. Logistic regression was used to test the hypothesis that individuals with baseline FP SRPE are significantly more likely to report PE at follow-up than individuals without baseline SRPE (hypothesis 1). The association between presence of baseline FP SRPE as the independent variable and presence 
of SRPE at follow-up as dependent variable was examined, a priori controlling for age and sex. As SRPE were either confirmed or rejected by clinical re-interview at follow-up we ran two models reflecting both outcomes as the dependent variables: (1) any SRPE (FP and validated PE combined); and (2) clinically validated PE only. Logistic regression was also used to test if baseline FP SRPE predicted presence of any mood, anxiety or substance use disorder in the last year before follow-up assessment and help-seeking in general and specifically for PE. Linear regression was used to test if baseline FP SRPE predicted reduced mental, social, physical and general health functioning in the last month at follow-up (hypothesis 2).

In order to test the hypothesis that risk indicators known to be associated with (transition to) psychotic disorder would predict continued self-report of PE (i.e. persistence of SRPE) over the follow-up period within the group with baseline FP SRPE (hypothesis 3), logistic regression was applied, a priori controlling for age and sex. Presence of SRPE (regardless if these were validated at clinical re-interview) as compared to absence of SRPE at follow-up, served as the dependent variable. Psychopathological and psychosocial risk indicators as well as PE characteristics served as independent variables. Furthermore, multinomial logistic regression, a priori controlling for age and sex, was applied to examine if associations with risk indicators would be more pronounced in individuals who persist in reporting FP SRPE and those who display progression towards validated PE, compared to individuals with remitted FP SRPE. In all regression models predictors were entered in separate analyses. 


\section{RESULTS}

\section{Sample}

The mean age of the total sample $(n=4683)$ with complete data available at baseline and follow-up was 44.8 ( $S D=12.3$, range 18-68), with comparable mean ages in the subgroups (table 1). The groups differed significantly on gender distributions $\left(\chi^{2}=17.0, p=0.004\right)$, education level $\left(\chi^{2}=38.2, p<0.001\right)$ and job status $\left(\chi^{2}=20.6, p=0.001\right)$. At baseline, participants available for clinical re-interview did not differ from non-responders with regard to age, lifetime psychiatric disorders, sex, or employment status, while educational attainment was significantly lower $\left(\chi^{2}=8.1, p=0.045\right)$. Non-responders were characterized by more SRPE than participants $(t(1079)=5.14, p<0.001)$. At follow-up participants available for clinical re-interview did not differ from non-responders with regard to age, lifetime anxiety and substance use disorder, sex, educational level or employment status as measured at baseline. However, non-responders had more SRPE $(t(438)=3.49, p<0.001)$ and lifetime mood disorders $\left(\chi^{2}=5.7, p=0.02\right)$ at baseline.

\section{Psychotic experiences}

FP SRPE at baseline and PE at follow-up

Sixty of the 372 participants with baseline FP SRPE (16.1\%) had at least one SRPE at follow-up. These were clinically validated at re-interview for 28 participants (46.7\%). Participants with baseline FP SRPE were significantly more likely to have any SRPE as well as clinically validated PE at follow-up than participants without baseline SRPE (Table 2).

FP SRPE at baseline and psychopathology and functioning at follow-up

The presence of baseline FP SRPE was significantly associated with the presence of any mood or anxiety disorder in the previous year, reduced current general mental, social, physical and overall health functioning, as well as general help-seeking at follow-up (Table 2). 
Table 1. NEMESIS-2 Baseline Sample and Prevalence Characteristics

\begin{tabular}{|c|c|c|c|}
\hline & $\begin{array}{l}\text { Total sample } \\
N(\%)\end{array}$ & $\begin{array}{l}\text { Controls } \\
N(\%)\end{array}$ & $\begin{array}{l}\text { Remitted FP SRPE } \\
N(\%)\end{array}$ \\
\hline \multirow[t]{3}{*}{ Total group } & $4683(100)$ & 4147 (88.6) & $312(6.7)$ \\
\hline & Mean age 44.8 & Mean age 44.9 & Mean age 44.7 \\
\hline & (SD 12.3) & (SD 12.3) & (SD 12.2) \\
\hline \multirow[t]{3}{*}{ Men } & $2141(45,7)$ & $1931(46.6)$ & $119(38.1)$ \\
\hline & Mean age 45.1 & Mean age 45.2 & Mean age 44.2 \\
\hline & (SD 12.3) & (SD 12.2) & (SD 12.7) \\
\hline \multirow[t]{3}{*}{ Women } & 2542 (54.9) & $2216(53.4)$ & $193(61.9)$ \\
\hline & Mean age 44.7 & Mean age 44.6 & Mean age 45.0 \\
\hline & (SD 12.3) & (SD 12.4) & (SD 11.9) \\
\hline Paid job & $3588(76.6)$ & 3205 (77.3) & $233(74.7)$ \\
\hline No Job & $1095(23.4)$ & $942(22.7)$ & $79(25.3)$ \\
\hline \multicolumn{4}{|l|}{ Education } \\
\hline Primary education & $191(4.1)$ & $162(3.9)$ & $14(4.5)$ \\
\hline Lower sec. education & $1200(25.6)$ & $1028(24.8)$ & $97(31.1)$ \\
\hline Higher sec. education & $1511(32.3)$ & $1330(32.1)$ & $105(33.6)$ \\
\hline $\begin{array}{l}\text { Higher professional/ } \\
\text { university education }\end{array}$ & $1781(38.0)$ & $1627(39.2)$ & $96(30.8)$ \\
\hline
\end{tabular}

FP, false positive; SRPE, self-reported psychotic experiences; PE, psychotic experiences

Table 2. Results of logistic and linear regression analyses: associations between presence of baseline FP SRPE and presence of SRPE and validated PE, current functioning, presence of psychopathology and help-seeking at follow-up, as compared to no baseline SRPE, adjusted for sex and age

\begin{tabular}{llll}
\hline Dichotomous variable & OR & 95\% int. & $P$ \\
\hline SRPE at follow-up & 3.58 & $2.38-4.40$ & $<0.001$ \\
Validated PE at follow-up & 6.26 & $3.91-10.02$ & $<0.001$ \\
Any mood disorder $^{\mathrm{a}}$ & 2.62 & $1.77-3.86$ & $<0.001$ \\
Any anxiety disorder $^{\mathrm{a}}$ & 2.56 & $1.81-3.64$ & $<0.001$ \\
Any substance disorder $^{\mathrm{a}}$ & 1.60 & $.90-2.85$ & $\mathrm{~ns}$ \\
Help seeking, general $^{\mathrm{a}, \mathrm{b}}$ & 2.05 & $1.56-2.69$ & $<0.001$ \\
Help seeking, specific $^{\mathrm{a}, \mathrm{c}}$ & 1.44 & $.54-3.82$ & $\mathrm{~ns}$ \\
\hline
\end{tabular}

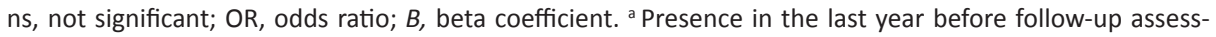
ment; ${ }^{b}$ General: psychiatric problems, including drug- or alcohol-related help seeking; ' Specific: psychotic experiences 


\begin{tabular}{|c|c|c|c|}
\hline Persistent FP SRPE & Transition to validated PE & Incident FP SRPE & Incident validated PE \\
\hline$N(\%)$ & $N(\%)$ & $N(\%)$ & $N(\%)$ \\
\hline $32(0.7)$ & $28(0.6)$ & $110(2.3)$ & $54(1.1)$ \\
\hline Mean age 45.8 & Mean age 45.9 ) & Mean age 44.7 & Mean age 43.0 \\
\hline (SD 12.5) & (SD 10.3 & (SD 12.4) & (SD 12.9) \\
\hline $17(53.1)$ & $6(21.4)$ & 45 (40.9) & $23(42.6)$ \\
\hline Mean age 43.5 & Mean age 49.5 & Mean age 44.2 & Mean age 42.2 \\
\hline (SD 13.9) & (SD 11.6) & (SD 12.0) & (SD 11.6) \\
\hline $15(46.9)$ & $22(78.6)$ & $65(59.1)$ & $31(57.4)$ \\
\hline Mean age 48.4 & Mean age 44.9 & Mean age 45.1 & Mean age 43.6 \\
\hline (SD 10.4) & (SD 10.0) & (SD 12.7) & (SD 11.9) \\
\hline $26(81.2)$ & $16(57.1)$ & $76(69.1)$ & $32(59.3)$ \\
\hline $6(18.8)$ & $12(42.9)$ & $34(30.9)$ & $22(40.7)$ \\
\hline $2(6.2)$ & $4(14.3)$ & $5(4.5)$ & $4(7.4)$ \\
\hline $10(31.3)$ & $7(25)$ & $38(34.6)$ & $20(37.0)$ \\
\hline $14(43.8)$ & $10(35.7)$ & 34 (30.9) & $18(33.3)$ \\
\hline $6(18.7)$ & $7(25)$ & $33(30.0)$ & $12(22.2)$ \\
\hline
\end{tabular}

\begin{tabular}{llll} 
Continuous variable & $\boldsymbol{B}$ & $95 \%$ int. & $\boldsymbol{P}$ \\
\hline General mental functioning & -2.37 & $-3.68--1.06$ & $<0.001$ \\
General social functioning & -3.74 & $-5.67--1.82$ & $<0.001$ \\
General physical functioning & -2.55 & $-4.37--.74$ & $<0.01$ \\
General health functioning & -4.37 & $-6.21--2.52$ & $<0.001$
\end{tabular}


Table 3. Results of logistic regression analyses: associations between baseline psychopathological, psychosocial and PE factors and persistence of SRPE at follow-up as compared to remission, adjusted for sex and age

\begin{tabular}{|c|c|c|c|}
\hline Dichotomous variable & OR & 95\% int. & $\boldsymbol{P}$ \\
\hline Lifetime mood disorder & 1.91 & $1.08-3.39$ & 0.03 \\
\hline Lifetime anxiety disorder & 2.08 & $1.16-3.70$ & 0.01 \\
\hline Lifetime substance disorder & 1.56 & $0.82-2.97$ & ns \\
\hline Neuroticism & 3.02 & $1.65-5.52$ & $<0.001$ \\
\hline Sexual abuse $<16$ & 1.40 & $0.65-3.04$ & ns \\
\hline Physical abuse $<16$ & 1.58 & $0.73-3.42$ & ns \\
\hline Emotional abuse $<16$ & 1.75 & $0.96-3.20$ & ns \\
\hline Psychological abuse $<16$ & 1.93 & $1.08-3.44$ & 0.03 \\
\hline Regular bullying <16 & 1.23 & $0.60-2.52$ & ns \\
\hline Negative life events past year & 1.45 & $0.79-2.68$ & ns \\
\hline Regular cannabis use ( $\geq 1 / w k$, last year) & 1.55 & $0.39-6.11$ & ns \\
\hline Help seeking, general ${ }^{a}$ & 1.97 & $1.06-3.66$ & 0.03 \\
\hline Help seeking, specific ${ }^{b}$ & 1.08 & $0.35-3.30$ & ns \\
\hline
\end{tabular}

ns, not significant; OR, odds ratio. a General: psychiatric problems, including drug- or alcohol-related help seeking; ${ }^{b}$ Specific: psychotic experiences

Table 4. Results of multinomial logistic regression showing the effect of baseline psychopathological and psychosocial characteristics on PE status at follow-up, adjusted for sex and age

\begin{tabular}{|c|c|c|c|}
\hline \multirow[b]{2}{*}{ Dichotomous variable } & \multicolumn{3}{|c|}{ Persistent FP SRPE vs. Remitted FP SRPE (ref) } \\
\hline & $R R R$ & 95\% int. & $\boldsymbol{P}$ \\
\hline Lifetime mood disorder & 1.59 & $0.74-3.44$ & ns \\
\hline Lifetime anxiety disorder & 1.68 & $0.77-3.67$ & ns \\
\hline Lifetime substance disorder & 1.35 & $0.59-3.12$ & ns \\
\hline Neuroticism (high/low) & 2.97 & $1.34-6.58$ & 0.007 \\
\hline Sexual abuse $<16$ & 1.62 & $0.57-4.62$ & ns \\
\hline Physical abuse $<16$ & 0.74 & $0.21-2.61$ & ns \\
\hline Emotional abuse $<16$ & 1.22 & $0.51-2.88$ & ns \\
\hline Psychological abuse $<16$ & 2.02 & $0.94-4.33$ & 0.07 \\
\hline Regular bullying $<16$ & 1.26 & $0.48-3.30$ & ns \\
\hline Negative life events past year & 1.78 & $0.77-4.14$ & ns \\
\hline Regular cannabis use ( $\geq 1 / w k$, last year) & 0.83 & $0.10-7.07$ & ns \\
\hline Help seeking, general ${ }^{a}$ & 1.81 & $0.78-4.19$ & ns \\
\hline Help seeking, specific ${ }^{b}$ & na & & \\
\hline
\end{tabular}

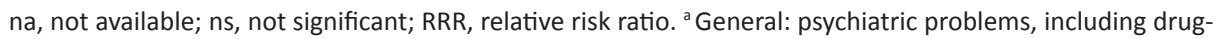
or alcohol-related help seeking; ${ }^{\text {b }}$ Specific: psychotic experiences 


$\begin{array}{llll}\text { Continuous variable } & \text { OR } & \text { 95\% int. } & \boldsymbol{P} \\ \text { General mental functioning } & 0.98 & 0.965-0.996 & 0.02 \\ \text { General social functioning } & 0.98 & 0.97-0.995 & 0.007 \\ \text { General physical functioning } & 0.99 & 0.99-1.01 & \mathrm{~ns} \\ \text { General health functioning } & 0.98 & 0.97-0.996 & 0.01 \\ \text { Onset of SRPE (age in years) } & 1.00 & 0.98-1.03 & \mathrm{~ns} \\ \text { Number of SRPE } & 1.43 & 1.09-1.87 & 0.01 \\ \text { Frequency of SRPE } & 1.48 & 1.05-2.09 & 0.03 \\ \text { Distress of SRPE } & 1.15 & 0.87-1.52 & \mathrm{~ns} \\ \text { Impact of SRPE } & 1.25 & 0.87-1.77 & \mathrm{~ns}\end{array}$

\begin{tabular}{|c|c|c|c|c|c|}
\hline \multicolumn{3}{|c|}{ Transition to validated PE vs. Remitted FP SRPE (ref) } & \multicolumn{3}{|c|}{ Transition to validated PE vs. Persistent FP SRPE (ref) } \\
\hline RRR & 95\% int. & $\boldsymbol{P}$ & RRR & 95\% int. & $\boldsymbol{P}$ \\
\hline 2.32 & $1.05-5.10$ & 0.04 & 1.45 & $0.51-4.15$ & ns \\
\hline 2.60 & $1.18-5.73$ & 0.02 & 1.54 & $0.54-4.42$ & ns \\
\hline 1.88 & $0.76-4.66$ & ns & 1.39 & $0.43-4.49$ & ns \\
\hline 3.08 & $1.31-7.28$ & 0.01 & 1.04 & $0.34-3.22$ & ns \\
\hline 1.24 & $0.44-3.49$ & ns & 0.76 & $0.19-3.11$ & ns \\
\hline 2.94 & $1.14-7.54$ & 0.03 & 3.96 & $0.88-17.72$ & 0.07 \\
\hline 2.45 & $1.10-5.44$ & 0.03 & 2.01 & $0.66-6.15$ & ns \\
\hline 1.83 & $0.82-4.08$ & ns & 0.90 & $0.31-2.59$ & ns \\
\hline 1.20 & $0.45-3.19$ & ns & 0.96 & $0.26-3.55$ & ns \\
\hline 1.17 & $0.51-2.69$ & ns & 0.66 & $0.21-2.06$ & ns \\
\hline 2.70 & $0.51-14.24$ & ns & 3.27 & $0.25-42.47$ & ns \\
\hline 2.15 & $0.94-4.93$ & 0.07 & 1.19 & $0.39-3.64$ & ns \\
\hline 2.45 & $0.77-7.85$ & ns & na & & \\
\hline
\end{tabular}


Risk factors for persistence of any SRPE at follow-up

Results of logistic regression analyses showed several risk indicators measured at baseline to be predictive for the continued presence or 'persistence' of SRPE at follow-up (Table 3). These included the occurrence of a lifetime mood disorder, a lifetime anxiety disorder, lower general health, social and mental functioning assessed over the last month, high level of neuroticism, the occurrence of psychological abuse before the age of 16 years and help seeking for general psychological problems. Moreover, persistence of SRPE was predicted by the number and frequency of baseline SRPE. More information about prevalence rates and other characteristics of the examined psychopathological and psychosocial variables can be found in supplementary tables S1 and S2.

\section{Persistence of FP SRPE and transition to validated PE}

Results of multinomial logistic regression analyses showed that persistence of FP SRPE, as compared to remission of FP SRPE at follow-up, was significantly predicted by presence of high neuroticism and lower general mental functioning. The occurrence of psychological abuse before the age of 16 years just failed to reach statistical significance (Tables 4 and 5).

Table 5. Results of multinomial logistic regression showing the effect of baseline psychopathological and SRPE characteristics on PE status at follow-up, adjusted for sex and age

\begin{tabular}{llll}
\hline & \multicolumn{2}{l}{ Persistent FP SRPE vs. Remitted FP SRPE (ref) } \\
\hline Continuous variable & $\boldsymbol{B}$ & $95 \%$ int. & $\boldsymbol{P}$ \\
\hline General mental functioning & -0.02 & $-0.04-0.0001$ & 0.05 \\
General social functioning & -0.01 & $-0.03-0.003$ & $\mathrm{~ns}$ \\
General physical functioning & -0.003 & $-0.02-0.02$ & $\mathrm{~ns}$ \\
General health & -0.01 & $-0.03-0.01$ & $\mathrm{~ns}$ \\
Onset of SRPE (age in years) & 0.01 & $-0.03-0.05$ & $\mathrm{~ns}$ \\
Number of SRPE & 0.12 & $-0.30-0.54$ & $\mathrm{~ns}$ \\
Frequency of SRPE & 0.35 & $-0.11-0.80$ & $\mathrm{~ns}$ \\
Distress of SRPE & 0.06 & $-0.33-0.44$ & $\mathrm{~ns}$ \\
Impact of SRPE & 0.29 & $-0.15-0.74$ & $\mathrm{~ns}$ \\
\hline
\end{tabular}

$b$, beta coefficient 
Transition to validated PE at follow-up was significantly predicted by presence of a lifetime anxiety disorder, a lifetime mood disorder, high neuroticism, the occurrence of physical and/or emotional abuse before age 16 and lower health in general. A greater number of baseline SRPE was also associated with transition to validated symptoms, while an increased frequency of these experiences just failed to reach significance. Furthermore, in general, effect sizes were larger than those of the group with persistent FP SRPE, although none reached statistical significance when directly compared (Tables 4 and 5).

\begin{tabular}{llllll}
\multicolumn{2}{l}{ Transition to validated PE vs. Remitted FP SRPE (ref) } & \multicolumn{4}{l}{ Transition to validated PE vs. Persistent FP SRPE (ref) } \\
\hline $\boldsymbol{B}$ & $95 \%$ int. & $\boldsymbol{P}$ & $\boldsymbol{B}$ & $95 \%$ int. & $\boldsymbol{P}$ \\
-0.02 & $-0.04-0.003$ & $\mathrm{~ns}$ & 0.003 & $-0.03-0.03$ & $\mathrm{~ns}$ \\
-0.02 & $-0.03--0.004$ & 0.01 & -0.006 & $-0.03-0.01$ & $\mathrm{~ns}$ \\
-0.007 & $-0.03-0.01$ & $\mathrm{~ns}$ & -0.004 & $-0.03-0.02$ & $\mathrm{~ns}$ \\
-0.03 & $-0.04--0.01$ & 0.004 & -0.02 & $-0.04-0.006$ & $\mathrm{~ns}$ \\
-0.005 & $-0.04-0.03$ & $\mathrm{~ns}$ & -0.02 & $-0.07-0.03$ & $\mathrm{~ns}$ \\
0.54 & $0.21-0.86$ & 0.001 & 0.41 & $-0.08-0.90$ & $\mathrm{~ns}$ \\
0.44 & $-0.03-0.91$ & 0.07 & 0.09 & $-0.53-0.71$ & $\mathrm{~ns}$ \\
0.22 & $-0.15-0.58$ & $\mathrm{~ns}$ & 0.16 & $-0.35-0.66$ & $\mathrm{~ns}$ \\
0.15 & $-0.34-0.64$ & $\mathrm{~ns}$ & -0.14 & $-0.76-0.48$ & $\mathrm{~ns}$ \\
\hline
\end{tabular}




\section{DISCUSSION}

\section{3-year outcomes of baseline FP SRPE: remission, persistence and transition}

Our study setup allowed us to collect information about PE in an adult general population sample through self-report and interview-based clinical assessment at baseline and 3-year follow-up. The distinction between 'false positive' and validated PE could therefore be made at both baseline and follow-up. This allowed for an investigation of the prognostic value of baseline FP SRPE on the continued report of PE, psychopathology and functioning at follow-up as well as examination of the association between possible risk indicators assessed at baseline and the differential outcomes of baseline FP SRPE at follow-up.

Discontinuity or remission of PE (83.9\%) was the most prevalent outcome, as previously reported ${ }^{4}$. However, results also confirmed the hypothesis that individuals with baseline FP SRPE were more likely to again report SPRE at follow-up. They were 3.5 times more likely to report any SRPE at follow-up and more importantly, 6 times more likely to report clinically validated PE than participants without baseline SRPE.

\section{Clinical implications of FP SRPE: current functioning, psychopathology and help-seeking}

Presence of baseline FP SRPE predicted lower current mental and social functioning as well as physical and general health functioning at follow-up. Additionally, presence of any current (in the previous year) mood or anxiety disorder and help-seeking behaviour were predicted by FP SRPE. Combined with a previous finding that FP SRPE were predictive of transition to psychotic disorder ${ }^{21}$, our results confirm the suggestion by van Nierop and colleagues ${ }^{20}$ that individuals reporting FP PE represent a subgroup with the mildest subthreshold expression of psychosis along the psychosis continuum, in which $\mathrm{PE}$ are more likely to remain subclinical although need for care may eventually develop. Therefore, SRPE not confirmed by clinical interview, also referred to as 'false positive SRPE', are not truly 'false' as they still index risk for validated psychosis as well as future presence of mood- and/or anxiety disorder and reduced functioning. In clinical practice, even false positive SRPE thus warrant a 'watchful waiting' approach, especially when they co-occur with additional psycho(social) problems, in order to intervene promptly when PE do become more crystallized and distressing and therefore clinically relevant. 


\section{Predictors of persistence of SRPE}

Our study extends the findings of previous general population studies that did not make a distinction between validated and FP SRPE and reported an effect of persistence of SPRE on help-seeking and impairment at follow-up ${ }^{8,36}$. It also extends the findings of Bak et $a^{21}$, who found baseline FP SRPE to be associated with transition to psychotic disorder while not examining possible associated psychopathological and psychosocial factors. More and more frequent baseline SRPE, a diagnosis of mood disorder, anxiety disorder, high neuroticism, lower social and mental functioning and general health in the previous month, childhood adversity (psychological abuse) and help seeking for psychological problems were identified as significant predictors for persistence of SRPE.

Not unexpected, more and more frequent baseline FP SRPE were found to predict persistence of SRPE, as both have been previously associated with risk of transition to psychotic disorder ${ }^{9}$. Previous studies have found an increase in help-seeking and need for subsequent mental health service use in individuals with $\mathrm{SRPE}^{37,38}$, especially when reporting multiple PE. In contrast, distress and impact did not predict persistence of SRPE. One explanation might be that at baseline any lifetime PE were assessed. Some of those might have existed for a long time and some might no longer have been present at baseline assessment, possibly lowering ratings of distress and impact. Less distress and impact was also reflected by the fact that only four participants (all with validated PE at follow-up) were seeking help specifically for PE. Furthermore, our results are in line with

other general population studies of individuals with $\mathrm{PE}^{13,17,39,40}$, as well as in individuals meeting criteria for the Ultra High Risk state for psychosis ${ }^{41}$, showing high comorbidity with mood and anxiety symptoms and disorders.

\section{Characteristics of persistence of FP SRPE and transition to validated PE}

This study is unique in the fact that it could directly investigate possible differences in psychopathological and psychosocial characteristics related to persistence of FP SRPE, as well as transition to validated PE. While the group with persistent FP SRPE was distinguishable from those with remitted FP SRPE by lower general mental functioning in the last month and high neuroticism, the transition group was, in addition to these factors, also characterized by the presence of a lifetime mood and/or anxiety disorder, instances of childhood adversities and lower health in general as well as more SRPE at baseline. Findings extend those of Van Nierop et $a .^{20}$ who reported that individuals with validated baseline PE were more often characterised by mood and anxiety disorder and four times more likely to seek help for their PE. In conclusion, the present study was able to show, 
in a longitudinal design, that those who will later develop validated PE were already characterized by high levels of lifetime psychopathology and exposure to psychosocial risk indicators at baseline

\section{Theoretical implications}

Van Os and Linscott ${ }^{2}$ proposed an "extended psychosis phenotype" reflecting a behavioural expression of vulnerability for psychotic disorder in the general population. It implies that PE are not exclusive to, and can occur independently of, psychotic disorder. At any point in time, most likely when PE persist over time, individuals may become help-seeking, with transition to psychotic disorder eventually occurring in some. This model has recently been reformulated into an "extended and transdiagnostic psychosis phenotype" to account for anxiety and affective symptoms often coexisting alongside $\mathrm{PE}^{42}$ and suggests that it is the co-expression of comorbid symptoms that may result in greater severity, socio-environmental risk and poorer functioning. Importantly, a recent study on PE in the general population showed that the relationship between PE and mental disorders is bi-directional in nature ${ }^{17}$. The probability of transition to a clinical psychotic disorder increases as the load of socio-environmental adverse factors such as instances of childhood trauma increases ${ }^{16}$. Our findings provide further evidence for the validity of this model.

\section{Strengths and limitations}

Results of this study should be interpreted in the context of its strengths and limitations. A strength is the size of the baseline sample. Furthermore, as the study set-up allowed us to distinguish between FP SRPE and clinically validated PE at baseline and follow-up, this is the first longitudinal study able to examine differential outcomes and characteristics of FP SRPE in the general population.

There are some methodological limitations. First, outcomes of persistence of FP SRPE and transition to validated PE were rare $(0.7 \%$ and $0.6 \%$ of the total baseline sample and $8.6 \%$ and $7.5 \%$ of those with SRPE at follow-up and available for re-interview, respectively), which may have impacted on the statistical power in analyses examining associations with psychopathological and psychosocial characteristics, especially when groups were compared. Second, we relied on retrospective reports of lifetime PE at baseline assessment and as a result could have occurred many years before which may have impacted on the recall of these experiences. Third, as self-report of PE was gathered during an interview with a lay interviewer this may have led to less acknowledgment of PE than on 
a traditional pen-and-paper self-report assessment. Fourth, as we could only select data of those participants with complete data at baseline and follow-up, not all tested individuals could be included in some of the analyses. At baseline, non-participants of clinical re-interview were characterized by higher number of SRPE. At follow-up, non-participants reported higher numbers of SRPE and had more often a lifetime mood disorder. It is therefore possible that the effect sizes would have been different if all data had been available. Finally, it has been shown that PE are more common in children compared to adolescents and adults ${ }^{43,44}$. The current sample comprises an adult sample with a wide age range and although the sample was nationally representative for The Netherlands, younger subjects were somewhat underrepresented ${ }^{23}$. This might have led to an underestimation of the prevalence of both the persistence of SRPE and transition to validate PE over time. Similarly, the impact of risk factors might be different in younger age groups and studies including child and adolescent samples are therefore needed.

In conclusion, this study showed SRPE not confirmed by clinical interview are often accompanied by symptoms of general psychiatric problems, reports of childhood adversity and lower psychosocial functioning, especially in those for whom FP SRPE persist or progress into clinically relevant psychotic symptoms. FP SRPE furthermore increase the likelihood of future general psychopathology and lower functioning and therefore warrant follow-up over time. 


\section{SUPPLEMENTARY MATERIALS}

Table S1. Baseline assessment - prevalence rates for dichotomous variables; psychopathological and psychosocial characteristics

\begin{tabular}{llll}
\hline & Total sample & Controls & Remitted FP SRPE \\
\hline Dichotomous variables & $N(\%)$ & $N(\%)$ & $N(\%)$ \\
\hline Lifetime mood disorder & $905 / 4683(19.3)$ & $743 / 4147(17.9)$ & $89 / 312(28.5)$ \\
Lifetime anxiety disorder & $854 / 4683(18.2)$ & $706 / 4147(17.0)$ & $76 / 312(24.7)$ \\
Lifetime substance disorder & $729 / 4683(15.6)$ & $607 / 4147(14.6)$ & $70 / 312(22.4)$ \\
Neuroticism (high/low) & $1548 / 4607(33.6)$ & $1285 / 4077(31.5)$ & $136 / 310(43.9)$ \\
Sexual abuse <16 & $357 / 4607(7.8)$ & $295 / 4077(7.2)$ & $40 / 310(12.9)$ \\
Physical abuse <16 & $348 / 4607(7.6)$ & $284 / 4077(7.0)$ & $35 / 310(11.3)$ \\
Emotional abuse <16 & $652 / 4607(14.2)$ & $527 / 4077(12.9)$ & $75 / 310(24.2)$ \\
Psychological abuse <16 & $728 / 4607(14.6)$ & $595 / 4077(14.6)$ & $81 / 310(26.1)$ \\
Regular bullying <16 & $615 / 4603(13.4)$ & $515 / 4073(12.6)$ & $56 / 310(18.1)$ \\
Negative life events past year & $2248 / 4607(48.8)$ & $1913 / 4077(46.9)$ & $196 / 310(63.2)$ \\
Regular cannabis use ( $\geq 1 /$ wk, past year) & $69 / 3780(1.8)$ & $52 / 3419(1.5)$ & $10 / 241(4.2)$ \\
Help seeking, general & $506 / 4607(11.0)$ & $398 / 4077(9.8)$ & $62 / 310(20.0)$ \\
Help seeking, specific ${ }^{b}$ & na & na & $19 / 292(6.1)$ \\
\hline
\end{tabular}

FP, false positive; SRPE, self-reported psychotic experiences; PE, psychotic experiences; na: not available;

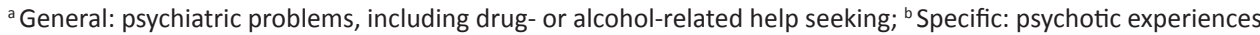

Table S2. Baseline assessment - means, minimum, maximum and SDs for continuous variables; psychopathology, general health, social functioning, and severity of SRPE

\begin{tabular}{llll}
\hline & Total sample & Controls & Remitted FP SRPE \\
\hline Continuous variables & $\begin{array}{l}\text { Mean }(\min -\max ) \\
(S D)\end{array}$ & $\begin{array}{l}\text { Mean }(\min -\max ) \\
(S D)\end{array}$ & $\begin{array}{l}\text { Mean }(\min -\max ) \\
(S D)\end{array}$ \\
\hline General mental functioning & $84.5(8-100)(12.4)$ & $85.1(8-100)(11.9)$ & $81.6(20-100)(14.6)$ \\
General social functioning & $91.5(0-100)(17.0)$ & $92.1(0-100)(16.4)$ & $87.9(0-100)(20.5)$ \\
General physical functioning & $92.6(0-100)(16.2)$ & $93.0(0-100)(15.8)$ & $90.1(10-100)(18.1)$ \\
General health functioning & $73.3(0-100)(17.5)$ & $73.9(0-100)(17.0)$ & $69.3(10-100)(19.5)$ \\
Onset of SRPE (age in years) & - & - & $27.9(3-62)(12.9)$ \\
Number of SRPE & - & - & $1.4(1-6)(0.8)$ \\
Frequency of SRPE & - & - & $1.7(1-4)(0.8)$ \\
Distress of SRPE & - & - & $1.8(0-4)(1.0)$ \\
Impact of SRPE & - & - & $1.4(0.5-4)(0.7)$ \\
\hline
\end{tabular}

FP, false positive; SRPE, self-reported psychotic experiences; PE, psychotic experiences; SD, standard deviation 


\begin{tabular}{llll}
\hline Persistent FP SRPE & Transition to validated PE & Incident FP SRPE & Incident validated PE \\
\hline$N(\%)$ & $N(\%)$ & $N(\%)$ & $N(\%)$ \\
\hline $12 / 32(37.5)$ & $14 / 28(50.0)$ & $28 / 110(25.4)$ & $19 / 54(35.2)$ \\
$11 / 32(34.4)$ & $13 / 28(46.4)$ & $33 / 110(30.0)$ & $15 / 54(27.8)$ \\
$10 / 32(31.3)$ & $8 / 28(28.6)$ & $21 / 110(19.1)$ & $13 / 54(24.1)$ \\
$21 / 31(67.7)$ & $20 / 28(71.4)$ & $61 / 109(56.0)$ & $25 / 52(48.1)$ \\
$5 / 31(16.1)$ & $5 / 28(17.9)$ & $9 / 109(8.3)$ & $3 / 52(5.8)$ \\
$3 / 31(9.7)$ & $7 / 28(25.0)$ & $10 / 109(9.2)$ & $9 / 52(17.3)$ \\
$8 / 31(25.8)$ & $13 / 28(46.4)$ & $14 / 109(12.8)$ & $15 / 52(28.9)$ \\
$13 / 31(41.9)$ & $11 / 28(39.3)$ & $18 / 109(16.5)$ & $10 / 52(19.2)$ \\
$6 / 31(19.4)$ & $6 / 28(21.4)$ & $20 / 109(18.3)$ & $12 / 52(23.1)$ \\
$23 / 31(74.2)$ & $19 / 28(67.9)$ & $62 / 109(56.9)$ & $35 / 52(67.3)$ \\
$1 / 26(3.9)$ & $2 / 23(8.7)$ & $3 / 90(3.2)$ & $1 / 47(2.1)$ \\
$9 / 31(29.0)$ & $10 / 28(35.7)$ & $18 / 109(16.5)$ & $9 / 52(17.3)$ \\
$0 / 32(0)$ & $4 / 28(14.3)$ & na & na \\
\hline
\end{tabular}

\begin{tabular}{|c|c|c|c|}
\hline Persistent FP SRPE & Transition to validated PE & Incident FP SRPE & Incident validated PE \\
\hline Mean $(\min -\max )(S D)$ & $\begin{array}{l}\text { Mean }(\min -\max ) \\
(S D)\end{array}$ & $\begin{array}{l}\text { Mean }(\min -\max ) \\
(S D)\end{array}$ & Mean $(\min -\max )(S D)$ \\
\hline $76.5(16-100)(18.9)$ & 76.1 (24-100) (19.9) & $79.5(16-100)(14.3)$ & $79.5(28-100)(16.6)$ \\
\hline $82.0(0-100)(24.0)$ & $75.9(0-100)(28.9)$ & $89.5(37.5-100)(16.5)$ & $85.4(25-100)(20.3)$ \\
\hline $89.1(40-100)(16.5)$ & $86.8(10-100)(20.8)$ & $90.0(25-100)(17.4)$ & $82.3(10-100)(25.3)$ \\
\hline $65.9(30-100)(17.9)$ & $57.1(0-100)(26.8)$ & $69.2(25-100)(17.5)$ & $65.6(15-100)(21.0)$ \\
\hline $29.8(5-52)(13.2)$ & $27.0(2-59)(15.5)$ & & \\
\hline $1.4(1-4)(0.8)$ & $2.0(1-7)(1.5)$ & - & - \\
\hline $1.9(1-4)(0.9)$ & $2.0(1-3)(0.7)$ & - & - \\
\hline $1.8(1-4)(1.0)$ & $2.0(1-4)(1.1)$ & - & - \\
\hline $1.5(1-4)(0.8)$ & $1.5(1-3)(0.6)$ & - & - \\
\hline
\end{tabular}




\section{REFERENCES}

1. Johns LC, van Os J. The continuity of psychotic experiences in the general population. Clin Psychol Rev. 2001; 21:1125-1141.

2. van Os J, Linscott RJ. Introduction: The Extended Psychosis Phenotype-Relationship With Schizophrenia and With Ultrahigh Risk Status for Psychosis. Schizophr Bull. 2012; 38:227-230.

3. van Os J, Linscott RJ, Myin-Germeys I, Delespaul P, Krabbendam L. A systematic review and meta-analysis of the psychosis continuum: evidence for a psychosis proneness-persistence-impairment model of psychotic disorder. Psychol Med. 2009; 39:179-195.

4. Linscott RJ, van Os J. An updated and conservative systematic review and meta-analysis of epidemiological evidence on psychotic experiences in children and adults: on the pathway from proneness to persistence to dimensional expression across mental disorders. Psychol Med. 2013; 43:1133-1149.

5. McGrath JJ, Saha S, Al-Hamzawi A, Alonso J, Bromet EJ, Bruffaerts R, . . Kessler RC. Psychotic experiences in the general population: a cross-national analysis based on 31,261 respondents from 18 countries. JAMA psychiatry. 2015; 72:697-705.

6. McGrath J, Saha S, Chant D, Welham J. Schizophrenia: a concise overview of incidence, prevalence, and mortality. Epidemiol Rev. 2008; 30:67-76.

7. Saha S, Chant D, Welham J, McGrath J. A systematic review of the prevalence of schizophrenia. PLoS Med. 2005; 2:e141.

8. Hanssen M, Bak M, Bijl R, Vollebergh W, van Os J. The incidence and outcome of subclinical psychotic experiences in the general population. Br J Clin Psychol. 2005; 44:181-191.

9. Kaymaz N, Drukker M, Lieb R, Wittchen HU, Werbeloff N, Weiser M, . . . van Os J. Do subthreshold psychotic experiences predict clinical outcomes in unselected non-help-seeking population-based samples? A systematic review and meta-analysis, enriched with new results. Psychol Med. 2012; 42:22392253.

10. Degenhardt L, Hall W. The association between psychosis and problematical drug use among Australian adults: findings from the National Survey of Mental Health and Well-Being. Psychol Med. 2001; 31:659668.

11. Johns LC, Cannon M, Singleton N, Murray RM, Farrell M, Brugha T, . . Meltzer H. Prevalence and correlates of self-reported psychotic symptoms in the British population. Br J Psychiatry. 2004; 185:298305.

12. Rossler W, Riecher-Rossler A, Angst J, Murray R, Gamma A, Eich D, . . Gross VA. Psychotic experiences in the general population: a twenty-year prospective community study. Schizophr Res. 2007; 92:1-14.

13. Varghese D, Scott J, Welham J, Bor W, Najman J, O'Callaghan M, . . McGrath J. Psychotic-Like Experiences in Major Depression and Anxiety Disorders: A Population-Based Survey in Young Adults. Schizophr Bull. 2011; 37:389-393.

14. Werbeloff N, Drukker M, Dohrenwend BP, Levav I, Yoffe R, van Os J, . . Weiser M. Self-reported attenuated psychotic symptoms as forerunners of severe mental disorders later in life. Arch Gen Psychiatry. 2012; 69:467-475.

15. Navarro-Mateu F, Alonso J, Lim CCW, Saha S, Aguilar-Gaxiola S, Al-Hamzawi A, ... McGrath JJ. The association between psychotic experiences and disability: results from the WHO World Mental Health Surveys. Acta Psychiatr Scand. 2017; 136:74-84.

16. McGrath JJ, Saha S, Lim CCW, Aguilar-Gaxiola S, Alonso J, Andrade LH, . . Kessler RC. Trauma and psychotic experiences: transnational data from the World Mental Health Survey. Br J Psychiatry. 2017; 211:373-380.

17. McGrath JJ, Saha S, Al-Hamzawi A, Andrade L, Benjet C, Bromet EJ, . . Kessler RC. The Bidirectional Associations Between Psychotic Experiences and DSM-IV Mental Disorders. Am J Psychiatry. 2016; 173:997-1006.

18. Linscott RJ, van Os J. Systematic reviews of categorical versus continuum models in psychosis: evidence for discontinuous subpopulations underlying a psychometric continuum. Implications for DSM-V, DSMVI, and DSM-VII. Annu Rev Clin Psychol. 2010; 6:391-419. 
19. Kelleher I, Harley M, Murtagh A, Cannon M. Are screening instruments valid for psychotic-like experiences? A validation study of screening questions for psychotic-like experiences using in-depth clinical interview. Schizophr Bull. 2011; 37:362-369.

20. van Nierop M, van Os J, Gunther N, Myin-Germeys I, de Graaf R, ten Have M, ... van Winkel R. Phenotypically continuous with clinical psychosis, discontinuous in need for care: evidence for an extended psychosis phenotype. Schizophr Bull. 2012; 38:231-238.

21. Bak M, Delespaul P, Hanssen M, de Graaf R, Vollebergh W, van Os J. How false are "false" positive psychotic symptoms? Schizophr Res. 2003; 62:187-189.

22. de Graaf R, ten Have M, van Gool C, van Dorsselaer S. Prevalence of mental disorders and trends from 1996 to 2009. Results from the Netherlands Mental Health Survey and Incidence Study-2. Soc Psychiatry Psychiatr Epidemiol. 2012; 47:203-213.

23. de Graaf R, Ten Have M, van Dorsselaer S. The Netherlands Mental Health Survey and Incidence Study-2 (NEMESIS-2): design and methods. Int J Methods Psychiatr Res. 2010; 19:125-141.

24. de Graaf R, van Dorsselaer S, Tuithof M, ten Have M. Sociodemographic and psychiatric predictors of attrition in a prospective psychiatric epidemiological study among the general population. Result of the Netherlands Mental Health Survey and Incidence Study-2. Compr Psychiatry. 2013; 54:1131-1139.

25. Andrews G, Peters L. The psychometric properties of the Composite International Diagnostic Interview. Soc Psychiatry Psychiatr Epidemiol. 1998; 33:80-88.

26. Wittchen $\mathrm{H}-\mathrm{U}$. Reliability and validity studies of the WHO-Composite International Diagnostic Interview (CIDI): A critical review. J Psychiatr Res. 1994; 28:57-84.

27. Helzer JE, Robins LN, McEvoy LT, Spitznagel EL, Stoltzman RL, Farmer A, Brockington IF. A comparison of clinical and diagnostic interview schedule diagnoses: Physician reexamination of lay-interviewed cases in the general population. Arch Gen Psychiatry. 1985; 42:657-666.

28. Spitzer RL, Williams JW, Gibbon M, First MB. The structured clinical interview for dsm-iii-r (scid): I: history, rationale, and description. Arch Gen Psychiatry. 1992; 49:624-629.

29. The ESEMeD/MHEDEA 2000 investigators, Alonso J, Angermeyer MC, Bernert S, Bruffaerts R, Brugha TS, ... Vollebergh WAM. Sampling and methods of the European Study of the Epidemiology of Mental Disorders (ESEMeD) project. Acta Psychiatr Scand. 2004; 109:8-20.

30. Eysenck SBG, Eysenck HJ, Barrett P. A revised version of the psychoticism scale. Pers Individ Dif. 1985; 6:21-29.

31. Eysenck SBG, White O, Eysenck HJ. Personality and Mental Illness. Psychol Rep. 1976; 39:1011-1022.

32. Brugha T, Bebbington P, Tennant $C$, Hurry J. The List of Threatening Experiences: a subset of 12 life event categories with considerable long-term contextual threat. Psychol Med. 1985; 15:189-194.

33. Stewart AL, Hays RD, Ware JE, Jr. The MOS short-form general health survey. Reliability and validity in a patient population. Med Care. 1988; 26:724-735.

34. Ware JE, Jr., Sherbourne CD. The MOS 36-item short-form health survey (SF-36). I. Conceptual framework and item selection. Med Care. 1992; 30:473-483.

35. Stata Statistical Software: Release 13. College Station, TX: StataCorp LP; 2013.

36. Dominguez MDG, Wichers M, Lieb R, Wittchen H-U, van Os J. Evidence That Onset of Clinical Psychosis Is an Outcome of Progressively More Persistent Subclinical Psychotic Experiences: An 8-Year Cohort Study. Schizophr Bull. 2011; 37:84-93.

37. Bhavsar V, Maccabe JH, Hatch SL, Hotopf M, Boydell J, McGuire P. Subclinical psychotic experiences and subsequent contact with mental health services. BJPsych Open. 2017; 3:64-70.

38. Murphy J, Shevlin M, Houston J, Adamson G. A Population Based Analysis of Subclinical Psychosis and Help-Seeking Behavior. Schizophr Bull. 2012; 38:360-367.

39. Hanssen M, Peeters F, Krabbendam L, Radstake S, Verdoux H, van Os J. How psychotic are individuals with non-psychotic disorders? Soc Psychiatry Psychiatr Epidemiol. 2003; 38:149-154.

40. Wigman JTW, van Nierop M, Vollebergh WAM, Lieb R, Beesdo-Baum K, Wittchen H-U, van Os J. Evidence That Psychotic Symptoms Are Prevalent in Disorders of Anxiety and Depression, Impacting on Illness Onset, Risk, and Severity-Implications for Diagnosis and Ultra-High Risk Research. Schizophr Bull. 2012; 38:247-257.

41. Fusar-Poli P, Nelson B, Valmaggia L, Yung AR, McGuire PK. Comorbid Depressive and Anxiety Disorders in 509 Individuals With an At-Risk Mental State: Impact on Psychopathology and Transition to Psychosis. Schizophr Bull. 2014; 40:120-131. 
42. van Os J, Reininghaus U. Psychosis as a transdiagnostic and extended phenotype in the general population. World Psychiatry. 2016; 15:118-124.

43. Kelleher I, Connor D, Clarke MC, Devlin N, Harley M, Cannon M. Prevalence of psychotic symptoms in childhood and adolescence: a systematic review and meta-analysis of population-based studies. Psychol Med. 2012; 42:1857-1863.

44. Maijer K, Begemann MJH, Palmen SJMC, Leucht S, Sommer IEC. Auditory hallucinations across the lifespan: a systematic review and meta-analysis. Psychol Med. 2017:1-10. 



$$
3
$$




\section{Chapter 3}

Evidence that polygenic risk for psychotic disorder is expressed in the domain of neurodevelopment, emotion regulation and attribution of salience

J. van $\mathrm{Os}^{1,2}$, Y. van der Steen ${ }^{1}$, M.A. Islam ${ }^{3}$, S. Gülöksüz ${ }^{1}$, B.P. Rutten ${ }^{1}$, C.J.P. Simons ${ }^{1,4}$ and GROUP Investigators

${ }^{1}$ Department of Psychiatry and Psychology, Maastricht University Medical Centre, Maastricht, the Netherlands

${ }^{2}$ Department of Psychosis Studies, King's College London, King's Health Partners, Institute of Psychiatry, London, UK

${ }^{3}$ University of Groningen, University Medical Center Groningen, University Center for Psychiatry, Groningen, the Netherlands

${ }^{4} \mathrm{GGzE}$, Institute for Mental Health Care Eindhoven and De Kempen, Eindhoven, the Netherlands

Psychological Medicine, 2017, 47: 2421-2437 


\section{ABSTRACT}

Background: The liability-threshold model of psychosis risk predicts stronger phenotypic manifestation of the polygenic risk score (PRS) in the healthy relatives of patients, as compared with healthy comparison subjects.

Methods: First-degree relatives of patients with psychotic disorder (871 siblings and 812 parents) and healthy comparison subjects $(n=523)$ were interviewed three times in 6 years. Repeated measures of two psychosis phenotypes, the Community Assessment of Psychic Experiences (CAPE; self-report - subscales of positive, negative and depressive symptoms) and the Structured Interview for Schizotypy - Revised (SIS-R; clinical interview - subscales of positive and negative schizotypy), were examined for association with PRS. Interview-based lifetime rate of depressive and manic episodes were also examined, as was association with repeated measures of intelligence quotient (IQ).

Results: In the relatives, PRS was associated with CAPE/SIS-R total score (respectively, $B=0.12,95 \% \mathrm{Cl} 0.02-0.22$ and $B=0.11,95 \% \mathrm{Cl} 0.02-0.20)$, the SIS-R positive subscale $(B=0.16,95 \% \mathrm{Cl} 0.04-0.28)$, the CAPE depression subscale $(\mathrm{B}=0.21,95 \% \mathrm{Cl} 0.07-0.34)$, any lifetime affective episode (OR 3.1, 95\% Cl 1.04-9.3), but not with IQ ( $B=-1.8,95 \% \mathrm{Cl}$ -8.0 to 4.4$)$. In the controls, similar associations were apparent between PRS on the one hand and SIS-R total score, SIS-R positive, SIS-R negative, any lifetime affective episode and, in contrast, lower IQ ( $B=-8.5,95 \% \mathrm{Cl}-15.5$ to 1.6$)$.

Conclusion: In non-ill people, polygenic risk for psychotic disorder is expressed pleiotropically in the domain of neurodevelopment, emotion regulation and attribution of salience. In subjects at elevated genetic risk, emerging expression of neurodevelopmental alterations may create floor effects, obscuring genetic associations. 


\section{INTRODUCTION}

There is strong evidence that measures of psychosis proneness in non-clinical populations are associated with a family history of psychotic disorder ${ }^{1,2}$. However, early reports on associations between measures of psychosis proneness in the general population and genome-wide association study (GWAS)-based polygenic risk scores (PRS) for schizophrenia $^{3,4}$ are inconclusive ${ }^{5-8}$. Any association between psychosis proneness and PRS may be stronger in relatives of patients, compared with the general population, given that expression of psychosis-related phenotypes likely is attributable to genes shared with the patient relative ${ }^{9,10}$, whereas expression of psychosis-related phenotypes in general population samples may be associated more with environmental effects ${ }^{2,11,12}$. We therefore hypothesized that the link between PRS and expression of psychosis phenotypes would be stronger in relatives of patients, who share liability genes with their ill relative, as compared with the general population, whose level of genetic liability is much lower.

Data pertained to patients with psychotic disorder ( $n=1119)$, their parents $(n=920)$ and siblings ( $n=1059)$ and healthy comparison subjects $(n=586)$ participating in the baseline, 3-year and 6-year follow-up assessments of the Genetic Risk and Outcome of Psychosis (GROUP) study. Repeated measures of two psychosis phenotypes, indexed with the Community Assessment of Psychic Experiences (CAPE; self-report) and the Structured Interview for Schizotypy - Revised (SIS-R; clinical interview), were examined for association with PRS. Given strong associations between psychosis phenotypes and measures of affective dysregulation ${ }^{13-18}$, affective outcomes were also included in the analyses. Given the commonly hypothesized notion that genetic effects in schizophrenia are mediated through altered neurodevelopment ${ }^{19}$, neurocognition was also examined in relation to PRS. 


\section{METHODS}

\section{GROUP study}

Full details of the GROUP study have been presented elsewhere ${ }^{20,21}$. In representative geographical areas in the Netherlands and Belgium, patients were identified through clinicians working in regional psychotic disorder services, whose caseload was screened for inclusion criteria. Subsequently, a group of patients presenting at these services either as out-patients or in-patients were recruited for the study. Healthy comparison subjects were selected through random mailings to addresses in the catchment areas of the cases. The GROUP study was not conducted in a geographically well-defined small area, as it in fact included the majority of mental health services in the Netherlands, and a substantial part of mental health services in Dutch-speaking Belgium. Healthy comparison subjects could not be representative in all aspects, as an exclusion criterion was absence of a family history of psychotic disorder. The goal was to collect a group of healthy comparison subjects that (i) was collected from the same geographical area as the case in the relevant mental health service, (ii) was sufficiently large to allow for chance variation and (iii) was frequency-matched in age- and sex distribution to the siblings and (iv) had absence of family history of psychotic disorder. Table 1 shows that healthy comparison subjects, siblings and parents had similar sex distributions whilst healthy comparison subjects and siblings did not have large differences in age.

Table 1. Baseline demographics of GROUP participants in current analysis

\begin{tabular}{llllllllllll}
\hline & \multicolumn{1}{l}{ Age } & \multicolumn{3}{c}{ Education $^{\mathrm{a}}$} & \multicolumn{1}{l}{ IQ } & \multicolumn{3}{c}{ Urbanicity at birth $^{\mathrm{b}}$} \\
\cline { 2 - 11 } & Mean & S.D. & \% Female & Mean & S.D. & Mean & S.D. & Mean & S.D. & $n$ \\
\hline $\begin{array}{l}\text { Healthy comparison } \\
\text { subjects }\end{array}$ & 31.10 & 10.70 & 0.55 & 2.95 & 1.27 & 110.16 & 14.79 & 2.57 & 1.68 & 523 \\
Siblingss & & & & & & & & & & \\
Parents & 27.85 & 8.32 & 0.53 & 2.63 & 1.48 & 104.00 & 15.21 & 2.52 & 1.63 & 871 \\
Total & 54.83 & 6.83 & 0.57 & 2.53 & 1.57 & 103.54 & 16.68 & 2.26 & 1.58 & 812 \\
\hline
\end{tabular}

${ }^{a}$ Education (Verhage): range 0 (no education), 3-5 (school diploma) to 8 (university degree).

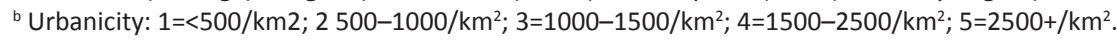

\section{Sample}

The full GROUP sample at baseline consisted of 1119 patients with non-affective psychotic disorder, 1059 siblings of these patients, 920 parents of the patients and 586 unrelated healthy comparison subjects. 
Inclusion criteria were: (i) age range 16-50 years and (ii) good command of Dutch language. For patients, an additional inclusion criterion was the presence of a clinical diagnosis of non-affective psychotic disorder. Healthy comparison subject status was confirmed by using the Family Interview for Genetic studies ${ }^{22}$ with the healthy comparison subject as informant, to establish absence of first degree relatives with a psychotic disorder. Diagnosis was based on the Diagnostic and Statistical Manual of Mental Disorder-IV (DSM-IV) criteria ${ }^{23}$, assessed with the Comprehensive Assessment of Symptoms and History (CASH) interview ${ }^{24}$ or Schedules for Clinical Assessment for Neuropsychiatry (SCAN 2.1) ${ }^{25}$. The majority of patients had a DSM-IV diagnosis of schizophrenia (DSM-IV 295.x; $n=940,84 \%)$. In the sibling and healthy comparison subject groups, there were respectively, 154 (14\%) and 59 participants (10\%) with a history of a common mental disorder at baseline, the majority of whom had a mood disorder (DSM-IV 296.x). The study was approved by the standing ethics committee, and all the subjects gave written informed consent in accordance with the committee's guidelines.

\section{Sample for analysis}

For the purpose of the current analyses, siblings, parents and healthy comparison subjects groups were included. Analyses were restricted to the European white ethnic group ( $n=2218$, or $87 \%$ out of a total of

2565 siblings, parents and healthy comparison subjects groups at baseline) given the fact that prevalence of risk alleles varies widely across ethnic groups, as may the risk associated with individual alleles, and evidence exists of differential effects of PRS across ethnic groups ${ }^{26}$. Observations of siblings and healthy comparison subjects who made a possible ( $n=2$, of whom 1 of European white ethnic group) or definite ( $n=16$, of whom 11 of European white ethnic group) transition to a psychotic disorder over the follow-up period, and thus were re-classified as patients, were excluded from analysis. Applying ethnicity and transition criteria thus resulted in a baseline sample of 523 healthy comparison subjects, 871 siblings and 812 parents of siblings (total sample: $n=2206$ ). Of the 2206, the number of individuals with data permitting calculation of the PRS was 1578 (72\%) with approximately equal proportions across healthy comparison subjects (73\%), siblings (67\%) and parents (75\%).

\section{SIS-R}

The SIS-R was administered to healthy comparison subjects, parents and siblings. The SIS-R is a semi-structured interview containing 20 schizotypal symptoms and 11 schizo- 
typal signs rated on a 4-point scale ${ }^{27,28}$. Symptoms are defined as verbal responses to standardized questions concerning, for example, magical ideation, illusions and referential thinking. Signs refer to behaviours that are rated by the interviewer such as goal directedness of thinking and flatness of affect. Questions and rating procedures are standardized. Guided by previous research, 33 item scores were reduced a priori to two-dimensional scores, representing the means of seven positive schizotypy items (covering the areas of referential thinking, psychotic phenomena, derealisation, magical ideation, illusions and suspiciousness) and eight negative-disorganized schizotypy items (covering the areas of social isolation, sensitivity, introversion, restricted affect, disturbances in associative and goal-directed thinking, poverty of speech and eccentric behaviour).

\section{CAPE}

The CAPE (www.cape42.homestead.com) was developed in order to rate self-reports of lifetime psychotic experiences ${ }^{29}$. Items are modelled on patient experiences as contained in the Present State Examination, 9th version ${ }^{30}$, schedules assessing negative symptoms such as the Scale for the Assessment of Negative Symptoms (SANS) ${ }^{31}$ and the Subjective Experience of Negative Symptoms (SENS) ${ }^{32}$ and scales assessing depressive symptoms such as the Calgary Depression Scale ${ }^{33}$. Items are scored on a 4-point scale. In the current analyses, CAPE dimensions of frequency of positive experiences (20 items), negative experiences (14 items) and depressive experiences (eight items) were included (measured at baseline and 3- and 6-year follow-up), representing the person's perceived psychosis load over the lifetime (at baseline) or in the past 3 years (follow-up). A total score representing the mean of all items was calculated for each dimension.

\section{Manic and depressive episodes}

Lifetime rate of depressive and manic episodes were derived from the CASH interview (data available for 3 of the 4 centres).

\section{Intelligence quotient (IQ)}

At baseline and 3-year follow-up, IQ was estimated based on the four-subtest version (Information, Block Design, Digit Symbol Coding and Arithmetic) ${ }^{34}$ of the Wechsler Adult Intelligence Scale (WAIS-III) ${ }^{35}$. At 6-year follow-up, IQ was estimated based on a short version of the WAIS-III short form: the Digit Symbol Coding subtest, uneven items of the Arithmetic subtest, uneven items of the Block Design subtest, every third item of the Information subtest ${ }^{36}$. 


\section{Follow-up}

Healthy comparison subjects and siblings were eligible for follow-up; parents were only assessed at baseline. Of the 523 healthy comparison subjects and 871 siblings at baseline, $80 \%$ ( $n=1115$ ) were assessed at 3-year follow-up (healthy comparison subjects: $79 \%$, $n=415$; siblings: $80 \%, n=700)$ and $69 \%(n=973)$ at 6-year follow-up (healthy comparison subjects: $68 \%, n=357$; siblings: $71 \%, n=616)$. Ratings of CASH, SCAN, SIS-R and CAPE at follow-up reflected the period between baseline and first follow-up, and between first and second follow-up, respectively. Mean time to first follow-up was 3.3 years (S.D. $=0.5$ ) and mean between first and second follow-up was 3.1 years (S.D.=0.4).

\section{Genotyping, imputation and PRS}

Genotyping was performed using two platforms. A total of 1434 participants (758 patients, 676 healthy comparison subjects) were genotyped on the Illumina platform for 547383 SNPs on the Illumina HumanHap 550k v3.0 beadchip. A second group of 1968 participants (393 patients, 154 controls and 1421 healthy relatives) were genotyped for 929556 SNPs using the Affymetrix genome-wide Human SNP Array version 6.0.

A binary data set of the Illumina platform was generated including 547383 genotyped variants in 1434 subjects. We excluded 36 samples showing a sex mismatch between recorded and the genetically determined gender type, leaving 1,398 people for further analysis. We excluded SNPs that were haploid or had missing rates per SNP of $>0.10$, or a MAF of $<0.01$ or a HWE $p$ value $<0.00001$ (in healthy comparison subjects) and excluded individuals, with a missing rate $>10 \%$, altogether yielding 515286 variants and 1393 individuals (737 patients and 656 healthy comparison subjects) for further analysis. Next, a binary data set of Affymetrix platform was generated including 929556 SNPs genotyped in 1968 subjects (393 patients and 1575 relatives), of which 729597 SNPs and 1968 individuals passed the standard quality processing checks. We successfully converted genetic coordination of all variants (except for 57 from Illumina and 86 from Affymetrix) from Human NCBI36/hg18 to GRCh37/hg19 using Liftover (online tools) for all samples. Next, we imputed both platform samples on the backbone of $1000 \mathrm{G}$ Phase-3 reference haploblocks, as implemented in the Haplotype Reference Consortium (HRC) ${ }^{37}$, using the Michigan Imputation Server and the SHAPEIT option for phasing. This yielded 46178 415 imputed variants, which was reduced to 16353433 SNPs after selecting SNPs with a quality score (info score) threshold of >0.30, of which 9067392 variants and 1393 subjects passed the post-imputation QC. As for Affymetrix genotypes, 1kG-based impu- 
tation yielded 46178419 imputed SNPs, which were reduced to 9122501 SNPs after implementing post-imputation quality controls in 1968 subjects. These were included in the next step.

In order to calculate PRS, we obtained summary statistics of the genome-wide association study from the Psychiatric Genomic Consortium-2 (PGC2) ${ }^{38}$, which included the GROUP subjects. We performed meta-analysis again while excluding GROUP samples as well as other Dutch samples, including a total of 17104566 SNPs, of which 8242 976 SNPs were common with imputed GROUP genotypes from Illumina-based variants and 8290712 variant from Affymetrix-based variants. Following the approach taken by the international psychiatric GWAS consortium, we calculated a PRS at the metagwas p-threshold of $<0.1$ for association with Schizophrenia by PGC2. This included 2302038 SNPs of which 1481064 SNPs were common with the Illumina genotype dataset, and 1 483770 SNPs were common with the Affymetrix genotype data set (1 455047 SNPs are common across both platforms). Furthermore, we repeated our association analysis at p-threshold of <0.01, which constituted 449794 SNPs (364 121 common with the Illumina platform, 363305common with the Affymetrix platform and 360150 SNPs common across both platforms). We used PRSice ${ }^{39}$ software to calculate PRS; by LD clumping of r2 value $<0.2$, at distance threshold of $250 \mathrm{~kb}$, while adjusting for 10 eigenvectors calculated by Eigenstrat ${ }^{40}$. This led to inclusion of 119653 SNPs from the Illumina platform and 119271 SNPs from Affymetrix for estimating PRS at p-metagwas<0.1; and 25250 SNPs from the Illumina and 25152 SNPs from the Affymetrix platform to estimate PRS at $p$-metagwas $<0.01$. We calculated different PRS using different $p$ value thresholds, from 0 to 0.50 , and checked the explained variances at the different threshold of PRS on schizophrenia using Nagelkerke's R-square. The analyses are based on the p-threshold of 0.01 with sensitivity analyses for the $\mathrm{p}$-threshold of 0.1 . For ease of interpretation, a constant was added to the two PRS scores, so that the minimum value was 0 .

\section{Analyses}

GROUP database version 5.0 was used for all analyses. Random intercept multilevel regression models (given clustering of individuals within families as well as clustering of repeated measures within subjects) with SIS-R and CAPE measures as dependent variables were fitted using the MIXED routine in the Stata program, version $14^{41}$. Independent variables were PRS, a priori corrected for age and sex. In addition, binary outcomes of CASH lifetime depressive and manic episode were modelled using the Stata MEQRLOGIT multilevel random intercept logistic regression routine, similarly adjusted for age and sex. 
In order to examine robustness of findings with regard to assumptions of normality, log-transformed outcomes were additionally examined, using the Stata LNSKEWO routine. LNSKEWO creates newvar=In(+/-exp- k), choosing $k$ and the sign of exp so that the skewness of newvar is zero. In order to assess to what degree associations between PRS and measures of psychosis proneness were independent, regression analyses were conducted for one measure of psychosis proneness, corrected for all the others. In order to examine to what degree any association between PRS and measures of psychosis proneness were mediated by IQ, IQ was added to the analyses as a covariate. 


\section{RESULTS}

\section{Descriptive results and interaction by group}

Sample characteristics are displayed in Table 1. Values of the CAPE and SIS-R total score, lifetime depressive and manic episodes and PRS are shown in Table 2, by group and sex. CAPE and SIS-R subscale scores, by group and sex, are shown in Table 3.

Table 2. Depression and mania outcomes, and polygenic risk scores by group and by sex

\begin{tabular}{llllllll}
\hline & \multicolumn{2}{l}{ \% Depressive episode } & \multicolumn{2}{l}{ \% Manic episode } \\
& Rate & $n$ & Rate & $n$ & Mean & S.D. & $n$ \\
\hline $\begin{array}{l}\text { Group } \\
\text { Healthy comparison subjects }\end{array}$ & 0.27 & 445 & 0.02 & 445 & 0.60 & 0.21 & 382 \\
Siblings & 0.33 & 656 & 0.04 & 656 & 0.83 & 0.15 & 586 \\
Parents & 0.30 & 583 & 0.02 & 583 & 0.83 & 0.15 & 610 \\
Sex & & & & & & & \\
Men & 0.22 & 739 & 0.03 & 739 & 0.77 & 0.20 & 720 \\
Women & 0.37 & 945 & 0.03 & 945 & 0.77 & 0.19 & 858 \\
Total & 0.30 & 1684 & 0.03 & 1684 & 0.77 & 0.19 & 1578 \\
\hline
\end{tabular}

PRS, polygenic risk score.

alifetime rate, calculated with baseline sample as denominator and including episodes occurring over the 6 -year post-baseline follow-up period in the numerator.

The PRS of the healthy comparison subjects $(0.60$, S.D. $=0.21)$ was significantly lower than the PRS in the combined group of parents and siblings $(0.83$, S.D. $=0.15 ; p<0.001)$. The PRS in the group of parents and siblings was significantly correlated with the PRS in the patient group $(r=0.30, p<0.0001)$.

Graphical examination of the scatterplots of PRS on the one hand and CAPE/SIS-R total scores (Fig. 1a-d), CAPE subscale scores (Fig. 2a-f), SIS-R subscales scores (Fig. 3a-d) and IQ (Fig. 4a, b) on the other suggests association between PRS and various aspects of psychopathology and cognition in both groups.

\section{Associations in relatives and healthy comparison subjects}

Given the graphical suggestion of differences in the pattern of associations, analyses were conducted separately for relatives and the healthy comparison group. The pattern of correlation between the CAPE and SIS-R total and subscale scores were similar for relative and healthy comparison subjects, in that within-instrument scale correlations were high, whereas between-scale correlations were only moderate (Table 4). 

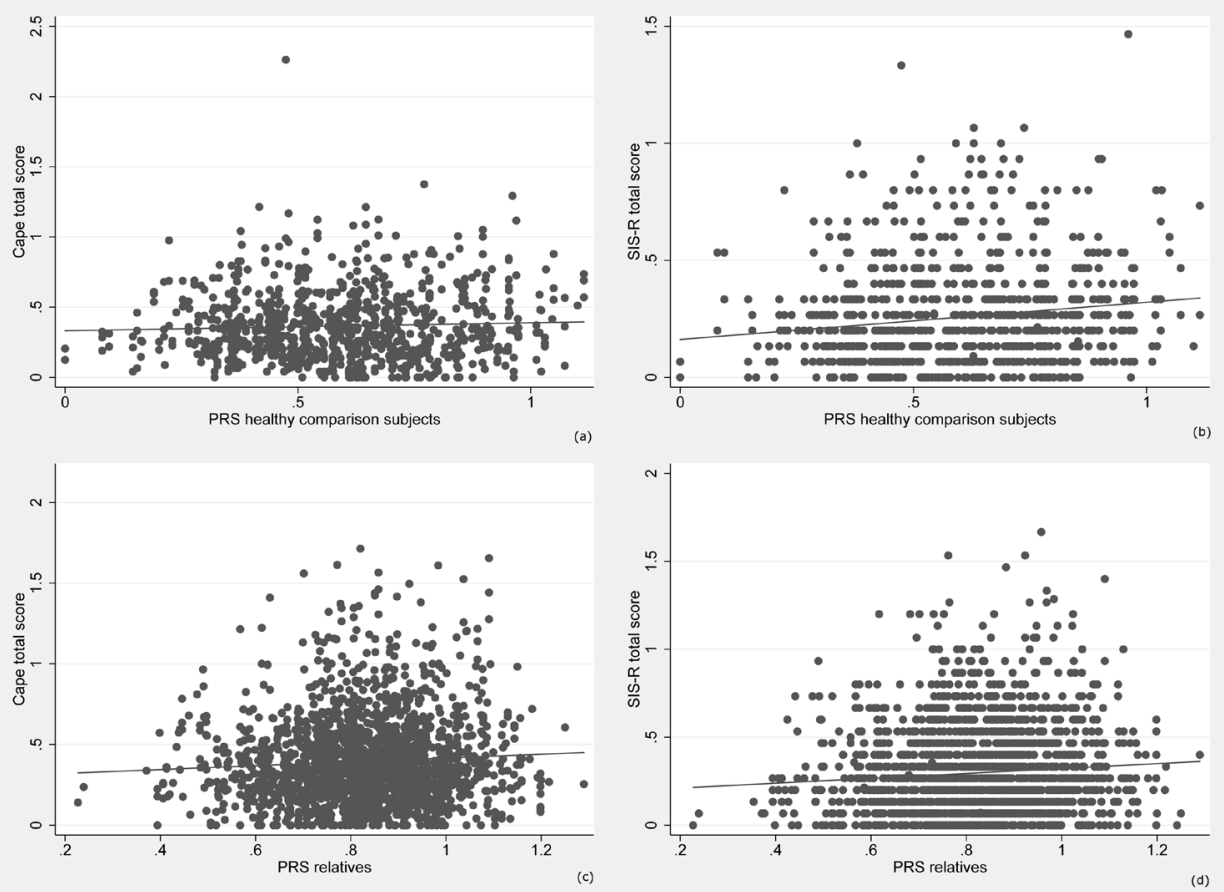

Fig. 1. (a-d) Scatterplots with linear regression line of polygenic risk score (PRS) on the one hand, and, on the other, Community Assessment of Psychic Experiences (CAPE) total score in healthy comparison subjects (Fig. 1a); Structured Interview for Schizotypy - Revised (SIS-R) total score in healthy comparison subjects (Fig. 1b); CAPE total score in relatives (Fig. 1c); and SIS-R total score in relatives (Fig. 1d).

Results of the multilevel random regression analyses are shown in Tables 5-7. In the relatives (Table 6), PRS was associated with CAPE total score $(B=0.12,95 \% \mathrm{Cl} 0.02-0.22$, $p=0.015)$, SIS-R total score $(B=0.11,95 \% \mathrm{Cl} 0.02-0.20, p=0.013)$ as well as with CAPE depression $(B=0.21,95 \% \mathrm{Cl} 0.07-0.34, p=0.004)$ and the SIS-R positive subscale $(B=0.16$, $95 \% \mathrm{Cl} 0.04-0.28, p=0.008)$. Analyses with log-transformed scales showed similar results (Table 5). Analyses of the CAPE the SIS-R subscales, in which subscales were controlled for each other, showed that associations were reducible to the association with CAPE depression, which continued to be associated with PRS $(B=0.10,95 \% \mathrm{Cl} 0.02-0.19$, $p=0.021$ ) whereas the association with the SIS-R positive subscale was rendered non-significant (Table 5).

The association between CAPE depression and PRS was not affected by IQ, as the association with CAPE depression remained similar when IQ was added in addition to age and $\operatorname{sex}(B=0.20,95 \% \mathrm{Cl} 0.06-0.34, p=0.005)$. 
Table 3. Cape and SIS-R subscale scores by group and by sex

\begin{tabular}{|c|c|c|c|c|c|c|c|c|c|c|}
\hline \multirow[b]{2}{*}{ Time } & & \multicolumn{2}{|c|}{ CAPE total } & \multirow[b]{2}{*}{$n$} & \multicolumn{2}{|c|}{ CAPE POS } & \multirow[b]{2}{*}{$n$} & \multicolumn{2}{|c|}{ CAPE-NEG } & \multirow[b]{2}{*}{$n$} \\
\hline & & Mean & S.D. & & Mean & S.D. & & Mean & S.D. & \\
\hline & Group & & & & & & & & & \\
\hline \multirow[t]{3}{*}{1} & $\mathrm{HCS}$ & 0.42 & 0.23 & 502 & 0.19 & 0.17 & 500 & 0.48 & 0.32 & 500 \\
\hline & Siblings & 0.45 & 0.27 & 767 & 0.19 & 0.18 & 765 & 0.54 & 0.38 & 765 \\
\hline & Parents $^{\mathrm{a}}$ & 0.41 & 0.23 & 692 & 0.13 & 0.13 & 692 & 0.50 & 0.33 & 692 \\
\hline \multirow[t]{3}{*}{2} & $\mathrm{HCS}$ & 0.30 & 0.23 & 401 & 0.08 & 0.12 & 401 & 0.39 & 0.31 & 400 \\
\hline & Siblings & 0.35 & 0.28 & 675 & 0.10 & 0.14 & 673 & 0.46 & 0.40 & 674 \\
\hline & Parents $^{\mathrm{a}}$ & - & - & - & - & - & - & - & - & - \\
\hline \multirow[t]{4}{*}{3} & $\mathrm{HCS}$ & 0.32 & 0.26 & 343 & 0.08 & 0.15 & 343 & 0.41 & 0.34 & 343 \\
\hline & Siblings & 0.35 & 0.28 & 594 & 0.08 & 0.12 & 593 & 0.47 & 0.40 & 593 \\
\hline & Parents $^{\mathrm{a}}$ & - & - & - & - & - & - & - & - & - \\
\hline & Sex & & & & & & & & & \\
\hline \multirow[t]{2}{*}{1} & Men & 0.40 & 0.23 & 890 & 0.17 & 0.16 & 889 & 0.50 & 0.33 & 889 \\
\hline & Women & 0.45 & 0.26 & 1071 & 0.17 & 0.17 & 1068 & 0.52 & 0.35 & 1068 \\
\hline \multirow[t]{2}{*}{2} & Men & 0.30 & 0.24 & 478 & 0.10 & 0.13 & 478 & 0.42 & 0.35 & 478 \\
\hline & Women & 0.36 & 0.28 & 598 & 0.09 & 0.13 & 596 & 0.45 & 0.39 & 596 \\
\hline \multirow[t]{2}{*}{3} & Men & 0.31 & 0.25 & 419 & 0.09 & 0.13 & 418 & 0.43 & 0.36 & 418 \\
\hline & Women & 0.36 & 0.29 & 518 & 0.08 & 0.13 & 518 & 0.46 & 0.39 & 518 \\
\hline
\end{tabular}

CAPE, Community Assessment of Psychic Experiences (subscales of positive, negative and depressive symptoms); SIS-R, Structured Interview for Schizotypy - Revised (subscales of positive and negative schizotypy).

a Parents baseline measures only.

In the healthy comparison subjects (Table 6), PRS was associated with the SIS-R total score $(B=0.16,95 \% \mathrm{Cl} 0.07-0.25, p=0.000)$ and both the SIS-R positive subscale $(B=0.22,95 \% \mathrm{Cl}$ $0.10-0.35, p=0.000)$ and the SIS-R negative subscale $(B=0.11,95 \% \mathrm{Cl} 0.03-0.19, p=0.10)$ (Table 6). Analyses with log-transformed scales were similar (Table 6). In the analysis in which all subscales were controlled for each other, only the association with the SIS-R positive subscale remained significant $(B=0.14,95 \% \mathrm{Cl} 0.05-0.24, p=0.004$; Table 6).

Analyses of association between PRS and CASH based lifetime depressive and manic episodes revealed evidence for association in both the relatives (OR any affective episode $=3.1,95 \% \mathrm{Cl} 1.04-9.3, p=0.043$ ) and the healthy comparison subjects (OR any affective episode=3.4, 95\% Cl 0.9-12.7, $p=0.075$ ) (Table 7).

In the relatives, no large or significant association was apparent between PRS and IQ in a separate model of IQ, corrected for age and $\operatorname{sex}(B=-1.8,95 \% \mathrm{Cl}-8.0$ to $4.4 ; p=0.566)$. In the healthy comparison subjects, there was evidence for an association between IQ 


\begin{tabular}{|c|c|c|c|c|c|c|c|c|c|c|c|}
\hline \multicolumn{2}{|c|}{ CAPE-DEP } & \multirow[b]{2}{*}{$n$} & \multicolumn{2}{|c|}{ SIS-R total } & \multirow[b]{2}{*}{$n$} & \multicolumn{2}{|c|}{$\begin{array}{l}\text { SIS-R } \\
\text { positive }\end{array}$} & \multirow[b]{2}{*}{$n$} & \multicolumn{2}{|c|}{$\begin{array}{l}\text { SIS-R } \\
\text { negative }\end{array}$} & \multirow[b]{2}{*}{$n$} \\
\hline Mean & S.D. & & Mean & S.D. & & Mean & S.D. & & Mean & S.D. & \\
\hline 0.59 & 0.34 & 502 & 0.27 & 0.25 & 515 & 0.30 & 0.35 & 515 & 0.24 & 0.23 & 514 \\
\hline 0.61 & 0.38 & 767 & 0.31 & 0.28 & 858 & 0.36 & 0.41 & 858 & 0.26 & 0.24 & 858 \\
\hline 0.60 & 0.35 & 692 & 0.29 & 0.24 & 806 & 0.25 & 0.30 & 806 & 0.32 & 0.28 & 806 \\
\hline 0.43 & 0.35 & 401 & 0.26 & 0.20 & 402 & 0.27 & 0.29 & 402 & 0.24 & 0.21 & 400 \\
\hline 0.49 & 0.40 & 675 & 0.29 & 0.25 & 683 & 0.31 & 0.34 & 683 & 0.28 & 0.25 & 683 \\
\hline- & - & - & - & - & - & - & - & - & - & - & - \\
\hline 0.48 & 0.41 & 343 & 0.27 & 0.21 & 336 & 0.28 & 0.29 & 336 & 0.25 & 0.22 & 336 \\
\hline 0.50 & 0.41 & 594 & 0.30 & 0.24 & 598 & 0.31 & 0.31 & 598 & 0.29 & 0.25 & 598 \\
\hline - & - & - & - & - & - & - & - & - & - & - & - \\
\hline 0.52 & 0.32 & 890 & 0.28 & 0.25 & 984 & 0.28 & 0.33 & 984 & 0.29 & 0.27 & 983 \\
\hline 0.67 & 0.38 & 1071 & 0.30 & 0.27 & 1195 & 0.33 & 0.38 & 1195 & 0.27 & 0.25 & 1195 \\
\hline 0.40 & 0.34 & 478 & 0.27 & 0.23 & 486 & 0.26 & 0.30 & 486 & 0.27 & 0.25 & 485 \\
\hline 0.53 & 0.40 & 598 & 0.29 & 0.24 & 599 & 0.32 & 0.34 & 599 & 0.26 & 0.23 & 598 \\
\hline 0.42 & 0.36 & 419 & 0.29 & 0.24 & 420 & 0.28 & 0.30 & 420 & 0.29 & 0.27 & 420 \\
\hline 0.55 & 0.44 & 518 & 0.29 & 0.22 & 514 & 0.31 & 0.31 & 514 & 0.27 & 0.22 & 514 \\
\hline
\end{tabular}

and PRS, adjusted for age and $\operatorname{sex}(B=-8.5,95 \% \mathrm{Cl}-15.5$ to $-1.6 ; p=0.017)$. The association between PRS and IQ in the healthy comparison subjects remained after controlling for SIS-R total score $(B=-7.5,95 \% \mathrm{Cl}-14.5$ to $-0.4 ; p=0.038)$. Similarly, the association between PRS and SIS-R total score in the healthy comparison subjects remained after controlling for IQ ( $B=0.16,95 \% \mathrm{Cl} 0.07-0.25 ; p=0.001)$.

\section{Sensitivity analyses at PRS p-threshold of 0.1}

Results for the sensitivity analyses were at the PRS p-threshold of 0.1 were very similar to the analyses at the P-threshold of 0.01. The association between PRS and IQ was slightly weaker in the healthy comparison group ( $B=-7.1,95 \% \mathrm{Cl}-15.1$ to $0.9, p=0.081)$. In the relatives group, associations between PRS and the CAPE positive and negative subscale were also significant and associations were not reducible to CAPE depression but to the SIS-R positive subscale. 
Table 4. Pattern of Pearson's correlation coefficients between psychopathology measures in relatives (top) and controls (bottom)

\begin{tabular}{|c|c|c|c|c|c|c|c|}
\hline & $\begin{array}{l}\text { SIS-R } \\
\text { total }\end{array}$ & $\begin{array}{l}\text { CAPE } \\
\text { total }\end{array}$ & $\begin{array}{l}\text { SIS-R } \\
\text { negative }\end{array}$ & $\begin{array}{l}\text { CAPE } \\
\text { negative }\end{array}$ & $\begin{array}{l}\text { SIS-R } \\
\text { positive }\end{array}$ & $\begin{array}{l}\text { CAPE } \\
\text { positive }\end{array}$ & $\begin{array}{l}\text { CAPE } \\
\text { depressive }\end{array}$ \\
\hline \multicolumn{8}{|l|}{ Relatives } \\
\hline SIS-R total & 1 & & & & & & \\
\hline CAPE total & 0.50 & 1 & & & & & \\
\hline SIS-R negative & 0.82 & 0.42 & 1 & & & & \\
\hline CAPE negative & 0.45 & 0.92 & 0.43 & 1 & & & \\
\hline SIS-R positive & 0.88 & 0.42 & 0.44 & 0.35 & 1 & & \\
\hline CAPE positive & 0.38 & 0.65 & 0.19 & 0.48 & 0.42 & 1 & \\
\hline CAPE depressive & 0.45 & 0.93 & 0.39 & 0.75 & 0.38 & 0.49 & 1 \\
\hline \multicolumn{8}{|l|}{ HCS } \\
\hline SIS-R total & 1 & & & & & & \\
\hline CAPE total & 0.46 & 1 & & & & & \\
\hline SIS-R negative & 0.82 & 0.36 & 1 & & & & \\
\hline CAPE negative & 0.40 & 0.90 & 0.36 & 1 & & & \\
\hline SIS-R positive & 0.89 & 0.42 & 0.46 & 0.33 & 1 & & \\
\hline CAPE positive & 0.33 & 0.68 & 0.16 & 0.49 & 0.39 & 1 & \\
\hline CAPE depressive & 0.43 & 0.92 & 0.35 & 0.72 & 0.38 & 0.50 & 1 \\
\hline
\end{tabular}

CAPE, Community Assessment of Psychic Experiences (subscales of positive, negative and depressive symptoms); SIS-R, Structured Interview for Schizotypy - Revised (subscales of positive and negative schizotypy); HSC, healthy control subjects. 

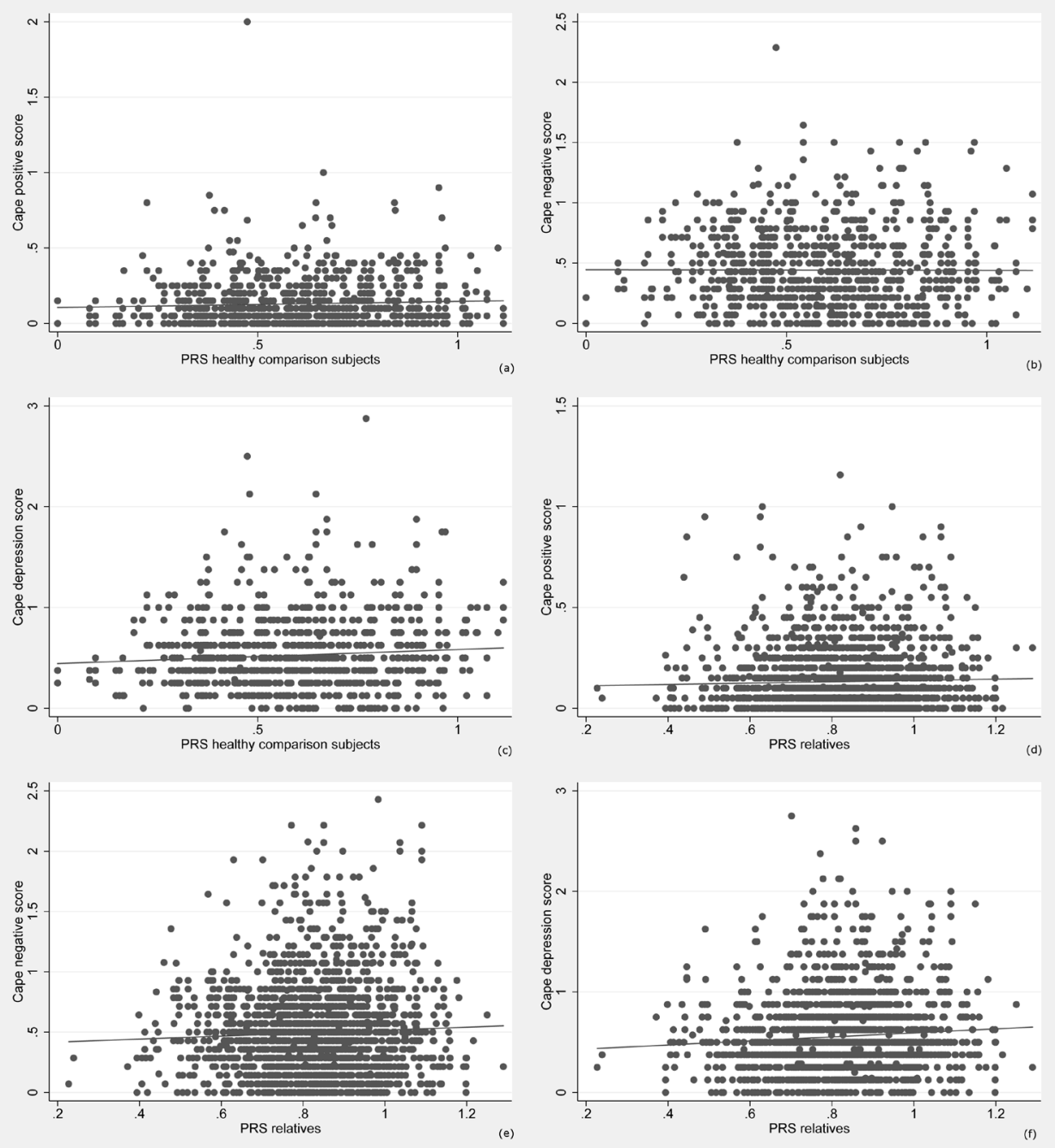

Fig. 2. (a-f) Scatterplots with linear regression line of polygenic risk score (PRS) on the one hand, and, on the other, Community Assessment of Psychic Experiences (CAPE) positive score in healthy comparison subjects (Fig. 2a), CAPE negative score in healthy comparison subjects (Fig. 2b), CAPE depression score in healthy comparison subjects (Fig. 2c), CAPE positive score in relatives (Fig. 2d), CAPE negative score in relatives (Fig. 2e), CAPE depression score in relatives (Fig. 2f). 
Table 5. Results of regression analyses in relatives of patients

Association of psychopathology measure with PRS

$B(0.95 \% \mathrm{Cl}) \quad p \quad n$

\begin{tabular}{|c|c|c|c|}
\hline \multicolumn{4}{|l|}{ Measure } \\
\hline CAPE total & $0.12(0.02-0.22)$ & 0.015 & 1916 \\
\hline CAPE positive & $0.04(-0.02$ to 0.10$)$ & 0.150 & 1913 \\
\hline CAPE negative & $0.13(-0.01$ to 0.27$)$ & 0.075 & 1914 \\
\hline CAPE depressive & $0.21(0.07-0.34)$ & 0.004 & 1916 \\
\hline SIS-R total & $0.11(0.02-0.20)$ & 0.013 & 2071 \\
\hline SIS-R positive & $0.16(0.04-0.28)$ & 0.008 & 2071 \\
\hline SIS-R negative & $0.08(-0.02$ to 0.17$)$ & 0.103 & 2071 \\
\hline \multicolumn{4}{|c|}{$\begin{array}{l}\text { a NA: analyses were conducted with the five subscales: CAPE positive, CAPE negative, CAPE depressive, } \\
\text { SIS-R positive, SIS-R negative. } \\
B \text {, regression coefficient; } 95 \% \mathrm{Cl}, 95 \% \text { confidence interval; } p, p \text {-value; } n \text {, number of observations, PRS, poly- } \\
\text { genic risk score; CAPE, Community Assessment of Psychic Experiences (subscales of positive, negative and } \\
\text { depressive symptoms); SIS-R, Structured Interview for Schizotypy - Revised (subscales of positive and neg- } \\
\text { ative schizotypy). }\end{array}$} \\
\hline
\end{tabular}

Table 6. Results of regression analyses in healthy control subjects

Association of psychopathology measure with PRS

$B(0.95 \% \mathrm{Cl}) \quad p \quad n$

\begin{tabular}{|c|c|c|c|}
\hline \multicolumn{4}{|l|}{ Measure } \\
\hline CAPE total & $0.04(-0.07$ to 0.14$)$ & 0.465 & 911 \\
\hline CAPE positive & $0.03(-0.04$ to 0.10$)$ & 0.451 & 910 \\
\hline CAPE negative & $-0.13(-0.15$ to 0.12$)$ & 0.848 & 909 \\
\hline CAPE depressive & $0.11(-0.04$ to 0.26$)$ & 0.147 & 911 \\
\hline SIS-R total & $0.16(0.07-0.25)$ & 0.000 & 921 \\
\hline SIS-R positive & $0.22(0.10-0.35)$ & 0.000 & 921 \\
\hline SIS-R negative & 0118 (0.03 to 0.19$)$ & 0.000 & 919 \\
\hline \multicolumn{4}{|c|}{$\begin{array}{l}\text { a NA: analyses were conducted with the five subscales: CAPE positive, CAPE negative, CAPE depressive, SIS-R } \\
\text { positive, SIS-R negative. } \\
B \text {, regression coefficient, } 95 \% \mathrm{Cl}, 95 \% \text { confidence interval; } p \text {, p-value; } n \text {, number of observations, PRS, poly- } \\
\text { genic risk score; CAPE, Community Assessment of Psychic Experiences (subscales of positive, negative and } \\
\text { depressive symptoms); SIS-R, Structured Interview for Schizotypy - Revised (subscales of positive and neg- } \\
\text { ative schizotypy). }\end{array}$} \\
\hline
\end{tabular}


Association of log-transformed psychopathology measure with PRS

\begin{tabular}{|c|c|c|c|c|c|}
\hline$B(0.95 \% \mathrm{Cl})$ & $p$ & $N$ & $B(0.95 \% \mathrm{Cl})$ & $p$ & $N$ \\
\hline $0.16(0.01-0.31)$ & 0.032 & 1916 & $N A^{a}$ & & \\
\hline $0.32(-0.01$ to 0.65$)$ & 0.059 & 1913 & $-0.01(-0.05$ to 0.04$)$ & 0.083 & 1884 \\
\hline $0.12(-0.05$ to 0.28$)$ & 0.170 & 1914 & $-0.04(-0.13$ to 0.05$)$ & 0.385 & 1884 \\
\hline $0.21(0.07-0.36)$ & 0.005 & 1916 & $0.10(0.02-0.19)$ & 0.021 & 1884 \\
\hline $0.24(0.04-0.43)$ & 0.016 & 2071 & $N A^{a}$ & & \\
\hline $0.51(0.19-0.83)$ & 0.002 & 2071 & $0.08(-0.02$ to 0.18$)$ & 0.136 & 1884 \\
\hline $0.14(-0.06$ to 0.33$)$ & 0.166 & 2071 & $0.02(-0.06$ to 0.10$)$ & 0.616 & 1884 \\
\hline
\end{tabular}

Association of psychopathology subscales with PRS, corrected for the other subscales
Association of log-transformed psychopathology measure with PRS

\begin{tabular}{lllllll}
\hline$B(0.95 \% \mathrm{Cl})$ & $p$ & $N$ & & $B(0.95 \% \mathrm{Cl})$ & $p$ & $N$ \\
\hline & & & & & \\
$0.01(-0.17$ to 0.19$)$ & 0.917 & 911 & $N A^{a}$ & & \\
$0.20(-0.27$ to 0.66$)$ & 0.400 & 910 & $-0.00(-0.06$ to 0.05$)$ & 0.872 & 889 \\
$-0.07(-0.24$ to 0.10$)$ & 0.431 & 909 & $-0.10(-0.19$ to 0.01$)$ & 0.030 & 889 \\
$0.07(-0.11$ to 0.24$)$ & 0.441 & 911 & $0.08(-0.02$ to 0.18$)$ & 0.093 & 889 \\
$0.40(0.18-0.63)$ & 0.000 & 921 & $N A^{a}$ & & \\
$0.60(0.28-0.93)$ & 0.000 & 921 & $0.14(0.05-0.24)$ & 0.004 & 889 \\
$0.31(0.09-0.33)$ & 0.005 & 919 & $0.04(-0.03$ to 0.11$)$ & 0.244 & 889
\end{tabular}

Association of psychopathology subscales with PRS, corrected for the other subscales 

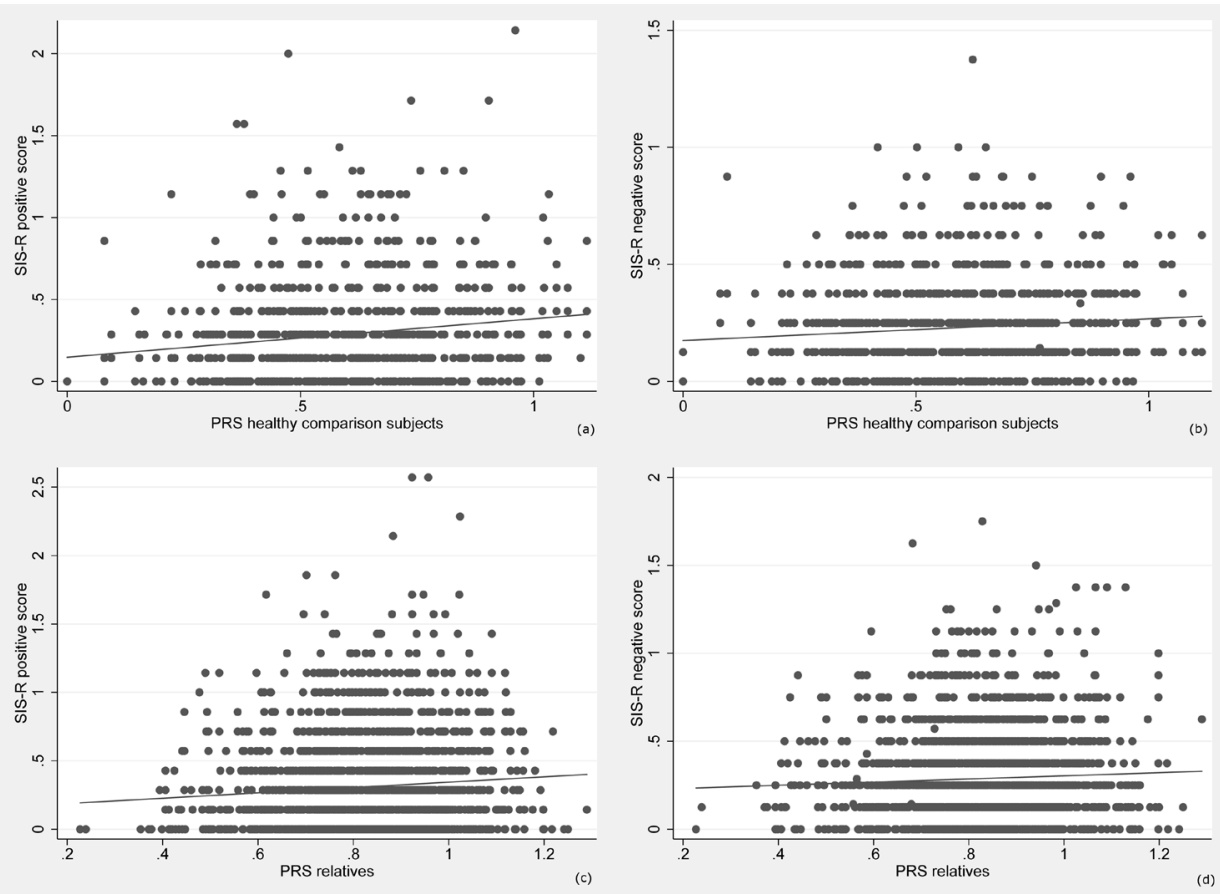

Fig. 3. (a-d) Scatterplots with linear regression line of polygenic risk score (PRS) on the one hand, and, on the other, Structured Interview for Schizotypy - Revised (SIS-R) positive score in healthy comparison subjects (Fig. 3a), SIS-R negative score in healthy comparison subjects (Fig. 3b), SIS-R positive score in relatives (Fig. 3c), SIS-R negative score in relatives (Fig. 3d).
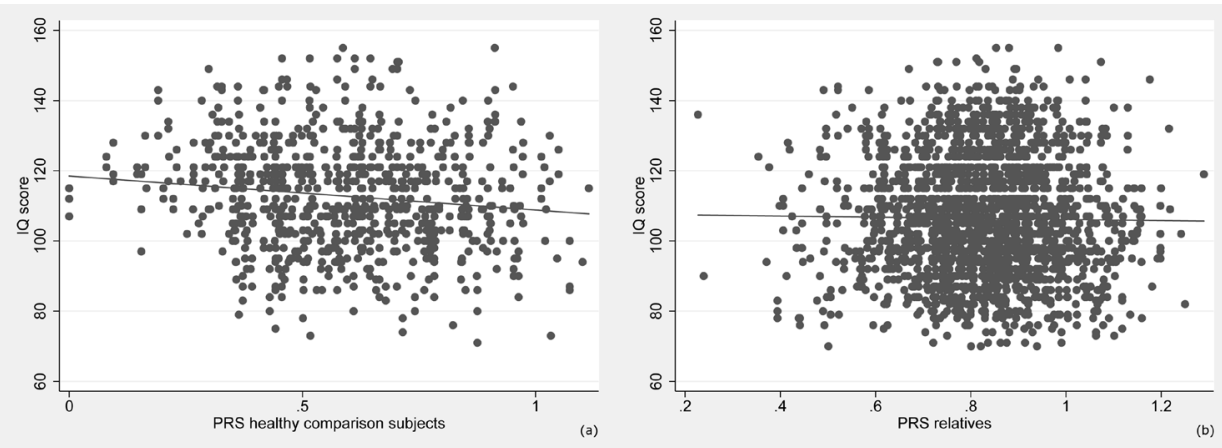

Fig. 4. (a, b) Scatterplots with linear regression line of polygenic risk score (PRS) on the one hand and, on the other, intelligence quotient (IQ) score in the healthy comparison subjects (Fig. 4a) and IQ score in the relatives (Fig. 4b). 
Table 7. Results of regression analyses in baseline sample for lifetime manic and depressive episodes (including episodes over 6-year follow-up) in relatives and healthy comparison subjects. Odds ratio reflects association between polygenic risk score on the one hand, and depressive/manic episode on the other

\begin{tabular}{|c|c|c|c|c|c|c|}
\hline & \multicolumn{3}{|l|}{ Relatives } & \multicolumn{3}{|c|}{ Healthy control subjects } \\
\hline & OR $(0.95 \% \mathrm{Cl})$ & $p$ & $n$ & OR $(0.95 \% \mathrm{CI})$ & $p$ & $N$ \\
\hline \multicolumn{7}{|l|}{ Measure } \\
\hline Depressive episode & $2.6(0.9-7.9)$ & 0.089 & 911 & $3.4(0.9-13.0)$ & 0.069 & 323 \\
\hline Manic episode & $6.4(0.3-132.6)$ & 0.228 & 910 & $0.7(0.01-38.2)$ & 0.867 & 323 \\
\hline Affective episode ${ }^{a}$ & $3.1(1.04-9.3)$ & 0.043 & 909 & $3.4(0.0-12.7)$ & 0.075 & 323 \\
\hline
\end{tabular}

${ }^{\text {a }}$ Any depressive or manic episode.

OR, odds ratio; $95 \% \mathrm{Cl}$, 95\% confidence interval; $p$, $p$-value; $n$, number of observations 


\section{DISCUSSION}

The main findings were that (i) PRS was pleiotropically associated with measures of affective dysregulation, aberrant salience and neurocognition; (ii) The association between neurocognition and PRS was present in the healthy comparison subjects but not in the relatives, and was independent of CAPE/SIS-R measures; (iii) Interview-based SIS-R measures appeared to be more sensitive than CAPE-based self-reports in detecting genetic association in the healthy comparison group.

According to the liability-threshold model, a person with a number of risk variants lower than or equal to the critical threshold would not develop schizophrenia, whereas a person with more risk variants would ${ }^{42}$. As individuals at higher than average genetic risk, such as the first-degree relatives of patients, have higher levels of psychometric and neurocognitive endophenotypes associated with psychotic disorder ${ }^{10,43}$, associations between PRS and such endophenotypes may be more apparent in this group. However, in the current analysis, there was no evidence that associations between PRS and measures of psychopathology and cognition were stronger in the relatives of patients as compared with a group of healthy comparison subjects. Indeed, given stronger evidence for association between PRS and cognition in the healthy control group, the results suggest it may be more, not less difficult to demonstrate associations in the relatives.

A previous investigation in this sample, focussing on the association between childhood trauma and IQ, reported a similar finding in that the association between IQ and childhood trauma was large in the healthy comparison group, intermediate in the relatives and not apparent in the patient group ${ }^{44}$. Thus, in subjects at higher than average (environmental or genetic) risk, emerging expression of phenotypic alterations may create floor effects, obscuring associations. The results of this study again suggest that particularly measures in the neurodevelopmental domain may be sensitive to such a floor effect, as associations between PRS and subthreshold measures of psychopathology were apparent in both the relative and the healthy comparison groups.

\section{Affective dysregulation, aberrant salience and genetic liability to psychosis}

There is a well-established link between affective dysregulation and psychosis, both at the level of clinical illness ${ }^{45,46}$, subthreshold psychotic experiences ${ }^{13-18}$, so-called clinical high-risk states ${ }^{47}$ and in the early prodromal stages ${ }^{48}$. In addition, many studies have suggested an important role of affective dysregulation in the formation of psychotic symp- 
toms $\mathrm{s}^{49-53}$, and molecular genetic studies suggest an overlap between schizophrenia and affective illness ${ }^{54,55}$.

There is evidence that psychosis represents a severity dimension of an initial state of affective dysregulation ${ }^{17,56}$ and that clinical high risk samples with high risk of conversion to psychotic disorder mainly consist of individuals with affective dysregulation ${ }^{57}$. Therefore, early states of affective dysregulation may give rise to more severe states in which psychotic symptoms arise ${ }^{58}$. Additional exposure may be required for psychotic symptom formation, research showing higher risks of psychotic symptom formation with progressively greater level of exposure to environmental risk factors ${ }^{59-61}$.

The findings agree with the literature, suggesting that the association between genetic risk and psychosis proneness is not only mediated by psychoticism and neurodevelopmental alterations, but also by measures of affective dysregulation. The effects of polygenic risk thus may be examined further in network models, focussing particularly on the strength of the connection between affective dysregulation, cognition and psychotic symptoms. Similarly, gene-environment interactions may converge at the level of the connection between affective dysregulation, cognition and psychotic symptoms.

\section{Cognitive alterations and neurodevelopmental hypothesis}

The premorbid cognitive alterations in schizophrenia are one of the core findings supporting the neurodevelopmental hypothesis ${ }^{62}$. There was evidence for an association between IQ and PRS, however it may be hypothesized that environmental exposures such as childhood trauma, that have been shown to also impact cognitive development ${ }^{63-66}$ may also play a causal role in the development of cognitive alterations in psychosis ${ }^{44,}$ 67-69. In addition, genetic variation and epistasis not included in the PRS may contribute to cognitive alterations as well. It has been reported that less than a fifth of the effect of family history on the occurrence of psychotic disorder is mediated by $\mathrm{PRS}^{70}$, leaving room for the impact of other genetic factors, assuming not all of the remainder of the effect of family history is 'environmental'.

Given evidence that most of the overall effect of a schizophrenia diagnosis on cognitive performance is mediated through a single common factor, indicating that a generalized cognitive deficit is a core underlying feature ${ }^{71}$, a general measure like IQ arguably is the most useful to examine in the context of associations with PRS. There have been conflicting reports on associations between measures of cognition and schizophrenia polygenic 
scores in patient and control samples using a variety of different cognitive measures ${ }^{19,72,}$ ${ }^{73}$, however no previous report has examined the association in a large sample of non-ill individuals at higher than average genetic risk with repeated measures of IQ over time. Given evidence for an association between PRS and IQ in healthy control group, it may be hypothesized that PRS for schizophrenia is expressed, at least in part, as a cognitive measure that correlates with IQ.

\section{Methodological issues}

The results should be interpreted in the light of several methodological considerations. First, although the sample size was substantial, it was still relatively small for a molecular genetic study. Nevertheless, effect sizes were detectable. A previous general population study with a larger sample suggested a weak association with CAPE negative scores however in that study ${ }^{5}$, CAPE positive and CAPE depression scores were not included. Given that CAPE negative scores are strongly associated with CAPE depression scores $(0.7$ in the current study), the reported association with CAPE negative scores may be considered compatible with the current findings ${ }^{7}$, given that CAPE depression in the healthy comparison group directionally showed the same type of association as in the relatives, albeit weaker. In any case, the results of this study show that self-reports of psychosis-proneness in the general population may not be sensitive in detecting genetic associations. Second, it could be argued that lack of association between IQ and PRS in the relatives cannot be interpreted fully without examination of the association between IQ and PRS in their patient relatives; if the association is present in the patient group but not in their relatives, this may indicate that PRS can contribute to IQ in interaction with other genetic or non-genetic factors that patients may have been differentially exposed to. However, analysis of the association between repeated measure of IQ and PRS in the patient group (1304 observations in 596 patients) similarly yielded no evidence of association ( $B=1.7$, $95 \% \mathrm{Cl}-4.5$ to $7.9 ; p=0.597)$. Third, it could be argued that the association between PRS and measures of affective dysregulation in the relatives is confounded by PRS-associated poor illness outcome in the patients, negatively impacting mental health of the relatives. However, the absence of an association between PRS and cognitive alterations, which are associated with poor outcome, makes it unlikely that PRS is associated with poor outcome. Although PRS was associated with positive symptoms of psychosis, positive symptoms are not associated with poor outcome. In order to verify this issue analytically, we re-examined the association between PRS and CAPE depression, additionally adjusting the analysis for the following outcome measures in the patient relative: number of unmet needs, measures with the Camberwell Assessment of Needs ${ }^{74}$, GAF-symptoms 
and GAF-disability ${ }^{75}$. This adjustment did not reduce the association $(B=0.22,95 \% \mathrm{Cl}$ $0.08-0.36, p=0.003)$. Finally, although two different genotyping platforms were used, one for controls and another for relatives, the use of imputation across platforms can be considered an effective way to control for this. In addition, analyses in the relatives were entirely within-platform, and analyses in the healthy comparison subjects was also largely within platform. 


\section{REFERENCES}

1. Jeppesen P, Larsen JT, Clemmensen L, Munkholm A, Rimvall MK, Rask CU, ... Skovgaard AM. The CCC2000 Birth Cohort Study of Register-Based Family History of Mental Disorders and Psychotic Experiences in Offspring. Schizophr Bull. 2015; 41:1084-1094.

2. Linscott RJ, van Os J. An updated and conservative systematic review and meta-analysis of epidemiological evidence on psychotic experiences in children and adults: on the pathway from proneness to persistence to dimensional expression across mental disorders. Psychol Med. 2013; 43:1133-1149.

3. Consortium IS, Purcell SM, Wray NR, Stone JL, Visscher PM, O’Donovan MC, ... Sklar P. Common polygenic variation contributes to risk of schizophrenia and bipolar disorder. Nature. 2009; 460:748-752.

4. lyegbe C, Campbell D, Butler A, Ajnakina O, Sham P. The emerging molecular architecture of schizophrenia, polygenic risk scores and the clinical implications for GxE research. Soc Psychiatry Psychiatr Epidemiol. 2014; 49:169-182.

5. Jones HJ, Stergiakouli E, Tansey KE, Hubbard L, Heron J, Cannon M, . . . Zammit S. Phenotypic Manifestation of Genetic Risk for Schizophrenia During Adolescence in the General Population. JAMA Psychiatry. 2016; 73:221-228.

6. Sieradzka D, Power RA, Freeman D, Cardno AG, McGuire P, Plomin R, . . Ronald A. Are Genetic Risk Factors for Psychosis Also Associated with Dimension-Specific Psychotic Experiences in Adolescence? PLoS One. 2014; 9:e94398.

7. van Os J. Measures of Psychosis Proneness and Genetic Risk for Schizophrenia. JAMA Psychiatry. 2016; 73:638.

8. Zammit S, Hamshere M, Dwyer S, Georgiva L, Timpson N, Moskvina V, . . O'Donovan MC. A population-based study of genetic variation and psychotic experiences in adolescents. Schizophr Bull. 2014; 40:1254-1262.

9. Cardno AG, Marshall EJ, Coid B, Macdonald AM, Ribchester TR, Davies NJ, . . Murray RM. Heritability estimates for psychotic disorders: the Maudsley twin psychosis series. Arch Gen Psychiatry. 1999; 56:162 168.

10. Kendler KS, McGuire M, Gruenberg AM, O’Hare A, Spellman M, Walsh D. The Roscommon family study. III. Schizophrenia-related personality disorders in relatives. Arch Gen Psychiatry. 1993; 50:781-788.

11. Svrakic DM, Zorumski CF, Svrakic NM, Zwir I, Cloninger CR. Risk architecture of schizophrenia: the role of epigenetics. Curr Opin Psychiatry. 2013; 26:188-195.

12. van Os J, Kenis G, Rutten BP. The environment and schizophrenia. Nature. 2010; 468:203-212.

13. Verdoux H, Van Os J, Maurice-Tison S, Gay B, Salamon R, Bourgeois M-L. Increased occurrence of depression in psychosis-prone subjects: A follow-up study in primary care settings. Compr Psychiatry. 1999; 40:462-468.

14. Hanssen M, Peeters F, Krabbendam L, Radstake S, Verdoux H, van Os J. How psychotic are individuals with non-psychotic disorders? Soc Psychiatry Psychiatr Epidemiol. 2003; 38:149-154.

15. van Rossum I, Dominguez M-d-G, Lieb R, Wittchen $\mathrm{H}-\mathrm{U}$, van Os J. Affective Dysregulation and Reality Distortion: A 10-Year Prospective Study of Their Association and Clinical Relevance. Schizophr Bull. 2011; 37:561-571.

16. Varghese D, Scott J, Welham J, Bor W, Najman J, O'Callaghan M, . . McGrath J. Psychotic-Like Experiences in Major Depression and Anxiety Disorders: A Population-Based Survey in Young Adults. Schizophr Bull. 2011; 37:389-393.

17. Wigman JT, van Nierop M, Vollebergh WA, Lieb R, Beesdo-Baum K, Wittchen HU, van Os J. Evidence that psychotic symptoms are prevalent in disorders of anxiety and depression, impacting on illness onset, risk and severity--implications for diagnosis and ultra-high risk research. Schizophr Bull. 2012; 38:247-257.

18. Stochl J, Khandaker GM, Lewis G, Perez J, Goodyer IM, Zammit S, . . Jones PB. Mood, anxiety and psychotic phenomena measure a common psychopathological factor. Psychol Med. 2015; 45:1483-1493.

19. Hubbard L, Tansey KE, Rai D, Jones P, Ripke S, Chambert KD, . . Zammit S. Evidence of Common Genetic Overlap Between Schizophrenia and Cognition. Schizophr Bull. 2016; 42:832-842.

20. Korver N, Quee PJ, Boos HB, Simons CJ, de Haan L. Genetic Risk and Outcome of Psychosis (GROUP), a multi-site longitudinal cohort study focused on gene-environment interaction: objectives, sample characteristics, recruitment and assessment methods. Int J Methods Psychiatr Res. 2012; 21:205-221. 
21. Steinberg S, de Jong S, Andreassen OA, Werge T, Borglum AD, Mors O, ... Stefansson K. Common variants at VRK2 and TCF4 conferring risk of schizophrenia. Hum Mol Genet. 2011; 20:4076-4081.

22. NIMH.Genetics.Initiative. Family Interview for Genetic Studies (FIGS). Rockville, Md: National Institute of Mental Health; 1992.

23. American Psychiatric Association. Diagnostic and statistical manual of mental disorders 4th Edition, Text Revision. Washington, DC: American Psychiatric Association; 2000.

24. Andreasen NC, Flaum M, Arndt S. The Comprehensive Assessment of Symptoms and History (CASH). An instrument for assessing diagnosis and psychopathology. Arch Gen Psychiatry. 1992; 49:615-623.

25. Wing JK, Babor T, Brugha T, Burke J, Cooper JE, Giel R, ... Sartorius N. SCAN. Schedules for Clinical Assessment in Neuropsychiatry. Arch Gen Psychiatry. 1990; 47:589-593.

26. Marden JR, Walter S, Tchetgen Tchetgen EJ, Kawachi I, Glymour MM. Validation of a polygenic risk score for dementia in black and white individuals. Brain Behav. 2014; 4:687-697.

27. Kendler KS, Lieberman JA, Walsh D. The Structured Interview for Schizotypy (SIS): a preliminary report. Schizophr Bull. 1989; 15:559-571.

28. Vollema MG, Ormel J. The reliability of the structured interview for schizotypy-revised. Schizophr Bull. 2000; 26:619-629.

29. Konings M, Bak M, Hanssen M, van Os J, Krabbendam L. Validity and reliability of the CAPE: a self-report instrument for the measurement of psychotic experiences in the general population. Acta Psychiatr Scand. 2006; 114:55-61.

30. Wing JK, Cooper JE, Sartorius N. The measurement and classification of psychiatric symptoms. London: Cambridge University Press; 1974.

31. Andreasen NC. Negative symptoms in schizophrenia. Definition and reliability. Arch Gen Psychiatry. 1982; 39:784-788.

32. Selten JP, Sijben NE, van den Bosch RJ, Omloo Visser J, Warmerdam H. The subjective experience of negative symptoms: a self-rating scale. Compr Psychiatry. 1993; 34:192-197.

33. Addington D, Addington J, Maticka-Tyndale E. Assessing depression in schizophrenia: the Calgary Depression Scale. Br J Psychiatry Suppl. 1993:39-44.

34. Blyler CR, Gold JM, lannone VN, Buchanan RW. Short form of the WAIS-III for use with patients with schizophrenia. Schizophr Res. 2000; 46:209-215.

35. Wechsler D. WAIS-III: Wechsler Adult Intelligence Scale, third edition. San Antonio, Texas: Psychological Corporation; 1997.

36. Velthorst E, Levine SZ, Henquet C, de Haan L, van Os J, Myin-Germeys I, Reichenberg A. To cut a short test even shorter: reliability and validity of a brief assessment of intellectual ability in schizophrenia--a control-case family study. Cogn Neuropsychiatry. 2013; 18:574-593.

37. McCarthy S, Das S, Kretzschmar W, Delaneau O, Wood AR, Teumer A, . . Durbin R. A reference panel of 64,976 haplotypes for genotype imputation. Nat Genet. 2016; 48:1279-1283.

38. Schizophrenia Working Group of the Psychiatric Genomic Consortium. Biological insights from 108 schizophrenia-associated genetic loci. Nature. 2014; 511:421-427.

39. Euesden J, Lewis CM, O’Reilly PF. PRSice: Polygenic Risk Score software. Bioinformatics. 2015; 31:14661468.

40. Price AL, Patterson NJ, Plenge RM, Weinblatt ME, Shadick NA, Reich D. Principal components analysis corrects for stratification in genome-wide association studies. Nat Genet. 2006; 38:904-909.

41. StataCorp. STATA Statistical Software: Release 14. Texas: College Station; 2015.

42. McGue M, Gottesman, II, Rao DC. The transmission of schizophrenia under a multifactorial threshold model. Am J Hum Genet. 1983; 35:1161-1178.

43. Toulopoulou T, Picchioni M, Rijsdijk F, Hua-Hall M, Ettinger U, Sham P, Murray R. Substantial genetic overlap between neurocognition and schizophrenia: genetic modeling in twin samples. Arch Gen Psychiatry. 2007; 64:1348-1355.

44. van Os J, Marsman A, van Dam D, Simons CJP, Investigators G. Evidence That the Impact of Childhood Trauma on IQ Is Substantial in Controls, Moderate in Siblings, and Absent in Patients With Psychotic Disorder. Schizophr Bull. 2017; 43:316-324.

45. Tsuang MT, Dempsey GM. Long-term outcome of major psychoses. II. Schizoaffective disorder compared with schizophrenia, affective disorders, and a surgical control group. Arch Gen Psychiatry. 1979; 36:13021304. 
46. McMillan KA, Enns MW, Cox BJ, Sareen J. Comorbidity of Axis I and II mental disorders with schizophrenia and psychotic disorders: findings from the National Epidemiologic Survey on Alcohol and Related Conditions. Can J Psychiatry. 2009; 54:477-486.

47. Fusar-Poli P, Nelson B, Valmaggia L, Yung AR, McGuire PK. Comorbid Depressive and Anxiety Disorders in 509 Individuals With an At-Risk Mental State: Impact on Psychopathology and Transition to Psychosis. Schizophr Bull. 2014; 40:120-131.

48. Hafner H, Loffler W, Maurer K, Hambrecht M, an der Heiden W. Depression, negative symptoms, social stagnation and social decline in the early course of schizophrenia. Acta Psychiatr Scand. 1999; 100:105118.

49. Freeman D, Garety PA. Worry, Worry processes and dimensions of delusions: an exploratory investigation of a role for anxiety processes in the maintenance of delusional distress. Behav Cogn Psychother. 1999; 27:47-62.

50. Freeman D, Garety PA. Connecting neurosis and psychosis: the direct influence of emotion on delusions and hallucinations. Behav Res Ther. 2003; 41:923-947.

51. Garety PA, Kuipers E, Fowler D, Freeman D, Bebbington PE. A cognitive model of the positive symptoms of psychosis. Psychol Med. 2001; 31:189-195.

52. Myin-Germeys I, van Os J. Stress-reactivity in psychosis: evidence for an affective pathway to psychosis. Clin Psychol Rev. 2007; 27:409-424.

53. Fowler D, Hodgekins J, Garety P, Freeman D, Kuipers E, Dunn G, . . Bebbington PE. Negative cognition, depressed mood, and paranoia: a longitudinal pathway analysis using structural equation modeling. Schizophr Bull. 2012; 38:1063-1073.

54. Cross-Disorder Group of the Psychiatric Genomics C. Identification of risk loci with shared effects on five major psychiatric disorders: a genome-wide analysis. Lancet. 2013; 381:1371-1379.

55. Cross-Disorder Group of the Psychiatric Genomics C, Lee SH, Ripke S, Neale BM, Faraone SV, Purcell SM, ... International Inflammatory Bowel Disease Genetics C. Genetic relationship between five psychiatric disorders estimated from genome-wide SNPs. Nat Genet. 2013; 45:984-994.

56. Kelleher I, Keeley H, Corcoran P, Lynch F, Fitzpatrick C, Devlin N, . . Cannon M. Clinicopathological significance of psychotic experiences in non-psychotic young people: evidence from four population-based studies. Br J Psychiatry. 2012; 201:26-32.

57. Addington J, Cadenhead KS, Cannon TD, Cornblatt B, McGlashan TH, Perkins DO, ... Heinssen R. North American Prodrome Longitudinal Study: a collaborative multisite approach to prodromal schizophrenia research. Schizophr Bull. 2007; 33:665-672.

58. van Os J, Reininghaus U. Psychosis as a transdiagnostic and extended phenotype in the general population. World Psychiatry. 2016; 15:118-124.

59. Cougnard A, Marcelis M, Myin-Germeys I, De Graaf R, Vollebergh W, Krabbendam L, ... Van Os J. Does normal developmental expression of psychosis combine with environmental risk to cause persistence of psychosis? A psychosis proneness-persistence model. Psychol Med. 2007; 37:513-527.

60. Guloksuz S, van Nierop M, Lieb R, van Winkel R, Wittchen HU, van Os J. Evidence that the presence of psychosis in non-psychotic disorder is environment-dependent and mediated by severity of non-psychotic psychopathology. Psychol Med. 2015; 45:2389-2401.

61. van Nierop M, Viechtbauer W, Gunther N, van Zelst C, de Graaf R, Ten Have M, . . van Winkel R. Childhood trauma is associated with a specific admixture of affective, anxiety, and psychosis symptoms cutting across traditional diagnostic boundaries. Psychol Med. 2015; 45:1277-1288.

62. Jones P, Rodgers B, Murray R, Marmot M. Child development risk factors for adult schizophrenia in the British 1946 birth cohort. Lancet. 1994; 344:1398-1402.

63. Majer M, Nater UM, Lin JM, Capuron L, Reeves WC. Association of childhood trauma with cognitive function in healthy adults: a pilot study. BMC Neurol. 2010; 10:61.

64. Gould F, Clarke J, Heim C, Harvey PD, Majer M, Nemeroff CB. The effects of child abuse and neglect on cognitive functioning in adulthood. J Psychiatr Res. 2012; 46:500-506.

65. Maguire SA, Williams B, Naughton AM, Cowley LE, Tempest V, Mann MK, ... Kemp AM. A systematic review of the emotional, behavioural and cognitive features exhibited by school-aged children experiencing neglect or emotional abuse. Child Care Health Dev. 2015; 41:641-653. 
66. Philip NS, Sweet LH, Tyrka AR, Carpenter SL, Albright SE, Price LH, Carpenter LL. Exposure to childhood trauma is associated with altered $n$-back activation and performance in healthy adults: implications for a commonly used working memory task. Brain Imaging Behav. 2016; 10:124-135.

67. Lysaker PH, Meyer PS, Evans JD, Clements CA, Marks KA. Childhood sexual trauma and psychosocial functioning in adults with schizophrenia. Psychiatr Serv. 2001; 52:1485-1488.

68. Aas M, Steen NE, Agartz I, Aminoff SR, Lorentzen S, Sundet K, . . Melle I. Is cognitive impairment following early life stress in severe mental disorders based on specific or general cognitive functioning? Psychiatry Res. 2012; 198:495-500.

69. Sahu G, Malavade K, Jacob T. Cognitive Impairment in Schizophrenia: Interplay of BDNF and Childhood Trauma? A Review of Literature. Psychiatr Q. 2016; 87:559-569.

70. Agerbo E, Sullivan PF, Vilhjálmsson BJ, et al. Polygenic risk score, parental socioeconomic status, family history of psychiatric disorders, and the risk for schizophrenia: A danish population-based study and meta-analysis. JAMA Psychiatry. 2015; 72:635-641.

71. Dickinson D, lannone VN, Wilk CM, Gold JM. General and specific cognitive deficits in schizophrenia. Biol Psychiatry. 2004; 55:826-833.

72. Hatzimanolis $A$, Bhatnagar $P$, Moes $A$, Wang $R$, Roussos $P$, Bitsios $P, \ldots$ Avramopoulos $D$. Common genetic variation and schizophrenia polygenic risk influence neurocognitive performance in young adulthood. Am J Med Genet B Neuropsychiatr Genet. 2015; 168:392-401.

73. Mark W, Toulopoulou T. Cognitive intermediate phenotype and genetic risk for psychosis. Curr Opin Neurobiol. 2016; 36:23-30.

74. Slade M, Phelan M, Thornicroft G, Parkman S. The Camberwell Assessment of Need (CAN): comparison of assessments by staff and patients of the needs of the severely mentally ill. Soc Psychiatry Psychiatr Epidemiol. 1996; 31:109-113.

75. World Health Organisation. WHO Coordinated Multi-Centre Study on the Course and Outcome of Schizophrenia. Geneva: World Health Organisation; 1992. 


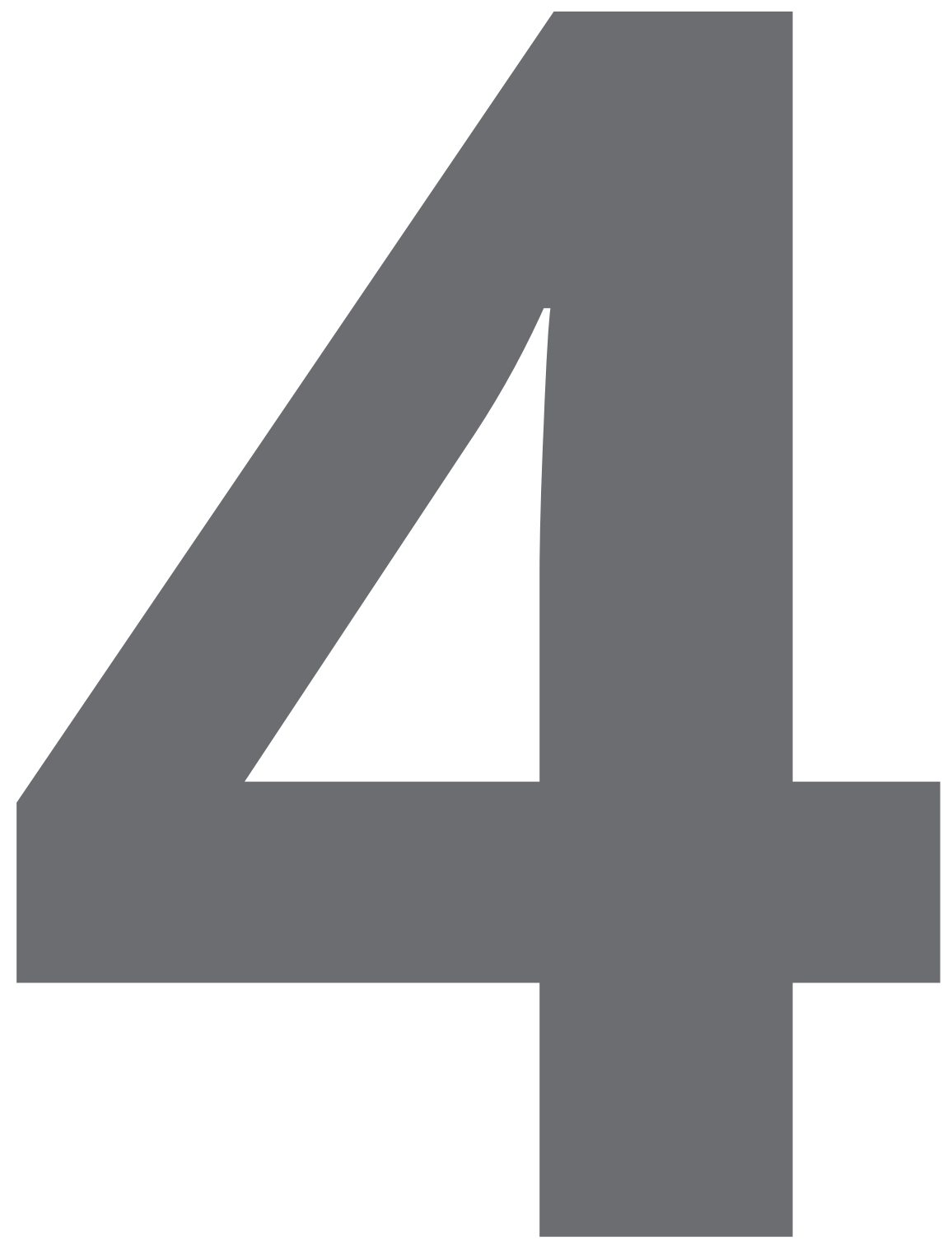




\section{Chapter 4}

Clinical High Risk for psychosis: the association between momentary stress, affective and psychotic symptoms.

Y. van der Steen ${ }^{1,2^{*}}$, J. Gimpel-Drees ${ }^{3 *}$, T. Lataster ${ }^{1}$, W. Viechtbauer ${ }^{1}$, C.J.P. Simons ${ }^{1,4}$, M. Lardinois $^{1}$, T.M. Michel ${ }^{5}$, B. Janssen ${ }^{6}$, A. Bechdolf7, M. Wagner ${ }^{3^{\wedge}}$, I. Myin-Germeys ${ }^{1,2^{\wedge}}$. *Shared first authors; 'Shared last authors

${ }^{1}$ Department of Psychiatry \& Neuropsychology, School for Mental Health and Neuroscience (MHeNS), Maastricht University, Maastricht, the Netherlands

${ }^{2} \mathrm{KU}$ Leuven - University of Leuven, Department of Neuroscience, Centre for Contextual Psychiatry, Leuven, Belgium

${ }^{3}$ Department of Psychiatry and Psychotherapy, University of Bonn, Bonn, Germany

${ }^{4} \mathrm{GGzE}$, Institute for Mental Health Care Eindhoven en De Kempen, Eindhoven, the Netherlands

${ }^{5}$ Department of Psychiatry Odense, Psychiatry in the region of Southern Denmark and Institute for Clinical Research, University of Southern Denmark, Denmark

${ }^{6}$ Department of Psychiatry and Psychotherapy, Heinrich-Heine University Düsseldorf, Düsseldorf, Germany

${ }^{7}$ Department of Psychiatry and Psychotherapy, University of Cologne, Cologne, Germany

Acta Psychiatrica Scandinavica, 2017, 136: 63-73 


\section{ABSTRACT}

Objective: The aim of this study was to assess associations between momentary stress and both affective and psychotic symptoms in everyday life of individuals at clinical high risk (CHR), compared to chronic psychotic patients and healthy controls, in search for evidence of early stress sensitization. It also assessed whether psychotic experiences were experienced as stressful.

Method: The experience sampling method was used to measure affective and psychotic reactivity to everyday stressful activities, events and social situations in 22 CHR patients, 24 patients with a psychotic disorder and 26 healthy controls.

Results: Multilevel models showed significantly larger associations between negative affect (NA) and activity-related stress for CHR patients than for psychotic patients $(p=0.008)$ and for CHR compared to controls $(p<0.001)$. Similarly, the association between activity-related stress and psychotic symptoms was larger in CHR than in patients $(p=0.02)$. Finally, the association between NA and symptoms $(p<0.001)$ was larger in CHR than in patients.

Conclusion: Stress sensitization seems to play a role particularly in the early phase of psychosis development as results suggest that CHR patients are more sensitive to daily life stressors than psychotic patients. In this early phase, psychotic experiences also contributed to the experience of stress. 


\section{INTRODUCTION}

It has long been suggested that stress plays an important role in the emergence and course of psychotic disorder ${ }^{1-5}$. Stressful life events ${ }^{6}$, childhood adversity ${ }^{7}$, as well as small everyday hassles ${ }^{8,9}$ have been associated with the development and course of psychotic disorder. In order to further elucidate the role of stress in the aetiology of psychotic disorder, attention has shifted to studies of the putative prodromal phase of a psychotic disorder. Participants in such studies are those who experience subclinical psychotic symptoms and meet well established prodromal criteria that describe them to be at ultra-high risk $(\mathrm{UHR})^{10}$ or clinical high risk $(\mathrm{CHR})^{11}$ for a transition to disorder. In the present study, the term clinical high risk is utilized.

$\mathrm{CHR}$ patients may be more exposed to stressful experiences. Findings regarding the number of life events in CHR patients compared to controls are mixed, with some studies reporting an association between the occurrence of traumatic experiences as well as other negative life events and the expression of subclinical psychotic symptomatology $^{12-19}$, while other studies reported no difference in the number of major life events ${ }^{20,21}$ or even significantly fewer life events ${ }^{22}$. Alternatively, CHR patients may specifically differ in their tolerance of stress. Indeed, life events ${ }^{19,22}$, as well as daily life hassles ${ }^{19}$ were appraised as significantly more upsetting by CHR patients than controls. Additionally, CHR patients reported impaired tolerance and increased functional impairment in response to normal stress compared to healthy controls ${ }^{20}$ and higher self-reported psychosocial stress levels compared to first-episode psychosis patients ${ }^{23}$.

Previous studies with the Experience Sampling Method (ESM, a structured diary technique in which subjects are asked in normal daily life to report their thoughts, feelings and symptoms, and also the context (e.g. location, company, activity) and the appraisal of the context, several times per day) have shown a higher emotional and psychotic reactivity to small daily life stressors, in psychotic patients, their unaffected relatives, and in those at psychometric risk for psychotic disorder when compared to healthy controls ${ }^{2}$ 24-27. It has been suggested that the (repeated) exposure to early severe stressors increases sensitivity to small stresses in daily life ${ }^{2,4,28}$, and that this process of 'behavioural sensitization' is a vulnerability marker for psychosis.

However, until now, only one ESM study ${ }^{29}$ has investigated both emotional and symptomatic reactivity to daily life stress in a sample of $\mathrm{CHR}$ participants. Compared to psychot- 
ic patients and controls, the CHR group experienced greater negative affect (NA) when confronted with stressful activities and social situations, but not after unpleasant events (i.e., emotional stress reactivity). Both the $\mathrm{CHR}$ and psychotic patient group showed an increase in psychotic symptoms in response to daily life stressors (i.e., psychotic stress reactivity), in comparison to controls. However, psychotic stress reactivity was comparable across patient groups. The results suggest that stress reactivity for small daily life stressors and therefore early stress sensitization occurs before the onset of psychotic disorders and is not just the consequence of a chronic illness.

What is often neglected in stress research is that psychotic experiences in themselves may be an important source of distress. A recent study ${ }^{30}$ has shown that intensity of distress related to subclinical symptoms was related to transition risk. Furthermore, ESM studies with psychotic patients have reported that psychotic symptoms are associated with distress and an increase of $\mathrm{NA}^{31-33}$. This may be particularly true for CHR patients, for whom these experiences are new.

\section{Aims of the study}

Our aim was to examine 1) whether emotional reactivity to stress differs in Clinical High Risk patients, chronic psychotic patients and healthy controls, 2) whether psychotic reactivity to stress differs in CHR patients versus chronic psychotic patients, and 3) whether psychotic symptoms in itself are increasing negative affect in both patient groups. 


\section{METHODS}

\section{Sample}

The sample consisted of 27 patients who were diagnosed with a non-affective psychotic disorder, 27 participants at CHR for psychosis, and 27 healthy controls. Participants in the CHR group were between 18 and 45 years of age, and had at least one of the following: (i) attenuated positive symptoms; (ii) brief limited intermittent psychotic symptoms (BLIPS), both assessed with the Structured Interview for Prodromal Symptoms (SIPS) ${ }^{34}$; (iii) presence of at least 2 basic symptoms (e.g., subtle thought and speech disturbances) assessed with the Schizophrenia Prediction Instrument, Adult version (SPI-A) ${ }^{35}$; (iv) a significant drop in functioning (30\% or more on the Global Assessment of Functioning (GAF) Scale for at least 1 month within the last year) in combination with genetic risk; or (v) a significant drop in functioning plus a diagnosis of schizotypal personality disorder. Momentary assessment data for the CHR group were collected in an add-on study of the 'PREVENT' project (for more details $\mathrm{see}^{36}$ ), a large German multisite early recognition and intervention in psychosis project. CHR participants who took part in PREVENT were randomly assigned to cognitive behavioural therapy, treatment with Aripiprazole (Abilify@) and medical management or placebo plus medical management. As the study is not finished yet, disclosure of the assignments of our participants is not yet possible. ESM data collection was started directly after inclusion in the PREVENT.

Controls between the ages of 18 and 45 years were recruited by advertisements at the University of Bonn and other public buildings in Bonn. The Structured Clinical Interview for DSM-IV axis I disorders (SCID-I) ${ }^{37}$ was used to assess axis I disorders in the CHR group and to exclude any participants with a psychiatric disorder from the control group. Control participants were also excluded in case of a family history of psychotic disorder.

The ESM data of the psychotic patients were gathered as part of an add-on study to the Genetic Risk and Outcome of Psychosis (GROUP) study ${ }^{38}$, which investigated risk and protective factors for psychosis. Patients were recruited through in-and out-patient mental health facilities in the Southern part of the Netherlands and (the Dutch speaking part of) Belgium. Inclusion criteria for the patient group were age 16-60 years and a diagnosis of schizophrenia or schizoaffective disorder as assessed with the Comprehensive Assessment of Symptoms and History (CASH) ${ }^{39}$. Patients with substance-related psychosis and psychosis with a known organic cause were excluded. For the current analyses, only those patients with minimum illness duration of 5 years since their first psychotic epi- 
sode were selected. Exclusion criteria for all three groups were a history of brain disease or head injury with loss of consciousness. All participants gave written informed consent, conforming to local ethics committee guidelines.

\section{The Experience Sampling Method}

The Experience Sampling Method (ESM) is a within-day, momentary self-assessment technique ${ }^{40,41}$. Participants received a digital wristwatch and self-assessment forms collected in a booklet for each day. Ten times a day on six consecutive days, the watch emitted a signal (beep) at unpredictable moments between 7:30 a.m. and 10:30 p.m. After each beep, participants were asked to immediately report their thoughts, mood, symptoms, current context (e.g., their location, social company, activities), and subjective appraisals of the current situation. All self-assessments were rated on 7-point Likert scales. To ensure reliability of the completed reports, participants also recorded the time of completion of the report, which was compared with the time at which the watch had emitted a signal. All reports completed more than 15 minutes after the signal were excluded from the analyses, since previous work ${ }^{42}$ has shown that reports completed after this interval are less reliable and consequently less valid. Participants with less than 20 valid reports (out of 60 ) were excluded from the analysis.

\section{Assessment of mood}

Negative affect was assessed at each beep with six mood related adjectives (down, guilty, insecure, lonely, anxious, irritated) rated on seven-point Likert scales (1=not at all, $7=$ very). However, detailed factor analyses based on the ESM data collected in several studies conducted in our department, have shown that the 'down' and 'irritated' variables have high negative cross-loadings on the positive affect measure (personal communication ${ }^{43}$ ). Therefore, mean scores on the items 'guilty', 'insecure', 'lonely' and 'anxious' were used as a measure of NA in the analyses.

\section{Assessment of momentary psychotic symptoms}

Psychotic symptomatology was assessed at each beep with seven symptom related items. Hallucinations were asked directly ('I hear voices' and 'I see things that are not really there'), while the presence of delusions was assessed indirectly by items that include aspects of mental states that are directly associated with delusions in schizophrenia ${ }^{44,45}$. These were: 'I cannot get these thoughts out of my head'; 'I feel suspicious'; 'I feel unreal' and 'My thoughts are influenced by others'. The item 'I am afraid I will lose control' is related to psychosis in general. 


\section{Assessment of momentary stress}

Stress was conceptualized as the subjectively appraised stressfulness of distinctive (social) events and minor disturbances that continually happen in the natural flow of daily life. Three different stress measures were computed. For Activity-related stress, the question 'What are you doing?' served as a starting point. Subsequently, three questions (i.e., 'I would rather do something else'; 'This is difficult for me' and 'I can do this well', reverse coded) were scored on a 7-point Likert scale (1 to 7), and were combined into a mean activity-related stress variable. Event-related stress was based on the question 'What was the most important event since the last beep?' Participants subsequently scored how pleasant/unpleasant the event was on a bipolar scale (-3 very unpleasant, 0 neutral, +3 very pleasant). Positive events (scores 1, 2 and 3 ) were recoded to zero, and negative scores multiplied by -1 (i.e., higher scores now reflect higher stress/unpleasantness levels) for the event-related stress variable. For Social stress participants were asked to indicate whether they were in the company of others or alone. If they were in company of one or more persons, they were asked to rate the item 'I would prefer to be alone' (1 to 7). This score was used as the social stress variable.

\section{Analyses}

Groups were compared with respect to continuously measured baseline characteristics by means of ANOVAs. Chi-square tests were used to compare groups with respect to categorical variables. Group comparisons (ANOVAs) were also performed to test whether the average levels of NA, momentary psychotic symptoms as well as stress related to unpleasant activities, events and social situations differed between the psychotic patients, CHR patients and controls.

For the further analyses, we used multivariate multilevel models ${ }^{46,47}$, an extension of standard hierarchical linear models when analysing multiple (correlated) outcomes. In particular, a certain pair of variables (e.g., activity stress and NA) was repeatedly measured within participants using ESM, as described earlier. For each participant, we therefore had up to 60 (measurement occasions) $\times 2$ (outcomes) $=120$ observations available. The data therefore conformed to a three-level structure, with the two outcomes nested within measurement occasions ("beeps"), which in turn were nested within participants. To model the association between the two outcomes at the participant and at the beep level, we used a linear mixed-effects model with two correlated random effects at the participant level (corresponding to two dummy variables indicating whether a particular row of data corresponded to outcome 1 or outcome 2) and with correlated residuals at 
the beep level. The variance-covariance matrices of the random effects at the participant level and the residuals at the beep level were allowed to be fully unstructured. Age and gender and their interactions with the dummy variables were included as covariates in the model, since previous ESM research has shown a heightened affective stress response in female compared to male psychotic patients ${ }^{48}$ and participants in the psychotic patient group were older than those in the CHR and control groups. As it can be hypothesized that the association between stress and psychotic symptoms is influenced by low mood (i.e., high NA), we ran the models testing the association between stressors and momentary psychotic symptoms both with and without NA and it's interactions with the dummy variables as covariates.

Models were fitted separately in each of the three groups. To test whether the degree of association (i.e., correlation) between two outcomes differed between the groups at the beep level, we extracted the estimated correlations with their corresponding standard errors and then conducted Wald-type tests (i.e., $z=\left(\hat{\rho}_{1}-\hat{\rho}_{2}\right) / \sqrt{S E\left[\hat{\rho}_{1}\right]^{2}+S E\left[\hat{\rho}_{2}\right]^{2}}$, where $\hat{\rho}_{1}$ and $\hat{\rho}_{2}$ are the beep-level correlations for the first and second group, respectively, and $S E\left[\hat{\rho}_{1}\right]$ and $S E\left[\hat{\rho}_{2}\right]$ denote the corresponding standard errors). The models were fitted with restricted maximum likelihood (REML) estimation using the mixed routine in Stata $13.1^{49}$.

We used this method to investigate whether: (i) the association strength between stress (activity-related, event-related and social) and NA differed between the CHR and psychotic patient groups as well as the CHR and healthy control groups; (ii) the association strength between stress and momentary psychotic symptoms differed between the CHR and psychotic patients groups, once in the standard model and once in the model with NA added as a covariate; and (iii) the association strength between momentary psychotic symptoms and negative emotions (symptoms as stressor) differed between CHR and psychotic patients. 


\section{RESULTS}

\section{Participants and descriptive statistics}

The total sample consisted of 27 healthy controls, 27 CHR patients, and 27 psychotic patients. Inclusion criteria were incomplete for three CHR participants and were therefore excluded. After dropping the invalid beeps (i.e., filled out more than 15 minutes after the actual beep) and selecting those participants who had filled out a minimum of 20 valid beeps, 26 healthy controls, $22 \mathrm{CHR}$, and 24 patients remained, with a total number of 2950 observations and a mean number of 41.0 (S.D=9.8) beeps.

Demographic and clinical characteristics are shown in Table 1. The patients were significantly older than both the CHR patients and controls $(F(2,69)=17.01, p<0.001$, Tukey-Kramer: patients $>$ CHR, controls, $p<0.001)$. Gender $\left(\chi^{2}=1.61, p=0.45\right)$ and education level $\left(\chi^{2}=6.13, p=0.41\right)$ were similarly distributed over the three groups.

Table 1. Sociodemographic and clinical characteristics of the research sample.

\begin{tabular}{|c|c|c|c|}
\hline & $\begin{array}{l}\text { Psychotic patients } \\
(n=24)\end{array}$ & $\begin{array}{l}\text { Clinical High Risk patients } \\
(n=22)\end{array}$ & $\begin{array}{l}\text { Control subjects } \\
(n=26)\end{array}$ \\
\hline \multicolumn{4}{|l|}{ Demographic variables } \\
\hline $\mathrm{Age}^{\mathrm{a}, \mathrm{b}}$, mean (SD), range & 33.9 (8.8), 20-50 & 25.2 (5.0), 19-38 & 24.5 (3.6), 19-33 \\
\hline Gender (m/f) & $15 / 9$ & $17 / 5$ & $16 / 10$ \\
\hline \multicolumn{4}{|l|}{ Civil status, $n(\%)$} \\
\hline Not married & $15(63)$ & $19(86)$ & $21(81)$ \\
\hline Married/living together & $6(25)$ & $1(5)$ & $4(15)$ \\
\hline Divorced & $3(12)$ & & \\
\hline Widowhood & & & $1(4)$ \\
\hline Missing & & $2(9)$ & \\
\hline \multicolumn{4}{|l|}{ Work situation, $n(\%)$} \\
\hline Household & $1(4)$ & & \\
\hline School/Education & $1(4)$ & $14(64)$ & $17(65)$ \\
\hline Regular work & $12(50)$ & $3(14)$ & $8(31)$ \\
\hline Structured work & $3(13)$ & & \\
\hline Non-structured activities & $5(21)$ & $4(18)$ & \\
\hline Other & & & $1(4)$ \\
\hline Missing & $2(8)$ & $1(4)$ & \\
\hline
\end{tabular}


Table 1. Continued.

\begin{tabular}{|c|c|c|c|}
\hline & $\begin{array}{l}\text { Psychotic patients } \\
(n=24)\end{array}$ & $\begin{array}{l}\text { Clinical High Risk patients } \\
(n=22)\end{array}$ & $\begin{array}{l}\text { Control subjects } \\
(n=26)\end{array}$ \\
\hline \multicolumn{4}{|l|}{ Education level, $n(\%)$} \\
\hline No education & & $1(5)$ & \\
\hline Secondary school & $17(71)$ & $15(68)$ & $22(85)$ \\
\hline Higher education & $7(29)$ & $5(23)$ & $4(15)$ \\
\hline Missing & & $1(5)$ & \\
\hline \multicolumn{4}{|l|}{ Clinical variables } \\
\hline \multicolumn{4}{|l|}{ DSM IV axis I diagnosis ( $n$ ) } \\
\hline Schizophrenia & 15 & & \\
\hline Schizoaffective Disorder & 7 & & \\
\hline Brief Psychotic Disorder & 1 & & \\
\hline Delusional Disorder & 1 & & \\
\hline Major Depression & & 7 & \\
\hline Dysthymia & & 1 & \\
\hline Social Phobia & & 2 & \\
\hline OCD & & 2 & \\
\hline PTSD & & 1 & \\
\hline Panic Disorder & & 1 & \\
\hline Alcohol misuse & & 1 & \\
\hline No diagnosis & & 10 & 26 \\
\hline $\begin{array}{l}\text { Psychotic episodes (PE), mean } \\
\text { (SD), range }\end{array}$ & $2.7(1.7), 1-8$ & & \\
\hline Illness duration, mean (SD), range & $9.6(5.2), 5.0-21.5$ & & \\
\hline Age of first $P E$, mean (SD), range & $24.3(6.7), 12-41$ & & \\
\hline $\begin{array}{l}\text { Anti-psychotic medication use } \\
y / n / ?\end{array}$ & $18 / 4 / 2$ & & \\
\hline PANSS Positive symptoms & $1.83(0.77)$ & & \\
\hline
\end{tabular}

${ }^{\text {a }}$ Patients are significantly older than controls $(p<0.001)$.

${ }^{b}$ Patients are significantly older than Clinical High Risk patients $(p<0.001)$.

The groups did not differ on the mean number of valid beeps (see Table 2). The CHR and psychotic patient groups reported significantly more NA and momentary psychotic symptoms when compared with the controls (see Table 2 for all results). The CHR group, but not the patient group reported significantly more activity-related and social stress in comparison to controls. Furthermore, social stress was significantly higher in CHR patients compared to psychotic patients, while the psychotic patients did not differ from controls. No other significant differences were observed. 
Table 2. Means (standard deviations) and $F$ test statistics of the number of valid beeps and ESM variables for psychotic patients, CHR patients and controls.

\begin{tabular}{|c|c|c|c|c|c|c|}
\hline & \multicolumn{3}{|c|}{ Mean $(S D)^{a}$} & \multirow[b]{2}{*}{$\begin{array}{l}F \\
(d f=2,69)\end{array}$} & \multirow[b]{2}{*}{$p$} & \multirow[b]{2}{*}{ Tukey-Kramer ${ }^{b}$} \\
\hline & $\begin{array}{l}\text { Psychotic } \\
\text { patients } \\
(n=24)\end{array}$ & $\begin{array}{l}\text { Clinical high } \\
\text { risk patients } \\
(n=22)\end{array}$ & $\begin{array}{l}\text { Control } \\
\text { subjects } \\
(n=26)\end{array}$ & & & \\
\hline Valid beeps & $\begin{array}{l}41.5(10.5), \\
\text { range } 20-60\end{array}$ & $\begin{array}{l}38.5(9.7), \\
\text { range } 21 \text { - } 58\end{array}$ & $\begin{array}{l}42.7(9.3), \\
\text { range } 23 \text { - } 56\end{array}$ & 1.14 & 0.33 & \\
\hline Activity-related stress & $2.53(0.87)$ & $2.80(0.69)$ & $2.28(0.53)$ & 3.22 & 0.046 & $3<2^{*}$ \\
\hline Event-related stress & $0.21(0.43)$ & $0.27(0.25)$ & $0.15(0.11)$ & 1.00 & 0.37 & \\
\hline Social stress & $1.66(0.75)$ & $2.59(1.27)$ & $1.54(0.60)$ & 9.42 & 0.0002 & $\begin{array}{l}1<2 * * \\
\& 3<2^{* * *}\end{array}$ \\
\hline NA & $1.95(0.98)$ & $2.02(0.84)$ & $1.17(0.21)$ & 10.11 & 0.0001 & $3<1^{* *}, 2^{* *}$ \\
\hline MPS & $1.67(0.71)$ & $1.68(0.61)$ & $1.07(0.17)$ & 10.38 & 0.0001 & $3<1^{* *}, 2^{* *}$ \\
\hline
\end{tabular}

NA, negative affect; MPS, momentary psychotic symptoms.

a For each subject, a mean was calculated over all reports, and the mean per subject was additionally aggregated over the group to obtain the group mean (SD).

${ }^{b} 1$. Psychotic patients; 2 . CHR; 3. Controls.

${ }^{*} p \leq 0.05, * * p \leq 0.01, * * * p \leq 0.001$.

\section{(i) Is the association between stress and negative affect different in the three groups?}

The results of the multivariate multilevel models showed the correlation coefficients between NA and activity-related, event-related and social stress all to be positive, for the psychotic patient group, CHR group and control group (range $0.11-0.28$, see Table $3)$. For NA and activity-related stress the association was significantly stronger in the CHR group compared to both the psychotic patient group $(Z=-2.67, p=0.008)$ as well as the healthy controls $(Z=3.68, p=0.0002)$, as displayed in Figure 1 . The associations between NA and event-related stress and NA and social stress were not significantly different in the three groups. 
Table 3. Multivariate multilevel model correlations at beep level between the stress variables, Negative Affect and Momentary Psychotic Experiences, controlled for age and gender.

$$
\text { Psychotic patients Clinical High Risk patients }
$$

\begin{tabular}{lllllll} 
Association & CC & SE & $95 \% \mathrm{Cl}$ & $\mathrm{CC}$ & $\mathrm{SE}$ & $95 \% \mathrm{Cl}$ \\
\hline AS \& NA & 0.16 & 0.03 & $0.09-0.22$ & 0.28 & 0.03 & $0.21-0.34$ \\
ES \& NA & 0.15 & 0.03 & $0.09-0.21$ & 0.16 & 0.03 & $0.09-0.23$ \\
SS \& NA & 0.20 & 0.04 & $0.13-0.27$ & 0.16 & 0.05 & $0.07-0.25$ \\
AS \& MPS & 0.14 & 0.03 & $0.07-0.20$ & 0.24 & 0.03 & $0.17-0.30$ \\
AS \& MPS & 0.09 & 0.03 & $0.03-0.15$ & 0.11 & 0.03 & $0.05-0.18$ \\
ES \& MPS & 0.08 & 0.03 & $0.01-0.14$ & 0.16 & 0.04 & $0.09-0.23$ \\
ES \& MPS & 0.03 & 0.03 & $-0.03-0.10$ & 0.08 & 0.04 & $0.01-0.15$ \\
SS \& MPS & 0.15 & 0.04 & $0.07-0.23$ & 0.19 & 0.04 & $0.10-0.27$ \\
SS \& MPS & 0.09 & 0.04 & $0.01-0.17$ & 0.12 & 0.05 & $0.03-0.21$ \\
NA \& MPS & 0.33 & 0.03 & $0.27-0.38$ & 0.53 & 0.03 & $0.48-0.58$
\end{tabular}

CC, correlation coefficient; SE, standard error; $95 \% \mathrm{Cl}$, 95\% confidence interval; NA, negative affect; MPS, momentary psychotic symptoms; AS, activity-related stress; ES, event-related stress; SS, social stress.

(ii) Is the association between stress and momentary symptoms different for Clinical High Risk vs. psychotic patients?

The correlation coefficients between momentary psychotic symptoms and activity-related, event-related and social stress were positive for both the CHR patients and psychotic patients (range 0.08 - 0.24, see Table 3 ). For momentary psychotic symptoms and activity-related stress the association was significantly stronger in the CHR group compared to the psychotic patient group $(Z=-2.29, p=0.02)$. While the association between symptoms and event-related stress was stronger in the CHR group as compared to psychotic patients, it did not reach statistical significance $(Z=-1.66, p=0.10)$. No group differences were detected for symptoms and social stress. In the additional analyses where NA was added as a covariate in the models, the association between activity-related stress and symptoms was no longer significantly different between groups $(Z=-0.53, p=0.60)$, as were none of the other comparisons.

\section{(iii) Are momentary psychotic symptoms more emotionally distressing for Clinical High}

\section{Risk vs. psychotic patients?}

Positive associations between momentary psychotic experiences and NA were found for the CHR and psychotic patient groups (see Table 3). Group comparison showed the association to be significantly larger in the CHR group than in the psychotic patients group $(Z=-5.42, p<0.001)$, as displayed in Figure 1. 
Control subjects

Group comparisons Wald test ${ }^{b}$

1 vs. 2 (ref)

2 vs.3 (ref)

CC

SE

$95 \% \mathrm{Cl}$

Z

$P$

Z

0.11

0.03

$0.05-0.17$

$-2,67$

0.008

3.68

$<0.001$

$0.12 \quad 0.03$

$0.06-0.18$

$-0.25$

0.80

1.00

0.32

0.15

0.04

$0.08-0.23$

0.74

0.46

0.08

0.93

-2.29 0.02

$-0.53$

0.60

$-1.66$

0.10

$-1.04$

0.30

$-0.60$

0.55

$-0.47$

0.64

$-5.42$ $<0.001$

a. Results of models with NA included as a covariate.

b. 1. Psychotic patients; 2. CHR; 3. Controls.

\section{aPsychosis $\square \mathrm{CHR} \quad \square$ Controls}

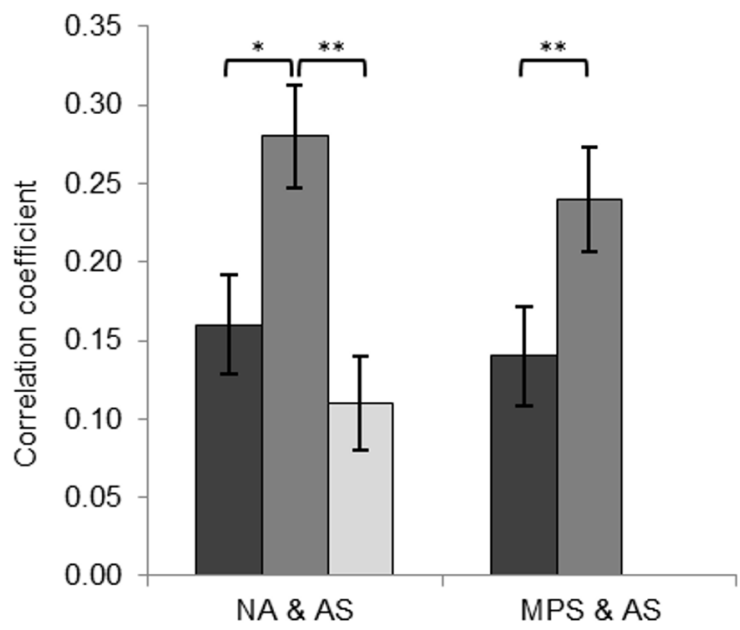

Fig. 1. Left: Correlation coefficients between negative affect (NA) and activity-related stress (AS) per group. Right: Correlation coefficients between momentary psychotic symptoms (MPS) and activity-related stress per group.

$* p \leq 0.01, * * p \leq 0.001$. 


\section{DISCUSSION}

This study investigated emotional and psychotic reactivity to daily life stress in those at risk for a psychotic disorder compared to chronic psychotic patients and healthy controls. As hypothesized, our results showed increased emotional stress reactivity, particularly related to activities, to be associated with psychosis, mainly at the early stages of illness. Contrary to our hypothesis, psychotic-reactivity in response to unpleasant activities was increased in CHR compared to chronic psychotic patients. This suggests that emotional and psychotic stress sensitization occurs prior to the development of a full-blown psychotic state. Furthermore, as hypothesized, CHR patients experienced the psychotic symptoms as more distressing compared to chronic patients.

\section{Emotional and psychotic stress reactivity}

Our results of increased emotional stress reactivity in CHR compared to chronic patients are replicating the findings of Palmier-Claus and colleagues ${ }^{29}$. Furthermore, results are in line with studies in CHR samples using questionnaires showing higher psychosocial stress sensitivity in CHR participants compared to controls ${ }^{23}$, reduced tolerance to normal stress ${ }^{20}$, higher self-reported distress in response to life events ${ }^{19,22}$ as well as to daily life stressors ${ }^{15,50}$, especially for those reporting life events to be more distressing, suggestive of stress sensitization ${ }^{19}$. Psychotic stress reactivity, however, was stronger in the $\mathrm{CHR}$ patients compared to psychotic patients, contrary to our hypothesis based on the findings of Palmier-Claus and colleagues ${ }^{29}$. One possible explanation for this difference may be related to selection of the psychotic patients. We specifically selected psychotic patients with an illness duration of at least 5 years, to compare our CHR group with chronic patients. The patient sample of Palmier-Claus and colleagues ${ }^{29}$ is likely more mixed with both recent onset and more chronic patients, as they did not provide specific inclusion criteria in that regard. This is reflected in the difference in mean illness duration, with our sample having a mean illness duration of $9.6(S D=5.2)$ years compared to $6.5(S D=8.2)$ years reported in their paper. Psychotic stress reactivity may thus be more characteristic of the early psychotic phase and becoming less prominent when illness duration progresses.

There are several other possible explanations for our findings of heightened emotional and psychotic stress reactivity in CHR patients compared to the chronic psychotic patients. First, the CHR may experience more severe stressors or these may occur more often than those experienced by the patient group, as was indeed confirmed by our 
findings of increased activity and social stress in this group. As high levels of social anxiety have been reported to characterize help-seeking CHR patients ${ }^{51,52}$, more exposure to social activities in our CHR group helps to explain the difference with the psychotic patients, who have possibly adjusted their lives in order to avoid stressful (social) situations. Alternatively, less exposure to activities, events and social situations might be a consequence of more negative symptoms ${ }^{53}$, which has been related to lower social functioning, work performance, and social skills. In accordance with this, a recent study comparing negative symptoms in psychotic and CHR patients ${ }^{54}$ reported that psychotic patients differed from CHR patients by reporting less motivation for engagement with family and recreational activities. However, as negative symptoms are profound not only in psychotic patients but also in help-seeking CHR patients ${ }^{55}$ and the recent study of Cressman and colleagues ${ }^{51}$ showed the level of anhedonia to be comparable to that of psychotic patients, the influence on the reported group difference in exposure to (social) activities is probably limited.

Second, a recent study has reported that CHR patients do not seem to possess the skills to effectively cope with stress in general. Compared to healthy controls, CHR patients used more maladaptive coping strategies (e.g., blaming one's self for the occurrence of the event) and fewer adaptive (e.g., choosing to reinterpret the event in a positive fashion) coping strategies, and the use of these strategies might limit their functioning even further or exacerbate symptoms ${ }^{56}$. Furthermore, use of adequate coping strategies like stress reduction has been found to predict an improvement with regard to psychotic symptoms over time ${ }^{57}$.

Third, most of our psychotic patients used anti-psychotic medication. It could therefore be that anti-psychotic medication partly dampens emotional and psychotic stress reactivity, resulting in the difference observed between our patient groups. Some evidence comes from a recent study ${ }^{58}$ in which psychotic patients who use antipsychotic medication subjectively reported dampened emotional experience. However, as not all our psychotic patients were using antipsychotic medication and some of the CHR patients have been using medication, use of antipsychotics is unlikely to fully explain the difference in stress reactivity between the groups.

Finally, the results of our sensitivity analyses investigating the influence of low mood on psychotic reactivity underscore the close relationship between stress, symptoms and low mood. When NA was added to the psychotic stress reactivity models, it was no 
longer significantly higher in the CHR group compared to more chronic patients, suggesting that psychotic stress reactivity is mediated by low mood at the early phases of illness.

\section{Psychotic symptoms and distress}

The current study provided evidence that psychotic symptoms in themselves may be a source of distress, particularly in CHR patients. These symptoms are relatively new for CHR patients and belief conviction may not have been fully developed. The unknown nature of these symptoms may intensify the levels of distress. Results of a recent study on stigma related to labels and symptoms of CHR also identified subclinical psychotic symptoms in themselves to be a source of distres ${ }^{59}$. CHR patients experienced more stigma from symptoms than from the psychosis risk-label, and specifically the "shame" related to symptoms was associated with depression.

Another possible explanation might be that $\mathrm{CHR}$ patients may have received no or limited treatment, either psycho-education or psychological treatment, for these symptoms as ESM assessment started just after identification of CHR status, which may result in less effective coping strategies. A previous ESM study of psychotic patients ${ }^{33}$ indeed showed that a greater endorsement of a psychological explanation of delusions and hallucinations was related to less disruption of functioning, less distress and less NA. On the other hand, chronic patients may differ from CHR patients in coping strategies they use to deal with the symptoms. Lardinois and colleagues ${ }^{31}$ showed that psychotic patients who used more non-psychotic coping strategies (i.e., active problem-solving or avoiding, passive illness behaviour and problem-avoiding) had more conscious appraisal of distress associated with symptoms than those who adopted a more symptomatic coping strategy, for example following or obeying orders induced by the symptoms or locking oneself in.

\section{Theoretical and clinical implications}

Overall, our findings further support the hypothesis that increased stress reactivity can be viewed as an affective pathway to psychosis ${ }^{2}$. They also highlight the important role of distress, represented in this study as an increase in NA, with the emergence of psychotic symptoms. The results suggest that CHR patients may get caught in a downward spiral of feeling distressed by their psychotic symptoms, which may in turn increase the intensity of psychotic symptoms.

Our findings underscore the need for early intervention in CHR patients in order to interrupt this vicious cycle. Decreasing stress reactivity as well as decreasing the distress 
associated with the psychotic symptoms is relevant in this respect. The newest generation of Cognitive Behavioural Therapies (CBTs) puts high emphasis on the context (hence the name "contextual CBT"). Stress reduction techniques, which incorporate elements of Mindfulness or Acceptance and Commitment Therapy may be an effective treatment strategy (for a review see ${ }^{60}$ ). Given the observation that CHR patients coping strategies are often ineffective and can enhance symptoms $s^{56}$ and use of adequate strategies have been found to be predictive of improvement in psychotic symptoms $\mathrm{s}^{57}$, interventions that help CHR patients to develop and apply adequate coping strategies are also likely to be effective.

\section{Limitations}

The results should be viewed in the light of several methodological issues. First, as with all ESM studies, measurements are based on subjective reports. Therefore, it can be argued that the results are not psychometrically precise. However, although subjective reports are considered less reliable (e.g., do all participants interpret or answer the questions identically?), previous research indicates that subjective reports can be valid and are important in order to understand the changes in symptoms ${ }^{61}$.

Second, the items used to assess momentary psychosis are relatively broad, as items were used that participants could self-report about. However, one could question whether they truly reflect a psychotic state. For example, 'I cannot get these thoughts out of my head' may equally reflect anxiety or depression. A principal component analysis on the psychosis items resulted in two factors, one factor representing hallucinations (the two hallucination items) and all the other items loading equally on a second factor, which would then reflect delusions. However, does this second factor truly reflect delusions? All items scored equally strong on the factor delusions including 'I feel suspicious', or 'My thoughts are influenced by others', suggesting that the composite score most likely represents delusions. Furthermore, previous studies from our group showed that the psychosis score as used in the current paper had concurrent validity (as the ESM psychosis scores were significantly correlated with the score on the positive items but not the negative items of the PANSS) and convergent validity using the known-groups technique las it distinguished patients from relatives and controls $\left.{ }^{26}\right)$. This supports that the composite score of all items does reflect psychosis. However, the psychosis items could be strengthened in future research for example by using focus groups with people who have experienced psychosis. 
Third, the study was cross-sectional and therefore no direct causality can be inferred from these results. Furthermore, the possibility of reverse causality cannot be excluded. There is a possibility that increased NA or increased levels of psychotic symptoms influence the subjective appraisal of the environment or that increased NA causes psychotic symptoms to be experienced as more intense. However, as was suggested previously, the overall effect would still be for the individual to experience psychosis associated with an environmental event ${ }^{26}$.

Fourth, the possible influence of medication use to the examined associations could not be tested in the current study, since CHR medication use was not yet available. While at present disclosure of treatment is not yet available, CHR participants did receive either cognitive behavioural therapy, treatment with Aripiprazole (Abilify@) plus medical management or a placebo plus medical management. The majority of psychotic patients used anti-psychotic medication at the time of testing. Future studies are needed to examine the effect of medication use properly by comparing patients groups with and without anti-psychotic medication use. 


\section{REFERENCES}

1. Corcoran CM, Walker E, Huot R, Mittal V, Tessner K, Kestler L, Malaspina D. The Stress Cascade and Schizophrenia: Etiology and Onset. Schizophr Bull. 2003; 29:671-692.

2. Myin-Germeys I, van Os J. Stress-reactivity in psychosis: evidence for an affective pathway to psychosis. Clin Psychol Rev. 2007; 27:409-424.

3. Phillips LJ, Francey SM, Edwards J, McMurray N. Stress and psychosis: Towards the development of new models of investigation. Clin Psychol Rev. 2007; 27:307-317.

4. van Winkel R, Stefanis NC, Myin-Germeys I. Psychosocial Stress and Psychosis. A Review of the Neurobiological Mechanisms and the Evidence for Gene-Stress Interaction. Schizophr Bull. 2008; 34:1095-1105.

5. Zubin J, Spring B. Vulnerability - a new view of schizophrenia. J Abnorm Psychol. 1977; 86:103-126.

6. Beards S, Gayer-Anderson C, Borges S, Dewey ME, Fisher HL, Morgan C. Life Events and Psychosis: A Review and Meta-analysis. Schizophr Bull. 2013; 39:740-747.

7. Varese F, Smeets F, Drukker M, Lieverse R, Lataster T, Viechtbauer W, . . Bentall RP. Childhood Adversities Increase the Risk of Psychosis: A Meta-analysis of Patient-Control, Prospective- and Cross-sectional Cohort Studies. Schizophr Bull. 2012; 38:661-671.

8. Malla AK, Cortese L, Shaw TS, Ginsberg B. Life events and relapse in schizophrenia. A one year prospective study. Soc Psychiatry Psychiatr Epidemiol. 1990; 25:221-224.

9. Norman RM, Malla AK. A prospective study of daily stressors and symptomatology in schizophrenic patients. Soc Psychiatry Psychiatr Epidemiol. 1994; 29:244-249.

10. Yung AR, Yung AR, Pan Yuen H, McGorry PD, Phillips LJ, Kelly D, . . Buckby J. Mapping the onset of psychosis: the Comprehensive Assessment of At-Risk Mental States. Aust N Z J Psychiatry. 2005; 39:964-971.

11. Miller TJ, McGlashan TH, Rosen JL, Somjee L, Markovich PJ, Stein K, Woods SW. Prospective Diagnosis of the Initial Prodrome for Schizophrenia Based on the Structured Interview for Prodromal Syndromes: Preliminary Evidence of Interrater Reliability and Predictive Validity. Am J Psychiatry. 2002; 159:863-865.

12. Addington J, Stowkowy J, Cadenhead KS, Cornblatt BA, McGlashan TH, Perkins DO, . . Cannon TD. Early traumatic experiences in those at clinical high risk for psychosis. Early Interv Psychiatry. 2013; 7:300-305.

13. Bechdolf A, Thompson A, Nelson B, Cotton S, Simmons MB, Amminger GP, . . Yung AR. Experience of trauma and conversion to psychosis in an ultra-high-risk (prodromal) group. Acta Psychiatr Scand. 2010; 121:377-384.

14. Sahin S, Yuksel C, Guler J, Karadayi G, Akturan E, Gode E, . . Ucok A. The history of childhood trauma among individuals with ultra high risk for psychosis is as common as among patients with first-episode schizophrenia. Early Interv Psychiatry. 2013; 7:414-420.

15. Tessner KD, Mittal V, Walker EF. Longitudinal study of stressful life events and daily stressors among adolescents at high risk for psychotic disorders. Schizophr Bull. 2011; 37:432-441.

16. Thompson JL, Kelly M, Kimhy D, Harkavy-Friedman JM, Khan S, Messinger JW, . . Corcoran CM. Childhood trauma and prodromal symptoms among individuals at clinical high risk for psychosis. Schizophr Res. 2009; 108:176-181.

17. Velthorst E, Nelson B, O'Connor K, Mossaheb N, de Haan L, Bruxner A, . . Thompson A. History of trauma and the association with baseline symptoms in an Ultra-High Risk for psychosis cohort. Psychiatry Res. 2013; 210:75-81.

18. Tikka M, Luutonen S, Ilonen T, Tuominen L, Kotimaki M, Hankala J, Salokangas RK. Childhood trauma and premorbid adjustment among individuals at clinical high risk for psychosis and normal control subjects. Early Interv Psychiatry. 2013; 7:51-57.

19. Trotman HD, Holtzman CW, Walker EF, Addington JM, Bearden CE, Cadenhead KS, ... McGlashan TH. Stress exposure and sensitivity in the clinical high-risk syndrome: initial findings from the North American Prodrome Longitudinal Study (NAPLS). Schizophr Res. 2014; 160:104-109.

20. Devylder JE, Ben-David S, Schobel SA, Kimhy D, Malaspina D, Corcoran CM. Temporal association of stress sensitivity and symptoms in individuals at clinical high risk for psychosis. Psychol Med. 2013; 43:259-568.

21. Miller P, Lawrie SM, Hodges A, Clafferty R, Cosway R, Johnstone EC. Genetic liability, illicit drug use, life stress and psychotic symptoms: preliminary findings from the Edinburgh study of people at high risk for schizophrenia. Soc Psychiatry Psychiatr Epidemiol. 2001; 36:338-342. 
22. Phillips LJ, Edwards J, McMurray N, Francey S. Comparison of experiences of stress and coping between young people at risk of psychosis and a non-clinical cohort. Behav Cogn Psychother. 2012; 40:69-88.

23. Pruessner M, Iyer SN, Faridi K, Joober R, Malla AK. Stress and protective factors in individuals at ultra-high risk for psychosis, first episode psychosis and healthy controls. Schizophr Res. 2011; 129:29-35.

24. Lardinois M, Lataster T, Mengelers R, Van Os J, Myin-Germeys I. Childhood trauma and increased stress sensitivity in psychosis. Acta Psychiatr Scand. 2011; 123:28-35.

25. Lataster T, Wichers M, Jacobs N, Mengelers R, Derom C, Thiery E, . . Myin-Germeys I. Does reactivity to stress cosegregate with subclinical psychosis? A general population twin study. Acta Psychiatr Scand. 2009; 119:45-53.

26. Myin-Germeys I, Delespaul P, van Os J. Behavioural sensitization to daily life stress in psychosis. Psychol Med. 2005; 35:733-741.

27. Myin-Germeys I, van Os J, Schwartz JE, Stone AA, Delespaul P. Emotional reactivity to daily life stress in psychosis. Arch Gen Psychiatry. 2001b; 58:1137-1144.

28. Collip D, Myin-Germeys I, Van Os J. Does the concept of "sensitization" provide a plausible mechanism for the putative link between the environment and schizophrenia? Schizophr Bull. 2008; 34:220-225.

29. Palmier-Claus JE, Dunn G, Lewis SW. Emotional and symptomatic reactivity to stress in individuals at ultra-high risk of developing psychosis. Psychol Med. 2012; 42:1003-1012.

30. Rapado-Castro M, McGorry PD, Yung A, Calvo A, Nelson B. Sources of clinical distress in young people at ultra high risk of psychosis. Schizophr Res. 2015; 165:15-21.

31. Lardinois M, Myin-Germeys I, Bak M, Mengelers R, Van Os J, Delespaul PAEG. The dynamics of symptomatic and non-symptomatic coping with psychotic symptoms in the flow of daily life. Acta Psychiatr Scand. 2007; 116:71-75

32. Myin-Germeys I, Nicolson NA, Delespaul PA. The context of delusional experiences in the daily life of patients with schizophrenia. Psychol Med. 2001a; 31:489-498.

33. Peters E, Lataster T, Greenwood K, Kuipers E, Scott J, Williams S, . . Myin-Germeys I. Appraisals, psychotic symptoms and affect in daily life. Psychol Med. 2012; 42:1013-1023.

34. Miller T, McGlashan T, Woods S, Stein K, Driesen N, Corcoran CM, . . Davidson L. Symptom assessment in schizophrenic prodromal states. Psychiatr Q. 1999; 70:273-287.

35. Schultze-Lutter F, Addington J, Ruhrmann S, eds. Schizophrenia Proneness Instument, Adult version (SPI-A): Giovanni Fioriti Editore 2007.

36. Bechdolf A, Muller H, Stutzer H, Wagner M, Maier W, Lautenschlager M, . . Klosterkotter J. Rationale and baseline characteristics of PREVENT: a second-generation intervention trial in subjects at-risk (prodromal) of developing first-episode psychosis evaluating cognitive behavior therapy, aripiprazole, and placebo for the prevention of psychosis. Schizophr Bull. 2011; 37 Suppl 2:S111-121.

37. Wittchen HU, Fydrich T. Strukturiertes Klinisches Iterview für DSM-IV. Manual zum SKID-I und SKID-II. [Structured Clinical Interview for DSM.IV]. Göttingen: Hogrefe; 1997.

38. Korver N, Quee PJ, Boos HB, Simons CJ, de Haan L. Genetic Risk and Outcome of Psychosis (GROUP), a multi-site longitudinal cohort study focused on gene-environment interaction: objectives, sample characteristics, recruitment and assessment methods. Int J Methods Psychiatr Res. 2012; 21:205-221.

39. Andreasen NC, Flaum M, Arndt S. The Comprehensive Assessment of Symptoms and History (CASH). An instrument for assessing diagnosis and psychopathology. Arch Gen Psychiatry. 1992; 49:615-623.

40. Csikszentmihalyi M, Larson R. Validity and Reliability of the Experience-Sampling Method. J Nerv Ment Dis. 1987; 175:526-536.

41. Myin-Germeys I, Oorschot M, Collip D, Lataster J, Delespaul P, van Os J. Experience sampling research in psychopathology: opening the black box of daily life. Psychol Med. 2009; 39:1533-1547.

42. Delespaul P. Assessing schizophrenia in daily life. Maastricht: Universitaire Pers; 1995.

43. Lataster T, Viechtbauer W, Oorschot M, Collip D, Janssens M, van Nierop M, . . Myin-Germeys I. Evidence for a two-factor positive and negative affect structure in daily life: presenting the Maastricht Momentary Mood Questionnaire (3MQ). internal communication.

44. APA. Diagnostic and Statistical Manual of Mental Disorders (DSM-IV). Washington, DC: American Psychiatric Association; 1994.

45. Junginger J, Barker S, Coe D. Mood theme and bizarreness of delusions in schizophrenia and mood psychosis. J Abnorm Psychol. 1992; 101:287-292.

46. Twisk JWR. Applied multilevel analysis. Cambridge, UK: Cambridge University Press; 2006. 
47. Snijders TAB, Bosker RJ. Multilevel analysis: An introduction to basic and advanced multilevel modeling. London: Sage; 1999.

48. Myin-Germeys I, Krabbendam L, Delespaul PA, van Os J. Sex differences in emotional reactivity to daily life stress in psychosis. J Clin Psychiatry. 2004; 65:805-809.

49. Stata Statistical Software: Release 13. College Station, TX: StataCorp LP; 2013.

50. Cullen $A E$, Fisher HL, Roberts RE, Pariante CM, Laurens KR. Daily stressors and negative life events in children at elevated risk of developing schizophrenia. Br J Psychiatry. 2014; 204:354-360.

51. Cressman VL, Schobel SA, Steinfeld S, Ben-David S, Thompson JL, Small SA, . . Corcoran CM. Anhedonia in the psychosis risk syndrome: associations with social impairment and basal orbitofrontal cortical activity. Npj Schizophrenia. 2015; 1:15020.

52. Rietdijk J, Ising HK, Dragt S, Klaassen R, Nieman D, Wunderink L, . . van der Gaag M. Depression and social anxiety in help-seeking patients with an ultra-high risk for developing psychosis. Psychiatry Res. 2013; 209:309-313.

53. Ventura J, Hellemann GS, Thames AD, Koellner V, Nuechterlein KH. Symptoms as mediators of the relationship between neurocognition and functional outcome in schizophrenia: A meta-analysis. Schizophr Res. 2009; 113:189-199.

54. Gur RE, March M, Calkins ME, Weittenhiller L, Wolf DH, Turetsky BI, Gur RC. Negative symptoms in youths with psychosis spectrum features: Complementary scales in relation to neurocognitive performance and function. Schizophr Res. 2015; 166:322-327.

55. Piskulic D, Addington J, Cadenhead KS, Cannon TD, Cornblatt BA, Heinssen R, . . McGlashan TH. Negative symptoms in individuals at clinical high risk of psychosis. Psychiatry Res. 2012; 196:220-224.

56. Jalbrzikowski M, Sugar CA, Zinberg J, Bachman P, Cannon TD, Bearden CE. Coping styles of individuals at clinical high risk for developing psychosis. Early Interv Psychiatry. 2014; 8:68-76.

57. Kommescher M, Wagner M, Putzfeld V, Berning J, Janssen B, Decker $\mathrm{P}, \ldots$. Bechdolf A. Coping as a predictor of treatment outcome in people at clinical high risk of psychosis. Early Interv Psychiatry. 2016; 10:17-27.

58. Moritz S, Andreou C, Klingberg S, Thoering T, Peters MJV. Assessment of subjective cognitive and emotional effects of antipsychotic drugs. Effect by defect? Neuropharmacology. 2013; 72:179-186.

59. Yang LH, Link BG, Ben-David S, Gill KE, Girgis RR, Brucato G, . . Corcoran CM. Stigma related to labels and symptoms in individuals at clinical high-risk for psychosis. Schizophr Res. 2015; 168:9-15.

60. Hayes SC, Villatte M, Levin M, Hildebrandt M. Open, aware, and active: contextual approaches as an emerging trend in the behavioral and cognitive therapies. Annu Rev Clin Psychol. 2011; 7:141-168.

61. Strauss JS. The person with schizophrenia as a person. II: Approaches to the subjective and complex. $B r J$ Psychiatry Suppl. 1994; 23:103-107. 


$$
5
$$




\section{Chapter 5}

Temporal dynamics of hallucinations and suspiciousness in clinical high risk and first episode psychosis

Y. van der Steen ${ }^{1,2}$, R. van Winkel ${ }^{3,4}$, T. Lataster ${ }^{1}$, M. Wagner ${ }^{5}$ \& I. Myin-Germeys ${ }^{1,2}$

${ }^{1}$ Maastricht University, School for Mental Health and Neuroscience (MHeNS), Department of Psychiatry \& Neuropsychology, Maastricht, the Netherlands ${ }^{2} \mathrm{KU}$ Leuven, Department of Neuroscience, Center for Contextual Psychiatry, Leuven, Belgium

${ }^{3}$ University Psychiatric Center, KU Leuven, Campus Kortenberg, Leuvensesteenweg, Kortenberg, Belgium

${ }^{4} \mathrm{KU}$ Leuven, Department of Neuroscience, Research Group Psychiatry, Center for Clinical Psychiatry, Leuven, Belgium

${ }^{5}$ University of Bonn, Department of Psychiatry and Psychotherapy, Bonn, Germany

In preparation for submission 


\section{ABSTRACT}

Background: Hallucinations and persecutory delusions are core features of (subclinical) psychosis, often causing considerable distress. The phenomenology of hallucinations and persecutory delusions has previously been investigated in the realm of daily life in psychosis spectrum patients and we aimed to extend this investigation to patients with a first psychotic episode (FEPs) and individuals at clinical high risk for psychosis (CHR-Ps). The prevalence, course and the co-occurrence of hallucinations and feelings of suspiciousness in daily life, as well as their temporal relation to emotions, anxiety and self-esteem were investigated over a 6-day period.

Methods: The Experience Sampling Method, a structured diary technique, was used to investigate hallucinatory experiences and suspiciousness in daily life in a pooled data-set of 33 CHR-Ps and 34 FEPs. Hallucinations were defined using participants' scores on the items "I see things that are not really there" and "I hear voices", and suspiciousness with the item "I feel suspicious".

Results: Overall, $24 \%$ of CHR-Ps and 39\% FEPs reported hallucinations and $91 \%$ and $58 \%$ reported suspiciousness, respectively. Hallucinations and suspiciousness co-occurred regularly within the same person in both CHR-Ps and FEPs. Anxiety, negative emotions, decreased self-esteem and delusional ideation accompanied hallucinatory and paranoid episodes. Decreased self-esteem preceded suspiciousness in FEPs and CHR-Ps, as did increased delusional intensity and visual hallucination intensity for CHR-Ps.

Discussion: Hallucinations and suspiciousness are common in CHR-P and FEP and regularly co-occur. Low self-esteem and delusional ideation may precede suspiciousness, while anxiety is elevated during hallucinatory and paranoid episodes. 


\section{INTRODUCTION}

Hallucinations and delusions including feelings of suspiciousness and persecution are considered core positive symptoms of psychosis spectrum disorders. These symptoms are reported by chronic patients, by patients experiencing a first psychotic episode (FEPs) and at an attenuated level in those individuals meeting criteria for clinical high risk for psychosis (CHR-Ps). However, the actual phenomenology of these experiences, especially in these early phases of psychosis, has hardly been investigated. The few reporting prevalence rates found hallucinations in $73 \%$ and delusions in $74 \%$ of FEPs ${ }^{1}$. In contrast, $34-60 \%$ of CHR-Ps reported hallucinations while $82 \%$ had delusions ${ }^{2,3}$. Furthermore, co-occurrence of hallucinations and delusions was found to be relatively high ( $40 \%$ ) in the CHR-P state ${ }^{2}$, and with $80 \%$ even higher in FEPs, while $18 \%$ reported only delusions and $2 \%$ had only hallucinations ${ }^{4}$.

Results of studies examining the content of these (attenuated) psychotic symptoms in more detail have shown that persecutory ideation including being 'monitored' was reported by $54 \%$ of FEPs ${ }^{1}$ and $54 \%$ of $\mathrm{CHR}-\mathrm{Ps}^{5}$. Auditory hallucinations have been reported by $70 \%$ of FEPs and $29-57 \%$ had visual hallucinations with the majority of those being relatively mild in nature and often described as 'vague shadows' ${ }^{1,6}$. Furthermore, visual and auditory hallucinations seem to co-occur in $84-88 \%$ of individuals $s^{6,7}$.

Previous studies have used the Experience Sampling Method to investigate persecutory delusions and auditory and visual hallucinations in daily life of psychosis spectrum patients. ESM is a structured self-assessment technique in which participants are prompted at random intervals throughout the day to report their current experiences ${ }^{8}$. With this method, it is possible to investigate subjective experiences that are related to delusions such as feeling suspicious, unreal, experiencing loss of control, having intruding thoughts or the idea that your thoughts are influenced by others as well as hallucinations. Prevalence rates in daily life were between $49-67 \%$ for persecutory delusions and $40-73 \%$ for hallucinations ${ }^{9-13}$. Furthermore, it was also clear that delusions and hallucinations are often reported together in daily life.

Two studies have used ESM to explore the temporal dynamics of delusions and hallucinations. For example, when the intensity of suspiciousness is increasing, how long does that last over time? And what is predictive of such an increase? For episodes of persecutory delusions, it was found that anxiety and low self-esteem preceded onset of these 
episodes whereas all negative emotions (feeling down, irritated, lonely, anxious) and reductions in self-esteem where present during an episode ${ }^{14}$. With regard to hallucinations, it was found that auditory and visual hallucinations are discrete phenomena with distinct points of onset and termination, which were associated with higher negative affect and may be preceded by delusional ideation ${ }^{10}$. Combined these findings indicate that the intensity of these experiences fluctuates over periods of hours and days ${ }^{10,13,15}$ and suggest that despite psychotic experiences in daily life being a persistent problem, patients are not constantly engulfed by their symptoms.

However, the phenomenology and temporal dynamics of delusions and hallucinations have not been examined in patients with a first psychotic episode or those at clinical high risk for the development of psychosis. Therefore, using ESM in a sample of CHR-P and FEP we examined (i) the prevalence and course of hallucinations and delusions with a specific focus on suspiciousness, over a 6-day period, (ii) the difference in prevalence and course of these experiences between the two patient groups, and (iii) the temporal association between the onset of a hallucinatory/suspicious episode and the intensity of emotional experiences and self-esteem. 


\section{METHODS}

\section{Sample}

The current sample comprised of $33 \mathrm{CHR}-\mathrm{P}$ individuals and 34 FEP patients. Momentary assessment data were pooled from two ESM studies investigating early psychosis. Data of 23 CHR-Ps were collected in an add-on study ${ }^{16}$ of the 'PREVENT' project, a large German multisite early recognition and intervention in psychosis project (for more details see ${ }^{17}$ ). The data of 10 CHR-Ps and 34 FEPs were collected the IThink study, as part of a study of early psychosis and participants were recruited in the south of the Netherlands and Belgium.

All participants were between 15 and 45 years of age. Participants in the CHR-P group had at least one of the following: (i) attenuated positive symptoms; (ii) brief limited intermittent psychotic symptoms (BLIPS), both assessed with the Structured Interview for Prodromal Symptoms (SIPS, for PREVENT) ${ }^{18}$ or the Comprehensive Assessment of At Risk Mental State (CAARMS) ${ }^{19}$; (iii) presence of at least 2 basic symptoms (e.g., subtle thought and speech disturbances) assessed with the Schizophrenia Prediction Instrument, Adult version (SPIA, for PREVENT ${ }^{20}$; (iv) genetic risk (i.e. a first degree relative with psychotic disorder) or a diagnosis of schizotypal personality disorder; all in combination with a significant drop in functioning of $30 \%$ or more on the Global Assessment of Functioning (GAF) Scale for at least 1 month within the last year. For the FEP group, participants were included if onset of their first and only psychotic episode had occurred within two years prior to participation and were assessed with the Comprehensive Assessment of Symptoms and History (CASH) ${ }^{21}$. Participants with psychosis due to a known organic cause were excluded. All participants gave written informed consent, conforming to local ethics committee guidelines.

\section{The Experience Sampling Method}

The Experience Sampling Method (ESM) is a within-day, momentary self-assessment technique ${ }^{8,22}$. Participants received either a digital wristwatch and self-assessment forms collected in a booklet for each day (PREVENT) or a PDA, the 'PsyMate'. Ten times a day on six consecutive days, the watch or PDA emitted a signal (beep) at unpredictable moments between 7:30 a.m. and 10:30 p.m. After each beep, participants were asked to immediately report their thoughts, mood, symptoms, current context (e.g., their location, social company, activities), and subjective appraisals of the current situation. All self-assessments were rated on 7-point Likert scales. To ensure reliability of the com- 
pleted reports, participants using the watch and booklets participants recorded the time of completion of the report which was compared with the time at which the watch had emitted a signal. All reports completed more than 15 minutes after the signal were excluded from the analyses, since previous work ${ }^{23}$ has shown that reports completed after this interval are less reliable and consequently less valid. Participants with less than 20 valid reports (out of 60 ) were excluded from the analysis.

\section{ESM measures}

\section{Suspiciousness and delusional intensity}

Intensity of suspicious feelings was measured using the item "I feel suspicious". Delusional intensity was measured using five items ("I feel suspicious", "I cannot get these thoughts out of my head", "I'm afraid I will lose control", "I feel unreal" and "My thoughts are influenced by others") rated on 7-point Likert scales.

\section{Hallucinatory intensity}

Auditory hallucinatory $(\mathrm{AH})$ intensity was assessed with the item "I hear voices" and visual hallucinatory (VH) intensity was assessed with the item "I see things that are not really there" (rated on 7-point Likert scales, ranging from 1 not at all to 7 very).

\section{Suspicious and hallucinatory episodes}

A suspicious episode was defined as one or more consecutive moments with a score of $\geq 3$ on the item "I feel suspicious". A hallucinatory episode was defined as one or more consecutive moments with a score of $\geq 3$ on either or both of the items "I hear voices" and "I see things that are not really there". As was done previously ${ }^{10,14}$, we took a liberal approach to missing data allowing a maximum of one missing data point per episode since this was a naturalistic study (although nights were considered as interruptions). In order to analyse temporal dynamics and relation to emotions, anxiety, self-esteem and delusions and if applicable suspiciousness and $\mathrm{AH}$ and $\mathrm{VH}$ hallucinations, moments were categorized as either the last moment before an suspicious or hallucinatory episode, the first moment in an episode, a moment during an episode (not first or last moment), the last moment during an episode, the first moment after an episode and unrelated to an episode (i.e., all the other moments; see Figures 1 and 2). Length of episodes was calculated by adding the number of beeps inside an episode. 


\section{Emotional experience, anxiety and self-esteem}

Participants' momentary mood states were assessed with 7 mood adjectives rated on 7-point Likert scales (1 not at all to 7 very). The mean score on items "I feel cheerful/ relaxed/ satisfied" represented positive affect (PA). The items "I feel insecure/lonely/ anxious/guilty" constituted negative affect (NA). All analyses were conducted with both this general measure of NA and with the single item "I feel anxious". The mean score on the items "I like myself", "I am ashamed of myself" and "I doubt myself" (both reverse coded) represented self-esteem.

\section{Statistical analyses}

The CHR-P and FEP groups were compared on sociodemographic and ESM characteristics by means of t-tests and chi-square tests for continuous and dichotomous variables, respectively. Two-sided independent samples T-test were used to examine group differences in momentary NA, PA, anxiety, self-esteem, suspiciousness, delusional as well as auditory and visual hallucinatory intensity between individuals reporting hallucinations and/or delusions during the ESM assessment period and those who did not in the CHR-P and FEP groups separately. T-tests were also used to directly compare the CHR-P and FEP groups on these variables. For the further analyses, multilevel linear modelling techniques were used to study the dynamics of suspiciousness and hallucinations. Models were fitted with maximum likelihood estimation (MLE) using the XTREG module in Stata $13.1^{24}$. Age and sex were a priori added to the models as covariates. Effect sizes from predictors in the multilevel model were expressed as $B$, representing the fixed regression coefficient. Analyses on episodes were carried out on participants reporting at least one suspicious or AH/VH episode, and separately per experience and per group. In the analyses on the dynamics of suspiciousness and hallucinations, moments within an episode were compared with observations unrelated to these experiences. In these models, current suspicious and delusional intensity, $\mathrm{AH}$ and $\mathrm{VH}$ intensity, affect and self-esteem were dependent variables and phase of the suspicious or hallucinatory episode (unrelated to episode, last moment before episode, first moment in episode, moment during episode, last moment during episode and first moment after episode, see Figures 1 and 3 ) the independent variable. The estimated $B$ 's with their corresponding standard errors were extracted from the models and entered in Wald-type tests in order to examine

differences in effect sizes between the CHR-P and FEP groups for each of the phases of suspicious and hallucinatory episodes. 


\section{RESULTS}

\section{Sample and descriptive statistics}

Sixteen (2 CHR-P and 14 FEP) of 83 recruited participants were excluded from the analyses because of an insufficient number of valid ESM observations $(<20)$. The final sample therefore comprised 67 participants, divided in 33 CHR-Ps and 34 FEPs. The groups did not differ on the number of valid reported moments. FEPs reported significantly higher levels of PA ( $M=3.55(.80)$ vs. $M=4.27(1.00), t=3.23, p<0.01)$ compared to CHR-Ps. CHRPs reported significantly higher delusional intensity ( $M=2.31$ (1.13) vs. $M=1.69(.87), t=-$ $2.52, p<0.05)$ and suspiciousness ( $M=2.15$ (1.04) vs. $M=1.61(.83), t=-2.37, p<0.05)$ than FEPs. In contrast, FEPs reported higher AH intensity than CHR-Ps, although this failed to reach statistical significance ( $M=1.62(1.46)$ vs. $M=1.16(.49), t=1.73, p=0.09)$, and groups did not differ on $\mathrm{VH}$ intensity. Additional information regarding sociodemographic characteristics and ESM reports is summarized in Table 1.

\section{Prevalence and course of suspiciousness and hallucinations}

Thirty of 33 CHR-Ps (91\%) reported ESM increased suspiciousness, at 400 out of 1140 moments (35\%), comprising a total of 173 suspicious episodes (mean 5.8, range 1-12). Mean episode duration was 2.3 moments and in $53 \%$ of these episodes the length was restricted to 1 moment. Twenty of 34 FEPs (59\%) reported ESM increased suspiciousness, at 160 out of 672 moments (24\%), resulting in 92 suspicious episodes (mean 4.6, range 1-16). Mean episode duration was 1.7 moments and in $68 \%$ of episodes the duration of the episode was 1 moment. Of all individuals reporting suspicious episodes, 22 CHR-Ps (73\%) and 9 FEPs (45\%) did not report additional hallucinations. In contrast, all eight CHR-Ps and 11 of 13 FEPs (85\%) with hallucinations reported also suspiciousness and both experiences occurred within the same moment for 6 of these CHR-Ps (75\%) and 7 (64\%) of these FEPs, respectively, representing $20 \%$ of all recorded moments. One CHR-P participant reported paranoia during all assessed moments.

Eight of 33 CHR-Ps (24\%) reported ESM-hallucinations. Of these, 1 reported only AHs, 3 reported only $\mathrm{VH}$, 1 reported both $\mathrm{AHs}$ and $\mathrm{VH}$ s although in separate moments and 3 reported $\mathrm{AHs}$ and $\mathrm{VH}$ s to co-occur in the same moment. Among those CHR-Ps reporting hallucinations (either AHs, VHs or both) hallucinations were present at 68 out of 298 moment (23\%), composing a total of 34 hallucinatory episodes (mean 4.3, range 1-9). Mean episode duration was 2.0 moments and the length was restricted to one moment in $68 \%$ of the hallucinatory episodes. 
Table 1. Demographic, clinical and ESM characteristics

\begin{tabular}{|c|c|c|c|}
\hline & $\begin{array}{l}\text { Clinical High Risk } \\
(n=33)\end{array}$ & $\begin{array}{l}\text { FEP } \\
(n=34)\end{array}$ & FEP vs. CHR \\
\hline \multicolumn{4}{|l|}{ Demographic variables } \\
\hline Age, mean (SD), range & 23.3 (5.3), 15-38 & $22.8(5.1), 16-31$ & $t=-.41, \mathrm{~ns}$ \\
\hline Gender (m/f) & $23 / 10$ & $19 / 15$ & ns* \\
\hline Civil status, $n(\%)$ & & & ns* \\
\hline Not married & $29(88)$ & 31 (91) & \\
\hline Married/living together & $2(6)$ & $3(8)$ & \\
\hline Unknown & $2(6)$ & - & \\
\hline Work situation, $n(\%)^{\text {a }}$ & & & ns* \\
\hline School/Education & $23(70)$ & $18(53)$ & \\
\hline Regular work & $4(12)$ & $6(18)$ & \\
\hline Structured work & - & $2(6)$ & \\
\hline Non-structured activities & $4(12)$ & $5(15)$ & \\
\hline Other/unknown & $2(6)$ & $3(9)$ & \\
\hline Education level, $n(\%)$ & & & $p<0.01$ \\
\hline No education & $1(3)$ & - & \\
\hline Primary school & - & $2(6)$ & \\
\hline Secondary school & $21(64)$ & $11(33)$ & \\
\hline Higher education & $10(30)$ & $20(61)$ & \\
\hline Unknown & $1(3)$ & - & \\
\hline \multicolumn{4}{|l|}{ ESM episode data } \\
\hline Number of valid reports, mean (SD), range & $38.2(8.8), 20-58$ & $35.8(9.4), 21-58$ & $t=-1.07, \mathrm{~ns}$ \\
\hline $\begin{array}{l}\text { Number of hallucinatory episodes, mean } \\
\text { (SD), range }\end{array}$ & $34,4.3(3.5), 1-9$ & $60,4.6(3.3), 1-9$ & $t=.24, \mathrm{~ns}$ \\
\hline $\begin{array}{l}\text { Length of hallucinatory episodes (mo- } \\
\text { ments), mean (SD), range }\end{array}$ & $2.0(1.8), 1-7$ & $3.7(3.1), 1-10$ & $t=2.92, p<0.01$ \\
\hline $\begin{array}{l}\text { Number of paranoid episodes, mean (SD), } \\
\text { range }\end{array}$ & $174,5.6(3.3), 1-12$ & $91,4.8(4.4), 1-16$ & $t=-.76, \mathrm{~ns}$ \\
\hline $\begin{array}{l}\text { Length of paranoid episodes (moments), } \\
\text { mean (SD), range }\end{array}$ & $2.3(2.0), 1-10$ & $1.7(1.5), 1-8$ & $t=-2.45, p<0.05$ \\
\hline
\end{tabular}

NOS, not otherwise specified; ESM, Experience Sampling Method; SD, standard deviation; ns, not significant. ${ }^{*}$ Fisher's Exact test ${ }^{\text {a }}$ due to rounding, percentages may not add exactly to $100 \%$.

Thirteen of 34 FEPs (39\%) reported ESM-hallucinations. Of these, 6 reported only AHs, 1 reported $\mathrm{VHs}$ and $\mathrm{AHs}$ on separate moments and 6 reported $\mathrm{AHs}$ and $\mathrm{VH}$ s to co-occur within the same moment. Together FEPs reported hallucinations (either AHs, VHs or both) at 221 out of 477 moments (46\%), comprising 60 hallucinatory episodes (mean 4.6 , range 1-9). Mean episode duration was 3.7 moments and in $37 \%$ of the episodes 
the length was 1 moment. One CHR-P participant and 4 FEPs reported hallucinations during at least $90 \%$ of all moments, with 1 FEP reporting hallucinations present during all assessed moments (56 out of 60 ).

\section{Difference in prevalence and course of suspiciousness and hallucinations in CHR-P ver- sus FEP}

More CHR-Ps than FEPs reported paranoia $\left(X^{2}=9.10, p=0.003\right)$. In contrast, the groups did not differ on the number of participants reporting hallucinations or the number of suspicious and hallucinatory episodes. However, the duration of suspicious episodes was significantly shorter in FEPs than in CHR-Ps, while the duration of hallucinatory episodes was significantly longer in FEPs than in CHR-Ps (see Table 1).

\section{Emotional state, anxiety, self-esteem and delusional and hallucinatory intensity}

\section{Suspicious episode}

CHR-Ps with suspicious episodes reported higher intensity of momentary psychotic experiences, anxiety and NA and lower PA and self-esteem than those without suspicious episodes, although none reached statistical significance (Table 2). In contrast, suspicious FEPs reported significantly lower levels of PA and self-esteem, higher levels of NA and anxiety as well as higher overall delusional intensity than non-suspicious FEPs. Direct comparison of FEPs and CHR-Ps with increased suspiciousness showed that FEPs reported significantly higher AH intensity, while the reverse effect was observed for PA.

Focussing on those participants who experienced episodes of suspiciousness, Figure 1a and $1 \mathrm{~b}$ illustrate that both CHR-Ps and FEPs reported the presence of some delusional ideation even in moments unrelated to suspicious episodes. Both CHR-Ps and FEPs reported significantly lower levels of self-esteem and PA as well as higher levels of NA, anxiety, $\mathrm{AH}$ intensity and delusional intensity during an episode compared to moments unrelated with the episodes (Table 3, Figure 1a \& 1b). In the CHR-P group there were small but significant increases in delusional and $\mathrm{AH}$ intensity even before episode onset and a small but significant peak in $\mathrm{AH}$ intensity occurred the first moment after the end of the suspicious episode (Table $3 \&$ figure 1a). Furthermore, small but significant levels of suspiciousness lingered even after the end of an episode, as did the decrease in self-esteem. In addition, FEPs showed a significant decrease in self-esteem and PA before the onset of an episode (Table $3 \&$ figure $1 \mathrm{~b}$ ). Finally, direct comparison of FEPs and CHR-Ps showed that the decrease in PA before onset of the episode in FEPs was also significant compared to CHR-Ps, for whom PA levels were comparable to moments 
unrelated to an episode. During an episode FEPs reported significantly higher AH and VH intensity, paranoia, delusional intensity, more NA and anxiety and lower self-esteem compared to CHR-Ps (Table 3).

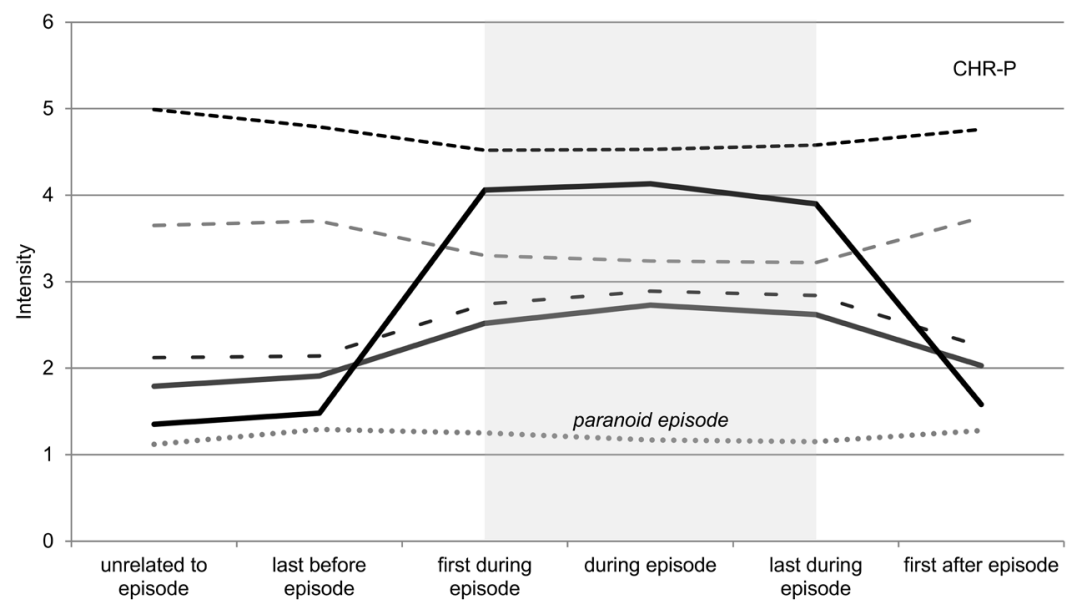

phase of episode

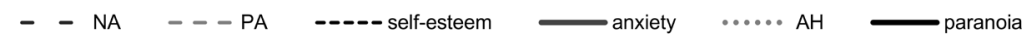

a.

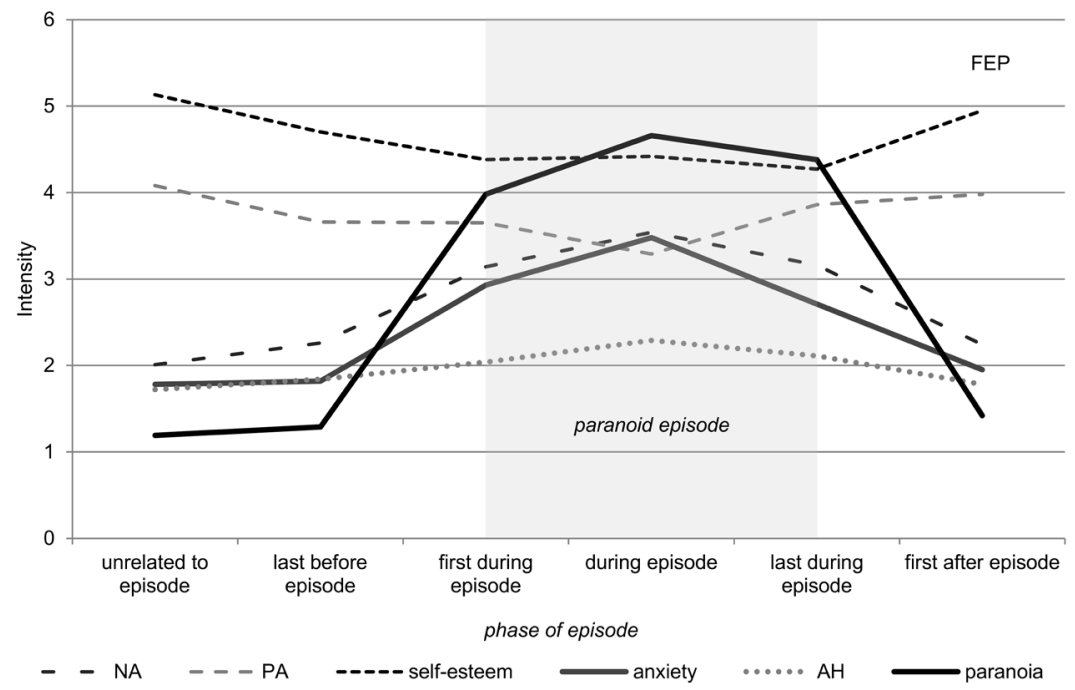

b.

Fig. 1. Dynamics of suspicious episodes in CHR-P (1a) \& FEP (1b) 
Table 2. Comparison on group level

\begin{tabular}{|c|c|c|c|c|}
\hline & & \multicolumn{2}{|c|}{ Mean (SD) } & \multirow[b]{2}{*}{ t-test 1 vs. 2} \\
\hline & & Hal (1) & No Hal (2) & \\
\hline \multirow[t]{2}{*}{ Negative affect } & CHR-P & $2.95(1.33)$ & $2.09(.86)$ & $t=2.14, p=0.04$ \\
\hline & FEP & $2.34(1.41)$ & $1.61(.57)$ & $t=2.14, p=0.04$ \\
\hline \multirow[t]{2}{*}{ Positive affect } & CHR-P & $3.40(.75)$ & $3.60(.82)$ & $t=-.64, \mathrm{~ns}$ \\
\hline & FEP & 4.05 (1.14) & $4.40(.91)$ & $t=-.99, \mathrm{~ns}$ \\
\hline \multirow[t]{2}{*}{ Self-esteem } & CHR-P & $4.14(1.50)$ & $5.10(1.23)$ & $t=-1.82, p=0.08$ \\
\hline & FEP & $4.82(.1 .57)$ & $5.72(.81)$ & $t=-2.22, p=0.03$ \\
\hline \multirow[t]{2}{*}{ Anxiety } & CHR-P & $2.48(1.46)$ & $1.88(.97)$ & $t=1.33, \mathrm{~ns}$ \\
\hline & FEP & $2.19(1.47)$ & $1.42(.47)$ & $t=2.25, p=0.03$ \\
\hline \multirow[t]{2}{*}{ Delusional intensity } & CHR-P & $2.89(1.36)$ & $1.91(.81)$ & $t=2.51, p=0.02$ \\
\hline & FEP & $2.14(1.12)$ & $1.28(.29)$ & $t=3.37, p<0.01$ \\
\hline \multirow[t]{2}{*}{ Suspiciousness } & CHR-P & $2.63(.98)$ & $2.17(1.19)$ & $t=.99, \mathrm{~ns}$ \\
\hline & FEP & $1.86(1.10)$ & $1.29(.43)$ & $t=2.16, p=0.04$ \\
\hline \multirow[t]{2}{*}{ AH intensity } & CHR-P & $1.65(.86)$ & $1.00(.01)$ & $t=3.90, p<0.001$ \\
\hline & FEP & $2.61(2.04)$ & $1.01(.02)$ & $t=3.63, p=0.001$ \\
\hline \multirow[t]{2}{*}{ VH intensity } & CHR-P & $1.70(1.25)$ & $1.00(.005)$ & $t=2.89, p=0.01$ \\
\hline & FEP & $1.93(1.67)$ & $1.00(.01)$ & $t=2.58, p=0.01$ \\
\hline
\end{tabular}

Hal: Hallucination(s) reported; Suspic: suspiciousness reported. ${ }^{*} p<0.05,{ }^{* *} p<0.01,{ }^{* * *} p<0.001$. 


\begin{tabular}{|c|c|c|c|c|}
\hline \multicolumn{2}{|c|}{ Mean (SD) } & \multirow[b]{2}{*}{ t-test 3 vs. 4} & \multicolumn{2}{|c|}{ FEP vs. CHR-P } \\
\hline Suspic (3) & No Suspic (4) & & t-test 1 & t-test 3 \\
\hline $2.40(1.04)$ & $1.25(.10)$ & $t=1.89, p=0.07$ & \multirow{2}{*}{$t=.98, \mathrm{~ns}$} & \multirow{2}{*}{$t=-.35, \mathrm{~ns}$} \\
\hline $2.29(1.16)$ & $1.31(.32)$ & $t=3.09 p<0.01$ & & \\
\hline $3.51(.82)$ & $3.95(.34)$ & $t=-.89, \mathrm{~ns}$ & \multirow{2}{*}{$t=1.44, \mathrm{~ns}$} & \multirow{2}{*}{$t=1.53, \mathrm{~ns}$} \\
\hline $3.92(1.07)$ & $4.76(.65)$ & $t=-2.59, p=0.01$ & & \\
\hline $4.77(1.36)$ & $5.88(.40)$ & $t=-1.39, \mathrm{~ns}$ & \multirow{2}{*}{$t=.98, \mathrm{~ns}$} & \multirow{2}{*}{$t=.50, \mathrm{~ns}$} \\
\hline $4.96(1.36)$ & $5.97(.65)$ & $t=-2.55, p=0.02$ & & \\
\hline $2.12(1.13)$ & $1.15(.10)$ & $t=1.46, \mathrm{~ns}$ & \multirow{2}{*}{$t=-.43, \mathrm{~ns}$} & \multirow{2}{*}{$t=-.17, \mathrm{~ns}$} \\
\hline $2.06(1.21)$ & $1.22(.33)$ & $t=2.51, p=0.02$ & & \\
\hline $2.24(1.04)$ & $1.26(.42)$ & $t=1.59, \mathrm{~ns}$ & \multirow{2}{*}{$t=-1.38, \mathrm{~ns}$} & \multirow{2}{*}{$t=-1.20, \mathrm{~ns}$} \\
\hline $1.89(.97)$ & $1.21(.27)$ & $t=2.55, p=0.02$ & & \\
\hline $2.40(1.13)$ & $1.06(.06)$ & $t=2.02, p=0.05$ & \multirow{2}{*}{$t=-1.61, n s$} & \multirow{2}{*}{$t=-1.82, p=0.07$} \\
\hline $1.85(.90)$ & $1.01(.03)$ & $t=3.50, p=0.001$ & & \\
\hline $1.17(.51)$ & $1.00(.00)$ & $t=.58, \mathrm{~ns}$ & \multirow{2}{*}{$t=1.26, \mathrm{~ns}$} & \multirow{2}{*}{$t=2.00, p=0.05$} \\
\hline $1.80(1.54)$ & $1.40(1.36)$ & $t=.75, \mathrm{~ns}$ & & \\
\hline 1.19 (.69) & $1.00(.00)$ & $t=.46, \mathrm{~ns}$ & \multirow{2}{*}{$t=.34, \mathrm{~ns}$} & \multirow{2}{*}{$t=1.40, \mathrm{~ns}$} \\
\hline $1.61(1.40)$ & $1.01(.01)$ & $t=1.59, \mathrm{~ns}$ & & \\
\hline
\end{tabular}


Table 3. Dynamics of suspiciousness

\begin{tabular}{|c|c|c|c|}
\hline & & Phase $1(B)$ & Phase $2(B)$ \\
\hline \multirow[t]{3}{*}{ Negative affect ${ }^{a}$} & CHR-P & $.01(.10)$ & $.61(.08)^{* * *}$ \\
\hline & FEP & $.26(.15)$ & $1.15(.11)^{* * *}$ \\
\hline & FEP vs. CHR-P & $\mathrm{Z}=1.31, \mathrm{~ns}$ & $Z=3.96, p<0.001$ \\
\hline \multirow[t]{3}{*}{ Positive affect ${ }^{a}$} & CHR-P & $.05(.14)$ & $-.35(.10)^{* *}$ \\
\hline & FEP & $-.43(.17)^{*}$ & $-.44(.12)^{* * *}$ \\
\hline & FEP vs. CHR-P & $Z=-2.19, p<0.05$ & $\mathrm{Z}=-.59, \mathrm{~ns}$ \\
\hline \multirow[t]{3}{*}{ Self-esteem ${ }^{a}$} & CHR-P & $-.20(.10)^{*}$ & $-.47(.07)^{* * *}$ \\
\hline & FEP & $-.43(.14)^{* *}$ & $-.75(.11)^{* * *}$ \\
\hline & FEP vs. CHR-P & $Z=-1.29, \mathrm{~ns}$ & $Z=-2.15, p p<0.05$ \\
\hline \multirow[t]{3}{*}{ Anxiety $^{a}$} & CHR-P & $.12(.14)$ & $.71(.11)^{* * *}$ \\
\hline & FEP & $.05(.20)$ & $1.18(.15)^{* * *}$ \\
\hline & FEP vs. CHR-P & $\mathrm{Z}=-.29, \mathrm{~ns}$ & $Z=2.55, p<0.05$ \\
\hline \multirow[t]{3}{*}{ Delusional intensity ${ }^{\mathrm{a}}$} & CHR-P & $.28(.07)^{* * *}$ & $1.07(.06)^{* * *}$ \\
\hline & FEP & $.11(.10)$ & $.910(.07)^{* * *}$ \\
\hline & FEP vs. CHR-P & $\mathrm{Z}=-1.35, \mathrm{~ns}$ & $\mathrm{Z}=-1.80, \mathrm{~ns}$ \\
\hline \multirow[t]{3}{*}{ Suspiciousness a } & CHR-P & $.14(.09)$ & $2.72(.07)^{* * *}$ \\
\hline & FEP & $.10(.12)$ & $2.78(.09)^{* * *}$ \\
\hline & FEP vs. CHR-P & $\mathrm{Z}=-.25, \mathrm{~ns}$ & $\mathrm{Z}=.53, \mathrm{~ns}$ \\
\hline \multirow[t]{3}{*}{ AH intensity ${ }^{a}$} & CHR-P & $.17(.06)^{* *}$ & $.14(.05)^{* *}$ \\
\hline & FEP & $.12(.15)$ & $.31(.11)^{* *}$ \\
\hline & FEP vs. CHR-P & $\mathrm{Z}=-.30, \mathrm{~ns}$ & $\mathrm{Z}=1.50, \mathrm{~ns}$ \\
\hline \multirow[t]{3}{*}{ VH intensity ${ }^{a}$} & CHR-P & $.02(.06)$ & $.04(.04)$ \\
\hline & FEP & $.05(.13)$ & $.07(.10)$ \\
\hline & FEP vs. CHR-P & $\mathrm{Z}=.22, \mathrm{~ns}$ & $Z=.29, \mathrm{~ns}$ \\
\hline
\end{tabular}

${ }^{*} p<0.05,{ }^{*} p<0.01,{ }^{* * *} p<0.001$. Phase 1: last moment before onset of episode; Phase 2: first moment of episode; Phase 3: during episode; Phase 4: last moment of episode; Phase 5: first moment after end of episode. $\mathrm{AH}=$ auditory hallucinations, $\mathrm{VH}=$ visual hallucinations ${ }^{\text {a }}$ Regression coefficient indicates the difference in intensity of the variables as compared to moments unrelated to a paranoid episode 


\begin{tabular}{lll}
\hline Phase $3(B)$ & Phase $4(B)$ & Phase $5(B)$ \\
\hline $.76(.09)^{* * *}$ & $.72(.10)^{* * *}$ & $.13(.10)$ \\
$1.53(.19)^{* * *}$ & $1.16(.19)^{* * *}$ & $.21(.17)$ \\
$Z=3.70, p<0.001$ & $\mathrm{Z}=2.04, p<0.05$ & $\mathrm{Z}=.43, \mathrm{~ns}$ \\
$-.41(.12)^{* *}$ & $-.43(.14)^{* *}$ & $.09(.14)$ \\
$-.79(.21)^{* * *}$ & $-.22(.21)$ & $-.08(.18)$ \\
$\mathrm{Z}=-1.59, \mathrm{~ns}$ & $\mathrm{Z}=.86, \mathrm{~ns}$ & $\mathrm{Z}=-.73, \mathrm{~ns}$ \\
$-.46(.09)^{* * *}$ & $-.41(.10)^{* * *}$ & $-.23(.10)^{*}$ \\
$-.71(.18)^{* * *}$ & $-.86(.18)^{* * *}$ & $-.17(.16)$ \\
$\mathrm{Z}=-1.24, \mathrm{~ns}$ & $\mathrm{Z}=-2.21, p<0.05$ & $\mathrm{Z}=.36, \mathrm{~ns}$ \\
$.93(.13)^{* * *}$ & $.82(.14)^{* * *}$ & $.24(.14)$ \\
$1.71(.24)^{* * *}$ & $.94(.24)^{* * *}$ & $.17(.22)$ \\
$\mathrm{Z}=2.87, p<0.01$ & $\mathrm{Z}=.42, \mathrm{~ns}$ & $\mathrm{Z}=-.27, \mathrm{~ns}$ \\
$1.04(.07)^{* * *}$ & $1.08(.08)^{* * *}$ & $.19(.08)$ \\
$1.31(.12)^{* * *}$ & $1.36(.12)^{* * *}$ & $.17(.11)$ \\
$\mathrm{Z}=2.00, p<0.05$ & $\mathrm{Z}=1.94, p=0.05$ & $\mathrm{Z}=-.16, \mathrm{~ns}$ \\
$2.78(.08)^{* * *}$ & $2.56(.09)^{* * *}$ & $.24(.09)^{*}$ \\
$3.46(.14)^{* * *}$ & $3.18(.14)^{* * *}$ & $.21(.13)$ \\
$\mathrm{Z}=4.16, p<0.001$ & $\mathrm{Z}=3.67, p<0.001$ & $\mathrm{Z}=-.16, \mathrm{~ns}$ \\
$.05(.06)$ & $.03(.06)$ & $.17(.07)^{*}$ \\
$.58(.18)^{* *}$ & $.39(.18)^{*}$ & $.06(.16)$ \\
$\mathrm{Z}=2.80, p<0.01$ & $\mathrm{Z}=1.87, \mathrm{~ns}$ & $\mathrm{Z}=-.61, \mathrm{~ns}$ \\
$.02(.05)$ & $-.04(.06)$ & $.02(.06)$ \\
$.31(.16)$ & $.69(.16)^{* * *}$ & $.05(.14)$ \\
$\mathrm{Z}=1.77, \mathrm{~ns}$ & $\mathrm{Z}=4.35, p<0.001$ & $\mathrm{Z}=.19, \mathrm{~ns}$ \\
\hline & & \\
\hline & & \\
\hline & &
\end{tabular}


Table 4. Dynamics of hallucinations

\begin{tabular}{|c|c|c|c|}
\hline & & Phase $1(B)$ & Phase $2(B)$ \\
\hline \multirow[t]{3}{*}{ Negative affect ${ }^{a}$} & CHR-P & $.10(.28)$ & $.43(.21)^{*}$ \\
\hline & FEP & $.54(.27)^{*}$ & $.91(.18)^{* * *}$ \\
\hline & FEP vs. CHR-P & $\mathrm{Z}=1.14, \mathrm{~ns}$ & $\mathrm{Z}=1.76, \mathrm{~ns}$ \\
\hline \multirow[t]{3}{*}{ Positive affect ${ }^{a}$} & CHR-P & $.51(.36)$ & $-.60(.26)^{*}$ \\
\hline & FEP & $.17(.30)$ & $-.38(.20)$ \\
\hline & FEP vs. CHR-P & $Z=-.73, \mathrm{~ns}$ & $\mathrm{Z}=.66, \mathrm{~ns}$ \\
\hline \multirow[t]{3}{*}{ Self-esteem ${ }^{a}$} & CHR-P & $.29(.26)$ & $.09(.19)$ \\
\hline & FEP & $-.36(.24)$ & $-.65(.16)^{* * *}$ \\
\hline & FEP vs. CHR-P & $Z=-1.83, n s$ & $Z=-2.96, p<.01$ \\
\hline \multirow[t]{3}{*}{ Anxiety ${ }^{a}$} & CHR-P & $.60(.40)$ & $.85(.29)^{* *}$ \\
\hline & FEP & $.63(.35)$ & $1.06(.23)^{* * *}$ \\
\hline & FEP vs. CHR-P & $\mathrm{Z}=.06, \mathrm{~ns}$ & $\mathrm{Z}=.56, \mathrm{~ns}$ \\
\hline \multirow[t]{3}{*}{ Delusional intensity ${ }^{a}$} & CHR-P & $-.03(.23)$ & $.53(.17)^{*}$ \\
\hline & FEP & $.29(.19)$ & $.91(.13)^{* * *}$ \\
\hline & FEP vs. CHR-P & $\mathrm{Z}=1.04, \mathrm{~ns}$ & $\mathrm{Z}=1.81, \mathrm{~ns}$ \\
\hline \multirow[t]{3}{*}{ Suspiciousness ${ }^{a}$} & CHR-P & $-.27(.43)$ & $.17(.32)$ \\
\hline & FEP & $.55(.34)$ & $.58(.22)^{* *}$ \\
\hline & FEP vs. CHR-P & $\mathrm{Z}=1.50, \mathrm{~ns}$ & $\mathrm{Z}=1.07, \mathrm{~ns}$ \\
\hline \multirow[t]{3}{*}{ AH intensity ${ }^{a}$} & CHR-P & $.02(.20)$ & $1.81(.14)^{* * *}$ \\
\hline & FEP & $-.08(.19)$ & $3.32(.13)^{* * *}$ \\
\hline & FEP vs. CHR-P & $\mathrm{Z}=-.33, \mathrm{~ns}$ & $Z=7.93, p<.001$ \\
\hline \multirow[t]{3}{*}{ VH intensity ${ }^{a}$} & CHR-P & $-.21(.20)$ & $1.30(.15)^{* * *}$ \\
\hline & FEP & $.02(.25)$ & $.81(.17)^{* * *}$ \\
\hline & FEP vs. CHR-P & $\mathrm{Z}=.71, \mathrm{~ns}$ & $Z=-2.16, p<0.05$ \\
\hline
\end{tabular}

${ }^{*} p<0.05,{ }^{*} p<0.01,{ }^{* * *} p<0.001$. Phase 1: last moment before onset of episode; Phase 2: first moment of episode; Phase 3: during episode; Phase 4: last moment of episode; Phase 5: first moment after end of episode. $\mathrm{AH}=$ auditory hallucinations, $\mathrm{VH}=$ visual hallucinations ${ }^{\text {a }}$ Regression coefficient indicates the difference in intensity of the variables as compared to moments unrelated to a paranoid episode 


\begin{tabular}{lll}
\hline Phase $3(B)$ & Phase $4(B)$ & Phase $5(B)$ \\
\hline $.85(.34)^{*}$ & $.27(.36)$ & $.10(.26)$ \\
$1.02(.20)^{* * *}$ & $.83(.22)^{* * *}$ & $.81(.44)$ \\
$\mathrm{Z}=.44, \mathrm{~ns}$ & $\mathrm{Z}=1.33, \mathrm{~ns}$ & $\mathrm{Z}=1.39, \mathrm{~ns}$ \\
$-.46(.41)$ & $.26(.45)$ & $.55(.33)$ \\
$-.53(.22)^{*}$ & $-.12(.25)$ & $-.39(.48)$ \\
$\mathrm{Z}=-.15, \mathrm{~ns}$ & $\mathrm{Z}=-.75, \mathrm{~ns}$ & $\mathrm{Z}=-1.62, \mathrm{~ns}$ \\
$-.38(.31)$ & $-.04(.33)$ & $.36(.24)$ \\
$-.78(.18)^{* * *}$ & $-.64(.20)^{* *}$ & $-.51(.39)$ \\
$\mathrm{Z}=-1.11, \mathrm{~ns}$ & $\mathrm{Z}=-1.53, \mathrm{~ns}$ & $\mathrm{Z}=-1.89, \mathrm{~ns}$ \\
$1.56(.48)^{* *}$ & $1.32(.40)^{*}$ & $.39(.38)$ \\
$1.30(.26)^{* * *}$ & $1.14(.29)^{* * *}$ & $1.19(.57)^{*}$ \\
$\mathrm{Z}=-.47, \mathrm{~ns}$ & $\mathrm{Z}=-.31, \mathrm{~ns}$ & $\mathrm{Z}=1.19, \mathrm{~ns}$ \\
$.72(.33)^{*}$ & $.34(.35)$ & $.26(.26)$ \\
$1.02(.14)^{* * *}$ & $1.06(.16)^{* * *}$ & $.21(.30)$ \\
$\mathrm{Z}=.90, \mathrm{~ns}$ & $\mathrm{Z}=1.69, \mathrm{~ns}$ & $\mathrm{Z}=-.09, \mathrm{~ns}$ \\
$.52(.51)$ & $-.27(.55)$ & $.61(.40)$ \\
$.81(.25)^{* *}$ & $.75(.28)^{* *}$ & $.68(.55)$ \\
$\mathrm{Z}=.52, \mathrm{~ns}$ & $\mathrm{Z}=1.64, \mathrm{~ns}$ & $\mathrm{Z}=.10, \mathrm{~ns}$ \\
$3.17(.22)^{* * *}$ & $2.80(.25)^{* * *}$ & $-.26(.18)$ \\
$3.65(.14)^{* * *}$ & $3.36(.16)^{* * *}$ & $-.26(.35)$ \\
$\mathrm{Z}=1.79, \mathrm{~ns}$ & $\mathrm{Z}=1.93, \mathrm{~ns}$ & $\mathrm{Z}=-.05, \mathrm{~ns}$ \\
$1.95(.25)^{* * *}$ & $2.12(.26)^{* * *}$ & $-.23(.19)$ \\
$1.02(.17)^{* * *}$ & $1.10(.21)^{* * *}$ & $.28(.40)$ \\
$\mathrm{Z}=-2.97, p<0.01$ & $\mathrm{Z}=-3.05, p<0.01$ & $\mathrm{Z}=1.13, \mathrm{~ns}$ \\
\hline & & \\
\hline & &
\end{tabular}




\section{Hallucinatory episode}

CHR-Ps with hallucinations reported significantly higher levels of NA, delusional intensity as well as $\mathrm{AH}$ and $\mathrm{VH}$ intensity compared to CHR-Ps without hallucinations, while self-esteem was lower at trend level (Table 2). FEPs reporting hallucinations had significantly higher levels of NA, anxiety, suspiciousness, delusional, AH and VH intensity as well as lower self-esteem compared to FEPs without hallucinations.

When we focus on those participants who did report hallucinations, Figures $2 a$ and $2 b$ illustrate that suspiciousness and delusional ideation are elevated in moments unrelated and just before onset of hallucinatory episodes, although especially in the CHR-P group. CHR-Ps reported a significantly lower level of PA and higher levels of NA, anxiety and delusional intensity during an episode compared to moments unrelated to an episode (Table 4 \& Figure 2a). FEPs reported significantly lower levels of self-esteem and PA as well as higher levels of NA, anxiety, delusional intensity and suspiciousness during a hallucinatory episode. For the CHR-Ps, no significant differences were found on moments prior or following an episode as compared to moments unrelated to an episode, whereas for FEPs a significant increase in NA occurred prior to the onset of a hallucinatory episode (Figure 2b). Furthermore, anxiety, NA and suspiciousness levels remained elevated after the episode ended, although the latter two this increase did not reach statistical significance. Direct comparison of CHR-P and FEP groups showed that FEPs were characterised by a significantly lower level of self-esteem and a higher level of AH intensity than CHR-Ps at the onset of an episode, while differences did not remain significant during an episode. In contrast, VH intensity was significantly increased in CHR-Ps compared to FEPs during all phases of a hallucinatory episode (Table 4). 


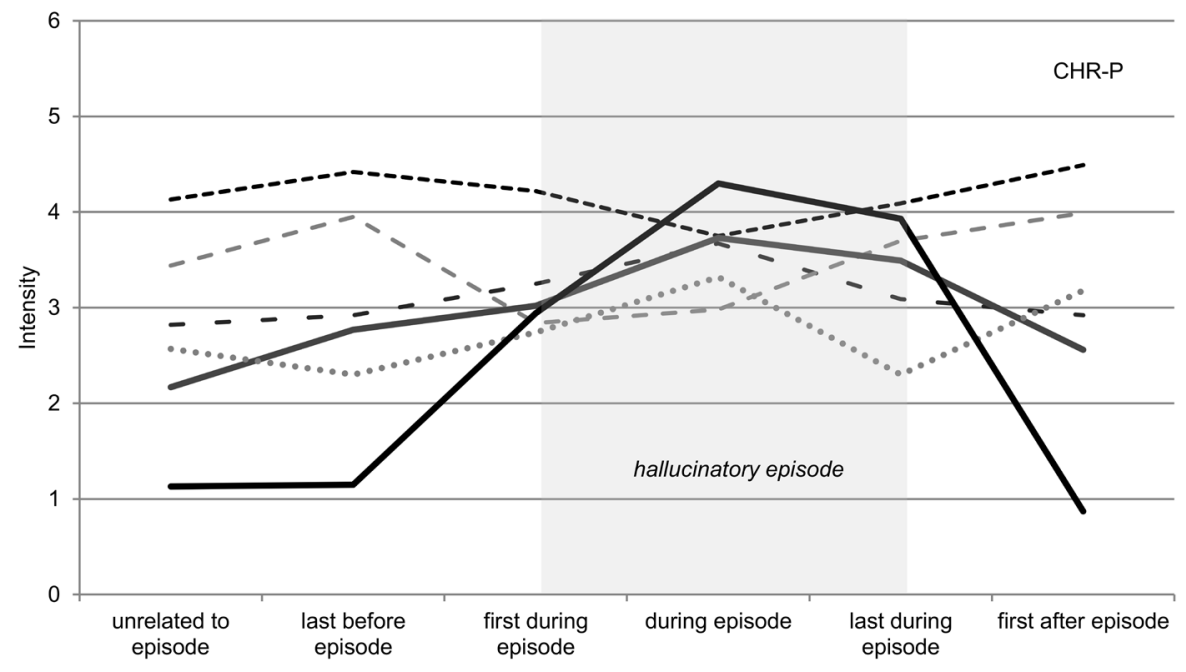

phase of episode

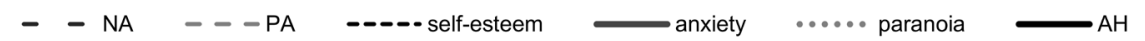

a.

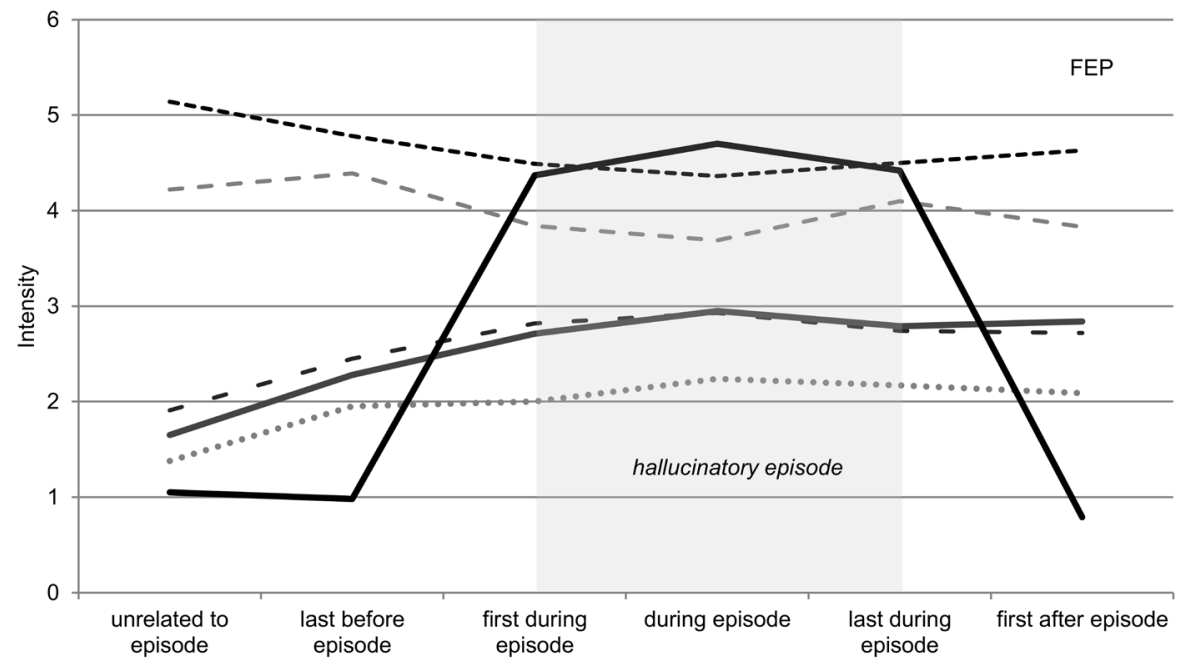

phase of episode

- - NA - - - PA - - - - self-esteem anxiety $\quad \cdots$ paranoia $\longrightarrow$ AH

b.

Fig. 2. Dynamics of hallucinations in CHR-P (2a) \& FEP (2b) 


\section{DISCUSSION}

\section{Main findings}

This is the first study to examine hallucinations and suspiciousness in the context of daily life over a six-day period in participants in the early stages of psychosis. More CHR-Ps than FEPs reported suspiciousness ( $91 \%$ vs. $58 \%$, respectively), the duration of suspicious episodes was longer and comprised more than a third of all recorded moments in CHR-Ps. FEPs reporting suspiciousness in daily life had more distress as reflected by more NA, anxiety and delusional intensity and lower self-esteem than those FEPs not reporting suspiciousness. In the CHR-P group these differences were less distinct. In contrast, hallucinations ( $\mathrm{AH}, \mathrm{VH}$ or both) were more often reported by FEPs than CHR-Ps (39\% vs. $24 \%$, respectively) and hallucinatory episodes lasted longer in FEPs. Whereas in the CHR-P group suspiciousness was reported as an isolated experience, report of hallucinations was accompanied by suspiciousness in almost all individuals regardless of clinical status. In both groups, individuals with hallucinations also reported significant higher NA, anxiety and delusional intensity and lower self-esteem than those without and intensity of $\mathrm{AH}$ was higher in FEPs than in CHR-Ps, suggesting that presence of hallucinations reflects a more severe illness state. This study furthermore showed that hallucinatory and suspicious episodes are discrete phenomena with distinct points of initiation and termination and are accompanied by increases in NA, anxiety and delusional ideation. Decreases in self-esteem were apparent in FEPs during both types of episodes, while it was only characteristic for suspicious episodes in CHR-Ps. Our findings showed that both groups, but especially CHR-Ps, showed elevated levels of suspiciousness and delusional ideation that increased further during episodes. Finally, only FEPs showed changes in affect prior to onset of both types of episodes.

\section{Phenomenology and temporal dynamics of suspicious and hallucinatory episodes}

Current results are in line with previous studies using ESM showing that despite psychotic experiences in daily life being a persistent problem, individuals are not constantly engulfed by their symptoms in their daily lives ${ }^{10-12,14}$, as symptoms were present in 23$46 \%$ of moments in those reporting symptoms. Fifty-nine percent of individuals suffering from a first psychotic episode reported suspicious feelings to occur in daily life, which is comparable to the $54 \%$ of FEPs who reported specific persecutory ideas including the feeling of being 'monitored' in a cross-sectional study ${ }^{1}$ and the $49-67 \%$ of psychotic disorder patients in previous studies using ESM $^{11,12}$. In contrast, $91 \%$ of individuals at clinical high risk for psychosis reported suspiciousness in daily life, even more than in a previ- 
ous study which found subclinical delusions in $82 \%$ of their sample ${ }^{2}$ and $54 \%$ reporting paranoid feelings ${ }^{5}$. Less than half of FEPs with daily life suspiciousness reported this as their only symptom compared to almost three-quarter of CHR-Ps. Currently suspicious FEPs were clearly distressed by these symptoms as they reported more NA, anxiety, delusional intensity and lower self-esteem than current symptom-free FEPs. In contrast, these effects were less apparent for currently suspicious CHR-Ps. Interestingly, episode duration was longer in CHR-P compared to FEPs and CHR-Ps reported significantly more suspiciousness and more general delusional ideation (i.e. feeling unreal, fear of losing control, getting stuck in ones thinking and the idea that other might influence ones thoughts) than FEPs. Therefore, the CHR-P state can be argued to reflect a primarily 'suspicious-delusional state'.

Hallucinations were reported by $39 \%$ of FEPs in daily life, a rate very similar to the $40 \%$ reported by Oorschot and colleagues ${ }^{10}$ in their study of psychosis spectrum patients, although lower than in other studies using ESM ${ }^{11,13}$. However, those studies used a more liberal approach in defining hallucinations (minimal score of 2 rather than 3 ) possibly explaining the difference with this study. Our reported rate is lower than that of $70 \%$ for auditory hallucinations $\mathbf{s}^{1,6}$, although more similar to $29-57 \%$ for visual hallucinations in FEPs in cross-sectional studies ${ }^{1,6}$. A possible explanation is that FEPs were allowed to be in remission if their psychotic episode had occurred within the previous 2 years. Furthermore, 31 of the 34 FEPs used or had previously used anti-psychotic medication likely resulting in less prevalent current symptoms in daily life.

Furthermore, reflecting results of previous cross-sectional studies and studies using $\mathrm{ESM}^{4,11,13}$, hallucinations and suspiciousness almost always clustered within the same individuals with a first psychotic episode. Similarly, even though only about a quarter of CHR-Ps reported hallucinations in daily life, which were less prevalent than in cross-sectional studies ${ }^{2,3}$, all these individuals also experienced feelings of suspiciousness. Both CHR-Ps and FEPs were thus characterised by a 'hallucinatory-delusional state', which was associated with more as reflected by higher NA, anxiety, delusional intensity and lower self-esteem compared to individuals without current hallucinations. Combined these results suggest that presence of hallucinations is related to a more severe stage of psychotic illness. However, FEPs spend more time in this mixed state as duration of hallucinatory episodes was significantly longer than in CHR-Ps. 
Our results confirm previous results showing that hallucinations have a fairly sudden onset and termination ${ }^{10,13}$ and show that this also applies to suspiciousness, overall suggesting that both are on/off phenomena as illustrated by Figures 1 and 2. However, these figures also show that both FEPs and CHR-Ps are reporting low intensity delusional ideation even in moments not related to suspicious and hallucinatory episodes and this is especially apparent for CHR-Ps with hallucinations. This might explain why we did not find a significant increase in delusional ideation before onset of a hallucinatory episode as reported by Oorschot and colleagues ${ }^{10}$ in psychosis spectrum patients. However, whereas suspiciousness and delusional ideation accompanied hallucinations at the onset and over the course of episodes in FEPs, delusional ideation increased only during longer episodes in CHR-Ps (i.e. episodes lasting $\geq 2$ moments). In contrast, a small increase in delusional intensity was apparent in CHR-Ps in the last moment before onset of suspicious episodes, as were small increases in $\mathrm{AH}$ which intensified over the course of the episodes in both groups. Similarly, Ben-Zeev and colleagues ${ }^{12}$ found that increased perceptual abnormalities in psychosis spectrum patients preceded persecutory ideation. Current results show that the interplay between hallucinations and delusions varies slightly over the different phases of illness.

Psychotic patients are characterised by highly variable levels of self-esteem and this instability was especially related to paranoid feelings ${ }^{15}$. In our study, reduced self-esteem was more apparent for suspicious episodes than for hallucinatory episodes, for which it was present in FEPs. In contrast, even before onset of suspicious episodes self-esteem was decreased and decreased further over the duration of episodes, as was reported for a sample of participants with experiences ranging across the paranoia continuum ${ }^{14}$. This reduction remained even after the end of an episode in CHR-Ps. Our findings further emphasise the important role of negative self-evaluation in the development of suspiciousness and consistent with the suggestion suspicious individuals assume others to share their own negative evaluations of themselves, which in elicits the perceived malevolence of others ${ }^{14}$.

As reported by previous ESM studies with participants across the psychosis continuum and psychotic patients with acute paranoia and hallucinations ${ }^{10,11,14}$, we found both experiences to be accompanied be a decrease in positive emotions and increases in negative emotions and anxiety in FEPs, although individual differences in these relationships have been reported ${ }^{25}$. Current results are furthermore in line with cross-sectional studies showing increased anxiety levels in patients with (auditory) hallucinations and per- 
secutory delusions ${ }^{26-29}$. Importantly, our results expand these findings by showing that these effects also apply in the clinical high risk for psychosis state.

Anxiety has been found to be a strong predictor of onset and intensity of paranoid and hallucinatory episodes in daily life ${ }^{13,14}$, although current results are less conclusive. Anxiousness was somewhat although not significantly elevated prior to onset of hallucinations or paranoia in both CHR-P and FEP patients. A previous study of Oorschot and colleagues $^{25}$ found that an anxious state was only apparent in the moment before a paranoid episode in a small number of their psychotic patients. This might also be the case for current participants. In contrast, hallucinations and suspiciousness were accompanied by increases in anxiety. Worrying and rumination have been found to predict delusional and hallucinatory experiences and distress ${ }^{9}$. Feeling worried and having ruminating thoughts, accompanied by a drop in self-esteem are likely triggers of psychotic experiences, which in turn elicit anxiety. This suggestion is supported by our finding that anxiety remained increased after the end of a hallucinatory episode for FEP patients, for whom the content of hallucination might be more disturbing and a source for ruminating thoughts, whereas anxiety dropped after the end of a hallucination in CHR-Ps.

\section{Theoretical implications}

Both cognitive and biological theories of psychosis argue that transition to psychosis is the results of the co-occurrence of hallucinations and delusions $\mathrm{s}^{30-32}$. Subtle perceptual alterations or anomalous experiences occurring in an early phase can be very disturbing and warrant an explanation resulting in the gradual formation of delusional ideas under the influence of emotional processes. In line with these theories, epidemiological studies have shown that these perceptual alterations or hallucinations along with the distress they cause and accompanied by depressive symptoms have been associated with development of more severe types or secondary delusions. These secondary delusions concern loss of control (e.g. thought withdrawal and insertion, thought broadcasting) and belief that emotions, impulses and/or actions are controlled by an outside force, which in turn are associated with poorer outcome in psychotic patients s3-37. $^{33}$

Taken together current findings on prevalence and phenomenology of psychotic experiences in daily life in the early phase of psychosis are in line with epidemiological studies showing that clustering of hallucinations and delusions as compared to either symptoms in isolation, results in a deepened psychotic state ${ }^{34,35}$. In this 'hallucinatory-delusional state' experiences become more persistent, associated with negative symptoms and an 
increased risk of clinical outcome ${ }^{38,39}$ and this state occurs more often in individuals with higher levels of exposure to genetic and environmental risk factors ${ }^{34}$, 35 , suggesting it forms a crucial stage in the development of psychotic disorder. It is therefore attractive to hypothesize that the relatively small current subsample of CHR-Ps (24\%) reporting both types of experiences in daily life are more likely to make the transition to psychotic disorder than those reporting suspiciousness only, although follow-up studies are needed to confirm this hypothesis.

\section{Clinical implications}

The current findings have implications for clinical practice. Thorough investigation of the exact nature of (attenuated) psychotic symptoms is needed as severity and risk for transition is likely to be higher for individuals reporting both suspiciousness and hallucinations. Clinicians need to be aware of the central role of emotion-related processes, anxiety and self-esteem for the occurrence of hallucinations and suspiciousness in daily life not only in patients with a first episode of psychosis for whom these processes are relevant with respect to prevention of illness progression, but also for those at high clinical risk for transition to psychosis. Use of momentary assessment can help to unravel symptom patterns as they supply both the individual patient and clinician with large amount of detailed information about symptoms and their relationships with mood, anxiety, self-esteem all in the social context of daily life.

In psychotic spectrum patients investigation of different 'types' of paranoia (i.e. "poor me" and "bad me") has shown that a complicated relationship exists with self-esteem, experiential avoidance and social stress in which paranoia sometimes has a beneficial effect on self-esteem and possibly serve a protective mechanism ${ }^{40-42}$. Future studies in CHR-P and FEP groups are needed to determine the exact role of all these processes in these populations. Taken together, these findings warrant for a systematic evaluation of the type of paranoia and self-esteem (variability) to determine the best treatment strategy which can help improve self-esteem regulation and in turn symptomatology and anxiety.

\section{Limitations}

The results of this study should be interpreted in the context of several methodological limitations. First, as with all ESM studies, measurements are based on subjective reports. Therefore, it can be argued that the results are not psychometrically precise. However, although subjective reports are considered less reliable (e.g., do all participants in- 
terpret or answer the questions identically?), previous research indicates that subjective reports can be valid and are important especially in order to understand the changes in symptoms ${ }^{43}$. In addition, as we combined two samples, data was gathered with help of an electronic device and by the use of a paper-and-pencil diary method. The paper-and pencil method has been questioned as it may lead to poor participant compliance. However, previous studies have demonstrated that the traditional paper-and-pencil diary methods are not inferior to electronic diary methods with regard to compliance rates ${ }^{44,45}$.

Second, our measure of paranoia 'I feel suspicious' was defined more narrowly than in previous ESM studies of paranoid or persecutory ideation ${ }^{9,14}$. However, prevalence rates were similar to earlier studies. Further investigation of the content of paranoid beliefs and their relationship to emotional processes may help therapies to focus on the mechanism of change in suspicious thinking instead of focussing solely on symptom reduction. Third, given the small number of CHR-P and FEP participants who only reported either visual or auditory hallucinations, we were not able to investigate the temporal dynamics of auditory and visual hallucinations separately as was done by Oorschot and colleagues $^{10}$ in a large sample of psychotic spectrum patients. Furthermore, as we were unable to assess the precise nature of content of auditory and visual hallucinations, we could not discern whether these were more crystallized in FEPs compared to CHR-Ps. However, results of this study showed that regardless of participant status, psychotic experiences in daily life were related with low mood and anxiety. Future studies with larger samples should examine these factors in more detail.

Fourth, as with all ESM studies of symptomatology, the random-sampling design might have caused an underestimation of hallucination and paranoia frequency, since we cannot rule out the possibility that patients are less prone to respond to a beep when hallucinating or feeling suspicious. Alternatively, we might have missed hallucinations or paranoia occurring between beeps. Furthermore, episode duration may have been overestimated as it is possible that we may have missed symptom-free periods in between consecutive beeps. In contrast, an episode duration may have been underestimated in participants who reported hallucinations or paranoia (almost) continuously as per definition we defined the end of an episode as the last moment of the day. However, our results also indicated that the majority of episodes were present only during one moment, suggesting that the on and offset of hallucinatory and paranoid episodes is highly variable. 


\section{REFERENCES}

1. Rajapakse T, Garcia-Rosales A, Weerawardene S, Cotton S, Fraser R. Themes of delusions and hallucinations in first-episode psychosis. Early Interv Psychiatry. 2011; 5:254-258.

2. Schultze-Lutter F, Renner F, Paruch J, Julkowski D, Klosterkotter J, Ruhrmann S. Self-reported psychotic-like experiences are a poor estimate of clinician-rated attenuated and frank delusions and hallucinations. Psychopathology. 2014; 47:194-201.

3. Zhang T, Li H, Woodberry KA, Seidman LJ, Zheng L, Li H, . . Wang J. Prodromal psychosis detection in a counseling center population in China: an epidemiological and clinical study. Schizophr Res. 2014; 152:391-399.

4. Compton MT, Potts AA, Wan CR, lonescu DF. Which came first, delusions or hallucinations? An exploration of clinical differences among patients with first-episode psychosis based on patterns of emergence of positive symptoms. Psychiatry Res. 2012; 200:702-707.

5. Salokangas RK, Schultze-Lutter F, Hietala J, Heinimaa M, From T, Ilonen T, . . Ruhrmann S. Depression predicts persistence of paranoia in clinical high-risk patients to psychosis: results of the EPOS project. Soc Psychiatry Psychiatr Epidemiol. 2016; 51:247-257.

6. Solesvik M, Joa I, Larsen TK, Langeveld J, Johannessen JO, Bjornestad J, . . Bronnick K. Visual Hallucinations in First-Episode Psychosis: Association with Childhood Trauma. PLoS One. 2016; 11:e0153458.

7. Clark ML, Waters F, Vatskalis TM, Jablensky A. On the interconnectedness and prognostic value of visual and auditory hallucinations in first-episode psychosis. Eur Psychiatry. 2017; 41:122-128.

8. Myin-Germeys I, Oorschot M, Collip D, Lataster J, Delespaul P, van Os J. Experience sampling research in psychopathology: opening the black box of daily life. Psychol Med. 2009; 39:1533-1547.

9. Hartley S, Haddock G, Vasconcelos e Sa D, Emsley R, Barrowclough C. An experience sampling study of worry and rumination in psychosis. Psychol Med. 2014; 44:1605-1614.

10. Oorschot M, Lataster T, Thewissen V, Bentall R, Delespaul P, Myin-Germeys I. Temporal dynamics of visual and auditory hallucinations in psychosis. Schizophr Res. 2012b; 140:77-82.

11. Peters E, Lataster T, Greenwood K, Kuipers E, Scott J, Williams S, . . Myin-Germeys I. Appraisals, psychotic symptoms and affect in daily life. Psychol Med. 2012; 42:1013-1023.

12. Ben-Zeev D, Ellington K, Swendsen J, Granholm E. Examining a Cognitive Model of Persecutory Ideation in the Daily Life of People With Schizophrenia: A Computerized Experience Sampling Study. Schizophr Bull. 2011; 37:1248-1256.

13. Delespaul $P$, deVries $M$, van Os J. Determinants of occurrence and recovery from hallucinations in daily life. Soc Psychiatry Psychiatr Epidemiol. 2002; 37:97-104.

14. Thewissen V, Bentall RP, Oorschot M, à Campo J, van Lierop T, van Os J, Myin-Germeys I. Emotions, self-esteem, and paranoid episodes: An experience sampling study. Br J Clin Psychol. 2011; 50:178-195.

15. Thewissen V, Bentall RP, Lecomte T, van Os J, Myin-Germeys I. Fluctuations in self-esteem and paranoia in the context of daily life. J Abnorm Psychol. 2008; 117:143-153.

16. van der Steen Y, Gimpel-Drees J, Lataster T, Viechtbauer W, Simons CJP, Lardinois M, . . Myin-Germeys I. Clinical high risk for psychosis: the association between momentary stress, affective and psychotic symptoms. Acta Psychiatr Scand. 2017; 136:63-73.

17. Bechdolf A, Muller H, Stutzer H, Wagner M, Maier W, Lautenschlager M, . . Klosterkotter J. Rationale and baseline characteristics of PREVENT: a second-generation intervention trial in subjects at-risk (prodromal) of developing first-episode psychosis evaluating cognitive behavior therapy, aripiprazole, and placebo for the prevention of psychosis. Schizophr Bull. 2011; 37 Suppl 2:S111-121.

18. Miller T, McGlashan T, Woods S, Stein K, Driesen N, Corcoran CM, . . . Davidson L. Symptom assessment in schizophrenic prodromal states. Psychiatr Q. 1999; 70:273-287.

19. Yung AR, Yung AR, Pan Yuen H, McGorry PD, Phillips LJ, Kelly D, . . Buckby J. Mapping the onset of psychosis: the Comprehensive Assessment of At-Risk Mental States. Aust N Z J Psychiatry. 2005; 39:964-971.

20. Schultze-Lutter F, Addington J, Ruhrmann S, eds. Schizophrenia Proneness Instument, Adult version (SPI-A): Giovanni Fioriti Editore 2007.

21. Andreasen NC, Flaum M, Arndt S. The Comprehensive Assessment of Symptoms and History (CASH). An instrument for assessing diagnosis and psychopathology. Arch Gen Psychiatry. 1992; 49:615-623. 
22. Csikszentmihalyi M, Larson R. Validity and Reliability of the Experience-Sampling Method. J Nerv Ment Dis. 1987; 175:526-536.

23. Delespaul P. Assessing schizophrenia in daily life. Maastricht: Universitaire Pers; 1995.

24. Stata Statistical Software: Release 13. College Station, TX: StataCorp LP; 2013.

25. Oorschot M, Lataster T, Thewissen V, Wichers M, Myin-Germeys I. Mobile assessment in schizophrenia: a data-driven momentary approach. Schizophr Bull. 2012a; 38:405-413.

26. Freeman D, Garety PA. Connecting neurosis and psychosis: the direct influence of emotion on delusions and hallucinations. Behav Res Ther. 2003; 41:923-947.

27. Lysaker PH, Salyers MP. Anxiety symptoms in schizophrenia spectrum disorders: associations with social function, positive and negative symptoms, hope and trauma history. Acta Psychiatr Scand. 2007; 116:290-298.

28. Smith B, Fowler DG, Freeman D, Bebbington P, Bashforth H, Garety P, . . Kuipers E. Emotion and psychosis: links between depression, self-esteem, negative schematic beliefs and delusions and hallucinations. Schizophr Res. 2006; 86:181-188.

29. Startup H, Freeman D, Garety PA. Persecutory delusions and catastrophic worry in psychosis: Developing the understanding of delusion distress and persistence. Behav Res Ther. 2007; 45:523-537.

30. Howes OD, Kapur S. The Dopamine Hypothesis of Schizophrenia: Version III-The Final Common Pathway. Schizophr Bull. 2009; 35:549-562.

31. Garety PA, Kuipers E, Fowler D, Freeman D, Bebbington PE. A cognitive model of the positive symptoms of psychosis. Psychol Med. 2001; 31:189-195.

32. Maher BA. The relationship between delusions and hallucinations. Curr Psychiatry Rep. 2006; 8:179-183.

33. Hanssen M, Krabbendam L, de Graaf R, Vollebergh W, van Os J. Role of distress in delusion formation. $\mathrm{Br}$ J Psychiatry. 2005; 187:s55-s58.

34. Smeets F, Lataster T, Dominguez MD, Hommes J, Lieb R, Wittchen HU, van Os J. Evidence that onset of psychosis in the population reflects early hallucinatory experiences that through environmental risks and affective dysregulation become complicated by delusions. Schizophr Bull. 2012; 38:531-542.

35. Smeets F, Lataster T, van Winkel R, de Graaf R, Ten Have M, van Os J. Testing the hypothesis that psychotic illness begins when subthreshold hallucinations combine with delusional ideation. Acta Psychiatr Scand. 2013; 127:34-47.

36. Krabbendam L, Myin-Germeys I, Hanssen M, Bijl RV, De Graaf R, Vollebergh W, ... Van Os J. Hallucinatory experiences and onset of psychotic disorder: evidence that the risk is mediated by delusion formation. Acta Psychiatr Scand. 2004; 110:264-272.

37. Krabbendam L, Myin-Germeys I, Hanssen M, de Graaf R, Vollebergh W, Bak M, van Os J. Development of depressed mood predicts onset of psychotic disorder in individuals who report hallucinatory experiences. Br J Clin Psychol. 2005; 44:113-125.

38. Dominguez MDG, Wichers M, Lieb R, Wittchen H-U, van Os J. Evidence That Onset of Clinical Psychosis Is an Outcome of Progressively More Persistent Subclinical Psychotic Experiences: An 8-Year Cohort Study. Schizophr Bull. 2011; 37:84-93.

39. Nuevo R, Van Os J, Arango C, Chatterji S, Ayuso-Mateos JL. Evidence for the early clinical relevance of hallucinatory-delusional states in the general population. Acta Psychiatr Scand. 2013; 127:482-493.

40. Udachina A, Bentall RP, Varese F, Rowse G. Stress sensitivity in paranoia: poor-me paranoia protects against the unpleasant effects of social stress. Psychol Med. 2017:1-10.

41. Udachina A, Thewissen V, Myin-Germeys I, Fitzpatrick S, O'Kane A, Bentall RP. Understanding the Relationships Between Self-Esteem, Experiential Avoidance, and Paranoia: Structural Equation Modelling and Experience Sampling Studies. J Nerv Ment Dis. 2009; 197:661-668.

42. Udachina A, Varese F, Oorschot M, Myin-Germeys I, Bentall RP. Dynamics of Self-Esteem in "Poor-Me" and "Bad-Me" Paranoia. J Nerv Ment Dis. 2012; 200:777-783.

43. Strauss JS. The person with schizophrenia as a person. II: Approaches to the subjective and complex. Br J Psychiatry Suppl. 1994; 23:103-107.

44. Bolger N, Shrout PE, Green AS, Rafaeli E, Reis HT. Paper or plastic revisited: Let's keep them both--Reply to Broderick and Stone (2006); Tennen, Affleck, Coyne, Larsen, and DeLongis (2006); and Takarangi, Garry, and Loftus (2006). Psychol Methods. 2006; 11:123-125.

45. Green AS, Rafaeli E, Bolger N, Shrout PE, Reis HT. Paper or plastic? Data equivalence in paper and electronic diaries. Psychol Methods. 2006; 11:87-105. 


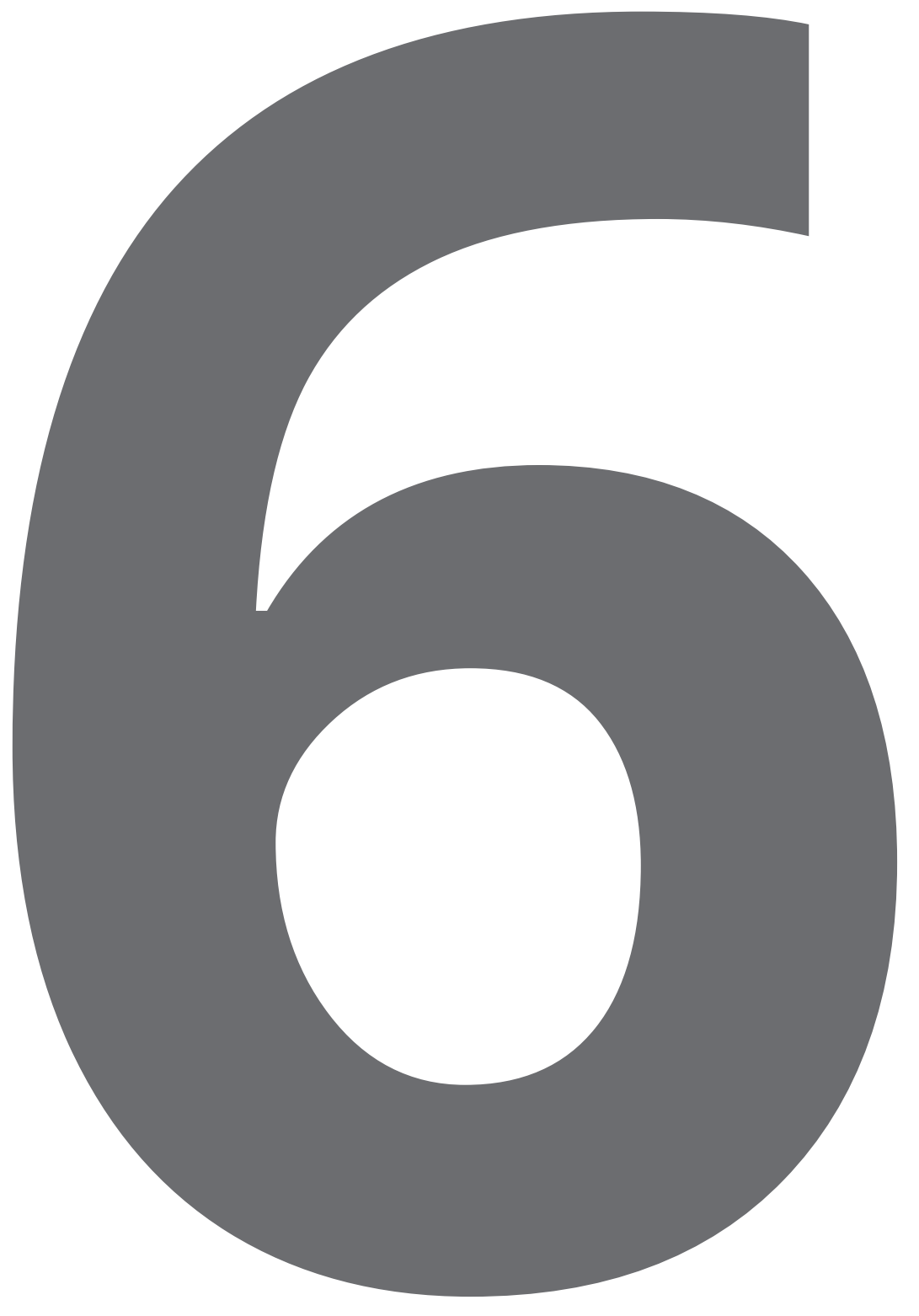




\section{Chapter 6}

General discussion 

Psychotic disorders are associated with a high burden for patients themselves as well as for their family members and friends. Early identification and intervention for subclinical psychotic symptoms may influence illness trajectory, possibly averting the transition to fully-fledged psychotic disorder and improving functioning and quality of life. To accomplish this goal psychosis research and clinical care have started to focus on investigation of subclinical psychotic symptoms in help-seeking individuals meeting criteria for clinical high risk for psychosis (CHR-P) as well as in non-help seeking individuals from the general population and unaffected first-degree relatives of psychotic disorder patients.

The current thesis aimed to gain more insight in mechanisms and risk factors involved in the development from subclinical psychotic symptoms to clinically relevant psychotic symptoms and psychotic disorder. The occurrence of (subclinical) psychotic symptoms was studied across the psychosis continuum in individuals from the general population, unaffected first-degree relatives of psychotic disorder patients, patients at clinical high risk for psychosis (CHR-P), patients with a first psychotic episode (FEP) and long-term psychotic disorder patients.

The first part of this thesis focussed on the epidemiology of development of subclinical psychotic symptoms in individuals from the general population and unaffected relatives of psychotic disorder patients as assessed through both self-report and clinical interview measures. Using a longitudinal design, in chapter $\mathbf{2}$ we examined the progression and outcome of baseline 'false-positive' self-reported psychotic experiences (FP SRPE) over a 3-year follow-up period in individuals from the general population, which have been suggested to represent the lowest expression of psychosis risk along the continuum. We showed that 'False positive SRPE', are not truly 'false' as they index risk for development of clinically relevant psychotic symptoms, presence of mood and anxiety disorders and reduced functioning. Self-reported $\mathrm{PE}$, even unconfirmed, therefore warrant 'watchful waiting' and follow-up over time especially when they are reported by individuals with reduced psychosocial functioning and general psychiatric problems. In chapter $\mathbf{3}$ we examined in a sample of unaffected first-degree relatives of psychotic disorder patients and healthy controls if genetic risk, as reflected by the Polygenic Risk Score for schizophrenia (PRS), was associated with the expression of psychosis conceptualized as subclinical psychotic symptoms assessed through both self-report and clinical interview. We found that while PRS was not associated with subclinical psychotic symptoms obtained through self-report, it was associated with subclinical symptoms obtained in a clinical 
interview in both unaffected first-degree relatives and healthy controls. PRS was furthermore positively associated with the lifetime number of affective episodes.

The second part of this thesis aimed at exploring the phenomenology of psychotic experiences in daily life in CHR-P patients, patients with a first episode of psychosis (FEP) and long-term psychotic disorder patients, to examine differences and similarities between the at-risk for psychosis stage, an 'intermediate' stage and an 'endpoint' stage along the extended psychosis continuum. The Experience Sampling method (ESM) was applied to zoom in into the microenvironment to study the dynamics of momentary psychotic experiences over time in the context of daily living. In chapter 4 we examined emotional and symptomatic stress-reactivity to daily life stressors as potential risk factors for psychosis development. We found that stress sensitization seems to play a role particularly in the early phase of psychosis development as results suggest that CHR-P patients are more sensitive to daily life stressors than long-term psychotic disorder patients, as they showed higher levels of emotional and symptomatic stress reactivity. In this early phase, momentary psychotic symptoms also contributed to the experience of stress as they were associated with an increase in negative affect.

Finally, in chapter $\mathbf{5}$ we specifically investigated the phenomenology of hallucinations and suspiciousness and their relationship with mood, anxiety and self-esteem in CHR-P and FEP patients. Episodes of suspiciousness were more prevalent than hallucinatory episodes and this was especially prominent for the CHR-P patients for whom episodes of suspiciousness lasted longer than for FEP patients, while only a minority reported hallucinations. Although hallucinations were more prevalent in FEP patients, episode duration was longer in CHR-P patients. Both symptoms were often reported by the same individual and co-occurred regularly at the same moment. Suspiciousness and hallucinations had a fairly sudden onset and ending, implying they are discrete on/off phenomena. Intensity of delusional ideation, negative affect and anxiety increased whereas self-esteem decreased during suspicious and hallucinatory episodes, indicating that these (subclinical) symptoms were distressing.

\section{The benefit of combining subjective self-report and objective interview measures in psychosis research}

Psychopathology relates per definition to the expression of subjectively distressing 'abnormal' experiences. In psychosis research and clinical practice, both self-report and interview measures are used to assess presence of anomalous experiences and the degree 
in which they are distressing and pathological. Self-report measures have the advantage of being less time consuming than interviews, however, these are subjective in nature making it uncertain whether all individuals interpret and answer questions identically. Especially when (subclinical) psychotic symptoms are retrospectively assessed through self-report, is it possible that interpretation and answer style are under the influence of factors such as personal relevance, recency effects, novelty, significance or mood. Furthermore, self-report measures are unable to filter contextual information needed to determine the clinical validity and relevance of reported 'psychotic symptoms' ${ }^{1}$. In contrast, contextual information can be elicited through semi-structured clinical interviews by trained and experienced clinicians. This distinction in results based on assessment method $^{2,3}$ is illustrated by findings that in general population studies prevalence rates of subclinical psychotic symptoms obtained by self-report measures are several times higher than those obtained through clinical interview ${ }^{4-8}$. Some of these self-reported psychotic symptoms are true (subclinical) psychotic symptoms, although around $40 \%$ are not truly psychotic in nature and are referred to as 'false-positive' self-reported psychotic experiences (FP SRPE).

Examples of FP SRPE are hearing or seeing a departed loved one during a bereavement period, or solely having hallucinations after use of a specific hallucinogenic drug $^{9}$. Furthermore, factor analyses of self-reported PLEs assessed with the CAPE ${ }^{10}$, the self-report instrument which was used in chapter 3, in help-seeking non-psychotic individuals and in individuals from the general population have identified several subtypes being persecution/paranoia, bizarre experiences, hallucinations, and paranormal beliefs/magical thinking ${ }^{11,12}$. Whereas persecution, bizarre experiences and hallucinations were more likely to be associated with distress and poor functioning and may represent expressions of underlying vulnerability for psychotic disorder, this was not found for paranormal beliefs and magical thinking, suggesting these may be a normal personality variant. Furthermore, in the general population sample very few endorsed experiencing bizarre experiences, perceptual abnormalities or persecutory ideas subtypes for a large proportion of time, and magical thinking was the most common subtype of self-reported psychotic symptoms that was endorsed as 'always or almost always' present ${ }^{12}$. We can therefore argue that the majority of self-reported psychotic symptoms in both healthy controls and unaffected relatives were those of the paranormal beliefs and magical thinking subtype, which are unlikely to present true risk for psychotic disorder. 
Some researchers have therefore argued that subclinical psychotic symptoms detected through self-report measures only have minimal direct clinical significance for the prediction of psychosis onset ${ }^{1,8,9}$. However, an earlier study with a different general population sample found FP SPRE to predict transition to psychotic disorder, although the effect size was smaller than in individuals with validated psychotic symptoms ${ }^{13}$. In chapter 2 we confirmed that even FP SRPE are clinically relevant for psychosis development as well as for the development of general psychopathology. Individuals reporting these were 6 times more likely to develop clinically significant (subclinical) psychotic symptoms and had a higher likelihood of reduced functioning and more general psychopathology than healthy controls. Interestingly, individuals who developed valid psychotic symptoms after first reporting FP SRPE were already different at baseline from individuals for whom FP SRPE were transitory in nature. This supports the suggestion that (subclinical) psychotic symptoms are the outcome of more severe baseline severity of multidimensional psychopathology ${ }^{14-16}$. The group of individuals that transitioned to valid psychotic symptoms showed more mood and anxiety problems, high neuroticism, reported more childhood adversities and were more often help-seeking and reported more and more frequent FP SRPE.

Use of self-report measures of psychotic experiences in both the general and clinical population will result in an overestimation of their prevalence. In turn, this might delude the effects of true subclinical symptoms on transition risk and functioning. However, when combined, self-report and clinical interview measures can provide valuable information about psychosis development and directions for future research into risk factors and targets for treatment, especially when used in longitudinal studies.

In clinical care, self-report measures of psychotic experiences should always be followed by a clinical interview. Importantly, chapter 2 illustrated that even non-confirmed or FP SRPE should not be dismissed as irrelevant, as they predicted higher levels of general psychopathology and help-seeking. Regular reassessment of even FP SRPE for individuals remaining in care for other psychological problems is therefore recommended.

Overall, the scientific and clinical significance of subclinical psychotic symptoms will thus depend strongly on the manner and context in which these are assessed. The findings of chapter 3 illustrate this point. We found that Polygenic Risk Score (PRS) for schizophrenia was positively and significantly associated with subclinical psychotic symptoms assessed with an objective interview measure in both unaffected first-degree relatives of psychotic patients and healthy controls. In contrast, PRS was not associated with PLES 
assessed with a self-report measure. These results thus suggest that studies of gene-environment relationships in psychosis are more likely to be informative when objective interview measures of subclinical psychotic symptoms are used. As suggested previous$1 y^{9}$, it can be recommended that future studies of subclinical psychotic symptoms should only use self-report measures as a screening tool. PLEs should then be examined in detail by clinical interview. The use of a semi-structured psychosis risk assessment interview like the CAARMS or the SIPS is advised as it allows validation of an experience as a true subclinical symptom while also obtaining detailed information about the frequency of a symptoms and determination of CHR-P or psychosis status.

Even though retrospective self-report has important issues that have to be considered, self-report measures can be very informative when experiences are not assessed retrospectively but in real time by use of simple and straightforward questions as is done with the Experiences Sampling Method (ESM) ${ }^{17,18}$. When assessment of experiences is in the moment', answers are less prone to the occurrence of biases and forgetting that hamper traditional retrospective assessment approaches ${ }^{19}$. The ESM method has several other advantages. It allows the assessment of various constructs including quality of life and psychopathology as well as psychological mechanisms like stress-sensitivity and coping that are difficult to assess using cross-sectional questionnaires. ESM studies are ecologically valid as they allow studying individuals within their own real-life environment. ESM is situated in the complex context of daily life and therefore able to measure the variation in symptoms and mood in response to environmental factors present in daily life, whereas questionnaires and most interviews do not focus on how contextual factors impact these outcome variables. In addition, questionnaires and interviews require patients to be aware of the dynamics of symptoms and their interactions with other factors. However, as different constructs like symptoms, mood, stress and social company are measured separately from each other and only associated to each other in the analyses conducted by the researcher, ESM provides information that the participant is not aware of and therefore not influenced by an individual's own expectations. Finally, ESM allows for the cross-sectional as well as longitudinal study of variation and dynamic relationships given that data collection encompasses multiple assessments over time which creates a detailed picture of the occurrence and the dynamics of symptoms, mood and other constructs in daily life.

Studies using ESM in psychotic disorder patients have provided valuable information on the phenomenology of positive symptoms ${ }^{20-26}$, negative symptoms ${ }^{27-29}$ and their relationship to emotions and contextual factors, but also social functioning ${ }^{29,30}$ in daily life. 
Importantly, ESM has significantly improved our understanding of the association between a number of putative psychological mechanisms and psychotic symptoms ${ }^{31}$. It has shown that psychotic patients are characterised by increased emotional and symptomatic reactivity when confronted with everyday small stressors ${ }^{32,33}$. Other ESM studies have investigated putative psychological mechanisms and their relationship with (subclinical) psychotic symptoms including cognitive self-consciousness ${ }^{34}$, meta-cognitive beliefs ${ }^{34}$, ${ }^{35}$, self-esteem ${ }^{26,35,36}$, coping $^{37}$, cognitive appraisal ${ }^{25}$, affective disturbance ${ }^{20,38}$, enhanced threat anticipation and experiences of aberrant novelty and salience ${ }^{39}$.

The studies in chapter $\mathbf{4}$ and chapter $\mathbf{5}$ have further extended ESM research to the early phase of psychosis in FEP patients and before onset of psychosis in CHR-P patients. Providing evidence for the hypothesis that enhanced stress sensitivity is an underlying mechanism for psychosis development, we found in chapter $\mathbf{4}$ that CHR-P patients show increased emotional stress reactivity for small daily life hassles not only compared to healthy controls, but to long-term psychotic disorder patients as well. Our results are very similar to findings of two other recent ESM studies in CHR-P and (first episode) psychotic disorder patients ${ }^{39,40}$, suggesting that stress sensitization seems to play a role particularly in the early phase of psychosis development. Furthermore, psychotic disorder patients show symptomatic reactivity to small daily life stressors. This process of 'behavioural sensitization' has been argued to reflect an affective pathway to psychosis that underlies a more reactive, episodic type of psychosis that characterizes a subgroup of patients with predominantly positive psychotic symptoms ${ }^{41}$. Results in chapter 4 showed that symptomatic stress reactivity for stressful activities was stronger in CHR patients than in long-term psychotic disorder patients, although the other two recent studies did not find differences between CHR-Ps and (first episode) psychotic patients ${ }^{39}, 40$. Behavioural sensitization thus occurs before onset of psychotic disorder and is not just the result of chronic psychotic illness.

The ESM study in chapter $\mathbf{5}$ is the first to examine the phenomenology of positive (subclinical) psychotic symptoms in daily life, thereby expanding our knowledge about the characteristics of these symptoms. Our results highlight the existence of similarities and differences between CHR-P and FEP patients regarding the prevalence and dynamics of suspiciousness and hallucinations in daily life and their dynamic relationships with mood, anxiety and self-esteem as such providing targets for early interventions. 


\section{Expanding the experience sampling method to clinical practice}

In scientific studies, important information regarding inter-individual and intra-individual differences is lost due to averaging data over groups. This is illustrated by a previous study where rather than performing group comparisons, particular symptoms patterns and internal and contextual triggers for paranoia were examined per individual ${ }^{24}$. Whereas previous studies 22,25 and our study in chapter $\mathbf{5}$ showed that paranoia is related to increased anxiety levels at group level, the study of Oorschot and colleagues ${ }^{24}$ focussed on emotions preceding and following paranoia in each individual and found that both the emotional state preceding paranoid thoughts and the emotional impact of these thoughts showed large and meaningful variation between individuals with psychotic disorder patients. In some, emotional changes preceded paranoia whereas anxiety resulted from having paranoid thoughts in others. For others, paranoia was followed by a state of relaxation. In addition, results of this particular study also pointed out the importance of intra-individual differences in symptoms in the flow of daily life. It was shown that whereas one patient had a clear 'peak' in paranoia-level and low paranoia intensity during the rest of the day, another reported a steady medium paranoia-level throughout the day. However, by averaging these scores as is done in group comparisons this resulted in an overall medium daily paranoia level for both patients, obscuring clinically relevant information.

These results clearly highlight the value of ESM as an additional diagnostic tool in regular clinical practice. It allows tailoring of diagnosis and treatment planning to the needs of a specific patient and treatment monitoring. Rapid feedback is now available due to data collection via smart phone applications, which have also simplified the user experience and reduced the logistic burden of data collection and analysis. This allows ESM to be applied as an ecological momentary intervention (EMI) ${ }^{42,43}$. In a review of the EMIs in psychiatry it was found that few studies have investigated the possibilities and the efficacy. However, these studies underscored feasibility and acceptability of mobile health (mHealth) approaches in patients with severe mental illness. Importantly, EMIs provide the opportunity for intervening in dynamics of daily life between the individual and his/her environment that may be at the core of psychiatric symptom. Furthermore, an integration of EMI and real-life assessment using ESM seems to promote greater efficacy, especially when the intervention can be provided in moments when intervention is needed ${ }^{44}$. Finally, it has been argued that costs may be reduced and outcomes may be improved by implication of blended care in which face-to-face treatment is combined with ESM-based intervention in daily life to enhance application of psychological inter- 
ventions under real-world conditions ${ }^{42}$. ESM offers the opportunity to enhance self-monitoring, self-insight and personalized health care, and the results of studies in this thesis suggest that EMIs should aim application of at stress reduction techniques in daily life in CHR-P and FEP patients. If stress reactivity is subsequently reduced this might reduce the occurrence of suspicious feelings and hallucinations, which in turn will have a positive effect on mood and prevent strong decreases of self-esteem which often occurs during these symptoms and reduce anxiety.

\section{Beyond the high-risk for psychosis state: importance of a broad clinical staging ap- proach of mental disorders}

In order to promote early detection of individuals at high risk for the development and active intervention with the goals to delay or even prevent onset of first episode psychotic disorder the Clinical High-Risk state for psychosis (CHR-P) paradigm was introduced about 2 decades ago. It has accumulated a lot of knowledge on subclinical psychotic symptoms and risk factors for psychosis development. The transition rate of up to $29 \%$ of CHR-P patients at 2-year follow-up and of $36 \%$ after 3 years ${ }^{45}, 46$ and the finding that $\sim 70 \%$ of CHR-P patients develop schizophrenic psychoses ${ }^{47}$, makes this CHR-P state a specific marker for research on predictors and mechanisms of developing psychosis ${ }^{48}$. This average transition rate of $36 \%$ after three years suggest that current CHR-P criteria, emphasizing onset or worsening of subclinical psychotic symptoms, are still insufficient in predicting imminent onset of psychosis and thus in need of refinement ${ }^{49}$. Recently, the CHR-P paradigm has also been critiqued on other points ${ }^{14}$, among them that the focus lies solely on 'risk' and 'transition' and that by doing so any subclinical positive symptoms are implicitly treated as a pathway to schizophrenia and imminent bad outcome. It has also been argued that determining psychosis risk solely on the presence of subclinical psychotic symptoms is too restrictive, transition rates are only high because of sample enrichment strategies rather than the criteria themselves, and differential outcomes other than transition (i.e. remission and persistence of subclinical symptoms) as well as the presence of other psychopathological symptoms as markers of relative poor outcome of multidimensional psychopathology in terms of functioning have been largely ignored. Furthermore, the fact that CHR-P patients are help-seeking limits their epidemiologically representativeness for the broad range of psychotic experiences and subclinical symptoms in the general population of which not all are associated with distress or other forms of psychopathology. Finally, referring to CHR-P patients as if they are a class is not warranted as samples differ widely due to different sampling strategies and exclusion criteria across studies regarding previous use of anti-psychotic medication, mood 
stabilizers, presence of manic symptoms and previous drug-induced psychotic states, which strongly limits generalisability of findings.

However, while these methodological concerns certainly demand attention and improvement, the other concerns raised have certainly been noted before ${ }^{50}$ and CHR-P researchers have acknowledged that the specific focus on psychosis is too narrow and epidemiologically incomplete. The need to refine criteria has prompted investigation of other factors than subclinical positive psychotic symptoms that might be predictive for transition including social and role functioning and negative symptoms, both found to predict transition and low functioning over time ${ }^{51-54}$. In addition, recent studies ${ }^{55-57}$ have shown that the 3 subgroups making up the CHR-P state differ in their risk for transition, with the BLIPS group having the highest risk followed by the subclinical symptoms group while the genetic vulnerability group was not associated with an increased transition rate compared to the group not meeting CHR-P criteria. However, by focussing on outcomes broader than transition, a very recent study showed that all 3 subgroups did not differ on severity of baseline negative symptoms or long-term non-transition outcomes including positive and negative symptom severity, psychosocial functioning and prevalence of non-psychotic disorders at follow-up ${ }^{58}$. This led the authors to suggest that when the CHR-P construct is viewed not simply as a marker of psychosis, but rather as a transdiagnostic risk state signifying need for clinical care, their findings do not support segregation of CHR-P groups into separate clinical entities as proposed based on the findings of differential transition risk ${ }^{55,59}$. Finally, the combined results of a number of studies indicate that the positive symptom category of thought disorder/conceptual disorganization may constitute a robust clinical predictor of transition in CHR-P sample ${ }^{60-66}$. In line with these findings a recent study found that prediction of onset of psychosis was improved by using a state-dependent prognostic model which included the negative psychotic symptoms of observed flattened affect and subjective impaired motor functioning, impaired social functioning and distress associated with suspiciousness ${ }^{49}$.

In recent years an increasing number of studies have investigated outcomes other than transition and focus has shifted to factors associated with low functioning. It has become apparent over the last decade that clinical implications of CHR-P status extend beyond risk of transition to psychosis. Most individuals who meet CHR-P criteria will not develop a psychotic disorder ${ }^{46,57,67}$ but will experience persistent subclinical psychotic symptoms ${ }^{67,68}$, large impairments in psychosocial functioning and quality of life, similar to those in other psychiatric disorders ${ }^{69,70}$ and high rates of non-psychotic, especially 
mood and anxiety symptoms and disorders ${ }^{68,70,71}$ which all warrant treatment in their own right, while only in $35 \%$ of individuals subclinical symptoms will fully remit ${ }^{72}$. Such findings have already driven a reframing of CHR-P as a clinical state signifying pluripotent, transdiagnostic risk and the need for clinical care, rather than simply a marker of psychosis risk and are in line with the clinical staging model of psychiatry ${ }^{50,73-79}$.

This model positions an individual along a continuum of illness which is defined according to stages: Stage 0: no current symptoms, Stage 1a: help-seeking with distress, Stage 1b: subclinical syndrome and Stages 2 to 4 : full threshold disorder with varying degrees of recurrence and severity ${ }^{76,77}$. In this broad model of staging in psychiatry the focus is shifted from the narrow focus in the CHR-P paradigm to a general syndrome of early mental distress requiring non-specific psychological self-management interventions to prevent more severe stages of psychopathology which includes the CHR-P state (stage 1b), which may develop in more specific, and relatively treatment-resistant, syndromes later on. This allows for the introduction of stage-specific treatments, varying from non-specific non-pharmacological self-management approaches in the early stages to more active treatments in the advanced stages ${ }^{50,75}$. It offers a conceptual framework than can guide the search for risk and protective factors for disease progression from incidental non-distressing PLEs in the general population to psychotic symptoms in longterm psychotic disorder patients.

Importantly, the general staging model allows for overlap in symptoms of different diagnostic outcomes in a particular individual, which is common especially in the earlier phases of disease progression but is not recognized by the current diagnostic criteria. This is also apparent for psychosis as studies have shown the existence of an important link between mood and anxiety symptoms and psychosis, which is found at the level of clinical illness ${ }^{80-82}$, subclinical psychotic symptoms ${ }^{83-85}$ and PLEs ${ }^{16,86-91}$, and many studies have suggested an important role for affective dysregulation in the formation of psychotic symptoms ${ }^{41,92-94}$. The results of chapter 3 add evidence to the transdiagnostic nature of psychosis as we found that genetic risk for psychosis reflected by PRS is not only expressed as subclinical psychotic symptoms, but also as affective dysregulation in the form of positive associations between PRS and the lifetime number of affective episodes in both unaffected first-degree relatives and healthy controls. This finding is in line with molecular genetic studies that suggest overlap between schizophrenia and affective disorders ${ }^{95,96}$. 


\section{Early identification of subclinical psychotic symptoms: when and where?}

Psychotic disorder has an enormous impact on the lives of patients and their loved ones, and even subclinical psychotic symptoms are often distressing. In addition, many individuals meeting CHR-P criteria have clinically debilitating symptoms of comorbid diagnoses, including anxiety, depression and substance abuse. Similar to psychotic disorder patients, CHR-P individuals are often characterised by high neuroticism and high levels of negative symptoms and significant impairments in academic performance and occupational functioning, difficulties with interpersonal relationships and a substantially compromised subjective quality of life ${ }^{97-102}$. Therefore, identification and intervention should happen as early as possible. Importantly, whereas extension of screening with self-report measures to help-seeking individuals in primary mental health care will help to detect individuals for whom subclinical psychotic symptoms are distressing and are at increased risk for psychotic disorder, extending early detection to non-help seeking populations by for example screening adolescents in schools or via the internet will not be efficient ${ }^{103}$. Given that psychotic experiences are reasonably common and mostly non-distressing in the general population ${ }^{104,105}$ and adolescents in particular ${ }^{12,15}$, and the study of van Nierop and colleagues ${ }^{7}$ has shown that psychotic experiences not validated by clinical interview (FP SPRE) were about 2 times more prevalent than confirmed psychotic symptoms, it can be argued that the detection of some people who are genuinely at risk will be at the cost of valuable resources invested in a high amount of clinical interviews of individuals whom are not distressed by or seeking help for these experiences in which it might trigger the development of self-perceived stigma. Taken together, early identification and intervention of subclinical psychotic symptoms is important and screening with short screening instrument like the Prodromal Questionnaire ${ }^{106}$ or CAPE- $15^{107}$ should be widely implemented in mental health care practice. In the Netherlands, the EDIE-NL project ${ }^{108}$ has resulted in implementation of the screening approach in all help-seeking patients in some of the large mental health services throughout the country. A positive score on the screening is followed by clinical interview to determine presence of CHR-P state or psychosis.

\section{Clinical implications and directions for future research}

Early intervention can be enhanced by gaining more insight in mechanisms and factors that determine increasing levels of subclinical psychotic symptoms and the eventual development of psychosis. Several studies of CHR-P patients have found low social functioning to be predictive for the development of psychosis. The study presented in chapter $\mathbf{2}$ further highlights the importance of targeting low social functioning in early 
interventions as it showed that individuals who developed future psychotic symptoms were already characterised by deterioration in social functioning. Social skills training and family involvement to create a supportive environment can help to improve social functioning ${ }^{109}$ which in turn might prevent further development of psychotic symptoms. Chapter $\mathbf{2}$ furthermore showed that individuals with baseline FP SRPE who subsequently developed psychotic symptoms were characterised by the personality trait of high neuroticism, which is a tendency to show emotional instability, and react with increased anxiety, fear, and sadness ${ }^{110}$. In addition, high neuroticism was the strongest predictor for the continued self-report of psychotic experiences. Given that psychotic patients with high neuroticism tend to have more severe and distressing positive symptoms ${ }^{111}$ and both psychotic and CHR-P patients often use ineffective coping styles under stress ${ }^{110}$, 111 that can even enhance symptoms ${ }^{112}$, and use of adequate strategies has been found to improve psychotic symptoms ${ }^{113}$, interventions that help CHR patients to develop and apply adequate coping strategies are likely to be effective.

Increased emotional stress reactivity in daily life can be regarded as an expression of the high neuroticism trait and chapter $\mathbf{4}$ provided evidence that increased emotional stress reactivity in daily life not only characterizes psychotic disorder patients but is present in CHR-P patients. This effect was even stronger than in long-term psychotic disorder patients. In line with psychological models on psychosis development ${ }^{92,94}$ and based on all findings we can conclude that increased emotional stress reactivity plays an important role in the development and maintenance of psychotic symptoms, particularly in the at-risk phase. Whether increased emotional stress reactivity is truly a causal mechanism underlying the affective pathway to psychosis remains to be examined. Future studies are needed to investigate whether CHR-P patients that convert are characterised by higher emotional stress reactivity than those who do not.

Finally, the ESM studies in chapter 4 and chapter 5 both provided evidence that (subclinical) psychotic symptoms are distressing. Detailed analysis of the temporal dynamics of suspiciousness and hallucinations showed that both are associated with increases in anxiety, negative affect and a decrease in positive affect and self-esteem. In the Dutch EDIE-NL early intervention protocol, CHR-P patients receive Cognitive Behavioural Therapy (CBT) that focusses on broad psychoeducation on dopamine sensitization and the effects on perception and reasoning, exercises to become aware of cognitive biases and to correct these, behavioural experiments and homework task in addition to care as usual for other mental health problems. CBT targets appraisal processes that accompany 
perceptual aberrations and suspiciousness to normalize these extraordinary experiences in order to prevent delusion formation and avoidance behaviours that consolidate symptoms.

In contrast to this traditional CBT protocol in which treatment focusses directly on the presence and content of (subclinical) psychotic symptoms, the newest generation of contextual CBTs puts high emphasis on the context and includes Acceptance and Commitment Therapy (ACT). ACT may be an effective treatment strategy as it encourages detached acceptance of unpleasant thoughts and experiences. Although more research is needed, results of pilot studies of ACT in psychotic disorder patients showed positive effects $^{114-116}$. Furthermore, a recent feasibility study in a sample of general outpatient population showed that ACT in daily life was an acceptable and feasible mHealth intervention, suitable for a broad range of mental health problems ${ }^{117}$. Currently, the effectiveness of a newly developed ecological momentary intervention that targets elevated stress sensitivity, altered reward-experience, and psychological flexibility based on principles of ACT in CHR-P patients is being evaluated. This ongoing ACT in daily life study extends standard ACT therapy with real life training and exercises through a dedicated device, thereby enhancing participants' ACT-based skills and techniques. If found to be effective, ACT can serve as a valuable alternative for patients who benefit less from CBT.

Finally, as discussed previously, ESM can now be used as a diagnostic tool to examine the dynamics of psychotic symptoms, mood, self-esteem and social factors for each individual patient. ESM can also be applied to monitor treatment progress, by investigating the effect on symptoms as well as mood, social functioning and quality of life. However, the studies in chapter $\mathbf{4}$ and chapter $\mathbf{5}$ used items to examine psychotic symptoms that were previously developed for psychotic disorder patients. Especially the item investigating auditory hallucinations needs refinement for the CHR-P population, as these are mostly characterised by subtle auditory alterations. The current item 'I hear voices' might have resulted in CHR-P patient not reporting other, more subtle forms of auditory disturbances, which implies that current results might reflect a underestimation of the prevalence of these experiences in individuals with subclinical symptoms. Refined items need to be developed and validated in both individuals with subclinical symptoms and psychotic disorder patients in order to improve not only ESM in psychosis research and clinical practice. 


\section{REFERENCES}

1. Fusar-Poli P, Raballo A, Parnas J. What Is an Attenuated Psychotic Symptom? On the Importance of the Context. Schizophr Bull. 2017; 43:687-692.

2. Granö N, Kallionpää S, Karjalainen M, Roine M, Ranta K, Heinimaa M. Discrepancy between self-reported and interviewed psychosis risk symptoms: auditory distortions are the most reliably reported symptom by self-report. Early Interv Psychiatry. 2016; 10:129-136.

3. Granö N, Karjalainen M, Itkonen A, Anto J, Edlund V, Heinimaa M, Roine M. Differential results between self-report and interview-based ratings of risk symptoms of psychosis. Early Interv Psychiatry. 2011; 5:309-314.

4. Kelleher I, Harley M, Murtagh A, Cannon M. Are screening instruments valid for psychotic-like experiences? A validation study of screening questions for psychotic-like experiences using in-depth clinical interview. Schizophr Bull. 2011; 37:362-369.

5. Linscott RJ, van Os J. Systematic reviews of categorical versus continuum models in psychosis: evidence for discontinuous subpopulations underlying a psychometric continuum. Implications for DSM-V, DSMVI, and DSM-VII. Annu Rev Clin Psychol. 2010; 6:391-419.

6. Linscott RJ, van Os J. An updated and conservative systematic review and meta-analysis of epidemiological evidence on psychotic experiences in children and adults: on the pathway from proneness to persistence to dimensional expression across mental disorders. Psychol Med. 2013; 43:1133-1149.

7. van Nierop M, van Os J, Gunther N, Myin-Germeys I, de Graaf R, ten Have M, ... van Winkel R. Phenotypically continuous with clinical psychosis, discontinuous in need for care: evidence for an extended psychosis phenotype. Schizophr Bull. 2012; 38:231-238.

8. Schultze-Lutter F, Renner F, Paruch J, Julkowski D, Klosterkotter J, Ruhrmann S. Self-reported psychotic-like experiences are a poor estimate of clinician-rated attenuated and frank delusions and hallucinations. Psychopathology. 2014; 47:194-201.

9. Ochoa S, Haro JM, Torres JV, Pinto-Meza A, Palacin C, Bernal M, . . . Autonell J. What is the relative importance of self reported psychotic symptoms in epidemiological studies? Results from the ESEMeD--Catalonia Study. Schizophr Res. 2008; 102:261-269.

10. Konings M, Bak M, Hanssen M, van Os J, Krabbendam L. Validity and reliability of the CAPE: a self-report instrument for the measurement of psychotic experiences in the general population. Acta Psychiatr Scand. 2006; 114:55-61.

11. Yung AR, Buckby JA, Cotton SM, Cosgrave EM, Killackey EJ, Stanford C, . . McGorry PD. Psychotic-Like Experiences in Nonpsychotic Help-Seekers: Associations With Distress, Depression, and Disability. Schizophr Bull. 2006; 32:352-359.

12. Yung AR, Nelson B, Baker K, Buckby JA, Baksheev G, Cosgrave EM. Psychotic-like experiences in a community sample of adolescents: implications for the continuum model of psychosis and prediction of schizophrenia. Aust N Z J Psychiatry. 2009; 43:118-128.

13. Bak M, Delespaul P, Hanssen M, de Graaf R, Vollebergh W, van Os J. How false are "false" positive psychotic symptoms? Schizophr Res. 2003; 62:187-189.

14. van Os J, Guloksuz S. A critique of the "ultra-high risk" and "transition" paradigm. World Psychiatry. 2017; 16:200-206.

15. Kelleher I, Connor D, Clarke MC, Devlin N, Harley M, Cannon M. Prevalence of psychotic symptoms in childhood and adolescence: a systematic review and meta-analysis of population-based studies. Psychol Med. 2012; 42:1857-1863.

16. Wigman JTW, van Nierop M, Vollebergh WAM, Lieb R, Beesdo-Baum K, Wittchen H-U, van Os J. Evidence That Psychotic Symptoms Are Prevalent in Disorders of Anxiety and Depression, Impacting on Illness Onset, Risk, and Severity-Implications for Diagnosis and Ultra-High Risk Research. Schizophr Bull. 2012; 38:247-257.

17. Csikszentmihalyi M, Larson R. Validity and Reliability of the Experience-Sampling Method. J Nerv Ment Dis. 1987; 175:526-536.

18. Delespaul P. Assessing schizophrenia in daily life. Maastricht: Universitaire Pers; 1995.

19. Oorschot M, Kwapil T, Delespaul P, Myin-Germeys I. Momentary assessment research in psychosis. Psychol Assess. 2009; 21:498-505. 
20. Delespaul P, deVries M, van Os J. Determinants of occurrence and recovery from hallucinations in daily life. Soc Psychiatry Psychiatr Epidemiol. 2002; 37:97-104.

21. Myin-Germeys I, Nicolson NA, Delespaul PA. The context of delusional experiences in the daily life of patients with schizophrenia. Psychol Med. 2001a; 31:489-498.

22. Oorschot M, Lataster T, Thewissen V, Bentall R, Delespaul P, Myin-Germeys I. Temporal dynamics of visual and auditory hallucinations in psychosis. Schizophr Res. 2012b; 140:77-82.

23. Oorschot M, Lataster T, Thewissen V, Lardinois M, van Os J, Delespaul P, Myin-Germeys I. Symptomatic remission in psychosis and real-life functioning. Br J Psychiatry. 2012; 201:215-220.

24. Oorschot M, Lataster T, Thewissen V, Wichers M, Myin-Germeys I. Mobile assessment in schizophrenia: a data-driven momentary approach. Schizophr Bull. 2012a; 38:405-413.

25. Peters E, Lataster T, Greenwood K, Kuipers E, Scott J, Williams S, . . Myin-Germeys I. Appraisals, psychotic symptoms and affect in daily life. Psychol Med. 2012; 42:1013-1023.

26. Thewissen V, Bentall RP, Oorschot M, à Campo J, van Lierop T, van Os J, Myin-Germeys I. Emotions, self-esteem, and paranoid episodes: An experience sampling study. Br J Clin Psychol. 2011; 50:178-195.

27. Gard DE, Kring AM, Gard MG, Horan WP, Green MF. Anhedonia in schizophrenia: Distinctions between anticipatory and consummatory pleasure. Schizophr Res. 2007; 93:253-260.

28. Myin-Germeys I, Delespaul PA, deVries MW. Schizophrenia patients are more emotionally active than is assumed based on their behavior. Schizophr Bull. 2000; 26:847-854.

29. Oorschot M, Lataster T, Thewissen V, Lardinois M, Wichers M, van Os J, . . Myin-Germeys I. Emotional Experience in Negative Symptoms of Schizophrenia-No Evidence for a Generalized Hedonic Deficit. Schizophr Bull. 2013; 39:217-225.

30. Schneider $M$, Reininghaus $U$, van Nierop $M$, Janssens $M$, Myin-Germeys I. Does the Social Functioning Scale reflect real-life social functioning? An experience sampling study in patients with a non-affective psychotic disorder and healthy control individuals. Psychol Med. 2017; 47:2777-2786.

31. Reininghaus U, Depp CA, Myin-Germeys I. Ecological Interventionist Causal Models in Psychosis: Targeting Psychological Mechanisms in Daily Life. Schizophr Bull. 2016; 42:264-269.

32. Myin-Germeys I, van Os J, Schwartz JE, Stone AA, Delespaul P. Emotional reactivity to daily life stress in psychosis. Arch Gen Psychiatry. 2001b; 58:1137-1144.

33. Lataster T, Valmaggia L, Lardinois M, van Os J, Myin-Germeys I. Increased stress reactivity: a mechanism specifically associated with the positive symptoms of psychotic disorder. Psychol Med. 2013; 43:13891400.

34. Palmier-Claus JE, Dunn G, Taylor H, Morrison AP, Lewis SW. Cognitive-self consciousness and metacognitive beliefs: Stress sensitization in individuals at ultra-high risk of developing psychosis. $\mathrm{Br} J$ Clin Psychol. 2013; 52:26-41.

35. Palmier-Claus JE, Dunn G, Morrison AP, Lewis SW. The role of metacognitive beliefs in stress sensitisation, self-esteem variability, and the generation of paranoia. Cogn Neuropsychiatry. 2011; 16:530-546.

36. Thewissen V, Bentall RP, Lecomte T, van Os J, Myin-Germeys I. Fluctuations in self-esteem and paranoia in the context of daily life. J Abnorm Psychol. 2008; 117:143-153.

37. Lardinois M, Myin-Germeys I, Bak M, Mengelers R, Van Os J, Delespaul PAEG. The dynamics of symptomatic and non-symptomatic coping with psychotic symptoms in the flow of daily life. Acta Psychiatr Scand. 2007; 116:71-75.

38. Ben-Zeev D, Ellington K, Swendsen J, Granholm E. Examining a Cognitive Model of Persecutory Ideation in the Daily Life of People With Schizophrenia: A Computerized Experience Sampling Study. Schizophr Bull. 2011; 37:1248-1256.

39. Reininghaus U, Kempton MJ, Valmaggia L, Craig TKJ, Garety P, Onyejiaka A, . . Morgan C. Stress Sensitivity, Aberrant Salience, and Threat Anticipation in Early Psychosis: An Experience Sampling Study. Schizophr Bull. 2016; 42:712-722.

40. Palmier-Claus JE, Dunn G, Lewis SW. Emotional and symptomatic reactivity to stress in individuals at ultra-high risk of developing psychosis. Psychol Med. 2012; 42:1003-1012.

41. Myin-Germeys I, van Os J. Stress-reactivity in psychosis: evidence for an affective pathway to psychosis. Clin Psychol Rev. 2007; 27:409-424.

42. van Os J, Verhagen S, Marsman A, Peeters F, Bak M, Marcelis M, ... Delespaul P. The experience sampling method as an mHealth tool to support self-monitoring, self-insight, and personalized health care in clinical practice. Depress Anxiety. 2017; 34:481-493. 
43. Verhagen SJ, Hasmi L, Drukker M, van Os J, Delespaul PA. Use of the experience sampling method in the context of clinical trials. Evidence-based mental health. 2016; 19:86-89.

44. Myin-Germeys I, Klippel A, Steinhart H, Reininghaus U. Ecological momentary interventions in psychiatry. Curr Opin Psychiatry. 2016; 29:258-263.

45. Schmidt SJ, Schultze-Lutter F, Schimmelmann BG, Maric NP, Salokangas RKR, Riecher-Rössler A, ... Ruhrmann S. EPA guidance on the early intervention in clinical high risk states of psychoses. Eur Psychiatry. 2015; 30:388-404.

46. Fusar-Poli P, Bonoldi I, Yung AR, Borgwardt S, Kempton MJ, Valmaggia L, . . Mcguire P. Predicting psychosis: Meta-analysis of transition outcomes in individuals at high clinical risk. Arch Gen Psychiatry. 2012; 69:220-229.

47. Fusar-Poli P, Bechdolf A, Taylor MJ, Bonoldi I, Carpenter WT, Yung AR, McGuire P. At Risk for Schizophrenic or Affective Psychoses? A Meta-Analysis of DSM/ICD Diagnostic Outcomes in Individuals at High Clinica Risk. Schizophr Bull. 2013; 39:923-932.

48. Webb JR, Addington J, Perkins DO, Bearden CE, Cadenhead KS, Cannon TD, . . Woods SW. Specificity of Incident Diagnostic Outcomes in Patients at Clinical High Risk for Psychosis. Schizophr Bull. 2015; 41:1066-1075.

49. Ising HK, Ruhrmann S, Burger NA, Rietdijk J, Dragt S, Klaassen RM, . . van der Gaag M. Development of a stage-dependent prognostic model to predict psychosis in ultra-high-risk patients seeking treatment for co-morbid psychiatric disorders. Psychol Med. 2016; 46:1839-1851.

50. Fusar-Poli P, Yung AR, McGorry P, van Os J. Lessons learned from the psychosis high-risk state: towards a general staging model of prodromal intervention. Psychol Med. 2014; 44:17-24.

51. Carrion RE, McLaughlin D, Goldberg TE, Auther AM, Olsen RH, Olvet DM, ... Cornblatt BA. Prediction of functional outcome in individuals at clinical high risk for psychosis. JAMA Psychiatry. 2013; 70:1133-1142.

52. Cornblatt BA, Carrion RE, Addington J, Seidman L, Walker EF, Cannon TD, . . . Lencz T. Risk factors for psychosis: impaired social and role functioning. Schizophr Bull. 2012; 38:1247-1257.

53. Fusar-Poli P, Byrne M, Valmaggia L, Day F, Tabraham P, Johns L, McGuire P. Social dysfunction predicts two years clinical outcome in people at ultra high risk for psychosis. J Psychiatr Res. 2010; 44:294-301.

54. Valmaggia LR, Stahl D, Yung AR, Nelson B, Fusar-Poli P, McGorry PD, McGuire PK. Negative psychotic symptoms and impaired role functioning predict transition outcomes in the at-risk mental state: a latent class cluster analysis study. Psychol Med. 2013; 43:2311-2325.

55. Fusar-Poli P, Cappucciati M, Borgwardt S, et al. Heterogeneity of psychosis risk within individuals at clinical high risk: A meta-analytical stratification. JAMA Psychiatry. 2016; 73:113-120.

56. Nelson B, Yuen K, Yung AR. Ultra high risk (UHR) for psychosis criteria: Are there different levels of risk for transition to psychosis? Schizophr Res. 2011; 125:62-68.

57. Nelson B, Yuen H, Wood SJ, et al. Long-term follow-up of a group at ultra high risk ("prodromal") for psychosis: The pace 400 study. JAMA Psychiatry. 2013; 70:793-802.

58. McHugh MJ, McGorry PD, Yuen HP, Hickie IB, Thompson A, de Haan L, . . Nelson B. The Ultra-High-Risk for psychosis groups: Evidence to maintain the status quo. Schizophr Res. in press.

59. Schultze-Lutter F, Michel C, Schmidt SJ, Schimmelmann BG, Maric NP, Salokangas RKR, . . Klosterkötter J. EPA guidance on the early detection of clinical high risk states of psychoses. Eur Psychiatry. 2015; 30:405416.

60. Addington J, Liu L, Buchy L, Cadenhead KS, Cannon TD, Cornblatt BA, ... McGlashan TH. North American Prodrome Longitudinal Study (NAPLS 2): The Prodromal Symptoms. J Nerv Ment Dis. 2015; 203:328-335.

61. Armando M, Pontillo M, De Crescenzo F, Mazzone L, Monducci E, Lo Cascio N, . . . Schultze-Lutter F. Twelve-month psychosis-predictive value of the ultra-high risk criteria in children and adolescents. Schizophr Res. 2015; 169:186-192.

62. Cornblatt BA, Carrion RE, Auther A, McLaughlin D, Olsen RH, John M, Correll CU. Psychosis Prevention: A Modified Clinical High Risk Perspective From the Recognition and Prevention (RAP) Program. Am J Psychiatry. 2015; 172:986-994.

63. Demjaha A, Valmaggia L, Stahl D, Byrne M, McGuire P. Disorganization/Cognitive and Negative Symptom Dimensions in the At-Risk Mental State Predict Subsequent Transition to Psychosis. Schizophr Bull. 2012; 38:351-359. 
64. DeVylder JE, Muchomba FM, Gill KE, Ben-David S, Walder DJ, Malaspina D, Corcoran CM. Symptom trajectories and psychosis onset in a clinical high-risk cohort: the relevance of subthreshold thought disorder. Schizophr Res. 2014; 159:278-283.

65. Hartmann JA, Yuen HP, McGorry PD, Yung AR, Lin A, Wood SJ, . . Nelson B. Declining transition rates to psychotic disorder in "ultra-high risk" clients: Investigation of a dilution effect. Schizophr Res. 2016; 170:130-136.

66. Raballo A, Nelson B, Thompson A, Yung A. The Comprehensive Assessment of At-Risk Mental States: From mapping the onset to mapping the structure. Schizophr Res. 2011; 127:107-114.

67. Simon $A E$, Velthorst $E$, Nieman $D H$, Linszen $D$, Umbricht $D$, de Haan L. Ultra high-risk state for psychosis and non-transition: A systematic review. Schizophr Res. 2011; 132:8-17.

68. de Wit S, Schothorst PF, Oranje B, Ziermans TB, Durston S, Kahn RS. Adolescents at ultra-high risk for psychosis: long-term outcome of individuals who recover from their at-risk state. Eur Neuropsychopharmacol. 2014; 24:865-873.

69. Fusar-Poli P, Rocchetti M, Sardella A, Avila A, Brandizzi M, Caverzasi E, . . . McGuire P. Disorder, not just state of risk: meta-analysis of functioning and quality of life in people at high risk of psychosis. Br J Psychiatry. 2015; 207:198-206.

70. Rutigliano G, Valmaggia L, Landi P, Frascarelli M, Cappucciati M, Sear V, . . Fusar-Poli P. Persistence or recurrence of non-psychotic comorbid mental disorders associated with 6-year poor functional outcomes in patients at ultra high risk for psychosis. J Affect Disord. 2016; 203:101-110.

71. Lin A, Wood SJ, Nelson B, Beavan A, McGorry P, Yung AR. Outcomes of nontransitioned cases in a sample at ultra-high risk for psychosis. Am J Psychiatry. 2015; 172:249-258.

72. Simon AE, Borgwardt S, Riecher-Rössler A, Velthorst E, de Haan L, Fusar-Poli P. Moving beyond transition outcomes: Meta-analysis of remission rates in individuals at high clinical risk for psychosis. Psychiatry Res. 2013; 209:266-272.

73. Appels MCM, Sitskoorn MM, Vollema MG, Kahn RS. Elevated Levels of Schizotypal Features in Parents of Patients With a Family History of Schizophrenia Spectrum Disorders. Schizophr Bull. 2004; 30:781-790.

74. McGorry P, Nelson B. Why we need a transdiagnostic staging approach to emerging psychopathology, early diagnosis, and treatment. JAMA Psychiatry. 2016; 73:191-192.

75. McGorry P, van Os J. Redeeming diagnosis in psychiatry: timing versus specificity. The Lancet. 2013; 381:343-345.

76. McGorry PD, Hickie IB, Yung AR, Pantelis C, Jackson HJ. Clinical Staging of Psychiatric Disorders: A Heuristic Framework for Choosing Earlier, Safer and more Effective Interventions. Aust N Z J Psychiatry. 2006; 40:616-622.

77. McGorry PD, Nelson B, Goldstone S, Yung AR. Clinical Staging: A Heuristic and Practical Strategy for New Research and Better Health and Social Outcomes for Psychotic and Related Mood Disorders. Can J Psychiatry. 2010; 55:486-497.

78. van Os J. The dynamics of subthreshold psychopathology: implications for diagnosis and treatment. Am J Psychiatry. 2013; 170:695-698.

79. Yung AR, Woods SW, Ruhrmann S, Addington J, Schultze-Lutter F, Cornblatt BA, ... McGlashan TH. Whither the attenuated psychosis syndrome? Schizophr Bull. 2012; 38:1130-1134.

80. McMillan KA, Enns MW, Cox BJ, Sareen J. Comorbidity of Axis I and II mental disorders with schizophrenia and psychotic disorders: findings from the National Epidemiologic Survey on Alcohol and Related Conditions. Can J Psychiatry. 2009; 54:477-486.

81. Reininghaus U, Bohnke JR, Hosang G, Farmer A, Burns T, McGuffin P, Bentall RP. Evaluation of the validity and utility of a transdiagnostic psychosis dimension encompassing schizophrenia and bipolar disorder. $\mathrm{Br}$ J Psychiatry. 2016; 209:107-113.

82. Reininghaus U, Priebe S, Bentall RP. Testing the Psychopathology of Psychosis: Evidence for a General Psychosis Dimension. Schizophr Bull. 2013; 39:884-895.

83. Fusar-Poli P, Nelson B, Valmaggia L, Yung AR, McGuire PK. Comorbid Depressive and Anxiety Disorders in 509 Individuals With an At-Risk Mental State: Impact on Psychopathology and Transition to Psychosis. Schizophr Bull. 2014; 40:120-131.

84. Rietdijk J, Ising HK, Dragt S, Klaassen R, Nieman D, Wunderink L, . . van der Gaag M. Depression and social anxiety in help-seeking patients with an ultra-high risk for developing psychosis. Psychiatry Res. 2013; 209:309-313. 
85. Gaudiano BA, Zimmerman M. Prevalence of attenuated psychotic symptoms and their relationship with DSM-IV diagnoses in a general psychiatric outpatient clinic. J Clin Psychiatry. 2013; 74:149-155.

86. Hanssen M, Peeters F, Krabbendam L, Radstake S, Verdoux H, van Os J. How psychotic are individuals with non-psychotic disorders? Soc Psychiatry Psychiatr Epidemiol. 2003; 38:149-154.

87. Krabbendam L, Myin-Germeys I, De Graaf R, Vollebergh W, Nolen WA, ledema J, Van Os J. Dimensions of depression, mania and psychosis in the general population. Psychol Med. 2004; 34:1177-1186.

88. Krabbendam L, Myin-Germeys I, Hanssen M, de Graaf R, Vollebergh W, Bak M, van Os J. Development of depressed mood predicts onset of psychotic disorder in individuals who report hallucinatory experiences. Br J Clin Psychol. 2005; 44:113-125.

89. Krabbendam L, van Os J. Affective processes in the onset and persistence of psychosis. Eur Arch Psychiatry Clin Neurosci. 2005; 255:185-189.

90. Stochl J, Khandaker GM, Lewis G, Perez J, Goodyer IM, Zammit S, . . Jones PB. Mood, anxiety and psychotic phenomena measure a common psychopathological factor. Psychol Med. 2015; 45:1483-1493.

91. Varghese D, Scott J, Welham J, Bor W, Najman J, O'Callaghan M, . . McGrath J. Psychotic-Like Experiences in Major Depression and Anxiety Disorders: A Population-Based Survey in Young Adults. Schizophr Bull. 2011; 37:389-393.

92. Freeman D, Garety PA. Connecting neurosis and psychosis: the direct influence of emotion on delusions and hallucinations. Behav Res Ther. 2003; 41:923-947.

93. Garety PA, Kuipers E, Fowler D, Freeman D, Bebbington PE. A cognitive model of the positive symptoms of psychosis. Psychol Med. 2001; 31:189-195.

94. Garety PA, Freeman D. Cognitive approaches to delusions: a critical review of theories and evidence. $B r \mathrm{~J}$ Clin Psychol. 1999; 38 ( Pt 2):113-154.

95. Cross-Disorder Group of the Psychiatric Genomics C, Lee SH, Ripke S, Neale BM, Faraone SV, Purcell SM, ... International Inflammatory Bowel Disease Genetics C. Genetic relationship between five psychiatric disorders estimated from genome-wide SNPs. Nat Genet. 2013; 45:984-994.

96. Cross-Disorder Group of the Psychiatric Genomics C. Identification of risk loci with shared effects on five major psychiatric disorders: a genome-wide analysis. Lancet. 2013; 381:1371-1379.

97. Addington J, Penn D, Woods SW, Addington D, Perkins DO. Social functioning in individuals at clinical high risk for psychosis. Schizophr Res. 2008; 99:119-124.

98. Bechdolf A, Pukrop R, Köhn D, Tschinkel S, Veith V, Schultze-Lutter F, . . Klosterkötter J. Subjective quality of life in subjects at risk for a first episode of psychosis: A comparison with first episode schizophrenia patients and healthy controls. Schizophr Res. 2005; 79:137-143.

99. Lencz T, Smith CW, Auther A, Correll CU, Cornblatt B. Nonspecific and attenuated negative symptoms in patients at clinical high-risk for schizophrenia. Schizophr Res. 2004; 68:37-48.

100. Piskulic D, Addington J, Cadenhead KS, Cannon TD, Cornblatt BA, Heinssen R, . . McGlashan TH. Negative symptoms in individuals at clinical high risk of psychosis. Psychiatry Res. 2012; 196:220-224.

101. Velthorst E, Nieman DH, Linszen D, Becker H, de Haan L, Dingemans PM, . . Ruhrmann S. Disability in people clinically at high risk of psychosis. Br J Psychiatry. 2010; 197:278-284.

102. Marshall C, Addington J, Epstein I, Liu L, Deighton S, Zipursky RB. Treating young individuals at clinical high risk for psychosis. Early Interv Psychiatry. 2012; 6:60-68.

103. Nelson B, Yuen HP, Lin A, Wood SJ, McGorry PD, Hartmann JA, Yung AR. Further examination of the reducing transition rate in ultra high risk for psychosis samples: The possible role of earlier intervention. Schizophr Res. 2016; 174:43-49.

104. Kaymaz N, Drukker M, Lieb R, Wittchen HU, Werbeloff N, Weiser M, . . van Os J. Do subthreshold psychotic experiences predict clinical outcomes in unselected non-help-seeking population-based samples? A systematic review and meta-analysis, enriched with new results. Psychol Med. 2012; 42:2239-2253.

105. van Os J, Linscott RJ, Myin-Germeys I, Delespaul P, Krabbendam L. A systematic review and meta-analysis of the psychosis continuum: evidence for a psychosis proneness-persistence-impairment model of psychotic disorder. Psychol Med. 2009; 39:179-195.

106. Ising HK, Veling W, Loewy RL, Rietveld MW, Rietdijk J, Dragt S, . . van der Gaag M. The Validity of the 16-Item Version of the Prodromal Questionnaire (PQ-16) to Screen for Ultra High Risk of Developing Psychosis in the General Help-Seeking Population. Schizophr Bull. 2012; 38:1288-1296. 
107. Bukenaite A, Stochl J, Mossaheb N, Schäfer MR, Klier CM, Becker J, . . . Amminger GP. Usefulness of the CAPE-P15 for detecting people at ultra-high risk for psychosis: Psychometric properties and cut-off values. Schizophr Res. 2017; 189:69-74.

108. van der Gaag M, Nieman DH, Rietdijk J, Dragt S, Ising HK, Klaassen RM, . . Linszen DH. Cognitive behavioral therapy for subjects at ultrahigh risk for developing psychosis: a randomized controlled clinical trial. Schizophr Bull. 2012; 38:1180-1188.

109. Thompson E, Millman ZB, Okuzawa N, Mittal V, DeVylder J, Skadberg T, . . Schiffman J. Evidence-based early interventions for individuals at clinical high risk for psychosis: a review of treatment components. $J$ Nerv Ment Dis. 2015; 203:342-351.

110. McCrae RR, Costa Jr PT, Martin TA. The NEO-PI-3: a more readable revised NEO Personality Inventory. J Pers Assess. 2005; 84:261-270.

111. So SH, Begemann MJ, Gong X, Sommer IE. Relationship between neuroticism, childhood trauma and cognitive-affective responses to auditory verbal hallucinations. Sci Rep. 2016; 6:34401.

112. Jalbrzikowski M, Sugar CA, Zinberg J, Bachman P, Cannon TD, Bearden CE. Coping styles of individuals at clinical high risk for developing psychosis. Early Interv Psychiatry. 2014; 8:68-76.

113. Kommescher M, Wagner M, Putzfeld V, Berning J, Janssen B, Decker P, . . Bechdolf A. Coping as a predictor of treatment outcome in people at clinical high risk of psychosis. Early Interv Psychiatry. 2016; 10:17-27.

114. Bach PA, Gaudiano B, Pankey J, Herbert JD, Hayes SC. Acceptance, Mindfulness, Values, and Psychosis: Applying Acceptance and Commitment Therapy (ACT) to the Chronically Mentally III. Mindfulness-based treatment approaches: Clinician's guide to evidence base and applications. San Diego, CA, US: Elsevier Academic Press; 2006:93-116.

115. Gaudiano BA, Herbert JD. Acute treatment of inpatients with psychotic symptoms using Acceptance and Commitment Therapy: Pilot results. Behav Res Ther. 2006; 44:415-437.

116. White R, Gumley A, McTaggart J, Rattrie L, McConville D, Cleare S, Mitchell G. A feasibility study of Acceptance and Commitment Therapy for emotional dysfunction following psychosis. Behav Res Ther. 2011; 49:901-907.

117. Batink T, Bakker J, Vaessen T, Kasanova Z, Collip D, van Os J, . . Peeters F. Acceptance and Commitment Therapy in Daily Life Training: A Feasibility Study of an mHealth Intervention. JMIR mHealth and uHealth. 2016; 4:e103. 


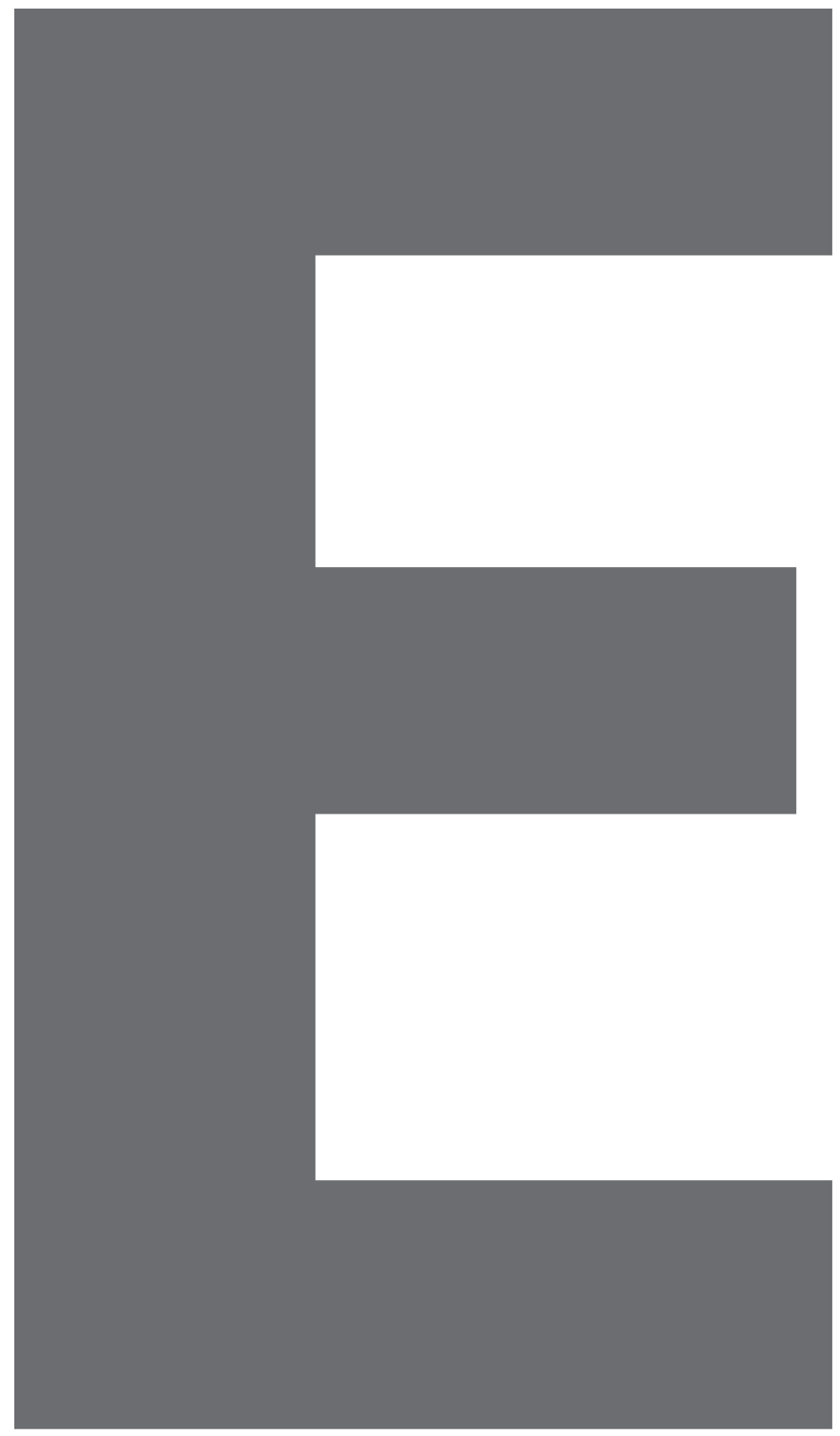




\section{Epilogue}

Summary

Samenvatting

Valorisation

Dankwoord

Curriculum Vitea

Publications

Thesis defences from MHeNS 



\section{SUMMARY}

Better knowledge of the risk factors for and mechanisms and processes underlying the developmental pathway(s) from psychotic experiences to psychotic disorders is crucial for the development of more effective early treatment options. The current thesis titled 'Dissecting the psychosis continuum risk factors along the pathway from experiences to disorder' examines potential mechanisms and risk factors for psychosis in the lower end of the psychosis continuum. The first part of this thesis focussed on psychotic experiences (self)reported by in individuals from the general population, and by family members of psychotic patients who represent a group of individuals at elevated genetic high risk for psychosis (chapter 2 and 3). The second part of this thesis focussed on the examination of affective and psychotic symptomatology in the daily lives of individuals at clinical high risk for psychosis and first episode psychotic patients (chapters 4 and 5).

Chapter 1 provides an overview on the epidemiology, aetiology and genetics of psychotic disorders and the clinical high risk state. The proposed 'affective pathway to psychosis' and findings of previous research with the Experience Sampling Method (ESM) are introduced.

In chapter 2, two different, often used measures of psychotic experiences were administered in a large longitudinal general population study (NEMESIS-II): a self-report measure and a more extensive clinical interview. For those individuals who had self-reported psychotic experiences that were subsequently assessed as "false-positive" after clinical interview (FP SRPE) at baseline the course and outcome 3-year follow-up was examined. We prospectively examined (1) the prevalence of remission and persistence of FP SRPE and transition to validated PE; (2) potential baseline psychopathological and psychosocial predictors of persistence of FP SRPE and transition to validated PE, and (3) whether those individuals with persistent FP SRPE and validated PE at follow-up were already differed on psychopathology and psychosocial factors at baseline compared to individuals who did not report new SRPE during the follow-up period. Results indicated that those individuals with baseline FP SRPE were significantly more likely to report SRPE and validated PE at follow-up. Baseline FP SRPE also predicted presence of mood and anxiety disorders, reduced functioning and help-seeking at follow-up. Several baseline psychopathological, psychosocial and PE characteristics were predictive for the persistence of SRPE. These baseline factors also differentiated groups with FP SRPE or validated PE from those with remitted FP SRPE at follow-up. 
In chapter 3, the association between self-report and interview based assessments of psychotic symptoms and the Polygenic Risk Score (PRS) as an index for genetic risk for psychosis was examined in non-psychotic sibling and parent of patients with a psychotic disorder, a group with elevated genetic risk for psychosis and (non-psychotic) controls who are at an average genetic risk for psychosis. This study uncovered that PRS as an index for genetic risk for psychosis was associated with positive psychotic symptoms obtained via clinical interview but not with the self-report measure. These results thus suggest that studies of gene-environment relationships in psychosis are more likely to be informative when objective interview measures of subclinical psychotic symptoms are used. PRS was also associated with presence of affective episodes (depression and/ or mania), suggesting that the association between genetic risk and psychosis proneness is not only mediated by positive symptomatology, but also by measures of affective dysregulation.

In the study presented in Chapter 4 affective and psychotic stress reactivity for small daily life stressors were examined in individuals at clinical high risk (CHR-P), chronic psychotic patients and healthy controls. Previous research has shown that psychotic disorder patients and their first-degree relatives are characterised by increased affective and psychotic stress reactivity. Early stress sensitisation might be an underlying mechanism in CHR-P patients for the transition from subclinical psychotic symptoms to full-blown psychosis. In chapter 4 , the association between small daily life stressors and negative affect (NA) and psychotic experiences measured with the Experience Sampling Method (ESM) was studied. Additionally, we assessed if psychotic experiences were experienced as stressful by examining the association between psychotic experiences and NA. We found that stress sensitization seems to play a role particularly in the early phase of psychosis development as results showed that CHR-P patients were more sensitive to daily life stressors than chronic psychotic patients. In this early phase, psychotic experiences also contributed to the experience of stress.

In Chapter 5, a study of the phenomenology of hallucinations and persecutory delusions in the realm of daily life is presented. Hallucinations and persecutory delusions are core features of (subclinical) psychosis, often causing considerable distress. The phenomenology of auditory and visual hallucinations and suspiciousness has previously been investigated in the realm of daily life in psychosis spectrum patients and we aimed to extend this investigation to patients with a first psychotic episode (FEP) and individuals at clinical high risk for psychosis (CHR-P), using ESM over a 6-day period. The prevalence, 
course and the co-occurrence of hallucinations and feelings of suspiciousness in daily life as well as the temporal relationship of these experiences with emotions, anxiety and self-esteem were examined. We found that hallucinations and suspiciousness are common in CHR-P and FEP and regularly occur together, although group differences were apparent. Furthermore, individuals with hallucinations reported more NA, anxiety and delusional intensity and lower self-esteem than those without, suggesting that presence of hallucinations reflects a more severe illness state. Finally, the results have clinical value as they provide information about changes in mood, and self-esteem preceding and during suspicious and hallucinatory episodes which can serve as targets for (personalised) treatment.

Finally, chapter 6 summarizes the results of the research presented in this thesis. Mechanisms and risk factors for the developmental pathway from psychotic experiences to psychotic disorder are discussed and integrated. Additionally, methodological considerations, implications for clinical practice and recommendations for future research are also provided. 



\section{SAMENVATTING}

Het vergroten van de kennis over de risicofactoren en de onderliggende mechanismen betrokken bij de ontwikkeling van psychotische ervaringen tot psychotische stoornissen is belangrijk. Deze kennis kan gebruikt worden om interventies die gericht zijn op preventie van psychose te verbeteren. Dit proefschrift getiteld 'Dissecting the psychosis continuum risk factors along the pathway from experiences to disorder' onderzoekt potentiële onderliggende mechanismen en risicofactoren voor de ontwikkeling van psychotische stoornissen aan de onderkant van het psychose continuüm. In het eerste deel van dit proefschrift worden psychotische ervaringen onderzocht die (zelf)gerapporteerd worden door individuen uit de algemene bevolking. Ook worden psychotische ervaringen van familieleden van patiënten met een psychotische stoornis onderzocht, een groep mensen met een verhoogd genetische risico op het ontwikkelen van een psychotische stoornis (hoofdstuk 2 en hoofdstuk 3). Het tweede deel van dit proefschrift omvat onderzoeken naar veranderingen in stemming en psychotische ervaringen in het dagelijks leven van individuen met verhoogd risico op psychose (clinical high risk, $\mathrm{CHR}$ ) en patiënten die hun eerste psychotische episode doormaken (hoofdstuk 4 en hoofdstuk 5).

Hoofdstuk 1 geeft een overzicht van de epidemiologische kenmerken, etiologie en genetica van psychotische stoornissen en de CHR groep. De zogenaamde 'affectieve weg naar psychose' en eerdere resultaten van onderzoeken met de Experience Sampling Methode (ESM) worden geïntroduceerd.

In hoofdstuk 2, werden twee vaak toegepaste meetinstrumenten voor psychotische ervaringen gebruikt in een groot longitudinaal onderzoek bij individuen van de algemene bevolking: een zelf-rapportage vragenlijst en een klinisch interview. De ontwikkeling en beloop van de psychotische ervaringen na drie jaar werd onderzocht bij de groep van individuen waarvan de zelf-gerapporteerde psychotische ervaringen op baseline met het klinisch interview als 'vals-positief' (FP SRPE) werden beoordeeld. We onderzochten (1) de prevalentie van a) remissie en b) persistentie van FP SPRE en c) transitie naar gevalideerde psychotische symptomen; (2) de voorspellende waarde van psychopathologische en psychosociale kenmerken gemeten op baseline voor de persistentie van FP SRPE en transitie naar gevalideerde psychotische symptomen; en (3) of de groepen ( $a, b$ en $c)$ op baseline al verschilden van elkaar op gebied van psychopathologische en psychosociale factoren. Er werd gevonden dat individuen met FP SRPE bij baseline een hogere kans hadden op het rapporteren van psychotische ervaringen bij follow-up 
dan degenen die niet eerder psychotische ervaringen rapporteerden. De aanwezigheid van baseline FP SRPE was voorspellend voor de aanwezigheid van een stemming en/of angststoornis, verminderd functioneren en het zoeken van hulp voor klachten bij follow-up. Het aanhouden van (zelf-gerapporteerde) psychotische ervaringen werd voorspeld door de aanwezigheid van ander psychische problemen en het aantal en de frequentie van zelf-gerapporteerde psychotische ervaringen bij baseline. De individuen met persistente vals-positieve psychotische ervaringen alsook individuen gevalideerde psychotische symptomen verschilden op deze baseline factoren van de individuen die geen psychotische ervaringen meer hadden gedurende de follow-up periode (remissiegroep).

In hoofdstuk 3 werd de associatie tussen psychotische ervaringen en de 'Polygenic Risk Score' (PRS), een index voor genetisch risico voor psychose, onderzocht. Psychotische ervaringen werden gemeten met een zelf-rapportage lijst en een interview. Dit werd gedaan in een groep van niet-psychotische eerstegraads familieleden (broers/zussen en ouders) van psychotische patiënten die een verhoogd genetisch risico hebben voor het ontwikkelen van een psychose en (niet-psychotische) controles, die een gemiddeld risico lopen. Deze studie toonde aan dat de PRS geassocieerd was met subklinische positieve psychotische symptomen die naar voren kwamen tijdens het interview. Deze relatie werd niet gevonden met zelf-gerapporteerde symptomen. De resultaten suggereren dat onderzoek naar gen-omgevingsrelaties bij psychose informatiever zal zijn wanneer een objectief interview wordt gebruikt om aanwezigheid van subklinische psychotische symptomen te bepalen. De PRS was ook geassocieerd met de aanwezigheid van affectieve episodes (depressie en/of manie). Dit resultaat suggereert dat de associatie tussen genetisch risico en psychosegevoeligheid niet alleen beïnvloed wordt door positieve symptomen, maar ook door de aanwezigheid van affectieve disregulatie.

In de studie gepresenteerd in hoofdstuk $\mathbf{4}$ werd affectieve en psychotische stress reactiviteit voor kleine stressoren in het dagelijks leven onderzocht in individuen met verhoogd psychoserisico (CHR-P), chronische psychotische patiënten en gezonde controles. Eerder onderzoek toonde aan dat patiënten met een psychotische stoornis en hun eerstegraads familieleden gekenmerkt worden door hogere affectieve en psychotische stress reactiviteit ten opzichte van controles. Vroege stress sensitisatie is mogelijk een mechanisme betrokken bij de transitie van subklinische psychotische symptomen naar psychose. In hoofdstuk 4 werd de associatie tussen dagelijkse stressoren en negatief affect (NA) en psychotische ervaringen onderzocht, gemeten met de Experience Sampling Methode (ESM). Daarnaast werd onderzocht of psychotische ervaringen als stressvol 
ervaren werden door de associatie tussen psychotische ervaringen en NA te onderzoeken. Uit deze studie blijkt dat stress sensitisatie een belangrijke rol in de vroege fase van het psychose ontwikkelingsproces speelt. CHR-P patiënten waren gevoeliger voor dagelijkse stressoren dan chronisch psychotische patiënten. In deze vroege fase blijken psychotische ervaringen zelf ook een bron van stress te zijn.

In hoofdstuk 5 werd een studie van de fenomenologie van hallucinaties en achterdochtwanen in het dagelijks leven gepresenteerd. Deze kernsymptomen van (subklinische) psychose veroorzaken vaak veel leed. De fenomenologie van auditieve en visuele hallucinaties en achterdocht is eerder onderzocht in het dagelijks leven in psychose spectrum patiënten. De huidige studie had als doel dit in kaart te brengen voor eerste psychose patiënten (FEP) en individuen met verhoogd risico op psychose (CHR-P) met behulp van ESM gedurende een zesdaagse periode. De prevalentie, het verloop en het tegelijk optreden van hallucinaties en gevoelens van achterdocht, maar ook de temporele relaties van deze ervaringen met emoties, angst en zelfvertrouwen werden onderzocht. $\mathrm{Er}$ werd gevonden dat hallucinaties en achterdocht vaak en geregeld samen voorkomen bij CHR-P en FEP patiënten, hoewel er ook groepsverschillen gevonden werden. Daarnaast rapporteerden individuen met hallucinaties meer NA, angst en hogere intensiteit van waanideeën en minder zelfvertrouwen dan individuen die geen hallucinaties ervaarden. Dit suggereert dat de aanwezigheid van hallucinaties een ernstiger ziekteproces reflecteert. De resultaten brengen veranderingen in stemming en zelfvertrouwen voorafgaand en tijdens episodes met achterdocht en hallucinaties in beeld. Deze informatie kan gebruikt worden om (gepersonaliseerde) zorg te optimaliseren.

Tot slot wordt in hoofdstuk 6 een samenvatting gegeven van de resultaten van het onderzoek gepresenteerd in dit proefschrift. Mechanismen en risico factoren onderliggend aan de ontwikkeling van psychotische ervaringen tot psychotische stoornis worden besproken. Daarnaast worden methodologische aandachtspunten, implicaties voor de klinische praktijk en aanbevelingen voor toekomstig onderzoek beschreven. 



\section{VALORISATION}

\section{Societal relevance}

Psychotic disorders are associated with high burden for patients themselves as well as for their family members and friends, although prevalence is relatively low $0.5-1 \%$ for schizophrenia, $2.5-3.5 \%$ for psychotic disorders ${ }^{1}$ ). This is directly due to significant impairments in academic performance and occupational functioning, difficulties with interpersonal relationships and experiences of stigmatisation and discrimination, all resulting in substantially reduction in quality of life. Additionally, expenses for mental disorders and psychotic disorders in particular are among the highest of all healthcare expenses in the Netherlands ${ }^{2}$. The total costs for mental disorders including psychotic disorders are the combination of direct healthcare costs, non-medical costs including extra resources for social service and education, and indirect costs due to work absence or early retirement. These indirect costs may emerge from impairments, disability, premature death, and legal problems due to loss of productivity ${ }^{3}$, and form the largest proportion of all costs for psychotic patients ${ }^{4}$. Overall, it can be concluded that psychotic disorders are a substantial burden for the affected individual, his/her social circle, those involved in the life and treatment of these patients and for society as a whole. Therefore, early diagnosis, intervention and preferably prevention are needed. A better understanding of the phenomenology, underlying mechanisms and psychological processes involved in the transition of subclinical symptoms towards disorder will help to reach that goal.

In order to elucidate the complex and multi-factorial aetiology of psychotic disorders and to improve prevention and intervention strategies focus of research has shifted from the population of psychotic disorder patients, especially schizophrenic patients, to first episode psychosis patients and at the lower end of the psychosis continuum to individuals with subclinical psychotic symptoms at clinical high risk for psychosis (CHR-P) as well as (non-help seeking) individuals in the general population with psychotic-like experiences. The current thesis investigated potential mechanisms and risk factors involved in the development from incidental psychotic-like experiences and subclinical psychotic symptoms to a first psychotic episode. The epidemiology and phenomenology of these experiences and associated factors was examined in both in longitudinal studies and Experiences Sampling Method (ESM) studies in daily life. 


\section{Target audience}

The findings of this thesis are relevant for individuals with subclinical psychotic symptoms, psychotic patients, health care professionals and policy makers.

The results of chapter $\mathbf{2}$ and chapter $\mathbf{3}$ provide important information for both health care professionals as well as policy makers. Self-report measures for psychotic experiences are effective as screening instruments for the presence of potential (subclinical) psychotic symptoms, which should then be examined in detail by clinical interview. The use of a semi-structured psychosis risk assessment interview like the CAARMS or the SIPS is advised as it allows validation of an experience as a true subclinical symptom while also obtaining detailed information about the frequency of a symptoms and determination of CHR-P or psychosis status. Importantly, it has been suggested that clinical early detection teams may need to further extend their services into the community so that these individuals have better access to specialized mental health care ${ }^{5}$. However, in chapter $\mathbf{2}$ it was found that (false-positive) self-reported psychotic experiences by individuals from the general population were mostly transitory in nature and only a small subsample of individuals developed true psychotic symptoms. This finding supports the recommendation that screening with self-report measures and subsequent assessment of CHR-P state should be primarily offered to selected samples of subjects who are already distressed by mental problems and seeking help for them ${ }^{6}$. Use for prevention in non-help-seeking subjects in the general population should be discouraged ${ }^{7}$, as this strategy is not cost-effective due to false-positive rates.

The results of chapter $\mathbf{2}$ highlight the importance of targeting low social functioning in early interventions as individuals who developed future psychotic symptoms were already characterised by deterioration in social functioning. Social skills training and family involvement to create a supportive environment can help to improve social functioning ${ }^{8}$ which in turn might prevent further development of psychotic symptoms.

Chapter 2 furthermore showed high neuroticism (i.e. a tendency to show emotional instability, and react with increased anxiety, fear, and sadness ${ }^{9}$ ) is an important predictor of persistence and further development of psychotic symptoms. The results of chapter 4 further highlight the close relationship between stress, symptoms and low mood. Increased emotional reactivity for small daily life stressors in individuals at clinical high risk for psychosis may be an important underlying mechanism in the process towards transition to psychotic disorder. Furthermore, (subclinical) psychotic symptoms can be 
regarded as an additional source of distress. So both CHR-P and first episode psychosis patients are thus likely to benefit from psychoeducation and non-specific early interventions aimed at stress-reduction and enhancement of effective coping skills.

Results of chapter $\mathbf{5}$ stress the need for thorough investigation of the exact nature of subclinical psychotic symptoms. Results tentatively suggest that severity of symptoms and risk for transition are likely to be higher for individuals reporting both feelings of suspiciousness as well as hallucinations, although this should be examined more carefully in a longitudinal study. Health care professionals need to be aware of the central role of emotion-related processes, anxiety and self-esteem for the occurrence of hallucinations and suspiciousness in daily life. Use of ESM can help bridge the gap between the professional's office and the patient's daily life. It can help to unravel symptomatic and behavioural patterns as it supplies both the individual patient and clinician with large amount of detailed, reliable and ecologically valid information about symptoms and their relationships with mood, anxiety, self-esteem all in the social context of daily life.

\section{Innovation and implementation}

Recently, studies have started to investigate the application of ESM interventions. Currently, the effectiveness of a newly developed ecological momentary intervention that targets elevated stress sensitivity, altered reward-experience, and psychological flexibility based on principles of Acceptance and Commitment Therapy (ACT) in CHR-P and first episode psychosis patients is being evaluated in the INTERACT study. The effectiveness of ACT is compared with a treatment as usual control group, of which some receive participants receive CBT specifically developed to treat (subclinical) psychotic symptoms. This ongoing ACT in daily life study extends standard ACT therapy with real life training and exercises through a dedicated device, thereby enhancing participants' ACT-based skills and techniques. Furthermore, a new study will use ESM as a monitoring and detection tool for changes in affective and psychotic symptomatology that could serve as warning signs for relapse in psychotic patients who are in symptomatic remission and want to gradually reduce and stop their anti-psychotic medication use.

The use of ESM in clinical practice and psychosis care specifically is still limited, but has great potential to improve personalized treatment as ESM is now available via mobile phone applications. Recent development and availability of web-based feedback systems offers patients and health care professionals access to real-life data on emotional en symptomatic dynamics. ESM can help to refine the diagnostic process and monitor af- 
fective and psychotic symptomatology in daily life. As mood and symptoms are assessed 'in the moment' and in the context of daily life, they are not influenced by memory biases hampering traditional retrospective clinical interviews and questionnaires assessing longer time periods. ESM allows patients to accurately report changes in their emotions and behavioural pattern and reveals which emotional and/or behavioural patterns are in need of change. The implementation of ESM in clinical practice does require that professionals are trained in how gain access to, and then interpret and use ESM data in a therapeutic fashion.

As part of my activities as a psychologist at the mental healthcare institute GGzE Eindhoven, division Early Psychosis, I am involved in the implementation of ESM as a diagnostic and monitoring tool as part of regular care for first episode psychosis patients. In this fashion I can implement the knowledge of ESM that I gained during my PhD track in clinical practice. Furthermore, I am able to contribute to both of the above mentioned ESM studies as a research practitioner.

\section{Knowledge dissemination}

The present research was and will be published in peer-reviewed journals and presented at national and international research conferences. In this way, research results and methodological developments can be discussed with other scientists, what in turn stimulates development and refinement of knowledge and theories about the development of psychotic disorders. Furthermore, the results were and will be made public at more clinically oriented conferences to inform health care professionals and policy makers. By involving health care professionals in research projects, especially those focussed on the development and refinement of treatment options, valuable information can be gained on flaws of current options and feasibility of proposed solutions. By working together, scientists and health care professionals can greatly impact on the lives of patients and their families and society as a whole by developing and implementing more efficient treatment options. Finally, results were and will be made public conferences and symposia, magazines and websites managed by patient organisations that are easily accessible to the general population including patients and their families. It is the responsibility of the scientific community to actively involve patients and their families in scientific research. They can provide valuable insights on challenges they are facing, provide feedback on interventions and when relevant, on the usability of (proposed) technological tools. Adequate dissemination of knowledge will help to reduce stigmatisation in professionals, patients and the general population. 


\section{REFERENCES}

1. Perala J, Suvisaari J, Saarni SI, Kuoppasalmi K, Isometsa E, Pirkola S, . . Lonnqvist J. Lifetime prevalence of psychotic and bipolar I disorders in a general population. Arch Gen Psychiatry. 2007; 64:19-28.

2. Verbeek M, Knispel A, Nuijen J. GGZ in tabellen 2013-2014. Utrecht: Trimbos Instituut, Netherlands Institute of Mental Health and Addiction; 2015.

3. Rössler W, Joachim Salize H, van Os J, Riecher-Rössler A. Size of burden of schizophrenia and psychotic disorders. Eur Neuropsychopharmacol. 2005; 15:399-409.

4. Gustavsson A, Svensson M, Jacobi F, Allgulander C, Alonso J, Beghi E, . . . Olesen J. Cost of disorders of the brain in Europe 2010. Eur Neuropsychopharmacol. 2011; 21:718-779.

5. Mills JG, Fusar-Poli P, Morgan C, Azis M, McGuire P. People meeting ultra high risk for psychosis criteria in the community. World Psychiatry. 2017; 16:322-323.

6. Fusar-Poli P. Why ultra high risk criteria for psychosis prediction do not work well outside clinical samples and what to do about it. World Psychiatry. 2017; 16:212-213.

7. Fusar-Poli P, Cappucciati M, Rutigliano G, Schultze-Lutter F, Bonoldi I, Borgwardt S, . . McGuire P. At risk or not at risk? A meta-analysis of the prognostic accuracy of psychometric interviews for psychosis prediction. World Psychiatry. 2015; 14:322-332.

8. Thompson E, Millman ZB, Okuzawa N, Mittal V, DeVylder J, Skadberg T, . . S Schiffman J. Evidence-based early interventions for individuals at clinical high risk for psychosis: a review of treatment components. $J$ Nerv Ment Dis. 2015; 203:342-351.

9. McCrae RR, Costa Jr PT, Martin TA. The NEO-PI-3: a more readable revised NEO Personality Inventory. J Pers Assess. 2005; 84:261-270. 



\section{DANKWOORD}

De laatste punt is gezet, met dit boekje sluit ik mijn promotietraject af. Hoewel mijn naam op de cover staat heb ik dit traject niet alleen afgelegd en in dit hoofdstuk wil ik graag iedereen bedanken die in welk opzicht dan ook een bijdrage heeft geleverd aan de totstandkoming van dit proefschrift.

Allereerst wil ik alle deelnemers bedanken die hebben deelgenomen aan de 'iThink' studie en de andere studies beschreven in dit proefschrift. Dank jullie voor het delen van jullie verhalen en ervaringen en het mogen meekijken in jullie dagelijkse leven. De bijdrage die jullie geleverd om de kennis over psychiatrische aandoeningen en psychose in het bijzonder te vergroten is onmisbaar.

Dan wil ik mijn promotieteam bedanken: Inez, dank je wel dat je me hebt meegenomen in de interessante en bijzondere wereld van (ESM) psychose onderzoek. Ik heb veel van je geleerd en wil je bedanken voor de ondersteuning die geleid heeft tot mooie ervaringen en artikelen alsook tijdens de uitdagende perioden binnen dit traject. Ruud, bedankt voor je begeleiding bij het schrijven van de artikelen, ik kon zelfs bij je thuis terecht voor afspraken toen de blessure aan jouw enkel je belemmerde om naar het werk af te reizen! Ook heb ik veel geleerd van jouw dubbele rol als onderzoeker en clinicus. Tineke, dank je wel voor een heel fijn eerste jaar als PhD student! Bedankt voor de structuur en regelmaat die je bood die zo ontzettend belangrijk zijn om orde te scheppen in dit chaotische bestaan. Bij jou was er altijd ruimte voor een lach en een traan.

Ik wil graag mijn iThink teamleden bedanken: Feikje, Debora, Ilse, Nele S en Patrick. Zonder jullie was het gelukt!

Lieve mede (ex)promovendi op Vijverdal: Annelie, Hennie, Thomas, Iris, Jindra, Esther, Eshan, Silvia, Ozan, Sophie, Stijn, Christian, Zuzana, Martine, Tim, Mayke, Suzanne, Dennis en Nicole. Ik wil jullie allemaal bedanken voor jullie gezelligheid tijdens en na werktijd bij lunches, pizza avonden met natuurlijk een potje weerwolven, borrels, bbq's, etentjes en feestjes, alsook voor het delen van alle tips, tricks en kennis over allerlei zaken in de onderzoekswereld.

Annelie, mijn kamergenootje! Ontelbare uren hebben we samen doorgebracht op ons kantoor, waarvan we ook regelmatig de opstelling van bureaus veranderden in de hoop 
dat dat de productiviteit zou kunnen beïnvloeden ;) Naast het kunnen bespreken van alle ups en downs die bij het leven als promovendus horen hebben samen ook veel gezelligheid en levenservaringen gedeeld. Ik mis jouw gezelschap op kantoor nu al. Het is dat het wondertje dat op dit moment nog in je buik verblijft ten tijde van mijn verdediging al je tijd en aandacht zal opeisen, maar ik hoop dat je in gedachte die dag achter me zal staan!

Rosalie, ESM buddy van divisie 1, wat ontzettend leuk dat ik jou heb leren kennen!

Heel erg bedankt mijn lieve paranimfen, Sanne en Tirza. Sanne, ik ben ontzettend blij dat we collega's waren en vriendinnen zijn! Ondanks dat we in verschillende fases van ons promotietraject zaten en totaal verschillende onderwerpen hadden klikte het vanaf het eerste moment. Ik kan met jou over alles praten en we hebben samen frustraties gedeeld en gehuild maar vooral gelachen en plezier gemaakt. Tirza, als ervaringsdeskundige partner van een gepromoveerde arts weet jij als geen ander hoeveel tijd en energie er gaat zitten in een promotietraject. Dank je wel dat je er altijd bent om te luisteren en meedenken. Als werkende moeder van 3 kinderen weet je als geen ander hoe belangrijk het is om de basis thuis in orde te hebben en je bent daarin een voorbeeld waar ik veel van geleerd heb. Fijn dat je ook straks tijdens de verdediging weer achter me staat.

Truda, Wendy en Debora, jullie waren mijn rotsen in de branding! Van onderzoeksperikelen tot persoonlijke fijne momenten en struggles, ik vond bij jullie voor van alles een luisterend oor en bruikbaar advies.

Ik wil ook iedereen bedanken die betrokken was bij het INTERACT project en in het bijzonder Silke, Uli, Nele V, Davinia, Evelyne en Lore. Tim, supertof dat ik bij jou de ACT cursus en heb kunnen volgen, ik maak er nu gebruik van!

Daarnaast wil ik mijn lieve collega's Karlijn, Aki, Rob, Aleks, Hugo, Maude, Robin, Martien en Hugo van het CCP in Leuven bedanken. Jullie maakten het altijd gezellig ook al was ik niet zo vaak aanwezig of St. Raf.

Ron bedankt voor alle technische ondersteuning op gebied van laptops, programma's en Psymates! Daphne, dank voor alle uren die je hebt besteed aan het invoeren van alle verzamelde data. Trees, Ine en Jolanda, bedankt voor jullie werk op de achtergrond! Verder wil ik ook alle andere collega's van Vijverdal bedanken! 
Ook wil ik graag alle leden van de beoordelingscommissie bedanken voor het beoordelen van mijn manuscript, en de coauteurs voor de prettige samenwerking en bijdrage aan de artikelen.

Suzanne, Carolien en Koos, Joost en Carlijn: bedankt voor jullie interesse en steun vanaf de zijlijn tijdens de oh zo belangrijke momenten van ontspanning buiten het werk.

Johan, bedankt voor alle hulp bij het ontwerpen van de kaft, misschien wel het belangrijkste onderdeel van dit proefschrift ;)

EDI \& ACT teamleden van GGzE en in het bijzonder Elise, Jeu en Machteld: Ik ben heel blij dat ik ruim 3 jaar met jullie heb samen kunnen werken in het vroegdetectie team alsook jullie hulp bij het werven van deelnemers voor mijn onderzoek. Door jullie en de overige teamleden heb ik daarnaast ook veel geleerd over de psychosezorg. Ik ben erg blij dat we de samenwerking na mijn promotie hebben voortgezet als collega's zijn binnen de vroege psychosezorg bij GGzE!

Pap en mam, jullie steun is altijd onvoorwaardelijk en onmisbaar geweest tijdens dit promotietraject. Van opbeurende woorden in moeilijke tijden tot oppasbeurten sinds de komst van Iris. Zonder jullie had ik het niet kunnen redden.

Harry en Renée, ook jullie stonden altijd klaar met een luisterend oor, advies of gewillige slachtoffers voor een oppasbeurt wanneer ik mijn vrije dag toch moest besteden aan het afronden van dit proefschrift.

Nadine en Matthijn, Roel en Tirza, Guido en Nadine, Patrick en Pascalle, Selma en natuurlijk Dominic, jullie toonden altijd interesse in mijn onderzoek ondanks dat het voor jullie misschien niet altijd helemaal duidelijk was wat het precies inhield.

Lieve Mark, echtgenoot en mijn grootste steun. Bedankt dat je er altijd voor me bent en in mij gelooft! Het zijn drukke en roerige jaren geweest met moeilijkere periodes maar vooral vele hele mooie hoogtepunten! Zonder jou had ik het nooit gered. Ik hou van je!

Lieve Iris, jouw komst zette alles in perspectief. 



\section{CURRICULUM VITAE}

Yori van der Steen werd geboren op 26 juli 1986 te Roermond. In 2004 behaalde zij haar VWO diploma aan het Bisschoppelijk College Schöndeln te Roermond. Hierna behaalde zij in 2008 haar Bachelor Cognitieve Psychologie aan de Universiteit Maastricht. In 2008 behaalde ze tevens haar Master Rechtspsychologie aan de Universiteit Maastricht. In 2010 vervolgde zij haar studies met de premaster en vervolgens Master Neuropsychologie aan de Universiteit Utrecht, waarvoor ze haar klinische en wetenschappelijke stage liep op de afdeling Psychiatrie van het Universitair Medisch Centrum Utrecht. Hier kwam ze voor het eerst in aanraking met patiëntenzorg en onderzoek binnen het spectrum van psychotisch stoornissen. In april 2012 behaalde zij hiervoor haar diploma. In juli 2013 startte zij haar promotietraject bij de afdeling Psychiatrie en Neuropsychologie van de Universiteit Utrecht in het team van Prof. Myin-Germeys. In 2015 startte ze ook met het doctoraat programma bij het Center for Contextual Psychiatry van de KU Leuven, België als onderdeel van het gezamenlijk promotietraject. Gedurende haar promotietraject werkte ze aan verschillende onderzoeksprojecten en werkzaam bij GGz Eindhoven binnen het vroegdetectie team voor psychose. Momenteel werkt Yori als psycholoog binnen het centrum voor vroege psychose van GGz Eindhoven, waarbij ze patiëntenzorg en onderzoek met de experience sampling methode combineert. 



\section{PUBLICATIONS}

\section{Scientific publications in international peer-reviewed journals}

van der Steen Y, Myin-Germeys I, van Nierop M, Ten Have M, de Graaf R, van Dorsselaer S, van Os J, van Winkel R. (2018) 'False-positive' self-reported psychotic experiences in the general population: an investigation of outcome, predictive factors and clinical relevance. Epidemiology and Psychiatric Sciences.

van Os J, van der Steen Y, Islam MA, Gülöksüz S, Rutten BP, Simons CJP. (2017) Evidence that polygenic risk for psychotic disorder is expressed in the domain of neurodevelopment, emotion regulation and attribution of salience. Psychological Medicine.

van der Steen Y, Gimpel-Drees J, Lataster T, Viechtbauer W, Simons CJP, Lardinois M, Michel TM, Janssen B, Bechdolf A, Wagner M, Myin-Germeys I. (2017) Clinical high risk for psychosis: the association between momentary stress, affective and psychotic symptoms. Acta Psychiatrica Scandinavica.

Lataster T, Viechtbauer W, Oorschot M, Collip D, Janssens M, van Nierop M, Menne-Lothmann C, Lardinois M, Lataster J, Jacobs N, Thewissen V, van der Steen Y, Wagner M, Gimpel-Drees J, Geschwind N, Simons C, Nicolson N, Delespaul P, Wichers M, Myin-Germeys I. Evidence for a two-factor positive and negative affect structure in daily life: presenting the Maastricht Momentary Mood Questionnaire (3MQ). Submitted for publication.

\section{In progress articles}

van der Steen Y, van Winkel R, Lataster T, Wagner M, Myin-Germeys I. Temporal dynamics of hallucinations and suspiciousness in clinical high risk and first episode psychosis. In preparation. 


\section{Scientific communications related to this thesis}

2017 Oral presentation at the Annual Conference of the Society for Ambulatory Assessment (Luxembourg, Luxumbourg)

2016 Poster presentation at the $5^{\text {th }}$ Biennial Schizophrenia International Research Society Conference of the Schizophrenia International Research Society (Florence, Italy)

2015 Poster presentation at the Annual Meeting of the Society for Research in Psychopathology (New Orleans, USA)

2014 Oral presentation at the $42^{\text {nd }}$ Voorjaarscongres van der Nederlandse Vereniging voor Psychiatrie (NVvP) (Maastricht, the Netherlands) 




\section{THESIS DEFENSES FROM MHENS - \\ SCHOOL FOR MENTAL HEALTH AND NEUROSCIENCE}

2013

Rob Havermans: Bipolar disorder in daily life; Mood and cortisol responses to naturally occurring events. Supervisor: Prof.dr. M. de Vries; Co-Supervisor: Dr. N. Nicolson.

Véronique Moers-Hornikx: Deep brain stimulation and the cerebellum. Supervisors: Prof.dr. J. Vles / Prof.dr. Y. Temel; Co-Supervisor: Dr. G. Hoogland.

Nicole Veldhorst-Janssen: Intranasal delivery of rapid acting drugs. Supervisors: Prof.dr. M. Marcus / Prof.dr. C. Neef; Co-Supervisor: Dr. P.H. van der Kuy.

Stéphanie Knippenberg: Vitamin D and Multiple Sclerosis: immunological and clinical outcome. Supervisor: Prof.dr. J. Cohen-Tervaert; Co-Supervisors: Dr. J. Damoiseaux / Dr. Y. Bols.

Erik D. Gommer: Dynamic Cerebral Autoregulation: from methodology towards clinical application. Supervisors: Prof.dr. W.H. Mess / Prof.dr. R.B. Panerai, UK; Co-Supervisor: Dr.ir. J.P.H. Reulen.

Olga A.H. Reneerkens: Can PDE inhibition improve cognition ? Translational insights. Supervisor: Prof.dr. H.W.M. Steinbusch; Co-Supervisor: Dr. J. Prickaerts.

Lyzel S. Elias-Sonnenschein: Clinical and biomarker correlates of genetic risk factors for Alzheimer's disease. Supervisor: Prof.dr. F.R.J. Verhey; Co-Supervisor: Dr. P.J. Visser.

Diego F. Mastroeni: Epigenetic Dysregulation and the Pathophysiology of of Alzheimer's Disease. Supervisors: Prof.dr. H.W.M. Steinbusch / Prof.dr. P.D. Coleman, Sun City, Arizona; Co-Supervisors: Dr. B.P.F. Rutten / Dr. D.L.A. van den Hove.

Leonidas Chouliaras: Epigenetic Regulation in Aging and Alzheimer's disease: A translational perspective. Supervisor: Prof.dr. H.W.M. Steinbusch; Co-Supervisors: Dr. B.P.F. Rutten / Dr. D.L.A. van den Hove. 
Liesbeth Knaepen: Perinatal events and altered pain sensitivity in later life. Supervisors: Prof.dr. E.A.J. Joosten / Prof.dr. D. Tibboel, EUR; Co-Supervisor: Dr. J. Patijn.

Marisela Martinez-Claros: Hippocampal plasticity and corticosterone: From dendrites to behaviour. Supervisor: Prof.dr. H.W.M. Steinbusch; Co-Supervisors: Dr. J.L. Pawluski / Dr. J. Prickaerts.

Marcus D. Lancé: A circle of improvement in bleeding management: from laboratory to clinic and back. Supervisors: Prof.dr. M.A.E. Marcu / Prof.dr. J.W.M. Heemskerk; Co-Supervisor: Dr. Y.M.C. Henskens.

Hilde Braakman: Imaging the brain; neuronal correlates of cognitive impairment in children with frontal lobe epilepsy. Supervisors: Prof.dr. A.P. Aldenkamp / Prof.dr. J.S.H. Vles; Co-Supervisors: Dr.ir. W.H. Backes / Dr. P.A.M. Hofman.

Willem H. van Zwam: Aneurysmal subarachnoid hemorrhage: imaging strategies and cost-effectiveness aspects in diagnostic work-up and post-therapeutic follow-up. Supervisors: Prof.dr. J.T. Wilmink / Prof.dr. J.E. Wildberger; Co-Supervisor: Dr. P.A.M. Hofman.

Klara De Cort: The Pathogenesis of Panic Disorder. Supervisors: Prof.dr. I. Myin-Germeys / Prof.dr. E.J.L. Griez; Co-Supervisors: Dr. K.R.J. Schruers / Dr. I. Van Diest, Leuven.

Kim van Wijck: Mind the Gap; experimental studies on splanchnic hyperfusion and gastrointestinal integrity loss in man. Supervisors: Prof.dr. W.A. Buurman / Prof.dr. C.H.C. Dejong; Co-Supervisor: Dr. K. Lenaerts.

Yvette Roke: Antipsychotic-induced hyperprolactinemia in children and adolescents with mainly autism spectrum disorders. Prevalence, symptoms, clinical consequences and genetic risk factors. Supervisors: Prof.dr. P.N. van Harten / Prof.dr. J.K. Buitelaar (RUN); Co-Supervisor: Dr. A. Boot (UMCG).

Fleur Goezinne: Retinal detachment surgery: pre and postoperative prognostic factors. Supervisors: Prof.dr. F. Hendrikse / Prof.dr. C.A.B. Webers; Co-Supervisor: Dr. E.C. La Heij (Amsterdam). 
Ralph L.J.G. Maassen: The Merits of Videolaryngoscopy during Glottic Visualisation for Endotracheal Intubation. Supervisors: Prof.dr. M. Marcus / Prof.dr. A. van Zundert (University of Queensland).

Maria J. de Sousa Guerreiro: The role of sensory modality in age-related distraction. Supervisor: Prof.dr. C.M. van Heugten; Co-Supervisor: Dr. P.W.M. van Gerven.

Ine Rayen: Effects of developmental fluoxetine exposure on neurobehavioral outcomes. Supervisor: Prof.dr. H.W.M. Steinbusch; Co-Supervisors: Dr. J.L. Pawluski / Dr. T.D. Charlier (Ohio University, USA).

Nynke M.G. Bodde: Psychogenic non-epileptic seizures; a separate disorder or part of a continuum? Supervisors: Prof.dr. R. van Oostenbrugge / Prof.dr. K. Vonck (UZ Gent); Co-Supervisors: Dr. R. Lazeron / Dr. A. de Louw (Epilepsiecentrum Kempenhaeghe, Heeze).

Alejandro M. Gomez: Novel strategies for making myasthenia less gravis: targeting plasma cells and the neuromuscular junction. Supervisor: Prof.dr. M.H. De Baets; Co-Supervisors: Dr. M. Losen / Dr. P. Martinez-Martinez.

Mohammad S. Rahnama'i: Prostaglandins and Phosphodiesterases in the Urinary Bladder Wall. Supervisors: Prof.dr. Ph. Van Kerrebroeck / Prof.dr. S. de Wachter (Universiteit Antwerpen); Co-Supervisor: Dr. G. van Koeveringe.

Mariken B. de Koning: Studying biomarkers in populations at genetic and clinical high risk for psychosis. Supervisors: Prof.dr. T. Amelsvoort / Prof.dr. J. Booij (AMC).

Fabien Boulle: Epigenetic regulation of BDNF/TrkB signaling in the pathophysiology and treatment of mood disorders. Supervisors: Prof.dr. H.W.M. Steinbusch / Prof.dr. L. Lanfumey (Universiteit Parijs); Co-Supervisors: Dr. D. van den Hove / Dr. G. Kenis.

2014

Iris Nowak-Maes: Tinnitus; assessment of quality of life \& cost-effectiveness. Supervisors: Prof.dr. M. Peters / Prof.dr. B. Kremer; Co-Supervisors: Dr. M. Joore / Dr. L. Anteunis. 
Marjolein Huijts: Cognitive function in patients with cerebral small vessel disease. Supervisor: Prof.dr. R.J. van Oostenbrugge; Co-Supervisors: Dr. A.A. Duits / Dr. J. Staals.

Markus Gantert: Fetal inflammatory injury as origin of long term disease: Lessons from animal models. Supervisors: Prof.dr. B. Kramer / Prof.dr. L. Zimmermann; Co-Supervisor: Dr. A. Gavilanes.

Elke Kuypers: Fetal development after antenatal exposures: Chorioamnionitis and maternal glucocorticoids. Supervisors: Prof.dr. B.W. Kramer / Prof.dr. H.W. Steinbusch / Prof. dr. Suhas G. Kallapur (University of Cincinnati, Ohio, USA).

Pieter Kubben: Ultra low-field strength intraoperative MRI for Glioblastoma Surgery. Supervisor: Prof.dr. J.J. van Overbeeke; Co-Supervisor: Dr. H. van Santbrink.

Laura Baijens: Surface electrical stimulation of the neck for oropharyngeal dysphagia in Parkinson's disease: therapeutic aspects and reliability of measurement. Supervisor: Prof.dr. B. Kremer; Co-Supervisor: Dr. R. Speyer, Townsville.

Janneke Hoeijmakers: Small fiber neuropathy and sodium channels; a paradigm shift. Supervisor: Prof.dr. R.J. van Oostenbrugge; Co-Supervisors: Dr. C.G. Faber / Dr. I.S.J. Merkies.

Stephanie Vos: The Role of biomarkers in preclinical and prodromal Alzheimer's disease. Supervisor: Prof.dr. F.R. Verhey; Co-Supervisor: Dr. P.J. Visser.

Muriël Doors: The Value of Optical Coherence Tomography in Anterior Segment Surgery. Supervisors: Prof.dr. R.M. Nuijts / Prof.dr. C.A. Webers; Co-Supervisor: Dr. T.T.J.M. Berendschot.

Anneke Maas: Sleep problems in individuals with genetic disorders associated with intellectual disability. Supervisors: Prof.dr. I. Curfs / Prof.dr. R. Didden.

Sebastiaan van Gorp: Translational research on spinal cord injury and cell-based therapies; a focus on pain and sensorimotor disturbances. Supervisors: Prof.dr. B. Joosten / Prof.dr. M. van Kleef; Co-Supervisors: Dr. J. Patijn / Dr. R. Deumens, KU Leuven. 
Andrea Sannia: High risk newborns and brain biochemical monitoring. Supervisor: Prof. dr. J.S.H. Vles; Co-Supervisors: Dr. D. Gazzolo, Alessandria, Italy / Dr. A.W.D. Gavilanes.

Julie A.D.A. Dela Cruz: Dopamine mechanisms in learning and memory: Evidence from rodent studies. Supervisors: Prof.dr. H.W.M. Steinbusch / Prof.dr. R.J. Bodnar, New York; Co-Supervisor: Dr. B.P.F. Rutten.

René Besseling: Brain wiring and neuronal dynamics; advances in MR imaging of focal epilepsy. Supervisors: Prof.dr. A.P. Aldenkamp / Prof.dr.ir. W.H. Backes; Co-Supervisor: dr. J.F.A. Jansen.

Maria Quint-Fens: Long-term care after stroke; development and evaluation of a longterm intervention in primary care. Supervisors: Prof.dr. J.F.M. Metsemakers / Prof.dr. C.M. van Heugten / Prof.dr. M. Limburg, Almere; Co-Supervisor: dr. G.H.M.I. Beusmans.

Veronique Moulaert: Life after survival of a cardiac arrest; the heart of the matter. Supervisors: Prof.dr. J.A. Verbunt / Prof.dr. C.M. van Heugten / Prof.dr. D.T. Wade, Oxford, UK.

Feikje Smeets: The hallucinatory-delusional state: a crucial connection in the psychosis symptom network. Supervisor: Prof.dr. J. van Os; Co-Supervisor: Dr. T. Lataster.

Lies Clerx: Alzheimer's disease through the MR-eye; novel diagnostic markers and the road to clinical implementation". Supervisor: Prof.dr. F. Verhey; Co-Supervisors: Dr. P.J. Visser / P. Aalten.

Sonny Tan: The subthalamic nucleus in Parkinson's disease. Supervisors: Prof.dr. Y. Temel / Prof.dr. H.W.M. Steinbusch / Prof.dr. T. Sharp, Oxford, UK / Prof.dr. V. Visser-Vandewalle, Koln.

Koen van Boxem: The use of pulsed radiofrequency in the management of chronic lumbosacral radicular pain. Supervisors: Prof.dr. M. van Kleef / Prof.dr. E.A.J. Joosten; Co-Supervisor: Assoc. Prof.dr. J. van Zundert.

Jérôme Waterval: Hyperostosis cranialis interna. Supervisors: Prof.dr. J.J. Manni / Prof. dr. R.J. Stokroos. 
Sylvie Kolfschoten-van der Kruijs: Psychogenic non-epileptic seizures; the identification of neurophysiological correlates. Supervisors: Prof.dr. A.P. Aldenkamp / Prof.dr. K.E.J. Vonck, Universiteit Gent; Co-Supervisors: Dr. J.F.A. Jansen / Dr. R.H.C. Lazeron, Kempenhaeghe.

Wouter Pluijms: Spinal cord stimulation and pain relief in painful diabetic: polyneuropathy, a translational approach. Supervisors: Prof.dr. M. van Kleef / Prof.dr. E.A. Joosten; Co-supervisor: Dr. C.G. Faber.

Ron Handels: Health technology assessment of diagnostic strategies for Alzheimer's disease. Supervisors: Prof.dr. F.R.J. Verhey / Prof.dr. J.L. Severens (EUR); Co-Supervisor: Dr. M.A. Joore / Dr. C.A.G. Wolfs.

Evelyn Peelen: Regulatory $\mathbf{T}$ cells in the pathogenesis of Multiple Sclerosis: potential targets for vitamin D therapy. Supervisors: Prof.dr. R.M.M. Hupperts / Prof.dr. J.W. Cohen Tervaert; Co-Supervisor: Dr. J.G.M.C. Damoiseaux / Dr. M.M.G.L.Thewissen, Diepenbeek.

Reint Jellema: Cell-based therapy for hypoxic-ischemic injury in the preterm brain. Supervisors: Prof.dr. B.W.W. Kramer / Prof.dr. H.W.M. Steinbusch; Co-Supervisor: Dr. W.T.V. Germeraad / Dr. P. Andriessen, Veldhoven.

Maria Wertli: Prognosis of Chronic Clinical Pain Conditions: The Example of Complex Regional Pain Syndrome 1 and Low Back Pain. Supervisors: Prof.dr. M. van Kleef; Co-Supervisor: Dr. F. Brunner, Zürich / Dr. R. Perez, VUmc.

Dagmar Zeef: An experimental model of Huntington's disease: Validation \& Stimulation. Supervisors: Prof.dr. Y. Temel / Prof.dr. H.W.M. Steinbusch; Co-supervisor: Dr. A. Jahanshahi.

Jeroen Decoster: Breaking Down Schizophrenia into phenes, genes and environment. Supervisors: Prof.dr. I. Myin-Germeys / Prof.dr. M. De Hert, KU Leuven; Co-Supervisor: Dr. R. van Winkel.

Eaja Anindya Sekhar Mukherjee: Fetal Alcohol Spectrum Disorders: exploring prevention and management. Supervisor: Prof.dr. L.M.G. Curfs; Co-Supervisor: Prof. S. Hollins, St. George's University of London, UK. 
Catherine van Zelst: Inside out; On stereotype awareness, childhood trauma and stigma in psychosis. Supervisors: Prof.dr. Ph. Delespaul / Prof.dr. J. van Os.

Ibrahim Tolga Binbay: Extended Psychosis Phenotype in the Wider Social Environment. Supervisor: Prof.dr. J. van Os; Co-Supervisor: Dr. M. Drukker.

Frank Van Dael: OCD matters in psychosis. Supervisors: Prof.dr. J. van Os / Prof.dr. I. Myin-Germeys.

Pamela Kleikers: NOXious oxidative stress: from head toe too and back. Supervisors: Prof.dr. H.H.H.W. Schmidt / Prof.dr. H.W.M. Steinbusch; Co-Supervisor: Dr. B. Janssen.

José Luis Gerardo Nava: In vitro assay systems in the development of therapeutic interventions strategies for neuroprotection and repair. Supervisors: Prof.dr.med. J. Weis / Prof.dr. H.W.M. Steinbusch; Co-Supervisor: Dr. G.A. Brook, RWTH Aachen.

Eva Bollen: Cyclic nucleotide signaling and plasticity. Supervisors: Prof.dr. H.W.M. Steinbusch / Prof.dr. R. D’Hooge, KU Leuven; Co-Supervisor: Dr. J. Prickaerts.

2015

Jessica A. Hartmann: A good laugh and a long sleep; Insights from prospective and ambulatory assessments about the importance of positive affect and sleep in mental health. Supervisor: Prof.dr. J. van Os; Co-Supervisors: C.J.P. Simons / Dr. M. Wichers.

Bart Ament: Frailty in old age; conceptualization and care innovations. Supervisors: Prof.dr. G.I.J.M. Kempen / Prof.dr. F.R.J. Verhey; Co-Supervisor: Dr. M.E. de Vugt.

Mayke Janssens: Exploring course and outcome across the psychosis-continuum. Supervisor: Prof.dr. I. Myin-Germeys; Co-Supervisor: Dr. T. Lataster.

Dennis M.J. Hernaus: Dopayours is not dopamine: genetic, environmental and pathological variations in dopaminergic stress processing. Supervisor: Prof.dr. I. Myin-Germeys; Co-Supervisors: Prof.dr. F.M. Mottaghy / Dr. D. Collip. 
Ingrid M.H. Brands: The adaptation process after acquired brain injury Pieces of the puzzle. Supervisors: Prof.dr. C.M. van Heugten / Prof.dr. D.T. Wade, Oxford UK; Co-Supervisors: Dr. S.Z. Stapert / Dr. S. Köhler.

Francesco Risso: Urinary and salivary S100B monitoring in high risk infants. Supervisor: Prof.dr. J.S.H. Vles; Co-Supervisors: Dr. D. Gazzolo, Genoa,Italy / Dr. A.W.D. Gavilanes.

Alessandro Borghesi: Stem and Progenitor Cells in Preterm Infants: Role in the Pathogenesis and Potential for Therapy. Supervisor: Prof.dr. L. Zimmermann; Prof.dr. B. Kramer; Co-Supervisors: Dr. D. Gazzolo, Genoa,Italy / Dr. A.W.D. Gavilanes.

Claudia Menne-Lothmann: Affect dynamics; A focus on genes, stress, and an opportunity for change. Supervisor: Prof.dr. J. van Os; Co-Supervisors: Dr. M. Wichers / Dr. N. Jacobs.

Martine van Nierop: Surviving childhood new perspectives on the link between childhood trauma and psychosis. Supervisors: Prof.dr. I. Myin-Germeys / Prof.dr. J. van Os; Co-Supervisor: Dr. R. van Winkel.

Sylvia Klinkenberg: VNS in children; more than just seizure reduction. Supervisors: Prof. dr. J. Vles / Prof.dr. A. Aldenkamp; Co-Supervisor: Dr. H. Majoie.

Anouk Linssen: Considerations in designing an adult hearing screening programme. Supervisor: Prof.dr. B. Kremer; Co-Supervisors: Dr. L. Anteunis / Dr. M. Joore.

Janny Hof: Hearing loss in young children; challenges in assessment and intervention. Supervisors: Prof.dr. B. Kremer / Prof.dr. R. Stokroos / Prof.dr. P. van Dijk, RUG; Co-Supervisor: Dr. L. Antheunis.

Kimberly Cox-Limpens: Mechanisms of endogenous brain protection; Clues from the transcriptome. Supervisors: Prof.dr. J. Vles / Prof.dr. L. Zimmermann; Co-Supervisor: Dr. A. Gavilanes.

Els Vanhoutte: Peripheral Neuropathy outcome measures; Standardisation (PeriNomS) study part 2: Getting consensus. Supervisors: Prof.dr. C. Faber / Prof.dr. P. van Doorn; Co-Supervisor: Dr. I. Merkies, Spaarne ziekenhuis Hoofddorp. 
Mayienne Bakkers: Small fibers, big troubles; diagnosis and implications of small fiber neuropathy. Supervisors: Prof.dr. C. Faber / Prof.dr. M. de Baets; Co-Supervisor: Dr. I. Merkies, Spaarne ziekenhuis Hoofddorp.

Ingrid Kramer: Zooming into the micro-level of experience: An approach for understanding and treating psychopathology. Supervisor: Prof.dr. J. van Os; Co-Supervisors: Dr. M. Wichers, UMC Groningen / Dr. C. Simons.

Esther Bouman: Risks and Benefits of Regional Anesthesia in the Perioperative Setting. Supervisors: Prof.dr. M. van Kleef / Prof.dr. M. Marcus, HMC, Qatar / Prof.dr. E. Joosten; Co-Supervisor: Dr. H. Gramke.

Mark Janssen: Selective stimulation of the subthalamic nucleus in Parkinson's disease; dream or near future. Supervisors: Prof.dr. Y. Temel / Prof.dr. V. Visser-Vandewalle, Keulen / Prof.dr. A. Benazzouz, Bordeax, France.

Reina de Kinderen: Health Technology Assessment in Epilepsy; economic evaluations and preference studies. Supervisors: Prof.dr. S. Evers / Prof.dr. A. Aldenkamp; Co-Supervisor: Dr. H. Majoie / Dr. D. Postulart, GGZ O-Brabant.

Saskia Ebus: Interictal epileptiform activity as a marker for clinical outcome. Supervisors: Prof.dr. A. Aldenkamp / Prof.dr. J. Arends, TUE / Prof.dr. P. Boon, Universiteit Gent, België.

Inge Knuts: Experimental and clinical studies into determinants of panic severity. Supervisor: Prof.dr. I. Myin-Germeys; Co-Supervisor: Dr. K. Schruers; Influencing panic.

Nienke Tielemans: Proactive coping post stroke: The Restored4Stroke Self-Management study. Supervisors: Prof.dr. C. van Heugten / Prof.dr. J. Visser-Meily, UMC Utrecht; Co-Supervisor: Dr. V. Schepers, UMC Utrecht.

Tom van Zundert: Improvements Towards Safer Extraglottic Airway Devices. Supervisors: Prof.dr. A.E.M. Marcus / Prof.dr. W. Buhre / Prof.dr. J.R. Brimacombe, Queensland, Australia / Prof.dr. C.A. Hagberg. 
Tijmen van Assen: Anterior Cutaneous Nerve Entrapment Syndrome Epidemiology and surgical management. Supervisors: Prof.dr. G.L. Beets / Prof.dr. M. van Kleef / Dr. R.M.H. Roumen / Dr. M.R.M. Scheltinga, MMC Veldhoven.

Rohit Shetty: Understanding the Clinical, Immunological and Genetic Molecular Mechanisms of Keratoconus. Supervisors: Prof.dr. R.M.M.A. Nuijts / Prof.dr. C.A.B. Webers.

Christine van der Leeuw: Blood, bones and brains; peripheral biological endophenotypes and their structural cerebral correlates in psychotic disorder. Supervisor: Prof.dr. J. van Os; Co-supervisor: Dr. M. Marcelis.

Sanne Peeters: The Idle Mind Never Rests; functional brain connectivity across the psychosis continuum. Supervisor: Prof.dr. J. van Os; Co-supervisor: dr. M. Marcelis.

Nick van Goethem: $\alpha 7$ nicotinic acetylcholine receptors and memory processes: mechanistic and behavioral studies. Supervisor: Prof.dr. H.W.M. Steinbusch; Co-supervisor: Dr. J. Prickaerts.

Nicole Leibold: A Breath of fear; a translational approach into the mechanisms of panic. Supervisor: Prof.dr. H.W.M. Steinbusch; Co-supervisors: Dr. K.R.J. Schruers / Dr. D.L.A. van den Hove.

Renske Hamel: The course of mild cognitive impairment and the role of comorbidity. Supervisor: Prof.dr. F.R.J. Verhey; Co-supervisors: Dr. I.H.G.B. Ramakers / Dr. P.J. Visser.

Lucia Speth: Effects of botulinum toxin A injections and bimanual task-oriented therapy on hand functions and bimanual activities in unilateral Cerebral Palsy. Supervisors: Prof.dr. J. Vles; Prof.dr. R. Smeets; Co-supervisor: Dr. Y. Janssen-Potten, Adelante Hoensbroek.

Yuan Tian: The effects of Lutein on the inflammatory pathways in age-related macular degeneration (AMD). Supervisors: Prof.dr. C. Webers; Prof.dr. A. Kijlstra, WUR; Co-supervisor: Dr. M. Spreeuwenberg; Dr. H. Tange.

Peggy Spauwen: Cognition and Type 2 diabetes; the interplay of risk factors. Supervisors: Prof.dr. F. Verhey; Prof.dr. C. Stehouwer; Co-supervisor: Dr. M. van Boxtel 
Marc Hilhorst: Crescentic glomerulonephritis in ANCA associated vasculitis. Supervisors: Prof.dr. J. Cohen-Tervaert; Co-supervisor: Dr. P. van Paassen

Martin Gevonden: The odd one out: exploring the nature of the association between minority status and psychosis. Supervisors: Prof.dr. J-P. Selten; Prof.dr. J. Booij, Uva; Prof. dr. I. Myin-Germeys

Bart Biallosterski: Structural and functional aspects of sensory-motor Interaction in the urinary bladder. Supervisors: Prof.dr. Ph. Van Kerrebroeck; Prof.dr. S. De Wachter, UvAntwerpen; Co-supervisors: Dr. G. van Koeveringe; Dr. M. Rahnama'i.

Alexandra König: The use of information and communication technologies (ICT) for the assessment of patients with Alzheimer's Disease and related disorders. Supervisors: prof.dr. F. Verhey; prof.dr. Ph. Robert, Nice, Fr; Co-supervisors: dr. P. Aalten; dr. R. David, Nice. Fr.

Michelene Chenault: Assessing Readiness for Hearing Rehabilitation. Supervisors: prof. dr. M.P.F. Berger; prof.dr. B. Kremer; Co-supervisor: dr. L.J.C. Anteunis.

Anand Vinekar: Retinopathy of Prematurity. Recent advances in tele-medicine screening, risk factors and spectral domain optical coherence tomography imaging. Supervisor: prof.dr. C.A.B. Webers; Co-supervisor: dr. N.J. Bauer

Fleur van Dooren: Diabetes and Depression: exploring the Interface between Pathophysiological and Psychological factors. Supervisors: prof.dr. F.R.J. Verhey; prof.dr. J.K.L. Denollet, UvT; prof.dr. F. Pouwer, UvT; Co-supervisor: dr. M.T. Schram.

Gabriëlla Pons van Dijk: Taekwondo and physical fitness components in middle-aged healthy volunteers; the Sekwondo study. Supervisors: prof.dr. J. Lodder; prof.dr. H. Kingma; Co-supervisor: dr. A.F. Lenssen.

Yara Pujol López: Development and psychoneuroimmunological mechanisms in depression. Supervisor: prof.dr. H.W.M. Steinbusch; Co-supervisors: Dr. G. Kenis; Dr. D. van den Hove; Dr. Aye Mu Myint, München. 
Romina Gentier: UBB $^{+1}$; an important switch in the onset of Alzheimer's disease. Supervisors: Prof. H. Steinbusch; Prof. D. Hopkins; Co-supervisor: Dr. F. van Leeuwen.

Sanne Smeets: Insights into insight: studies on awareness of deficits after acquired brain injury. Supervisor: Prof. C. van Heugten; Prof. R. Ponds; Co-supervisor: Dr. I. Winkens

Kim Beerhorst: Bone disease in chronic epilepsy: fit for a fracture. Supervisor: Prof. A. Aldenkamp; Prof. R. van Oostenbrugge; Co-supervisor: Dr. P. Verschuure.

Alex Zwanenburg: Cerebral and cardiac signal monitoring in fetal sheep with hypoxic-ischemic encephalopathy. Supervisor: Prof. T. Delhaas; Prof. B. Kramer; Co-supervisors: Dr. T. Wolfs; Dr. P. Andriessen, MMC.

Ismail Sinan Guloksuz: Biological mechanisms of environmental stressors in psychiatry. Supervisor: Prof. J. van Os; Co-supervisors: Dr. B. Rutten; Dr. M. Drukker.

Seyed Ehsan Pishva MD: Environmental Epigenetics in mental health and illness. Supervisor: Prof.dr. J. van Os; Co-supervisors: Dr. B.P.F. Rutten; Dr. G. Kenis.

Ankie Hamaekers: Rescue ventilation using expiratory ventilation assistance; innovating while clutching at straws. Supervisors: Prof.dr. W.F. Buhre; Prof.dr. M. van Kleef.

Rens Evers. 22q11.2 deletion syndrome: intelligence, psychopathology and neurochemistry at adult age. Supervisors: Prof.dr. L.M.G. Curfs; Prof.dr. T. v. Amelsvoort.

Sarah-Anna Hescham. Novel insights towards memory restoration. Supervisor: Prof.dr. Y. Temel; Co-supervisor: Dr. A. Blokland; Dr. A. Jahanshahi.

João P. da Costa Alvares Viegas Nunes. Insulin receptor sensitization improves affective pathology in various mouse models. Supervisor: Prof.dr. H.W.M. Steinbusch; Co-supervisors: Dr. K-P. Lesch; Dr. T. Strekalova; Dr.B.H. Cline, Oxford.

Yanny Ying-Yee Cheng. Clinical Outcomes After Innovative Lamellar Corneal Transplantation Surgery. Supervisor: Prof.dr. R.M.M.A. Nuijts; Co-supervisor: Dr. J.S.A.G. Schouten. 


\section{6}

Oliver Gerlach. Parkinson's disease, deterioration during hospitalization. Supervisor: Prof.dr. R. van Oostenbrugge; Co-supervisor: Dr. W. Weber.

Remo Arts. Intracochlear electrical stimulation to suppress tinnitus. Supervisor: Prof.dr. R.J. Stokroos; Co-supervisor: Dr. E.L.J. Georg.

Mitchel van Eeden. The $€$ - Restore4stroke study: Economic evaluation of stroke care in the Netherlands. Supervisors: Prof.dr.mr. S.M.A.A. Evers; Prof.dr. C.M. v. Heugten; Co-supervisor: dr. G.A.P. van Mastrigt.

Pim Klarenbeek. Blood pressure and cerebral small vessel disease. Supervisor: Prof.dr. R.J. van Oostenbrugge; Co-supervisor: Dr. J. Staals.

Ramona Hohnen. Peripheral pharmacological targets to modify bladder contractility. Supervisor: Prof.dr. Ph.E.V. van Kerrebroeck; Co-supervisors: Dr. G.A. van Koeveringe; Dr. M.A. Sahnama'i; Dr. C. Meriaux.

Ersoy Kocabicak. Deep brain stimulation of the subthalamic nucleus: Clinical and scientific aspects. Supervisors: Prof.dr. Y. Temel; Prof.dr. K. van Overbeeke; Co-supervisor: Dr. A. Jahanshahi.

Sven Akkerman. Temporal aspects of cyclic messenger signaling in object recognition memory; a pharmalogical approach. Supervisor: Prof.dr. H.W.M. Steinbusch; Co-supervisors: dr. J. Prickaerts; dr. A. Blokland.

Anja Moonen. Emotion and Cognition in Parkinson's disease; etiology and neurobiological mechanisms. Supervisor: Prof.dr. F.R.J. Verhey; Co-supervisor: dr. A.F.G. Leentjens.

Anna Schüth. Three-dimensional bladder tissue morphology. Supervisors: Prof.dr. G.A. van Koeveringe; Prof.dr. M. v. Zandvoort, Aachen; Prof.dr. Ph. V. Kerrebroeck.

Elisabeth van der Ven. Ethnic minority position as risk indicator for autism-Spectrum and psychotic disorders. Supervisors: Prof.dr. J.P. Selten; Prof.dr. J. van Os. 
Zuzana Kasanova. Environmental reactivity for better or worse; The impact of stress and reward on neurochemistry, affect and behavior across the psychosis continuum. Supervisor: Prof.dr. I. Myin-Germeys, KU Leuven/UM; Co-supervisor: dr. D. Collip.

Danielle Lambrechts. Ketogenic diet therapies; treatment for children and adults with refractory epilepsy. Supervisors: Prof.dr. H.J.M. Majoie; Prof.dr. J.S.H. Vles; Prof.dr. A.P. Aldenkamp; Co-supervisor: dr. A.J.A. de Louw, Kempenhaghe, Heeze.

Frank van Bussel. Advanced MRI in diabetes; cerebral biomarkers of cognitive decrements. Supervisors: Prof.dr.ir. W.H. Backes; Prof.dr. P.A.M. Hofman; Co-supervisor: dr. J.F.A. Jansen.

Lisa Schönfeldt. Neurostimulation to treat brain injury? Supervisors: Prof.dr. Y. Temel; Prof.dr. S. Hendrikx, Hasselt; Co-supervisor: dr. A. Jahanshahi.

Rianne Geerlings. Transition in patients with childhood-onset epilepsy; a long way to adulthood. Supervisor: Prof.dr. A.P. Aldenkamp; Co-supervisors:dr. A.J.A. de Louw, dr. L.M.C. Gottmer, Kempenhaeghe.

Nele Claes. B cells as multifactorial players in multiple sclerosis pathogenesis: insights from therapeutics. Supervisors: Prof.dr. V. Somers, Hasselt; Prof.dr. R. Hupperts Co-supervisors: Prof.dr. P. Stinissen, dr. J. Fraussen, Hasselt.

Olaf Schijns. Epilepsy surgery and biomarkers from history to molecular imaging. Supervisors: Prof.dr. J.J. van Overbeeke; Prof.dr. H. Clustermann, Aachen; Co-supervisors: dr. G. Hoogland; dr. M.J.P. v. Kroonenburgh.

Lizzy Boots. Balanced and Prepared; development and evaluation of a supportive e-health intervention for caregivers of people with early-stage dementia. Supervisors: Prof.dr. F.R.J. Verhey; Prof.dr. G.I.J.M. Kempen; Co-supervisor: dr. M.E. de Vugt.

Wouter Donders. Towards patient-specific (cerebro-) vascular model applications. Supervisors: Prof.dr. T. Delhaas; Prof.dr.ir. F.N. van de Vosse, TUE; Co-supervisor: dr.ir. W. Huberts. 
Sizzle Vanterpool. The implications of intrauterine invasion by microbes for placental Pathology and the occurrence of adverse pregnancy outcomes. Supervisor: Prof.dr. B.W. Kramer. Co-supervisors: dr. J.V. Been, Erasmus MC Rotterdam, dr. U von Rango.

Manuela Heins. The Relationship between Social Adversity, Psychosis, and Depression across an Individual's Life Span. Supervisor: Prof.dr. I. Myin-Germeys.

Christianus van Ganzewinkel. NEONATAL PAIN; Out of Sight, Out of Mind? Supervisor: Prof.dr. B.W.W. Kramer; Co-supervisor: dr. P. Andriessen, MMC Veldhoven.

Anne-Hilde Muris. Hype or hope? Vitamin D in multiple sclerosis; A clinical and immunological perspective. Supervisor: Prof.dr. R.M.M. Hupperts; Co-supervisor: dr. J.G.M.C. Damoiseaux.

Gerard Bode. The link between ceramide transporters, innate Immunity and Alzheimer's disease. Supervisor: Prof.dr. M.H.V. de Baets; Co-supervisors: dr. P. Martinez, dr. M. Losen.

Jo Stevens. Advanced diagnostics and therapeutics for Alzheimer's disease. Supervisor: Prof.dr. M. de Baets; Co-supervisors: dr. M. Losen, dr. P. Martinez-Martinez.

Rosan Luijcks. Stress and pain in muscles and brain; developing psychophysiological paradigms to examine stress and pain interactions. Supervisors: Prof.dr. J.J. van Os; Prof.dr.ir. H.J. Hermens, UT; Co-supervisor: dr. R. Lousberg.

M.C. Haanschoten. Towards efficient cardiac surgery - the integrating role of anesthesiology and intensive care. Supervisors: Prof. dr. W. Buhre; Prof. dr. A. van Zundert (Queensland); Co-supervisors: Dr. M.A. Soliman Hamad; Dr. A. van Straten (Catharina zkhs.)

Harmen Jan van de Haar. Microvascular and blood-brain barrier dysfunction in Alzheimer's disease. Supervisor: Prof.dr.ir. W. Backes; Prof.dr. F. Verhey; Co-supervisor: Dr. J. Jansen; Dr.ir. M. v. Osch, LUMC. 
Coenraad Itz. Chronic low back pain, considerations about: Natural Course, Diagnosis, Interventional Treatment and Costs. Supervisor: Prof.dr. M. van Kleef; Prof.dr. F. Huygen, EUR; Co-supervisor: Dr. B. Ramaekers.

Willemijn Jansen. The Path of Alzheimer's disease: from neuropathology to clinic. Supervisor: Prof.dr. F. Verhey; Co-supervisors: Dr. P.J. Visser; Dr. I. Ramakers.

Ligia dos Santos Mendes Lemes Soares. Phosphodiesterase inhibitors: a potential therapeutic approach for ischemic cerebral injury. Supervisor: Prof.dr. H.W.M. Steinbusch; Co-supervisors: Dr. R.M. Weffort de Oliveira, Brazil; Dr. J. Prickaerts

Martijn Broen. Anxiety and depression in Parkinson's disease. Supervisor: Prof.dr. R.J. van Oostenbrugge; Co-supervisors: Dr. A.F.G. Leentjens; Dr. M.L. Kuijf.

Sandra Schipper. Extrasynaptic receptors as a treatment target in epilepsy. Supervisor: Prof.dr. J.H.S. Vles; Co-supervisors: Dr. G. Hoogland; Dr. S. Klinkenberg; Dr. M.W. Aalbers, RUG.

João Casaca Carreira. Making sense of Antisense Oligonucleotides Therapy in Experimental Huntington's disease. Supervisor: Prof.dr. Y. Temel; Co-supervisors: Dr. A. Jahanshahi; Dr. W. van Roon-Mom, LUMC.

Dominique IJff. Trick or Treat? Cognitive side-effects of antiepileptic treatment. Supervisors: Prof.dr. A.P. Aldenkamp; Prof.dr. M. Majoie; Co-supervisors: Dr. J. Jansen; Dr. R. Lazeron, Kempenhaeghe.

Alfredo Ramirez. Neurogenetic approach in neurodegenerative disorders. Supervisors: Prof.dr. B.P.F. Rutten; Prof.dr. H.W.M. Steinbusch; Prof.dr. M.M. Nöthen, University of Bonn.

Nienke Visser. Toric Intraocular lenses in cataract surgery. Supervisor: Prof.dr. R.M.M.A. Nuijts; Co-supervisor: Dr. N.J.C. Bauer.

Jakob Burgstaller. Prognostic indicators for patients with degenerative lumbar spinal stenosis. Supervisor: Prof.dr. M. van Kleef; Co-supervisors: Dr. M.M. Wertli, University of Zurich; Dr. H.F. Gramke. 
Mark van den Hurk. Neuronal Identity and Maturation: Insights from the Single-Cell Transcriptome. Supervisors: Prof.dr. H.W.M. Steinbusch; Prof.dr. B.P.F. Rutten; Co-supervisors: Dr. G. Kenis; Dr. C. Bardy, Adelaide.

Maria Nikiforou. Prenatal stress and the fetal gut. Potential interventions to prevent adverse outcomes. Supervisors: Prof.dr. B.W. Kramer; Prof.dr. H.W. Steinbusch; Co-supervisor: Dr. T.G. Wolfs.

Janneke Peijnenborgh. Assessment of cognition, time perception, and motivation in children. Supervisors: Prof.dr. J.S.H. Vles; Prof.dr. A.P. Aldenkamp; Co-supervisors: Dr. J. Hendriksen; Dr. P. Hurks.

Joany Millenaar. Young onset dementia; towards a better understanding of care needs and experiences. Supervisors: Prof.dr. F. Verhey; Prof.dr. R. Koopmans, RUN; Co-supervisors: Dr. M. de Vugt; Dr. C. Bakker, RUN.

\section{7}

Adriana Smits. Perinatal factors and hearing outcome. Supervisors: Prof.dr. R.J. Stokroos; Prof.dr. B.W. Kramer; Prof.dr. B. Kremer.

Angela Bouwmans. Transcranial sonography in parkinsonian disorders: clear window or blurred vision. Supervisor: Prof.dr. W.H. Mess; Co-promotores: Dr. W.E.J. Weber; Dr. A.F.G. Leentjens.

Björn K. Stessel. Patient centred care after day surgery: scope for improvement. Supervisors: Prof.dr. W. Buhre; Prof.dr. B. Joosten. Co-supervisor: Dr. A.H. Gramke.

Jan Guy Bogaarts. Quantitative EEG and machine learning methods for the detection of epileptic seizures and cerebral asymmetry. Supervisor: Prof.dr. W.M. Mess; Co-supervisor: Dr.ir. J.P.H. Reulen; Dr.ir. E.D. Gommer.

Martin M. Müller. Pregnancy derived products for treatment of perinatal brain injuries. Supervisors: Prof.dr. B.W.W. Kramer; Prof.dr. D. Surbek, Bern; Co-supervisors: Dr. T. Wolfs; Dr. G. Gavilanes. 
Daan Ophelders. Novel treatment strategies for the protection of the preterm brain; Re-balancing inflammation and regeneration. Supervisor: Prof.dr. B. Kramer; Co-supervisor: Dr. T. Wolfs; Dr. R. Jellema.

Rosalie van Knippenberg. Experience sampling in dementia care; an innovative intervention to support caregivers in daily life. Supervisors: Prof.dr. F. Verhey; Prof.dr. R. Ponds; Prof.dr. I. Myin-Germeys, KU Leuven; Co-supervisor: Dr. M. de Vugt.

Claudia Vingerhoets. Investigating neurobiological mechanisms underlying comorbid cognitive symptoms in psychosis and substance use. Supervisors: Prof.dr. T. van Amelsvoort; Prof.dr. J. Booij, UvA; Co-supervisor: Dr. O. Bloemen

Dennis Oerlemans. Evolution of Neuromodulation for Lower Urinary Tract Dysfunction; Past, Present and Future. Supervisors: Prof.dr. Ph. van Kerrebroeck; Prof.dr. G. van Koeveringe. Co-supervisors: Dr. E. Weil; Dr. T. Marcelissen.

Marion Levy. Evaluation of BDNF/TrkB signaling as a common target in the treatment of major depression and Alzheimer's disease. Supervisors: Prof.dr. H. Steinbusch; Prof. L. Lanfumey, Université Paris Descartes, France. Co-supervisors: Dr. G. Kenis; Dr. D. van den Hove.

Patrick Domen. Stay connected: a family-based diffusion imaging study in psychotic disorder. Supervisor: Prof.dr. J. van Os. Co-supervisor: Dr. M. Marcelis

Geor Bakker. Innovative Approaches to Understanding the Neurobiology of Psychosis. Supervisors: Prof.dr. T. van Amelsfoort; Prof.dr. J. Booij, UvA. Co-supervisor: dr. M. Caan, UvA; dr. O. Bloemen.

Wilma Boevink. HEE! Over Herstel, Empowerment en Ervaringsdeskundigheid in de psychiatrie. Supervisors: Prof.dr. J. van Os; Prof.dr. Ph. Delespaul. Co-supervisor: dr. H. Kroon.

Nataliia Markova . Modified swim test as a mouse depression paradigm of enhanced Cognitive processing: the role of GSK3 3 . Supervisor: Prof.dr. H. Steinbusch; Prof.dr. K-P. Lesch, University of Wuerzburg. Co-supervisor: Dr. T. Strekalova. 
Merijn van de Laar. Individual differences in insomnia; implications of Psychological factors for diagnosis and treatment. Supervisor: Prof.dr. A. Aldenkamp; Prof.dr. D. Pevernagie, Universiteit Gent. Co-supervisor: Dr. S. Overeem, TUE.

Willem Buskermolen. If only I could tell ...; Measuring predictors for challenging behaviour in people with both intellectual disability and hearing impairment. Supervisor: Prof.dr. A. Aldenkamp. Co-supervisor: Dr. J. Hoekman, UL.

Kay Deckers. The role of lifestyle factors in primary prevention of dementia; an epidemiological perspective. Supervisor: Prof.dr. F. Verhey. Co-supervisor: Dr. M. van Boxtel; Dr.S. Köhler.

Brechje Dandachi-FitzGerald. Symptom validity in clinical assessments. Supervisors: Prof.dr. R. Ponds; Prof.dr. F. Verhey.

Maurice Theunissen. Understanding factors affecting postoperative Quality of Life.Supervisors: Prof.dr. M. Peters, Prof.dr. M. Marcus. Co-supervisor: Dr. H. Gramke.

Anna Cleutjens. COgnitive-Pulmonary Disease? Neuropsychological functioning in patients with COPD. Supervisors: Prof.dr. E. Wouters, Prof.dr. R. Ponds. Co-supervisors: Dr. D. Janssen, Horn, Dr. J. Dijkstra.

Laura Serpero. Next Generaton Biomarkers in Perinatal Medicine: S100B Protein. Supervisors: Prof.dr. D. Gazzalo, Alessandria, Italy; Prof.dr. B..W.W. Kramer. Co-supervisor: Dr. A.W.D. Gavilanes.

Alessandro Varrica. S100B Protein and Congential Heart Diseases: Brain Aspects. Supervisors: Prof.dr. D. Gazzalo, Alessandria, Italy; Prof.dr. J.S.H. Vles; Prof.dr. L.J.I. Zimmermann. Co-supervisor: Dr. A.W.D. Gavilanes.

Pim R.A. Heckman. Targeting phosphodiesterase type 4 for improving cognitive fronto-striatal function: a translational approach. Supervisor: Prof.dr. J.G. Ramaekers. Co-supervisors: Dr. J.H.H.J.. Prickaerts; Dr. A. Blokland. 
Sven van Poucke. Platelets, form sample to big data; exploring granularity in platelet research. Supervisors: Prof.dr. M.A.E. Marcus; Prof.dr. W. Buhre. Co-supervisor: Dr. M. Lancé.

Désirée M.J. Vrijens. Dysfunctions of the Lower Urinary Tract and Affective Symptoms. Supervisors: Prof.dr. Ph.E.V. van Kerrebroeck; Prof.dr. G.A. van Koeveringe. Co-supervisors: Dr. C. Leue.

Tamar van Veenendaal. Neurotransmitters \& Networks. An MR view on epilepsy and antiepileptic drugs. Supervisors: Prof.dr.ir. W.H. Backes; Prof.dr. A.P. Aldenkamp. Co-supervisor: Dr. J.F.A. Jansen.

Evelien M. Barendse. Autism Spectrum Disorders in High functioning Adolescents; Diagnostic considerations (AHA). Supervisors: Prof.dr. A.P. Aldenkamp; Prof.dr. R.P.C. Kessels, Radboud University.

Roy Lardenoije. A venture into the epigenetics of aging and Alzheimer's Disease. Supervisors: Prof.dr. B.P.F. Rutten; Prof.dr. H.W.M. Steinbusch. Co-supervisors: Dr. D. van den Hove; Dr. C.A. Lemere, USA.

Charlotte L. Mentzel. The course recognition and treatment of movement disorders in severe mental illness. Supervisors: Prof.dr. P.N. van Harten; Prof.dr. M.A.J. de Koning-Tijssen, UMCG. Co-supervisor: Dr. P.R. Bakker.

Tim Batink. Third Wave Behaviour Therapy: Process Measures and Contextual Interventions. Supervisors: Prof.dr. F.P.M.L. Peeters; Prof.dr. J.J. van Os; Prof.dr. M.C. Wichers, UMC Groningen.

Kevin L.J. Rademakers. Detrusor Underactivity: From Theory To Clinical Assessment. Supervisors: Prof.dr. G.A. van Koeveringe; Prof.dr. Ph.E.V. van Kerrebroeck. Co-supervisor: Dr. M. Oelke.

Iris M.J. Lange. Should I stay or should I go ? Brain mechanisms underlying fear and safety learning, and explosure therapy outcome. Supervisors: Prof.dr. K.R.J. Schruers;Prof.dr. T.A.M.J. van Amelsfoort. Co-supervisor: Dr. L. Goossens. 
Ruben G.F. Hendriksen. Evidence for a dystrophin-associated encephalopathy in Duchenne Muscular Dystrophy. Supervisor: Prof.dr. J.S.H. Vles. Co-supervisors: Dr. G. Hoogland; Dr. M.W. Aalbers, UMC Groningen.

Michael Gofeld. Strengths and limitations of the lumbar spine ultrasound-guided interventions. Supervisor: Prof.dr. M. van Kleef. Co-supervisor: Dr. M. Sommer.

Willem A.R. Zwaans. Strategies for chronic inguinal pain. Supervisor: Prof.dr. M. van Kleef. Co-supervisors: Dr. R.H.M. Roumen; Dr. M.R.M. Scheltinga, MMC Veldhoven.

Linda M. Rolf. Mapping the effects of vitamin D in multiple sclerosis A 3D Perspective. Supervisor: Prof.dr. R.M.M. Hupperts. Co-supervisors: Dr. J.G.M.C. Damoiseaux; Dr. J.J.F.M. Smolders, CWZ Nijmegen.

Maarten van Beek. Spinal Cord Stimulation in Clinical and Experimental Painful Diabetic Polyneuropathy. Supervisors: Prof.dr. E.A. Joosten; Prof.dr. M. van Kleef. Co-supervisor: Dr. S.M.J. van Kuijk.

Melina Barkhuizen. Genetic and perinatal risk factors for movement disorders. Supervisors: prof.dr. B.W.W. Kramer, prof.dr. H.W.M. Steinbusch, Prof.dr. A.F. Grobler. Co-supervisor: dr. A.W.D.Gavilanes-Jimenez.

Renske Uiterwijk. Cognitive function and cerebral small vessel disease in hypertension. Supervisor: prof.dr. R.J. van Oostenbrugge. Co-supervisor: Dr. J.E.A. Staals.

Elles Douven. Depression and apathy after stroke. Supervisor: prof.dr. F.R.J. Verhey. Co-supervisors: Dr. P. Aalten, dr. J. Staals.

Mauro Pessia. Brain K+ Channels: from molecular and physiological features to autism spectrum disorder and intellectual disability. Supervisors: prof.dr. H.W.M. Steinbusch, prof.dr. M.B. Donati, It.

Carsten Leue. Hyperarousal in the Hospital and what to do about it: the MED-PSYCHNET - a transitional network approach fostering personalized care in psychosomatic medicine. Supervisors: Prof.dr. J. van Os, Prof.dr. A. Masclee. Co-supervisors: Dr. J. Strik, Dr. J. Kruimel 
Andrea S. Herrera Soto. Aminochrome, an endotoxin for inducing a new rat model of Parkinson's Disease. Supervisor: prof.dr. H.W.M. Steinbusch. Co-supervisors: Prof.dr. Juan Segura-Aquilar; prof. G. Diaz-Veliz, Santiago of Chile

Eline E.B. de Clerck. Ocular neurodegenerative changes and macular cysts in prediabetes and type 2 diabetes. Supervisors: Prof.dr. C.A.B. Webers, Prof.dr. C.D.A. Stehouwer. Co-supervisor: Dr. J.S.A.G. Schouten

Steven T.H. Honings. Exploring psychosis and multidirectional violence: a prospective study in the general population. Supervisor: Prof.dr. J. van Os. Co-supervisor: Dr. M. Drukker

\section{8}

Sau May Wong. Advances in Microvasculair MRI Techniques: Breaking the Pathophysiological Barriers in Cerebral Small Vessel Disease. Supervisor: Prof.drir. W.H. Backes, Porf.dr. R.J. van Oostenbrugge. Co-supervisor: Dr. J.F.A. Jansen

Mark B.N. van Winkel. Lonely at heart and stressed in company of others; the influence of daily life social experiences and emotions on depression. Supervisors: prof.dr. F. Peeters; prof.dr. I. Myin-Germeys, KU Leuven/UM; prof.dr. M. Wichers, UMC Groningen

Harsha Birur Laxmana Rao. Revisiting the vascular theory of glaucoma using optical coherence tomography angiography. Supervisors: prof.dr. C.A.B. Webers; prof.dr. R.N. Weinreb, University of California, San Diego

Babette L.R. Reijs. Cognitive correlates of cerebrospinal fluid biomarkers for Alzheimer's disease. Supervisor: prof.dr. F.R.J. Verhey. Co-supervisors: Dr. P.J. Visser; dr. I.H.G.B. Ramakers

Rachel Slangen. Spinal cord stimulation in painful diabetic peripheral Neuropathy. Clinical- and cost-effectiveness. Supervisors: prof.dr. M. van Kleef; Prof.dr. C. Dirksen; prof. dr. C. Faber

Ganne Chaitanya. Epilepsy: A network disorder. Supervisors: prof.dr. A.P. Aldenkamp; prof. P. Satishchandra, NIMHANS, Bangalore, India. Co-supervisors: Dr. J.F.A. Jansen; Dr. S. Zinger, TUE 
Sumitha Rajendrarao. New Insight into the Multifaceted Pathogenic Mechanisms of Sporadic Amyotrophic Lateral Sclerosis. Supervisors: prof.dr. B.W. Kamer; prof.dr. H.W. Steinbusch. Co-supervisor: prof. T.R. Raju, NIMHANS, Bangalore, India

Suzanne Roggeveen. Interference of mobile phone with electrophysiology and emotions; results from short-term experimental studies. Supervisor: Prof.dr. J. van Os. Co-supervisor: Dr. R. Lousberg.

Matthias Walter. Multi-methodological approaches to investigate lower urinary tract function in health and disease. Supervisors: Prof.dr. Ph.E.V.A. van Kerrebroek; Prof.dr. G.A. van Koeveringe; Prof.dr. A. Curt, Zürich, $\mathrm{CH}$.

Lalit Gupta. Inhomogeneities in spontaneous brain fluctuations. Supervisors: Prof.dr.ir. WH. Backes; Prof.dr. P.A.M. Hofman. Co-supervisor: Dr. J.F.A. Jansen.

Chaitra Jayadev. Impact of imaging the pediatric retina. Supervisor: Prof.dr. C.A.B. Webers. Co-supervisor: Dr. N.J.C. Bauer; Dr. A. Vinekar.

Annelie Klippel. Navigating through complexity; processes and mechanisms underlying the development of psychosis. Supervisors: Prof.dr. I. Myin-Germeys, KU-Leuven; Prof. dr. M.C. Wichers, UMC Groningen. Co-supervisor: Dr. U. Reininghaus.

Kürşat Altinbaş. Reconstructing The Diagnostic Framework of Bipolarity. Supervisor: Prof.dr. J. van Os. Co-supervisor: Dr. I.S. Gülöksüz.

Andrea J.R. Balthasar. Eyes of the needle; Spectral tissue sensing, an innovative technology for detecting various tissue types during percutaneous needle-based procedures in locoregional anesthesia and pain medicine. Supervisor: Prof.dr. M. van Kleef. Co-supervisor: Dr. G-J. van Geffen, Radboud UMC Nijmegen.

Walmari Pilz. Shedding light on oropharyngeal dysphagia in myotonic dystrophy type 1. Supervisor: Prof.dr. B. Kremer. Co-supervisors: Dr. L.W.J. Baijens; Dr. V. Lima Passos.

Nynke J. van den Hoogen. Repetitive painful procedures in the neonate: Treatment and adult pain sensitivity. Supervisors: Prof.dr. E.A.J. Joosten, Prof.dr. D. Tibboel, Erasmus MC-Sophia, Rotterdam. Co-supervisor: Dr. J. Patijn. 
Carlota Mestres Gonzalvo. Medication optimisation; Methodological aspects and new strategies. Supervisors: Prof.dr. F.R.J. Verhey, Prof.dr. P.H.M. van der Kuy, Erasmus MC Rotterdam. Co-supervisors: Dr. R. Janknegt, Zuyderland MC.

Carolin Hoffmann. The Brain under Attack: Autoantibodies in Psychotic Disorders. Supervisors: Prof.dr. P. Martinez, Prof.dr. B. Rutten, Prof.dr. J. van Os, UU/UM.

Jindra M. Bakker. On the bumpy road of happiness: Mechanisms of daily life reward processing and how it can be changed. Supervisors: Prof.dr. M. Wichers, UMC Groningen, Prof.dr. I. Myin-Germeys, KU Leuven/UM. Co-supervisor: Dr. L. Goossens. 